\title{
Development of Novel Thin-ply Technology for Carbon Fibre Composite Materials
}

\author{
Rebecca Ann Blows
}

Academic Supervisor: Professor Cris Arnold Industrial Supervisor: Dr. Geraint Havard

Submitted to Swansea University in fulfilment of the requirements for the Degree of Doctor of Engineering

\section{Swansea University}

\section{0}

Copyright: The author, Rebecca A. Blows, 2020. 


\section{Abstract}

The increasing popularity of carbon fibre reinforced polymers means that enhancement of material properties is of high commercial value. Thin-ply technology is one area of research focussed on achieving this goal. The aim of this work was to investigate the use of thin-ply technology by studying the effect of ply thickness on the physical and mechanical properties of carbon fibre composite materials, after exposure to various environmental conditions. A review of mechanical properties at ambient conditions and after exposure to both high temperature and moisture was conducted. Quasi-isotropic thin-ply carbon fibre composites were found to have enhanced mechanical properties, compared to thicker ply materials comprising the same resin and matrix, under various loading conditions. One of the main mechanisms for this is thought to be the lower interfacial stresses seen with thin-ply materials, as demonstrated through the use of high-speed camera video recording and digital image correlation. An investigation into the effect of ply thickness on moisture absorption and diffusion rate was also conducted. For the material under investigation, diffusion rates remained constant with changes to ply thickness, whereas moisture absorption was greater for the thinner ply material. In addition, the effect of ply thickness on viscoelastic properties was also studied. The use of dynamic mechanical analysis suggested that the material under investigation tended to a two-phase state. This is thought to be the result of phase-separation of the epoxy resin matrix and poly-ether-sulfone (PES) toughening particles. Ply thickness was shown to have some effect on the phase separation of epoxy and PES. 


\section{Declaration}

This work has not previously been accepted in substance for any degree and is not being concurrently submitted in candidature for any degree.

Signed

Date $. . .18 / 10 / 2020$

\section{Statement 1}

This thesis is the result of my own investigations, except where otherwise stated. Other sources are acknowledged by footnotes giving explicit references. A bibliography is appended.

Signed

Date $18 / 10 / 2020$

\section{Statement 2}

I hereby give consent for my thesis, if accepted, to be available for photocopying and for inter-library loan, and for the title and summary to be made available to outside organisations.

Signed

Date .... 18/10/2020 


\section{Acknowledgments}

I would like to take this opportunity to thank the many people who have provided help and guidance throughout my Engineering Doctorate. Thank you to R-Tech Materials, in particular Tony Franks, for initiating the project and to my industrial supervisor, Geraint Havard, for his help over the years. Having the opportunity to be based in industry has provided me with valuable experience for the future. A special thank you also goes to Carl Maus, for sharing all of his testing expertise and to Peter Smith, for his time spent helping to machine samples.

Equally, I would like to say thank you very much to my academic supervisor, Cris Arnold, for all of the help, advice and ideas throughout the project. The guidance has been pivotal to completion of the thesis. Similarly, thank you very much to Sue Alston. The time spent helping throughout the duration of the project, particularly with thermal analysis, and the task of conditioning lots of samples is very much appreciated!

I would also like to extend my gratitude to North Thin Ply Technology for their support and for providing sample material. In particular I would like to say thank you to Yannick Prioux, who's help has been extremely useful.

Finally, but by no means least, a thank you to Swansea University and the M2A for making the research possible and for enabling such a great opportunity. 


\section{Abbreviations}

\begin{tabular}{|c|c|}
\hline Acronym & Definition \\
\hline AFM & Atomic force microscope \\
\hline ASTM & $\begin{array}{l}\text { International standards organisation (formally known as American } \\
\text { Society for Testing and Materials) }\end{array}$ \\
\hline BS & British Standard \\
\hline BSI & British Standards Institute \\
\hline CAI & Compression after impact \\
\hline CFRP & Carbon fibre reinforced polymer \\
\hline DIC & Digital image correlation \\
\hline DMA & Dynamic mechanical analysis \\
\hline$E^{\prime}$ & Storage modulus \\
\hline$E^{\prime \prime}$ & Loss modulus \\
\hline FAW & Fibre areal weight \\
\hline FEG-SEM & Field emission gun scanning electron microscope \\
\hline fps & Frames per second \\
\hline FRP & Fibre reinforced polymer \\
\hline$v_{f}$ & Fibre volume fraction \\
\hline $\mathrm{g} / \mathrm{m}^{2}$ & Grams per metre squared \\
\hline $\mathrm{GPa}$ & Gigapascal \\
\hline ILSS & Interlaminar shear strength \\
\hline IPS & In-plane shear \\
\hline ISO & International Organisation for Standardisation \\
\hline $\mathrm{MPa}$ & Megapascal \\
\hline $\mathrm{OHC}$ & Open-hole compression \\
\hline OHT & Open-hole tensile \\
\hline PES & Poly-ether-sulfone \\
\hline QI & Quasi-isotropic \\
\hline $\mathrm{T}_{\mathrm{g}}$ & Glass transition temperature \\
\hline UD & Unidirectional \\
\hline UKAS & United Kingdom Accreditation Service \\
\hline UNC & Unnotched compression \\
\hline UNT & Unnotched tensile \\
\hline UTS & Ultimate tensile strength \\
\hline
\end{tabular}




\section{Contents}

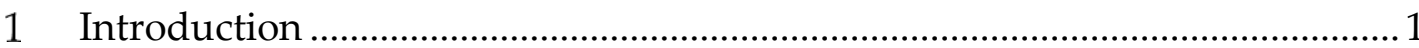

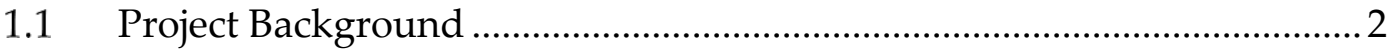

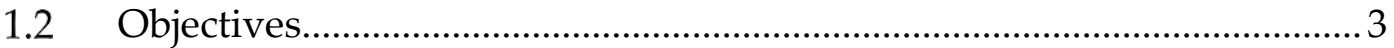

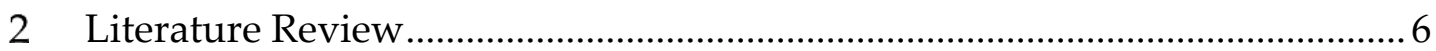

2.1 Introduction to Composite Materials ..................................................... 7

2.1.1 Fibre Reinforced Polymer Composite Manufacturing Methods ......8

2.2 Thin-ply Carbon Fibre Composites .......................................................... 9

2.3 Physical and Structural Properties of Composite Materials ....................12

2.4 Mechanical Properties of Composite Materials ....................................... 17

2.4.1 Quasi-static Tensile Behaviour ......................................................20

2.4.2 Quasi-static Open-hole Tensile Behaviour.......................................29

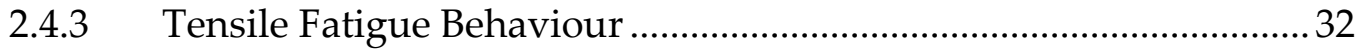

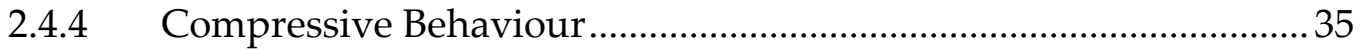

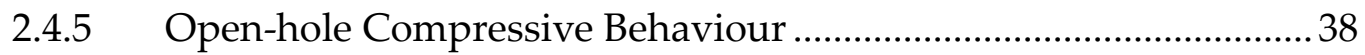

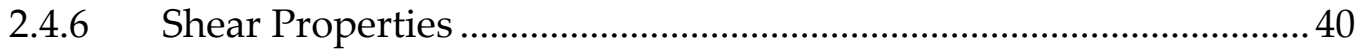

2.4.7 Compression after Impact Behaviour ................................................. 40

2.4.8 Mechanical Behaviour Summary ....................................................... 44

2.5 Influence of Moisture and High Temperature on the Behaviour of

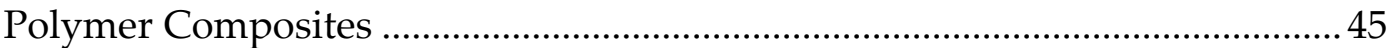

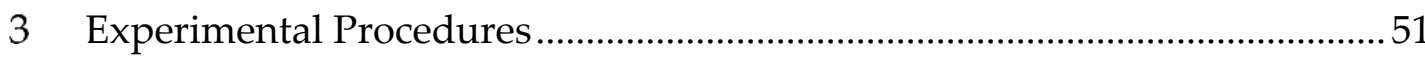

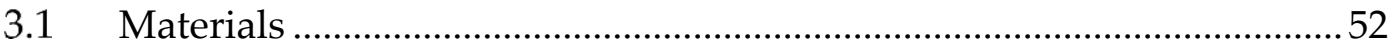

3.2 Material Quality Control ..................................................................... 54

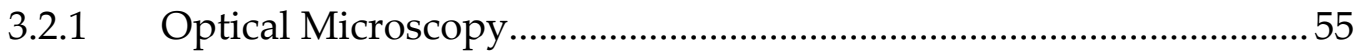




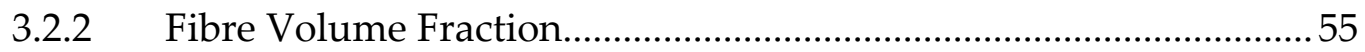

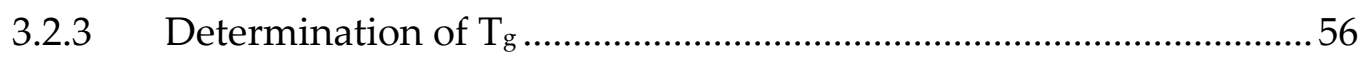

3.3 Production of Test Samples ….................................................................. 57

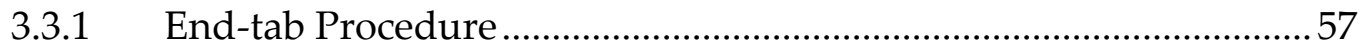

3.3.2 Production of Test Coupons............................................................... 58

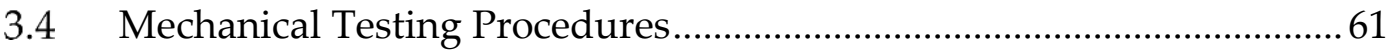

3.4.1 Mechanical Behaviour of Unconditioned Samples at Ambient Temperature

3.4.2 Tension-tension Fatigue Behaviour of Unconditioned Samples at

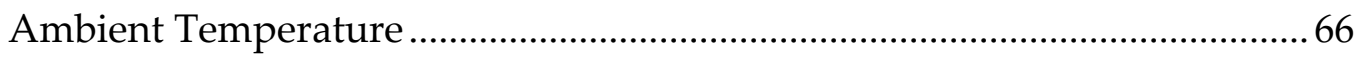

3.4.3 Mechanical Behaviour of Unconditioned Samples at High Temperature.

3.4.4 Mechanical Behaviour of Conditioned Samples at Ambient Temperature. .68

3.5 Investigating the Effect of Ply Thickness on Moisture Ingress ................68

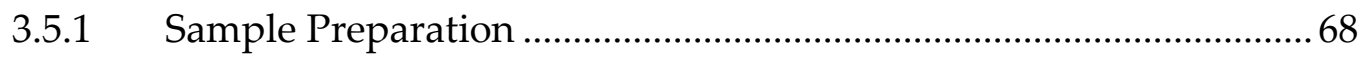

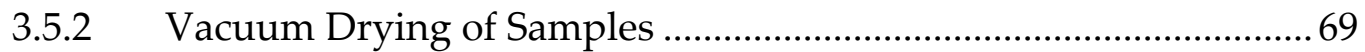

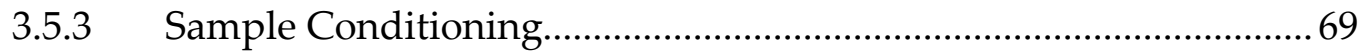

3.6 High Speed Camera Imaging Coupled with Digital Image Correlation 70

3.7 Field Emission Gun Scanning Electron Microscopy .71

3.8 Atomic Force Microscopy ……...............................................................

4 Investigation into the effect of Ambient and High Temperature on the Behaviour of Carbon Fibre Composites ……......................................................... 73

4.1 Introduction .74 
4.2.1 Optical Microscopy Analysis …….................................................... 75

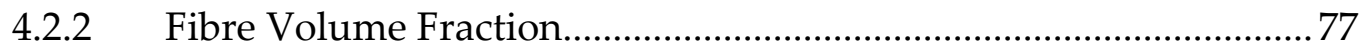

4.2.3 Determination of Glass Transition Temperature .............................. 78

4.3 Mechanical Behaviour of Unconditioned Samples at Ambient Temperature .87

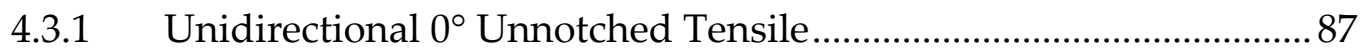

4.3.2 Unidirectional $90^{\circ}$ Unnotched Tensile................................................90

4.3.3 Quasi-isotropic Unnotched Tensile.................................................. 92

4.3.4 Quasi-isotropic Open-hole Tensile ................................................... 96

4.3.5 Unidirectional Unnotched Compression (Combined Loading) ... 100

4.3.6 Quasi-isotropic Unnotched Compression (Combined Loading)..103

4.3.7 Quasi-isotropic Open-hole Compression ......................................105

4.3.8 Interlaminar Shear Stress (Unidirectional and Quasi-Isotropic)... 107

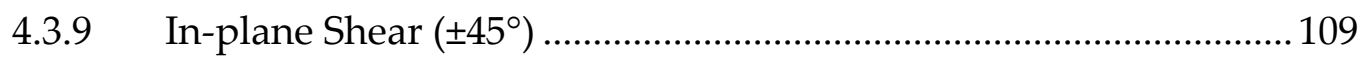

4.4 Tension-tension Fatigue Behaviour of Unconditioned Samples at Ambient Temperature

4.5 Mechanical Behaviour of Unconditioned Samples at High Temperature 112

4.5.1 Quasi-isotropic Unnotched Tensile

4.5.2 Quasi-isotropic Open-hole Tensile

4.5.3 Quasi-isotropic Open-hole Compression.....

4.6 Summary of Results

5 Investigation into the Effect of Moisture on the Behaviour of Thin-ply Carbon Fibre Composites 
5.2 Investigation into the Effect of Ply Thickness on Moisture Ingress ..... 121

5.2.1 Vacuum Drying

5.2.2 Monitoring the Effect of Ply Thickness on Moisture Ingress 123

5.2.3 Assessing the Effect of Ply Thickness on Diffusion Coefficient.... 127

5.3 Investigation into the Effect of Moisture on Mechanical Properties.... 129

5.3.1 Interlaminar Shear Stress (ILSS) 129

5.3.2 Unidirectional $90^{\circ}$ Unnotched Tension 131

5.3.3 Quasi-isotropic Open-hole Compression. 132

5.3.4 In-plane Shear $\left( \pm 45^{\circ}\right)$ 133

5.3.5 Summary 135

6 Effect of Ply Thickness on Mechanical Properties Discussion 137

6.1 Mechanical Testing Discussion 138

6.1.1 Quasi-static Unnotched Tensile Behaviour.... 138

6.1.2 Quasi-static Open-hole Tensile Behaviour. 154

6.1.3 Quasi-static Unnotched Compressive Behaviour 165

6.1.4 Quasi-static Open-hole Compressive Behaviour ............................166

6.1.5 Interlaminar Shear Strength Behaviour ......................................... 169

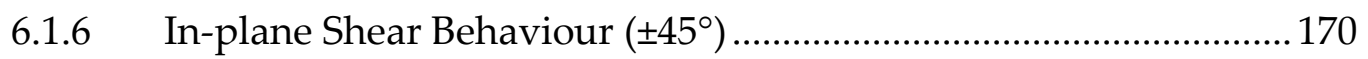

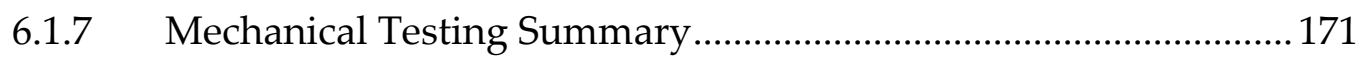

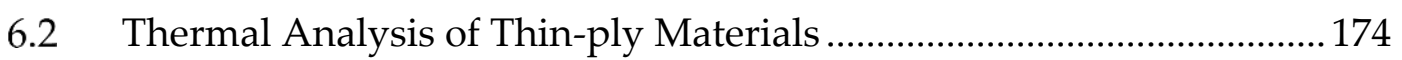

6.2.1 Investigation into Material Aging ................................................ 177

6.2.2 Effect of Ply Thickness on DMA Tan Delta.................................... 179

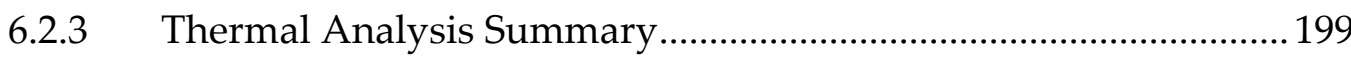




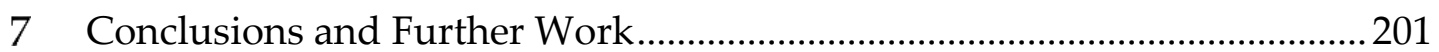

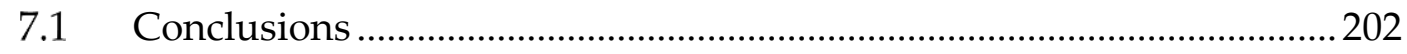

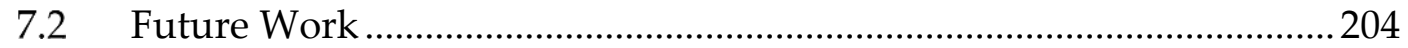

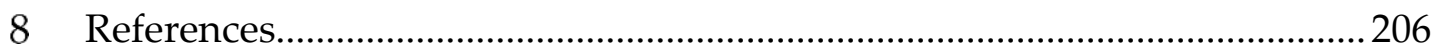




\section{List of Figures}

Figure 2.1 Prepreg stacking to form a $[-45 / 90 /+45 / 0]$ laminate................................ 9

Figure 2.2 Pneumatic fibre tow spreading technology [16] ................................... 11

Figure 2.3 Progression of air flow during tow spreading [16] ............................... 11

Figure 2.4 Fibre tow spreading schematic [16] ................................................... 11

Figure $2.512 \mathrm{~K}$ carbon fibre tow, before and after spreading: a) original tow (6 mm width), b) $12 \mathrm{~mm}$ spread-tow, c) $20 \mathrm{~mm}$ spread-tow [16]...................................... 12

Figure 2.6 a) Sub-laminate scaling b) Ply block scaling ........................................22

Figure 2.7 Micrographs to show test specimens made from spread-tow thin plies: a) thin-ply laminate (sub-laminate scaled), b) thick-ply laminate (ply block scaled) [16] .23

Figure 2.8 Stress/strain curves for QI thin and thick-ply laminates under quasi-static unnotched tensile loading [16] .23

Figure 2.9 Comparison of UTS, onset of damage and failure modes for QI material with varying ply thicknesses, tested in unnotched quasi-static tension [14] .......25 Figure 2.10 Impact of laminate thickness (and effective ply thickness) on openhole tensile strength (3.175 mm hole) [71] 30

Figure 2.11 X-ray images of: a) thick-ply and b) thin-ply laminates after static open-hole tensile loading applied at $448 \mathrm{MPa}$ [16]

Figure 2.12 Unnotched tensile stress/strain curves for QI thin and thick-ply laminates before and after 50,000 cycles of fatigue loading at $483 \mathrm{MPa}$ [16] ........33 Figure 2.13 X-ray images of QI unnotched tensile fatigue samples after 50,000 cycles at $60 \%$ of ultimate quasi-static strength: a) thick-ply, b) thin-ply [16] .....34 Figure 2.14 X-ray images of QI open-hole tensile fatigue specimens after 100,000 cycles at $70 \%$ of the ultimate quasi-static strength: a) thin-ply, b) thick-ply [16]35 Figure 2.15 Compressive strength of UD samples produced using different prepreg thicknesses [14] .37

Figure 2.16 Micrographs of unidirectional laminates made from various thickness prepregs (left $300 \mathrm{~g} / \mathrm{m}^{2}$, middle $150 \mathrm{~g} / \mathrm{m}^{2}$, right $50 \mathrm{~g} / \mathrm{m}^{2}$ ) [74] 37 
Figure 2.17 Compressive strength as a function of coupon thickness for sub-laminate scaled (solid line) and ply block scaled (dashed line) laminates [68]

Figure 2.18 CAI stress/strain curves of QI thick and thin-ply laminates [16] ...... 42

Figure 2.19 Correlation between delamination area and CAI strength [61] ........ 43

Figure 2.20 Cross sectional images of: a) thick-ply and b) thin-ply specimens after CAI testing. Grey areas represent the $0^{\circ}$ layers, bold black lines represent the transverse cracks and delamination areas (figure adapted from original) [61] ...43 Figure 4.1 Microscopy images (140× magnification) to assess laminate quality: a) panel 251 (QI, $\left.50 \mathrm{~g} / \mathrm{m}^{2}\right)$, b) panel 258 (QI, $\left.150 \mathrm{~g} / \mathrm{m}^{2}\right)$, c) panel 265 (QI, $\left.300 \mathrm{~g} / \mathrm{m}^{2}\right)$, d) panel $274\left(\mathrm{UD}, 50 \mathrm{~g} / \mathrm{m}^{2}\right)$, e) panel $276\left(\mathrm{UD}, 150 \mathrm{~g} / \mathrm{m}^{2}\right)$ .76

Figure 4.2 Scatter graph to show the glass transition temperature of all QI panels ( $\mathrm{T}_{\mathrm{g}}$ determined via onset of storage modulus) ..... .86

Figure 4.3 Scatter graph to show the glass transition temperature of all UD and IPS panels ( $\mathrm{T}_{\mathrm{g}}$ determined via onset of storage modulus). .86

Figure 4.4 Stress/strain curves for $0^{\circ}$ unnotched tensile specimens: a) $50 \mathrm{~g} / \mathrm{m}^{2}$, b) $150 \mathrm{~g} / \mathrm{m}^{2}$ .88

Figure $4.50^{\circ}$ unnotched tensile failure modes: a) $50 \mathrm{~g} / \mathrm{m}^{2}$, b) $150 \mathrm{~g} / \mathrm{m}^{2}$ .89

Figure 4.6 Mean $0^{\circ}$ unnotched tensile stress and strain data (normalised) [set of six samples per material] .90

Figure $4.790^{\circ}$ unnotched tensile failure modes: a) $50 \mathrm{~g} / \mathrm{m}^{2}$, b) $150 \mathrm{~g} / \mathrm{m}^{2}$ .91 Figure 4.8 Mean $90^{\circ}$ unnotched tensile stress and strain data (not normalised) [set of eight samples per material] .92

Figure 4.9 Stress/strain curves for QI unnotched tensile specimens: a) $50 \mathrm{~g} / \mathrm{m}^{2}$, b) $150 \mathrm{~g} / \mathrm{m}^{2}$, c) $300 \mathrm{~g} / \mathrm{m}^{2}$. .. 94

Figure 4.10 QI unnotched tensile failure modes: a) $50 \mathrm{~g} / \mathrm{m}^{2}$, b) $150 \mathrm{~g} / \mathrm{m}^{2}$, c) $300 \mathrm{~g} / \mathrm{m}^{2}$

Figure 4.11 Mean QI unnotched tensile stress and strain data (normalised) [set of six samples per material] .96 
Figure 4.12 Stress/strain curves for QI open-hole tensile specimens: a) $50 \mathrm{~g} / \mathrm{m}^{2}$, b) $\left.150 \mathrm{~g} / \mathrm{m}^{2}, \mathrm{c}\right) 300 \mathrm{~g} / \mathrm{m}^{2}$ .98

Figure 4.13 QI open-hole tensile failure modes: a) $50 \mathrm{~g} / \mathrm{m}^{2}$, b) $150 \mathrm{~g} / \mathrm{m}^{2}$, c) $300 \mathrm{~g} / \mathrm{m}^{2}$ .99

Figure 4.14 Mean QI open-hole stress and strain data (normalised) [set of six samples per material] 100

Figure 4.15 Stress/strain curves for $0^{\circ}$ unnotched compression specimens: a) $50 \mathrm{~g} / \mathrm{m}^{2}$, b) $150 \mathrm{~g} / \mathrm{m}^{2}$ (note: deformation based on crosshead displacement, not strain gauge data) 101

Figure $4.160^{\circ}$ unnotched compression failure modes: a) $50 \mathrm{~g} / \mathrm{m}^{2}$, b) $150 \mathrm{~g} / \mathrm{m}^{2} .102$ Figure 4.17 QI unnotched compression failure modes: a) $50 \mathrm{~g} / \mathrm{m}^{2}$, b) $150 \mathrm{~g} / \mathrm{m}^{2} 104$ Figure 4.18 QI open-hole compression failure modes: a) $50 \mathrm{~g} / \mathrm{m}^{2}$, b) $150 \mathrm{~g} / \mathrm{m}^{2}$, c) $300 \mathrm{~g} / \mathrm{m}^{2}$ (note: images refer to the sides of the specimens) 106 Figure 4.19 Force/displacement curves for $0^{\circ}$ ILSS specimens: a) $50 \mathrm{~g} / \mathrm{m}^{2}$, b) $150 \mathrm{~g} / \mathrm{m}^{2}$ 108

Figure 4.20 Mean $0^{\circ}$ and QI ILSS data (not normalised) [set of six samples per material] 109

Figure 4.21 Example in-plane shear stress/strain curves for $50 \mathrm{~g} / \mathrm{m}^{2}, 150 \mathrm{~g} / \mathrm{m}^{2}$ and $300 \mathrm{~g} / \mathrm{m}^{2}$ test coupons 110

Figure $4.22 \mathrm{~S}-\mathrm{N}$ curve for $50 \mathrm{~g} / \mathrm{m}^{2}$ and $150 \mathrm{~g} / \mathrm{m}^{2}$ open-hole tension-tension fatigue samples 111

Figure 4.23 Percentage of mean, quasi-static, open-hole tensile stress verses number of cycles for $50 \mathrm{~g} / \mathrm{m}^{2}$ and $150 \mathrm{~g} / \mathrm{m}^{2}$ open-hole tension-tension fatigue samples

Figure 4.24 Mean QI unnotched tensile (UNT) stress data at various test temperatures (normalised) [minimum of 5 samples per test]. 113 Figure 4.25 Mean QI open-hole tensile (OHT) stress data at various test temperatures (normalised) [minimum of 5 samples per test]. 114 
Figure 4.26 Mean QI open-hole compressive (OHC) stress values at various test temperatures (normalised) [minimum of five samples per test] 115

Figure 5.1 Vacuum oven drying of T800 TP135 to a constant mass 122 Figure 5.2 Mean percentage mass increase for QI T800 TP135 material manufactured using varying ply thicknesses and conditioned at $70{ }^{\circ} \mathrm{C}$ with different relative humidity environments 125 Figure 5.3 Mean percentage mass increase for UD T800 TP135 material, manufactured using varying ply thicknesses and conditioned at $70{ }^{\circ} \mathrm{C}$ with different relative humidity environments 126

Figure 5.4 Removal of long-term moisture absorption to give an estimation of Fickian behaviour 127 Figure 5.5 Mean diffusion coefficient values for $50 \mathrm{~g} / \mathrm{m}^{2}, 150 \mathrm{~g} / \mathrm{m}^{2}$ and $300 \mathrm{~g} / \mathrm{m}^{2}$ material, conditioned in different relative humidity environments (three replicate samples per material)

Figure 5.6 Mean $0^{\circ}$ ILSS data after conditioning in different relative humidity environments (not normalised) [minimum of five samples per test] 130 Figure 5.7 Mean $90^{\circ}$ unnotched tensile (UNT) stress data, after conditioning in different relative humidity environments (not normalised) [minimum of five samples per test] 131 Figure 5.8 Mean QI open-hole compressive (OHC) stress data, after conditioning in different relative humidity environments (normalised) [minimum of five samples per test] 133

Figure 5.9 Mean in-plane shear (IPS) stress data, after conditioning in different relative humidity environments (not normalised) [minimum of four samples per test]

Figure 5.10 Example in-plane shear stress/strain curves for, $50 \mathrm{~g} / \mathrm{m}^{2}, 150 \mathrm{~g} / \mathrm{m}^{2}$ and $300 \mathrm{~g} / \mathrm{m}^{2}$ samples, tested after conditioning in different humid environments (blue curves: unconditioned, orange curves: $65 \% \mathrm{RH}$, green curves: $85 \% \mathrm{RH}$ ) 
Figure 6.1 Microscopy images (140× magnification) of: a) UD, $50 \mathrm{~g} / \mathrm{m}^{2}$, b) UD, $150 \mathrm{~g} / \mathrm{m}^{2}$ laminates 139

Figure 6.2 Stills from high speed camera video recording of a $50 \mathrm{~g} / \mathrm{m}^{2}$ unnotched tensile failure mechanism (shot at 8,000 fps) 143

Figure 6.3 Stills from high speed camera video recording of a $150 \mathrm{~g} / \mathrm{m}^{2}$ unnotched tensile failure mechanism (shot at 8,000 fps) 144

Figure 6.4 Stills from high speed camera video recording of a $300 \mathrm{~g} / \mathrm{m}^{2}$ unnotched tensile failure mechanism (shot at 8,000 fps) 145

Figure 6.5 Change in strain (tensile load direction) during unnotched tensile tests: a) $50 \mathrm{~g} / \mathrm{m}^{2}$, b) $150 \mathrm{~g} / \mathrm{m}^{2}$. Images show strain maps immediately prior to sample break. 148

Figure 6.6 Graph to show the glass transition temperature of each panel used for the unnotched tensile samples under various test conditions $\left(50 \mathrm{~g} / \mathrm{m}^{2}\right.$ samples: orange, $150 \mathrm{~g} / \mathrm{m}^{2}$ samples: blue, $300 \mathrm{~g} / \mathrm{m}^{2}$ samples: green)

Figure 6.7 Stills from high speed camera video recording of a $50 \mathrm{~g} / \mathrm{m}^{2}$ open-hole tensile failure mechanism (shot at 8,000 fps) 156

Figure 6.8 Stills from high speed camera video recording of a $150 \mathrm{~g} / \mathrm{m}^{2}$ open-hole tensile failure mechanism (shot at 8,000 fps) 157

Figure 6.9 Stills from high speed camera video recording of a $300 \mathrm{~g} / \mathrm{m}^{2}$ open-hole tensile failure mechanism (shot at 8,000 fps) [initial failure, specimen 1] 158 Figure 6.10 Stills from high speed camera video recording of a $300 \mathrm{~g} / \mathrm{m}^{2}$ open-hole tensile failure mechanism (shot at 8,000 fps) [final failure, specimen 2] 159 Figure 6.11 Change in strain (tensile load direction) during open-hole tensile tests: a) $50 \mathrm{~g} / \mathrm{m}^{2}$, b) $150 \mathrm{~g} / \mathrm{m}^{2}$, c) $300 \mathrm{~g} / \mathrm{m}^{2}$ ). Images show strain map immediately prior to sample break 161

Figure 6.12 Graph to show the glass transition temperature of each panel used for the open-hole tensile samples, under various test conditions $\left(50 \mathrm{~g} / \mathrm{m}^{2}\right.$ samples: orange, $150 \mathrm{~g} / \mathrm{m}^{2}$ samples: blue, $300 \mathrm{~g} / \mathrm{m}^{2}$ samples: green) 164 
Figure 6.13 Mean QI open-hole compressive stress data, tested under different environmental conditions (normalised) [minimum of four samples per test] .. 169 Figure 6.14 Bar charts to show the impact of ply thickness on different mechanical properties after exposure to various environment conditions $\left(50 \mathrm{~g} / \mathrm{m}^{2}\right.$ : green, $150 \mathrm{~g} / \mathrm{m}^{2}$ : pink, $300 \mathrm{~g} / \mathrm{m}^{2}:$ blue) 173

Figure 6.15 Graph showing tan delta curves for three different samples from panel 255, a) blue curve: $15 \mathrm{~mm}$ span and $0.05 \mathrm{~mm}$ strain deflection, b) green curve: $10 \mathrm{~mm}$ span and $0.03 \mathrm{~mm}$ strain deflection, c) red curve: $10 \mathrm{~mm}$ span and $0.03 \mathrm{~mm}$ strain deflection 176

Figure 6.16 DMA tan delta heating curves for laminates with different ply thicknesses (50 g/m²: blue, $150 \mathrm{~g} / \mathrm{m}^{2}$ : orange, $300 \mathrm{~g} / \mathrm{m}^{2}:$ purple) 180 Figure 6.17 DMA tan delta cooling curves for laminates with different ply thicknesses (50 g/m²: blue, $150 \mathrm{~g} / \mathrm{m}^{2}$ : orange, $300 \mathrm{~g} / \mathrm{m}^{2}$ : purple) 180 Figure 6.18 DMA tan delta curve for a $50 \mathrm{~g} / \mathrm{m}^{2}$ sample from panel number 250 (first heat and re-heat) [second heat and cool denoted by '(2R)' and represented by dashed lines] 181

Figure 6.19 DMA tan delta curve for a $150 \mathrm{~g} / \mathrm{m}^{2}$ sample from panel number 261 (first heat and re-heat) [second heat and cool denoted by ' $(2 \mathrm{R})^{\prime}$ and represented by dashed lines] 181

Figure 6.20 DMA tan delta curve for a $300 \mathrm{~g} / \mathrm{m}^{2}$ sample from panel number 268 (first heat and re-heat) [second heat and cool denoted by '(R)' and represented by dashed lines] 182

Figure 6.21 DMA tan delta and storage modulus heating curves for a $50 \mathrm{~g} / \mathrm{m}^{2}$ sample from panel number 251, after exposure to different humid environments [second heat denoted by '(R)' and represented by dashed lines] 184

Figure 6.22 DMA tan delta curves for $50 \mathrm{~g} / \mathrm{m}^{2}$ samples from panel numbers 251 and 253, after exposure to different humid environments [second heat denoted by '(R)'] 184 
Figure 6.23 DMA tan delta and storage modulus heating curves for a $150 \mathrm{~g} / \mathrm{m}^{2}$ sample from panel number 259, after exposure to different humid environments [second heat denoted by '(R)' and represented by dashed lines] 185

Figure 6.24 DMA tan delta curves for $150 \mathrm{~g} / \mathrm{m}^{2}$ samples from panel numbers 259 and 263, after exposure to different humid environments [second heat denoted by '(R)'] 185

Figure 6.25 AFM images of a $50 \mathrm{~g} / \mathrm{m}^{2}$ sample: a) AFM height map (proud areas represented by brighter colours) b) force modulation image (stiffer areas represented by brighter colours). White box indicates the magnified area shown in Figure 6.26. 189

Figure 6.26 Higher magnification AFM images of the $50 \mathrm{~g} / \mathrm{m}^{2}$ sample shown in Figure 6.25: a) AFM height map (proud areas represented by brighter colours) b) force modulation image (stiffer areas represented by brighter colours) 190 Figure 6.27 AFM images of a $50 \mathrm{~g} / \mathrm{m}^{2}$ sample: a) AFM height map (proud areas represented by brighter colours) b) force map data (stiffer areas represented by brighter colours). The force map image shows excessive noise 191

Figure 6.28 Epoxy resin, phenol resin and PES mixture phase diagram [123] .. 192 Figure 6.29 FEG-SEM images of freezer stored T800 TP135 QI material: a) 50 g/m², b) $150 \mathrm{~g} / \mathrm{m}^{2}$, c) $300 \mathrm{~g} / \mathrm{m}^{2}$ [note, arrows indicate example second phase particles within the material] 195

Figure 6.30 FEG-SEM images of T800 TP135 QI material stored at room temperature for three months: a) $50 \mathrm{~g} / \mathrm{m}^{2}$, b) $150 \mathrm{~g} / \mathrm{m}^{2}$, c) $300 \mathrm{~g} / \mathrm{m}^{2}$ [note, arrows indicate example second phase particles within the material] 196 Figure 6.31 FEG-SEM images of T800 TP135 QI material after curing at $180{ }^{\circ} \mathrm{C}$ for two hours: a) $50 \mathrm{~g} / \mathrm{m}^{2}$, b) $150 \mathrm{~g} / \mathrm{m}^{2}$, c) $300 \mathrm{~g} / \mathrm{m}^{2}$ [note, arrows indicate example second phase particles within the material] 197 Figure 6.32 FEG-SEM images of T800 TP135 QI material after conditioning until saturation at $85 \% \mathrm{RH}, 70{ }^{\circ} \mathrm{C}$ : a) $50 \mathrm{~g} / \mathrm{m}^{2}$, b) $150 \mathrm{~g} / \mathrm{m}^{2}$, c) $300 \mathrm{~g} / \mathrm{m}^{2}$ [note, arrows indicate example second phase particles within the material] 198 


\section{List of Tables}

Table 2.1 Static tensile test results for sub-laminate scaled specimens (recreated from [64])

Table 2.2 Static tensile test results for ply level scaled specimens (recreated from [64])

Table 3.1 List of T800 TP135 carbon fibre composite panels, including panel stacking sequence, panel number, ply thickness and panel dimensions (Page 1 of 2)

Table 3.2 Test coupon specification (Page 1 of 2) .59

Table 3.3 Mechanical testing programme (Page 1 of 2). Shaded numbers refer to the number of samples tested. Numbers in brackets denote the number of samples tested with valid failures (applicable if invalid tests or failure modes occurred)

Table 3.4 Mechanical testing parameters (quasi-static loading)

Table 4.1 Mean fibre volume fraction for each ply thickness and ply orientation

Table 4.2 DMA results and the specific testing parameters for all QI carbon fibre panels used for testing. All panels have the same overall thickness of $2.1 \mathrm{~mm}$ $\pm 0.3 \mathrm{~mm}$ (page 1 of 2 )

Table 4.3 DMA results and the specific testing parameters for all UD carbon fibre panels used for testing. All panels have an overall thickness of $2.0 \mathrm{~mm} \pm 0.3 \mathrm{~mm}$, except for the panels shaded in green. The panels shaded in green have an overall thickness of $1.0 \mathrm{~mm} \pm 0.15 \mathrm{~mm}$

Table 4.4 DMA results and the specific testing parameters for all $\pm 45^{\circ}$ carbon fibre panels used for testing. All panels have an overall thickness of $2.1 \mathrm{~mm} \pm 0.25 \mathrm{~mm}$

Table 4.5 Mean glass transition temperature values .84

Table 4.6 Mean $0^{\circ}$ unnotched tensile stress, strain and modulus values (normalised) [set of six samples per material] .90 
Table 4.7 Mean $90^{\circ}$ unnotched tensile stress, strain and modulus values (not normalised) [set of eight samples per material]. .92

Table 4.8 Mean QI unnotched tensile stress, strain and modulus values (normalised) [set of six samples per material] .96

Table 4.9 Mean QI open-hole tensile stress, strain and modulus values (normalised) [set of six samples per material]. 100

Table 4.10 Mean $0^{\circ}$ unnotched compressive stress and modulus values (normalised) 102

Table 4.11 Mean QI unnotched compressive stress values (normalised) [set of five samples per material] 103

Table 4.12 Mean QI open-hole compressive stress values (normalised) [set of six samples per material] 105

Table 4.13 Mean $0^{\circ}$ and QI ILSS values (not normalised) [set of six samples per material] 108

Table 4.14 Mean in-plane shear stress and modulus values (not normalised) .. 110 Table 4.15 Summary of maximum stress values for all unconditioned and high temperature tested samples (numbers highlighted in pink denote the values which are significantly greater for that particular test and condition). Fibre dominated test results have been normalised, as described in Section 3.2.2 ….117 Table 4.16 Summary of strain at break values for all unconditioned and high temperature tested samples (numbers highlighted in pink denote the values which are significantly greater for that particular test and condition) 118 Table 4.17 Summary of modulus values for all unconditioned and high temperature tested samples (numbers highlighted in pink denote the values which are significantly greater for that particular test and condition) 119 Table 5.1 Mean diffusion coefficient values for $50 \mathrm{~g} / \mathrm{m}^{2}, 150 \mathrm{~g} / \mathrm{m}^{2}$ and $300 \mathrm{~g} / \mathrm{m}^{2}$ material, conditioned in different relative humidity environments (three replicate samples per material) 128 
Table 6.1 Mean QI unnotched tensile stress values in MPa (normalised) [minimum of five samples per test] 150

Table 6.2 Comparison of ultimate tensile stress values for $300 \mathrm{~g} / \mathrm{m}^{2}$ samples tested after exposure to different environments. .151

Table 6.3 Mean QI open-hole tensile stress values in MPa (normalised) [minimum of five samples per test] 162

Table 6.4 Effect of storage environment on glass transition temperature for samples of panel $255\left(\mathrm{QI}, 50 \mathrm{~g} / \mathrm{m}^{2}\right)$ 177

Table 6.5 Glass transition temperatures of samples with different ply thicknesses, stored in different environment for approximately 12 weeks 178 
1 Introduction 


\subsection{Project Background}

A composite is defined as the amalgamation of two or more materials with distinctly different properties, which, when combined together, create properties which are better than either of its individual constituents [1,2]. Typically, a composite material will take the form of a strong, stiff material embedded within a softer matrix material. There are three main classes of synthetic composite, categorised by the matrix material: polymer, metal and ceramic [3]. Of these, polymer matrix composites are the most common [1]. Polymer matrix composites, or fibre reinforced polymers (FRPs), are manufactured using stiff fibres (such as glass, polyaramid or carbon) and a more flexible matrix. They are well known for having desirable properties, such as high specific strength and specific stiffness, good corrosion resistance and low weight $[4,5]$. These properties have enabled FRPs to become prevalent in a wide range of industries, including aerospace [4], automotive [6], construction [7] and marine [8] to name a few.

Carbon fibres are a popular constituent of fibre reinforced polymers. To demonstrate, between 2008 and 2013 the annual growth rate for carbon fibre was $8.1 \%$ [9] and in more recent years, the annual growth rate has increased to approximately $11 \%[10,11]$. Almost all of the manufactured carbon fibre is combined with a matrix to form carbon fibre reinforced polymers (CFRPs) [9]. This increasing popularity has encouraged research focused on enhancing material performance, for example by improving mechanical properties, or reducing material costs. One example of this is the development of thin-ply materials. As the name suggests, thin-ply materials consist of thinner layers (plies) than those conventionally used in composites. Typically, the layers within a thin-ply material are less than $100 \mu \mathrm{m}$ in thickness [12] and can be as low as $15 \mu \mathrm{m}$ for certain fibre types [13].

The use of thin-ply technology has attracted attention in recent years, particularly since the industrialisation of spread-tow methods [12]. This is due to the benefits 
that can be provided compared to conventional composites. For example, thin-ply materials allow for a greater variation of ply orientation [14]. Put simply, using thinner plies means more layers can be used within a given space, compared to traditional composites. This provides more freedom to optimise the orientation of the plies within the material, to suit the desired application accordingly. In addition, previous research has shown thin-ply materials to have enhanced mechanical properties and improved onset of damage compared to conventional materials, particularly for non-unidirectional laminates [14-16]. The use of thin-ply technology has also been shown to provide the benefit of a more homogeneous laminate [14]. This is attributed to the fibre spreading process, which spreads the fibre tow into a more uniform layer, with less resin rich areas [17].

Previous research into the performance of thin-ply materials was largely focussed on mechanical properties at ambient conditions. However, given their wide-spread use, composite materials often need to withstand a range of different environmental conditions, such as non-ambient temperatures and changes in humidity. With this in mind, the aim of this Engineering Doctorate was to expand on the current knowledge of thin-ply carbon fibre composites, by investigating the effect of ply thickness on mechanical properties, not only at ambient conditions, but after exposure to high temperature and high humidity environments. The project was initiated by R-Tech Services Ltd.

\subsection{Objectives}

The objectives of this thesis were:

- to investigate the effect of ply thickness on the mechanical properties of carbon fibre composite materials under different environmental conditions:

a) ambient temperature 
b) high temperature

c) after exposure to humid environments

- to determine if ply thickness has an effect on the absorption of moisture into the material

- to further understand why variations to ply thickness lead to changes in properties, using techniques such as high-speed camera video recording and thermal analysis

By conducting this research, it was envisioned that the expertise of R-Tech Service's composites testing department would be enhanced. As such, secondary aims of this research were:

- to develop current in-house methods for laminate and coupon manufacture and preparation, to comply with the tolerances outlined in international standards (including ASTM and BS ISO)

- to develop in-house expertise on characterisation of composite materials, such as microscopy and thermal analysis techniques

- to expand on R-Tech Services' understanding of different international composite testing standards, with a view to expand the UKAS (United Kingdom Accreditation Service) testing capabilities and to obtain Nadcap accreditation

In summary, the focus of this research was to investigate the mechanical properties of thin-ply carbon fibre composites under differing environmental conditions, whilst enhancing the expertise of R-Tech Services' composite department.

The thesis structure is as follows: firstly, to highlight areas of required research, a review of the current scientific literature relating to the effect of ply thickness on the performance of composite materials is presented. Next, a comprehensive description of the experimental procedures used throughout the project is 
documented. Chapter 4 then details the results of the ambient and high temperature mechanical testing. The chapter begins with the results of the material characterisation tests, which were conducted to ensure meaningful comparisons between test coupons with different prepreg thicknesses. The tests carried out include: microscopy analysis, fibre volume fraction analysis and determination of glass transition temperature $\left(\mathrm{T}_{\mathrm{g}}\right)$. Subsequently, the results of the ambient temperature mechanical tests, and the quasi-static high temperature tests are given. Due to the large volume of data in this chapter, only a limited discussion of the results is provided. Instead, a more comprehensive discussion of all the mechanical tests can be found later in the thesis. Chapter 5 describes the work conducted relating to the exposure of CFRPs to humid environments. This includes the experimental data for moisture ingress tests (used to assess the effect of ply thickness on moisture absorption and diffusion rate) as well as the mechanical test results for coupons tested after exposure to humid environments. Chapter 6 provides a comprehensive discussion of all experimental results, categorised by environmental condition (ambient temperature, high temperature and humidity conditioned) and test type (tensile, compression or shear). The section also details the techniques used to obtain further understanding of the thin-ply behaviour, such as high-speed camera video recording and digital image correlation (DIC). Further to this, additional work, carried out to understand the thermo-mechanical behaviour of thin-ply composites, is discussed. This includes the use of dynamic mechanical analysis (DMA), field emission gun scanning electron microscopy (FEG-SEM) and atomic force microscopy (AFM). Finally, the last chapter in the thesis presents the conclusions for the project and concludes with a summary of potential future work. 
2 Literature Review 


\subsection{Introduction to Composite Materials}

A composite is described as a material which consists of two or more distinct parts which, when combined, create superior properties to that of each of the individual constituents [1]. The materials used to make a composite are microscopically distinct; they do not form homogeneous mixtures [2]. Many naturally occurring materials are examples of composites. Wood, for example, comprises long cellulose fibres, embedded in a substance called lignin. Both materials are weaker by themselves, compared to when combined. The benefit of joining two materials together to create a superior product has been apparent for many years. One of the earliest examples of a man-made composite is concrete. The unique combination of aggregate, cement and sand create a product with far greater compressive strength than would be possible for any of the materials alone.

Some of the most commonly used composites in the world today are those comprising stiff fibres and a more flexible, polymer matrix. Fibres commonly used in polymer composites include glass, polyaramids and carbon. The benefit of glass fibres is their low cost, compared to either carbon or aramid fibres, and polyaramid fibres are known for their high toughness [18]. Carbon fibres are stiff and strong and are most commonly used in structurally demanding roles. Carbon fibre reinforced polymers are a combination of fibre (carbon) and, commonly, a thermosetting resin matrix (such as polyester, epoxy or vinyl ester). Thermoplastic resin matrices are also an option, however they tend to be more difficult to process due to their high viscosity. That said, thermoplastics are gaining popularity, due to their low cost and their ability to be recycled [19-21]. The resin, or 'matrix', holds the fibres (the load bearing phase) together, whilst also acting to transmit stresses between the fibres and protect them from damage. Without the matrix the fibres have extremely limited use, but the combination of both fibre and resin offers very desirable mechanical properties. 
The predominant reason for the popularity of synthetic composites is the well-known weight savings, relative to their high stiffness and strength, that they offer. Some CFRPs have five times greater strength than 1020 grade steel, whilst being only a fifth of the weight [22]. Compared to 6061 grade aluminium alloy, carbon fibre composite is up to seven times stronger and has twice the modulus values [22], albeit less of a weight saving when compared to 1020 steel. Furthermore, carbon fibre composites also benefit from enhanced corrosion resistance. Airbus state that manufacturing aircraft components (such as the fuselage and the wing) from composite materials, instead of traditional metallic materials, has reduced the number of structure maintenance tasks by as much as $50 \%$ [23]. This is largely due to the lack of corrosion. As a result of the aforementioned benefits, composite materials are now widespread in various industries, such as aerospace. An example is the Boeing 787 commercial aircraft which is manufactured from $50 \%$ advanced composite materials [24]. This growing popularity is a key driver for material development, both structurally and economically.

\subsubsection{Fibre Reinforced Polymer Composite Manufacturing Methods}

Fibre reinforced polymer composite materials can be manufactured in numerous ways. Typical manufacturing routes include hand lay-up, vacuum infusion, resin transfer moulding, filament winding and the use of prepreg. The hand lay-up method typically requires little investment and is used for low-volume manufacturing. Resin is manually applied to layers (called plies) of dry fibre mat, using a roller, to create a laminate. The laminate is then cured in an oven according to the required curing schedule. The vacuum infusion method involves stacking plies of dry reinforcement (in the required orientations) into a mould, before using a vacuum to draw resin through the material. This is then cured to give the final laminate. Resin transfer moulding is similar; dry fabric is laid into a two-part mould which is closed using a heat press. Resin is injected at pressure until the fabric is impregnated and then the material is cured. Filament winding 
(often used to manufacture pipes) is when fibre tows are passed through liquid resin and wound onto a rotating cylindrical mandrel [25]. The final method, and the one which is used to manufacture the thin-ply carbon fibre composites used in this project, is the use of prepreg. Prepreg consists of unidirectional fibres pre-impregnated with a semi-cured resin system. This negates the need to add resin at the lay-up stage. The prepreg layers are stacked in the required fibre orientation and heated under pressure, typically in an autoclave, according to the required cure schedule. A schematic of a carbon fibre laminate formed using prepreg is shown in Figure 2.1.

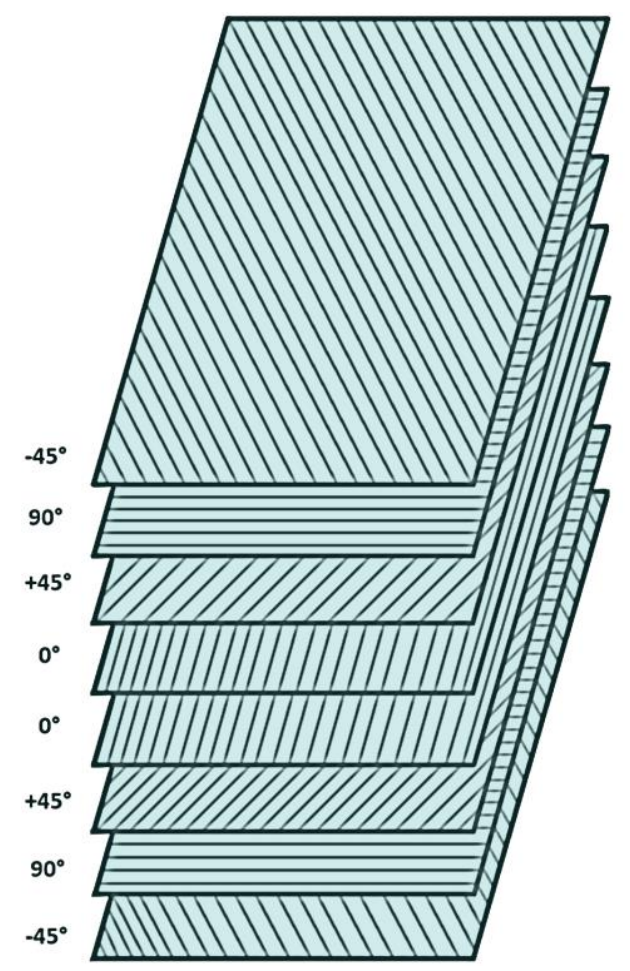

Figure 2.1 Prepreg stacking to form a [-45/90/+45/0] laminate

\subsection{Thin-ply Carbon Fibre Composites}

As the name suggests, thin-ply means that the prepreg used to manufacture the composite laminate is thinner than those conventionally used. Typical thin-ply materials have prepreg weights of between $20 \mathrm{~g} / \mathrm{m}^{2}$ and $50 \mathrm{~g} / \mathrm{m}^{2}$, in comparison to conventional thicknesses of between $100 \mathrm{~g} / \mathrm{m}^{2}$ and $300 \mathrm{~g} / \mathrm{m}^{2}$. Therefore, a thin-ply laminate contains more layers than a conventional ply thickness laminate, of the same overall thickness. This is one of the main advantages of 
thin-ply CFRPs. The design space of the laminate is enhanced, allowing for greater variation of ply orientation. As the laminate consists of a larger number of plies, the manufacturer can produce materials with a greater variation of fibre orientations [14]. This can lead to increased strength, either by orientating fibres directionally along one axis, to create an anisotropic material, or by varying the fibre orientations to give increased isotropic strength.

The manufacture of thin-ply prepreg requires specialised technology that prevents damage to the fibres. Fibre damage leads to reduced mechanical performance of the finished material. The Industrial Technology Centre in Fukui Prefecture demonstrated a thin-ply prepreg manufacturing method whereby the fibre tow (a bundle of untwisted, continuous fibres) is spread to reduce its thickness $[16,26]$. A conventional thickness tow, such as $12 \mathrm{k}(12,000$ filaments per tow) is passed through a spreading machine, which contains an air duct and a vacuum. The vacuum draws the air downwards through the air duct, which is located in-between two guide rolls, as seen in Figure 2.2. Forcing the air downwards between these rolls causes the tow to sag and lose tension, resulting in a momentary tension-free state (see Figure 2.3). The difference in velocity of the airflow directly next to the tow and further away from the tow cause changes in pressure. The pressure directly next to the tow increases, creating the aerodynamic force that aids the loss of tension within the filaments. As the tow begins to spread, air is able to flow in between the individual filaments, causing the process to speed up. By uniformly applying the airflow, the tow will spread evenly. The method is non-destructive to the fibres, due to the low velocity of the airflow. Schematic and photographic examples of an original 'un-spread' 12k carbon fibre tow and the resulting spread-tow material are shown in Figure 2.4 and Figure 2.5 [16]. 


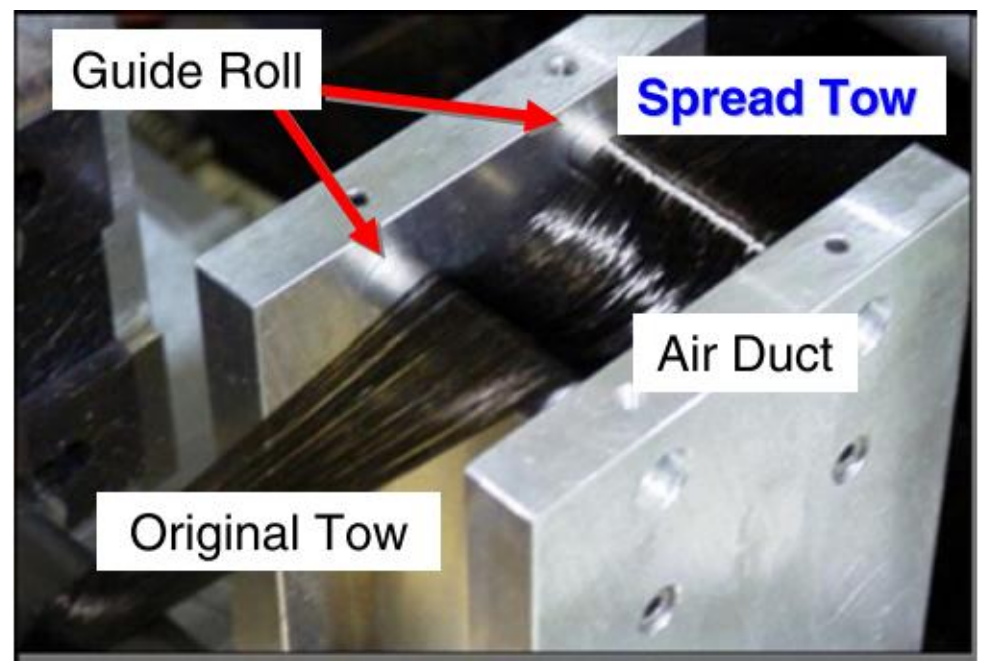

Figure 2.2 Pneumatic fibre tow spreading technology [16 $]^{1}$

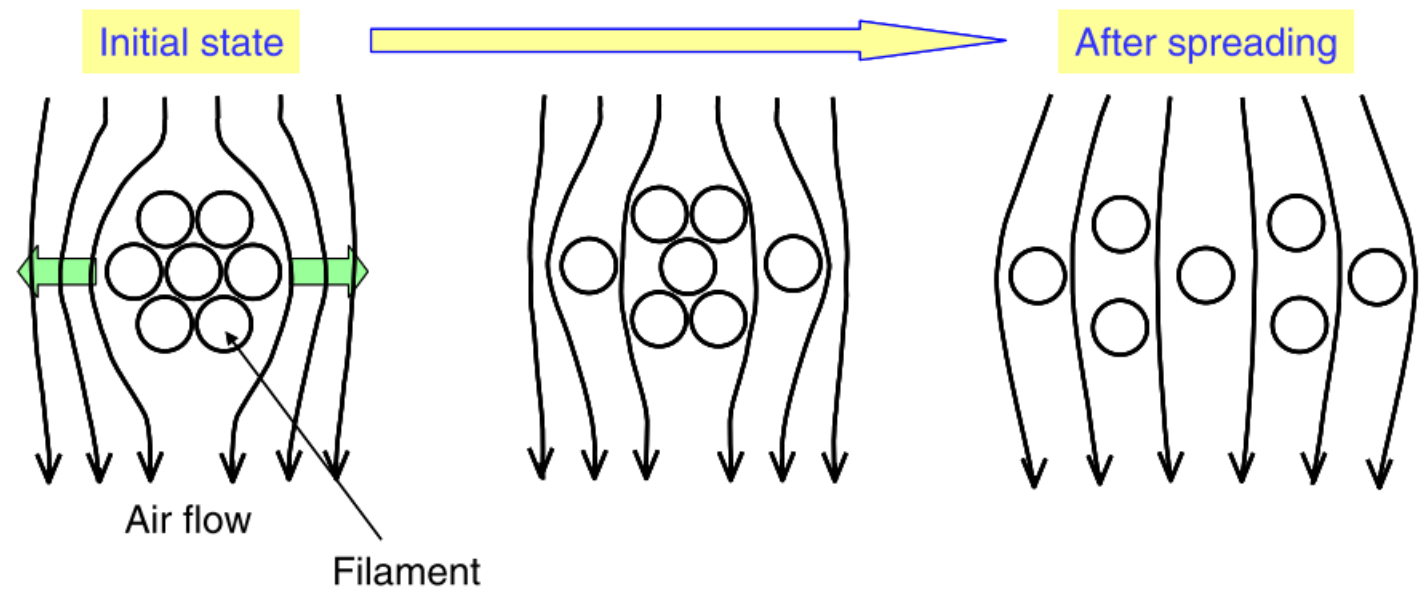

Figure 2.3 Progression of air flow during tow spreading [16] ${ }^{1}$

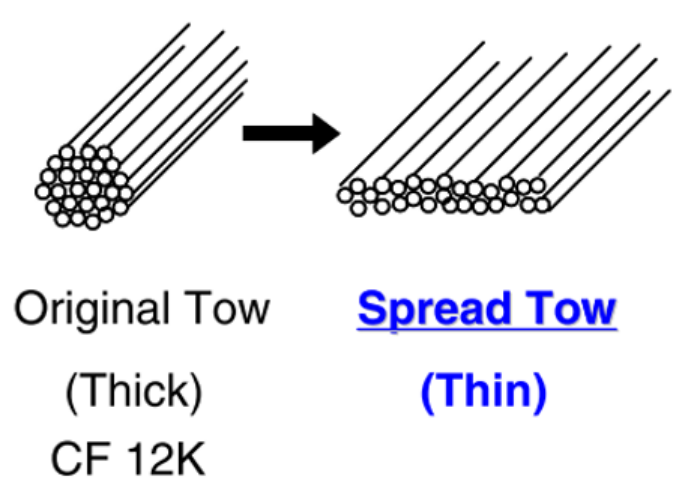

\section{Spread Width 16-32mm}

Figure 2.4 Fibre tow spreading schematic $[16]^{1}$

\footnotetext{
${ }^{1}$ Reprinted from Composites Science and Technology, 67(6), Sihn S, Kim RY, Kawabe K, Tsai SW, Experimental studies of thin-ply laminated composites, pp. 996-1008, Copyright (2006), with permission from Elsevier.
} 


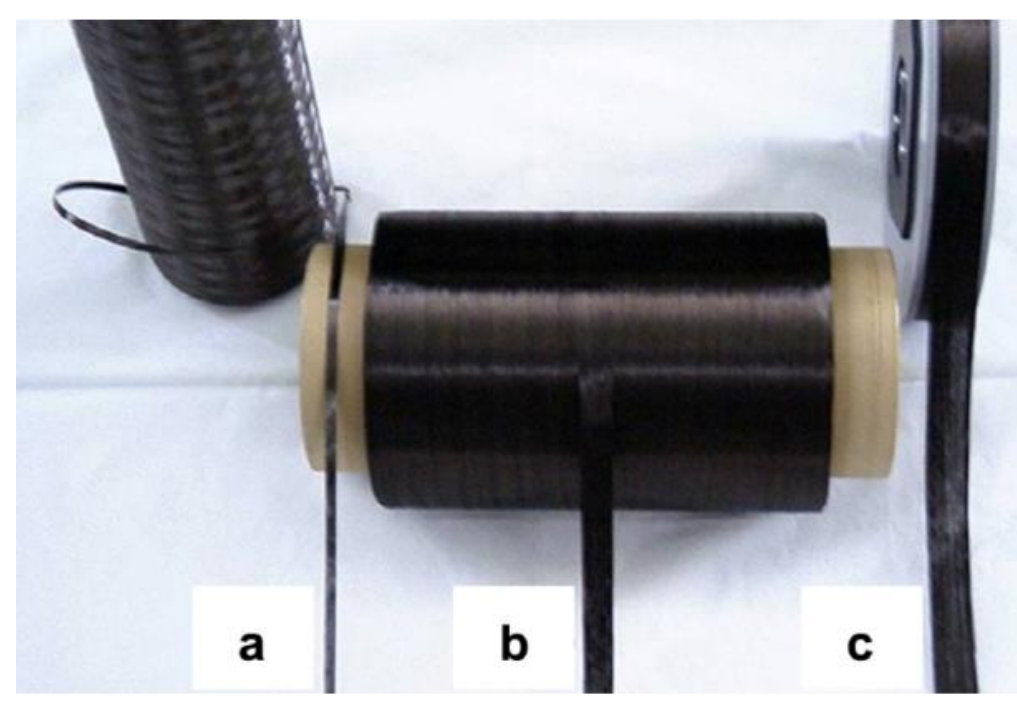

Figure $2.512 \mathrm{~K}$ carbon fibre tow, before and after spreading: a) original tow (6 $\mathrm{mm}$ width), b) $12 \mathrm{~mm}$ spread-tow, c) $20 \mathrm{~mm}$ spread-tow [16 ${ }^{1}$

\subsection{Physical and Structural Properties of Composite Materials}

The combination of resin and fibre in a composite material can offer extremely desirable properties. Achieving these properties and manufacturing a product suitable for the end application is dependent on numerous factors. These include not only the specific fibre and resin matrix used, but physical and structural properties of the material, such as: glass transition temperature, fibre volume fraction, fibre/matrix interface, and the fibre/matrix microstructure. Such factors should be considered in the material fabrication process.

Polymer composite materials are commonly reinforced with fibres such as carbon, glass and aramid. As described earlier, the type of fibre used is dependent on the application of the material; glass fibres are comparatively cheap, whereas carbon fibres are more expensive, but provide greater specific strength and modulus values. Carbon fibres are produced by high temperature carbonisation (via oxidation and thermal pyrolysis) of polyacrylonitrile (PAN) or Pitch-based precursors [27]. Depending on the manufacturing method used, carbon fibre

\footnotetext{
${ }^{1}$ Reprinted from Composites Science and Technology, 67(6), Sihn S, Kim RY, Kawabe K, Tsai SW, Experimental studies of thin-ply laminated composites, pp. 996-1008, Copyright (2006), with permission from Elsevier.
} 
strength and stiffness properties can be altered to suit the end application. This versatility is achieved by varying the heat treatment in the production of the reinforcement, which allows the fibres to be classified into categories such as: ultra-high modulus, high modulus, intermediate modulus, standard elastic modulus type and low elastic modulus type [28]. Aside from high strength and stiffness, carbon fibres offer other desirable properties such as corrosion resistance [29], good electrical and thermal conductivity and low linear coefficient of thermal expansion [30].

Aside from fibre choice, the type of resin used in an FRP is an important consideration. Polymer composite materials can be manufactured using many different resin matrices. Epoxy resins are a popular choice, as they offer a combination of strength, low shrinkage and good processability [31], however other thermosets, such as polyesters, or thermoplastic matrices are also options. The job of the matrix is to hold the fibres in place, facilitate stress transfer and provide protection from abrasion and the environment [32].

Despite their aforementioned desirable properties, epoxy resins are typically brittle and notch sensitive $[33,34]$. To alleviate this issue, toughening agents can be used. The toughness of a material is described as the total energy required to cause failure; the purpose the toughening agents is to enhance the energy absorption capacity [33]. A common method of toughening is to incorporate a dispersed toughening phase, such as a liquid rubber, thermoplastics, or rigid particulates, into the resin [35]. Many mechanisms have been proposed to explain how toughening agents work to improve resin toughness. A summary of these include: tearing or stretching of the rubber particles, crazing, shear yielding, shear band formation, crack pinning, crack bridging and crack deflection [34].

Ideally, the addition of toughening agents would improve the toughness of the resin without compromising other properties. In reality, rubber toughened epoxies have been shown to suffer reductions of properties such as glass 
transition temperature, modulus and yield strength [34,36]. Modulus reduction can be avoided with the use of different toughening methods, such as thermoplastic or rigid particulate modification [34]. Resistance to shear failure is intrinsically low for FRPs [37]. Both interlaminar shear strength (ILSS) and inplane shear (IPS) properties have been shown to increase as a result of resin toughening [38-41]. In general, improvement of interlaminar shear strength as a result of toughening is dependent on the quality of the fibre/matrix interface. For example, Jang et al. [38] investigated the effect of rubber modification on the interlaminar shear strength of a carbon fibre phenolic composite. Varied results were observed, depending on the type of rubber used. Interlaminar shear strength was found to increase in the material with a good fibre/matrix interface. Conversely, the material with a weaker interface gained no benefit from the toughened matrix. This was because the material with the weaker interface displayed an adhesive failure mode (between the resin and the fibres) instead of the cohesive failure observed by the first material. Failure of the material due to the weak interfacial bond, prior to cohesive failure, meant that any toughening benefits that could have been provided by the modified resin were not realised. Day et al. [40] found that ILSS was improved after the addition of toughening agents, but, in agreement with Jang et al. [38], a weak interfacial bond limited the effectiveness of the modified matrix. Similarly, Varada Rajulu et al. [42] found that the use of polycarbonate as a toughening agent for epoxy resin gave no benefit to ILSS, again as a result of poor interfacial bonding. Nguyen et al. [39] studied the effect of shear damage on a toughened composite using a $\pm 45^{\circ}$ tensile test. Increased shear toughness was found. This was attributed to a delayed onset of delamination and the promotion of intra-ply cracking leading to large shear strains, and therefore greater energy dissipation. Likewise, Ricciardi et al. [41] found that the in-plane shear properties of composites made with rubber modified resins had $210 \%$ greater elongation at final failure compared to nonmodified resin. 
As discussed earlier, the bond between the fibres and matrix (the interface) has a large impact on the mechanical performance of the material. A strong interface enables stresses to be transferred between fibres efficiently [43], resulting in a material with high strength and stiffness. That said, a strong interface can also lead to the material being brittle, with crack propagation occurring more easily through the matrix and fibre. Fibre pull out and debonding are more likely to occur when the interface is weak [44].

Further to resin type and the fibre/matrix interface, the glass transition temperature $\left(\mathrm{T}_{\mathrm{g}}\right)$ is a very important polymer characteristic which should be considered. It refers to the temperature range where a polymer transitions from its "glassy" state, where it is brittle and hard, to a more "rubbery" state, where the material is more flexible [45]. As such, the $T_{g}$ determines the useable service temperature of the polymer [46]. Some polymers, for example rubber elastomers, are used at temperatures above their $\mathrm{T}_{\mathrm{g}}$, whereas hard polymers are used at temperatures below the $\mathrm{T}_{\mathrm{g}}$, in their "glassy" state [47]. The difference in properties is due to changes in molecular mobility; the molecules have more freedom of movement at temperatures above the $\mathrm{T}_{\mathrm{g}}$, in comparison to temperatures below the $\mathrm{T}_{\mathrm{g}}$ [48]. The glass transition temperature is dependent on multiple factors, such as the composition of the resin, curing agent, cure time and cure temperature [48]. The curing process can be described as the cross-linking of monomer chains; the extent of cross-linking determines how cured the material is. As monomer cross-linking increases, the mobility of the chains reduces and, as such, the glass transition temperature increases [49]. As well as the degree of cure, water ingress is also widely known to impact $\mathrm{T}_{\mathrm{g}}$. Water acts as a plasticiser [50], leading to a reduction in glass transition temperature and consequently a reduction in service temperature [46,51]. To ensure suitability for the end application, the effect of water and cure schedule on the glass transition temperature should be known and taken into account during the design process. 
$\mathrm{T}_{\mathrm{g}}$ determination can be conducted using various methods; dynamic mechanical analysis (DMA) and differential scanning calorimetry (DSC) are two such examples. DMA is a method of characterising a material's viscoelastic properties; it is typically more sensitive than DSC and can measure more subtle polymer transitions [52]. DMA methodology involves applying a sinusoidal stress, or strain, to the sample at a given frequency, as a function of time. The resulting strain, or stress, is then measured [53]. This process can be performed over a specified temperature range or isothermally. For a viscoelastic material, the material's response will be out of phase with the applied stress. According to Hooke's law, the relationship between the applied stress, or strain, and the material's response is demonstrated by the complex modulus, $E^{*}[52,53]$.

$$
E^{*}=E^{\prime}+i E^{\prime \prime}
$$

The complex modulus is a combination of an in-phase component, $\mathrm{E}^{\prime}$ (storage modulus) and an out of phase component, E" (loss modulus).

$$
\begin{aligned}
& E^{\prime}=\left(\sigma_{0} / \varepsilon_{0}\right) \cos \delta \\
& E^{\prime \prime}=\left(\sigma_{0} / \varepsilon_{0}\right) \sin \delta
\end{aligned}
$$

Where $\sigma_{0}$ is the maximum stress and $\varepsilon_{0}$ is the strain at maximum stress. The storage modulus relates to the energy stored within the material and demonstrates the materials elastic behaviour. The loss modulus relates to the energy lost by the material and demonstrates the materials viscous behaviour. The ratio of the loss modulus (lost energy) to the storage modulus (stored energy) is the tangent of the phase angle (tan delta) [52,53]. The tan delta is also called damping. It indicates how efficiently energy is lost and, therefore, how well the material can absorb energy [54]. 


$$
\tan \delta=\frac{E^{\prime \prime}}{E^{\prime}}
$$

Measurement of glass transition temperature using DMA can be achieved by monitoring changes in the loss modulus, tan delta or storage modulus, as a function of temperature. Each of these methods will give a different $\mathrm{T}_{\mathrm{g}}$ result, by as much as $30^{\circ} \mathrm{C}$ [55]. Measurement of the glass transition temperature using the onset of the reduction in storage modulus is the most conservative of the three methods and indicates the point where the material properties being to reduce [52].

Aside from the glass transition temperature, fibre volume fraction is another key fabrication consideration. There is a positive correlation between fibre volume fraction and the strength and stiffness of a material, up to a certain extent [56]. Generally, the practical maximum fibre content is $70 \%$ [3]. Additions beyond this can be detrimental to tensile strength, due to a deficiency of resin to hold to fibres together. Fibre distribution in a laminate with a low fibre volume fraction often results in irregularities such as fibre bunching and areas of large resin pockets [3]. As the fibre provides strength to the material, an irregular distribution is undesirable. In addition, the condition of the fibre/matrix microstructure greatly impacts the performance of the material. During fabrication it is important to avoid defects such as voids, broken fibres, fibre waviness and fibre misalignment. Inclusion of these defects can lead to deviations from the expected mechanical properties [57].

\subsection{Mechanical Properties of Composite Materials}

There are numerous factors which can influence the mechanical properties of FRPs. As described previously, the individual mechanical properties of both the matrix and the reinforcement material will greatly impact the end material. For example, the properties of the matrix depend on both the chemicals used to manufacture the resin and the degree of cross-linking between the monomer units 
[3]. The properties of carbon fibres are dependent on the particular manufacturing process used [58]. The specific resin matrix and carbon fibre used in the material will determine the end application of the product.

Aside from the resin and fibre type, there are other key features within a composite material that impact mechanical properties. Fibre orientation, for example, is vastly important. Unidirectional composites (where fibres are all orientated in the same direction) are highly anisotropic [3]. Fibres provide strength along their length; they cannot withstand high loads across their width. By orientating fibres in the load direction, it is possible to create a material with extremely desirable mechanical properties for the required loading. To create a more isotropic material the fibres can be orientated in numerous directions, depending on the number of plies in the finished laminate. This is one area where the use of thin-ply materials becomes favourable compared to conventional thickness prepregs. A greater design space for ply orientation is achieved, due to the thinner ply thickness allowing more layers to be stacked in the same volume of space [14].

The marked anisotropy of composite materials needs to be considered during the process of mechanical testing. For example, a unidirectional laminate, where all fibres are aligned along the $0^{\circ}$ axis, will have a high tensile strength when tested in the $0^{\circ}$ direction. When tested in the transverse direction, the same material will display far weaker tensile properties. The material is weaker in this direction, as it is the resin, not the fibre, which is predominantly being tested. This demonstrates that fibre orientation is vastly important in the design process of composite materials.

In addition to material anisotropy, precise alignment is important to achieve accurate and reliable mechanical test results. This is in terms of the test coupon itself, the test machine used, and the alignment of the specimen within the test machine. Firstly, alignment of the test coupon requires precise machining 
processes. For a UD specimen, misalignment of the fibres by $1^{\circ}$ can lead to reduced measured strengths of over $30 \%$ [37]. Alignment of the machine used for testing, and the gripping of the specimen within the machine, must also be precise. Misalignment can lead to additional twisting and bending stresses being applied to the sample and, consequently, lower reported strengths. A poorly aligned test coupon can also lead to high scatter in the results [37].

Another factor to consider during the mechanical testing of FRPs is the type of load applied to the specimen. Materials can be subjected to a wide range of different loading conditions when used in components or structures. The type of loading experienced will mainly depend on the application of the product. Examples of load include tensile, compression, flexure and shear. The length of time that the material can bear these loads for also needs to be considered, be it short-term, long-term, or cyclically.

Furthermore, the type of environment that the material will be subjected to in service should be considered. Composite materials are being used more frequently in industrial applications such as aerospace and marine. These industries require the use of materials that can withstand high or low temperatures and exposure to water. It is well documented that the properties of resin-based composites deteriorate with moisture ingress [50,59], or when used above the glass transition temperature [52]. As such, the effect of exposure to different environmental conditions is of high interest.

Given the numerous variables which can influence the mechanical properties of a composite material, a clear understanding of how the material will behave under different loads and environments is an important part of the design process. Despite the development of modelling making it possible to predict certain properties, mechanical testing is still a key part of development. Manufacturing a product using materials with insufficient properties can be financially costly or potentially dangerous. 
In recent years, studies have taken place to research the effect of ply thickness on mechanical properties. The potential advantages over conventional thickness prepregs, and the reasons for this, have been investigated. Given the number of variables that can affect composite mechanical properties, fully understanding the behaviour of thin-ply material is a complex task. As such, some areas of research within this field are still yet to be explored. The sections below cover the main findings on how thin-ply technology has impacted the measured mechanical performance of CFRPs. In summary, thin-ply materials have been shown to have enhanced mechanical properties in situations including: quasi-isotropic tensile strength [14-16,60], quasi-isotropic compressive strength [15], compressive strength after impact $[15,16,61]$, enhanced short beam shear properties [62], and more durable tensile fatigue for woven [63] and non-woven [14-16] spread-tow materials. Furthermore, the use of thin plies has been shown to delay the onset of damage and create a more brittle failure mode [14]. There are multiple potential mechanisms for these differences. Firstly, with thinner plies there may less variation in stress orientation between each layer, leading to reduced shear stresses between layers of differently orientated fibres. Furthermore, the spread-tow procedure is thought to enhance the uniformity of fibre distribution within each layer, allowing for more uniform properties and reducing local stress peaks [14]. In addition, there may be more resin rich areas and fibre defects, such as kinks and bending, with thick-ply materials, which could lead to reduced properties. Lastly, differences in fibre volume fraction (particularly if thin-ply materials don't allow resin to flow out as easily) may also lead to differences in properties. These findings will be discussed in more detail in the following sections.

\subsubsection{Quasi-static Tensile Behaviour}

A tensile test generates information regarding the ultimate tensile stress (UTS), the tensile modulus (E) and Poisson's ratio for a given material. Inspection of the material both during and after the test can provide insight into the reason for 
failure [37]. This is useful information when comparing the behaviour of thick and thin-ply laminates.

Sihn et al. [16] were among the first to evaluate the performance of tow-spread, thin-ply carbon fibre composites. A comprehensive mechanical testing programme was carried out and techniques such as X-ray imaging and acoustic emission analysis were used to provide reasoning for the results produced. Despite investigating the effect of ply thickness, Sihn et al. [16] used the same material, an epoxy based prepreg with thickness of $0.04 \mathrm{~mm}$, for all of the specimens. The difference between test coupons was the way in which the individual plies were stacked within the laminate. They adopted the method of 'ply block scaling'. Ply bock scaling is when plies of the same orientation are stacked together in blocks to achieve, in effect, a thicker ply [64]. An example of this is $\left[0^{\circ} / 90^{\circ} n\right]_{s}$, where $n=$ number of plies and $s=$ symmetrical. Another commonly used method of ply scaling is called 'sub-laminate scaling'. This is where a single ply is used for each orientation and the total lay-up sequence is continuously repeated until a (symmetrical) laminate of the required thickness is produced (for example, $\left[0^{\circ} / 90^{\circ}\right] \mathrm{ns}$ ) [64]. Examples of each, in an unsymmetrical laminate, are shown in Figure 2.6. The two methods of lamina scaling are thought to initiate different failure mechanisms [14,64]. It has been said that laminates comprising sub-laminate scaling tend to have a fibre pull-out or brittle failure mode [65], whereas ply block scaled laminates tend to fail due to delamination [16]. Thus, dispersing conventional thickness plies with the same orientation will help to supress microcracking and delamination damage; the use of thinner plies will help this even further [16]. As a result, the method of ply scaling is an important factor to consider when investigating effect of ply thickness. 


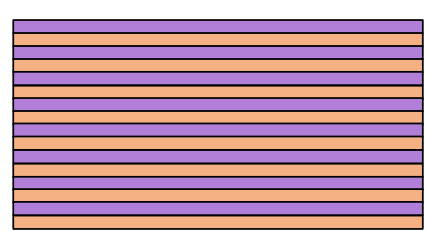

A

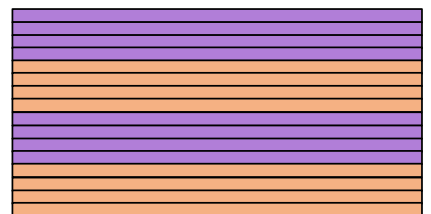

B

Figure 2.6 a) Sub-laminate scaling b) Ply block scaling

As previously mentioned, Sihn et al. [16] used ply block scaling to compare the performance of 'thick' $(0.2 \mathrm{~mm})$ and 'thin' $(0.04 \mathrm{~mm})$ ply laminates. The 'thick' plies consisted of five thin plies grouped together in the same fibre orientation to produce one thick-ply, as demonstrated in Figure 2.7. The basic laminate properties were tested using unidirectional (UD) laminates, to ensure the laminate was of good quality. Because only one prepreg thickness was used throughout the investigation, data from the UD tests cannot be used to compare the behaviour of thick and thin plies. Instead, unnotched quasi isotropic (QI) laminates were investigated. Both the thick and thin-ply QI laminates had a lay-up of (25/50/25), where the numbers in brackets represent the percentage of $\left[0^{\circ}\right],\left[ \pm 45^{\circ}\right]$ and $\left[90^{\circ}\right]$ plies respectively. Importantly, the dimensions of the thick and thin-ply coupons were kept constant (length, width and thickness) to reduce the impact of size effects. A size effect is a well-known phenomenon in composites [66]. It refers to when a specimens strength changes due to changes in dimensions [64]. Typically, specimen strength decreases with increasing coupon volume $[66,67]$. One of the main factors contributing to the size-effect phenomenon is the enhanced probability of critical material defects with a larger volume of material $[66,67]$. Sihn et al. [16] tested three duplicate samples for both the thick and thin-ply prepreg. Ideally, the number of test specimens would be greater than three, however, concurring results were produced, which gives reassurance in the data. The fibre volume fraction was stated to be approximately $60 \%$ for all laminates. It is important to have consistent fibre volume fraction values for each laminate used, as differences can impact mechanical properties [68]. 
a

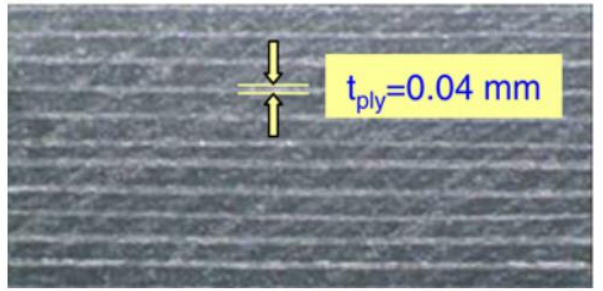

b

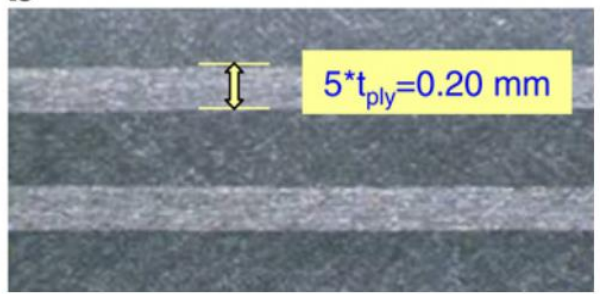

Figure 2.7 Micrographs to show test specimens made from spread-tow thin plies: a) thin-ply laminate (sub-laminate scaled), b) thick-ply laminate (ply block scaled) [16] ${ }^{1}$

The stress/strain curves produced for the quasi-static, quasi-isotropic (QI), unnotched tensile specimens were almost identical for both the thick and thin-ply materials. However, very close to the ultimate failure stress $(\sim 690 \mathrm{MPa})$ of the thick-ply laminate, the strain on the sample suddenly increased, as shown in Figure 2.8. This was attributed to unrecoverable damage, most likely due to delamination and microcracks within the material [16]. The ultimate tensile strength of the thin-ply coupons was found to be $10 \%$ greater than the thick-ply specimens (0.94 GPa compared to $0.85 \mathrm{GPa}$ ) [16]. It should be considered how much of an effect ply block scaling has had on this result. A direct comparison of two laminates made from two different prepregs, manufactured from the same fibre and resin, but spread to varying thicknesses, would help to consolidate that the effect of the spread-tow prepreg is causing the increased strength.

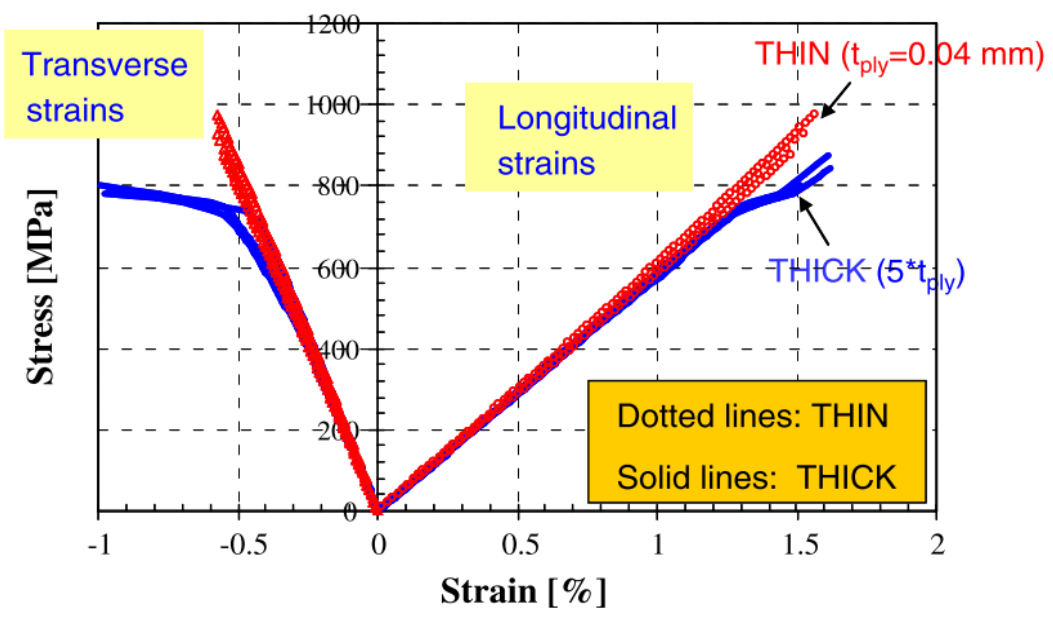

Figure 2.8 Stress/strain curves for QI thin and thick-ply laminates under quasi-static unnotched tensile loading [16 $]^{1}$

\footnotetext{
${ }^{1}$ Reprinted from Composites Science and Technology, 67(6), Sihn S, Kim RY, Kawabe K, Tsai SW, Experimental studies of thin-ply laminated composites, pp. 996-1008, Copyright (2006), with permission from Elsevier.
} 
Amacher et al. [14] utilised both sub-laminate and ply block scaling in their investigation into ply thickness. As with the previous investigation, Amacher et al. [14] began by looking at ply level properties. Three different ply thicknesses were used, $30 \mathrm{~g} / \mathrm{m}^{2}, 100 \mathrm{~g} / \mathrm{m}^{2}$ and $300 \mathrm{~g} / \mathrm{m}^{2}$ to manufacture thin, intermediate and thick-ply laminates. All laminates had a reproducible fibre volume fraction of $55 \%$. Results for the static tensile test on UD laminates showed no significant differences between the three different ply thicknesses. However, this was not the case for the QI laminates. The stacking sequence for the QI laminates was $\left[45^{\circ} / 90^{\circ} /-45^{\circ} / 0^{\circ}\right]_{\mathrm{ns}}$, where $\mathrm{n}=10,3$ and 1 for the thin, intermediate and thick-ply laminates respectively. Despite a change in ply thickness, the overall laminate thickness was kept constant. A sample size of eight coupons per ply thickness was used, which is thought to be a suitable number to observe trends in the data. The results are shown in Figure 2.9. The average ultimate tensile strength for the thin-ply laminate $(847 \mathrm{MPa} \pm 18 \mathrm{MPa})$ was an increase of $42 \%$ compared to the thick-ply laminate ( $595 \mathrm{MPa} \pm 27 \mathrm{MPa})$. The average UTS for the intermediate laminate was $753 \mathrm{MPa} \pm 27 \mathrm{MPa}$, which lies between both the thin and thick-ply values. Acoustic emission analysis was used on all laminates to identify the damage initiation point. Interestingly, damage initiation in the thin-ply laminate occurred at just $3 \%$ below the UTS, at $822 \mathrm{MPa}$. However, the damage initiation point for the thick-ply laminate was $248 \mathrm{MPa}$. This means that, for the thin-ply specimens, the stress at the point of damage initiation was increased by $230 \%$ compared to the $300 \mathrm{~g} / \mathrm{m}^{2}$ coupons. Visual examination of the mechanical test coupons clearly showed different failure modes, dependent on ply thickness, which corresponded to the acoustic emission results. The thicker ply laminate failed progressively by a mixture of shear, transverse cracking and delamination, before final failure. The thinner ply laminate failed in a quasi-brittle manner, with no sign of damage before failure. Amacher et al. [14] attributed the increased UTS of thin-ply laminates to the delayed damage onset brought about by reduced ply thickness. However, ply thickness was not the only variable which was changed 
in this experiment. The number of sub-laminate repetitions (n) was also varied, with $n=10$ for the thin-ply laminates and $n=1$ for the thick-ply laminates. It is possible therefore, that the number of sub-laminate repetitions had an effect on UTS. To test this hypothesis, Amacher et al. [14] tested thin-ply QI laminates where $n=3$ and $n=1$, to compare with the $100 \mathrm{~g} / \mathrm{m}^{2}$ and $300 \mathrm{~g} / \mathrm{m}^{2}$ laminates respectively. An increase in onset of damage (+12\%) was seen when comparing the $\mathrm{n}=3$ thin and intermediate-ply laminates, however the UTS for each were not statistically different. Despite a large difference in overall laminate thickness, the $\mathrm{n}=1$ thin-ply laminate had a $29 \%$ increase in UTS compared to the $\mathrm{n}=1$ thick-ply laminate [14]. In addition, the corresponding damage initiation point was $187 \%$ greater in thin-ply than thick-ply. This suggests that the increases in damage onset and UTS were due to ply thickness and not the number of sub-laminate repetitions.

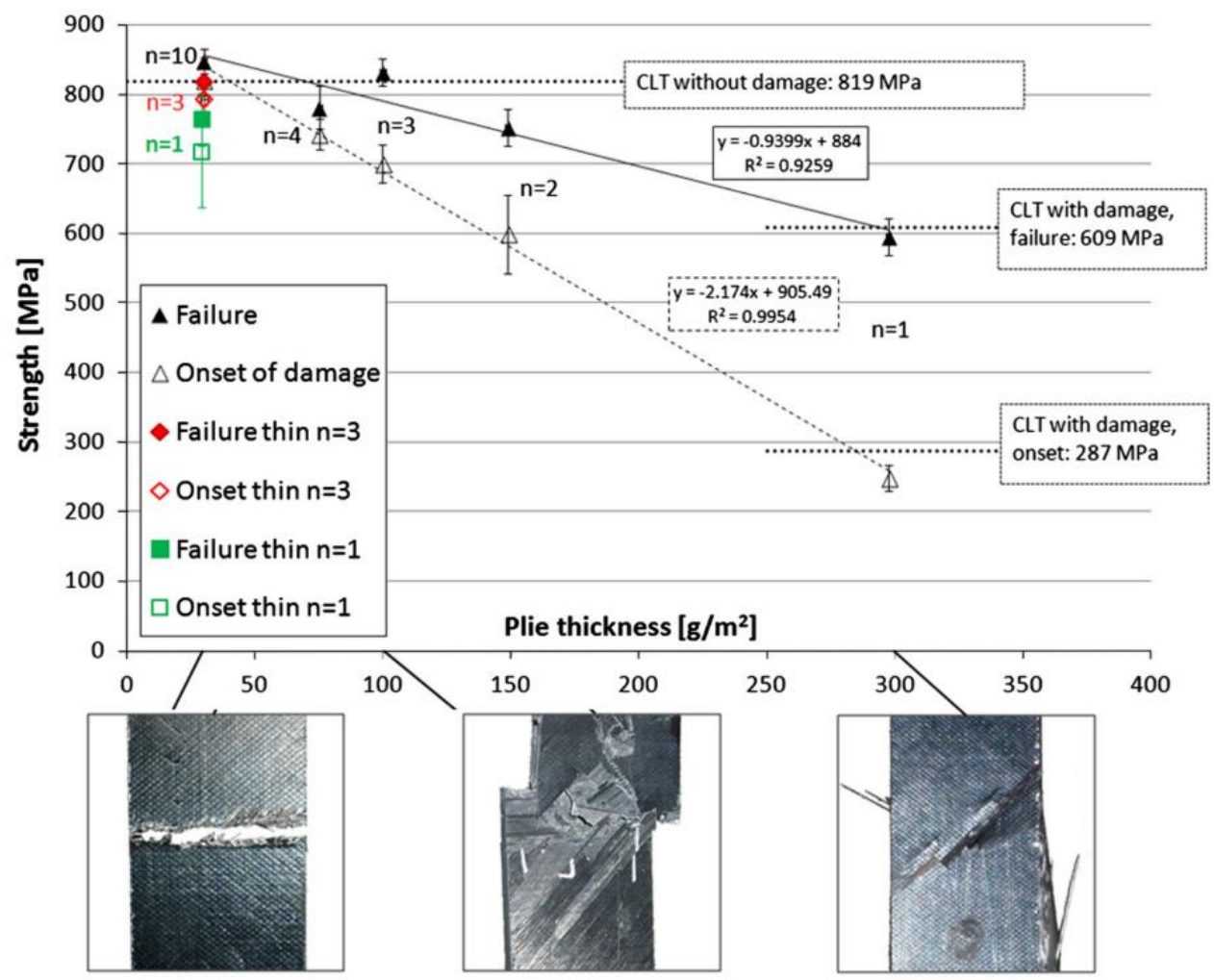

Figure 2.9 Comparison of UTS, onset of damage and failure modes for QI material with varying ply thicknesses, tested in unnotched quasi-static tension [14] ${ }^{2}$

\footnotetext{
2 Reprinted from Composites Science and Technology, 101, Amacher R, Cugnoni J, Botsis J, Sorensen L, Smith W, Dransfeld C, Thin ply composites: Experimental characterization and modeling of size-effects, pp. 121-132, Copyright (2014), with permission from Elsevier.
} 
Amacher et al. [14] also investigated thin-ply $\left(30 \mathrm{~g} / \mathrm{m}^{2}\right)$ laminates manufactured using ply block scaling (the scaling method used by Sihn et al. [16]). The stacking sequence used was $\left[45^{\circ} 10 / 90^{\circ} 10 /-45^{\circ} 10 / 0^{\circ}{ }_{10}\right]_{s}$ which, in effect, is the same as the sub-laminate scaled $300 \mathrm{~g} / \mathrm{m}^{2}$ material with orientation $\left[45^{\circ} / 90^{\circ} /-45^{\circ} / 0^{\circ}\right] 1$ s. The average UTS of the thin-ply material with ply block level stacking was $532 \mathrm{MPa} \pm 31 \mathrm{MPa}$, compared to $847 \mathrm{MPa} \pm 18 \mathrm{MPa}$ for the thin-ply material with the same overall coupon thickness, but manufactured using sub-laminate level stacking $\left(\left[45^{\circ} / 90^{\circ} /-45^{\circ} / 0^{\circ}\right] 10\right.$ s. The sample size of the ply block level stacked coupons was small (three coupons tested) however the results suggest that materials with ply block scaled thin plies (which, in effect, generates a thicker ply) have reduced ultimate strength compared to sub-laminate scaled thin-ply materials. The $\mathrm{n}=10$, ply block scaled, thin-ply material is nominally the same as the $300 \mathrm{~g} / \mathrm{m}^{2} \mathrm{n}=1$ sample. Indeed, the mean tensile results for these two materials was $532 \mathrm{MPa} \pm 31 \mathrm{MPa}$ and $595 \mathrm{MPa} \pm 27 \mathrm{MPa}$ respectively. There was also little difference in the damage initiation point. This demonstrates that the potential benefits of using spread-tow prepreg is reduced when ply block scaling is used, thus highlighting the impact that overall ply thickness has on mechanical properties.

In other work, Yokozeki et al. [15] used two different prepreg thicknesses $\left(145 \mathrm{~g} / \mathrm{m}^{2}\right.$ and $\left.75 \mathrm{~g} / \mathrm{m}^{2}\right)$ to manufacture standard $\left(\left[45^{\circ} / 0^{\circ} /-45^{\circ} / 90^{\circ}\right]_{2 \mathrm{~s}}\right)$ and thin-ply $\left(\left[45^{\circ} / 0^{\circ} /-45^{\circ} / 90^{\circ}\right] 4 \mathrm{~s}\right)$ laminates. All test coupons had the same dimensions and fibre volume fractions. Despite only a small sample size (three coupons per ply thickness) the results corroborated with both Amacher et al. [14] and Sihn et al. [16]. The thin-ply material had an increased tensile strength (974 MPa) compared to the thick-ply laminates (812 MPa) [15]. Acoustic emission data indicated that damage onset in the thin-ply laminate occurred later than in the thicker ply laminate. This corroborates with the results of Amacher et al. [14]. 
Wisnom et al. [64] studied size effects in carbon epoxy composites using both sub-laminate scaling and ply block scaling on QI laminates. While this work was not inherently based on investigating spread-tow thin-ply materials, the effect of nominal ply thickness on tension properties can still be observed. As discussed earlier, tension properties of a ply block scaled material with ten $30 \mathrm{~g} / \mathrm{m}^{2}$ plies in the orientation $\left[45^{\circ} 10 / 90^{\circ} 10 /-45^{\circ} 10 / 0^{\circ} 10\right]_{s}$ gives very similar results to a sub-laminate scaled $300 \mathrm{~g} / \mathrm{m}^{2}$ material with orientation $\left[45^{\circ} / 90 \%-45^{\circ} / 0^{\circ}\right]$ s [14]. Thus, by focussing on the results of Wisnom et al. [64] for ply block scaled laminates, it is possible to see the effect of ply thickness. Laminate orientations and the corresponding tensile test results are shown in Table 2.1 and Table 2.2. The results corroborate with Amacher et al. [14] to show that the ply block scaled laminates have decreased strength when compared to the sub-laminate scaled material of the same dimensions. For example, the laminate with a $\left[45^{\circ} / 90^{\circ} /-45^{\circ} / 0^{\circ}\right]$ ss lay-up had a failure stress of $929 \mathrm{MPa}$, whereas the $\left[45^{\circ} 4 / 90^{\circ} 4 /-45^{\circ} 4 / 0^{\circ} 4\right]_{s}$ laminate had a failure stress of $458 \mathrm{MPa}$. Both laminates had the same dimensions and the same proportion of plies of different orientations. Conventional laminate failure strength predictions, based on ply stresses or strains, would quote identical strengths for both laminates [64]. Experimentally this is not the case. To predict the strengths of such laminates, the development of damage, particularly in the form of delamination from the free edge, needs to be considered [64].

Table 2.1 Static tensile test results for sub-laminate scaled specimens (recreated from [64]) $)^{3}$

\begin{tabular}{|l|c|c|c|c|c|c|}
\hline Case & Lay-up & $\begin{array}{c}\text { Gauge } \\
\text { length } \\
(\mathrm{mm})\end{array}$ & $\begin{array}{c}\text { Width } \\
(\mathrm{mm})\end{array}$ & $\begin{array}{c}\text { No. of } \\
\text { specimens }\end{array}$ & $\begin{array}{c}\text { Failure } \\
\text { stress } \\
(\mathrm{MPa})\end{array}$ & $\begin{array}{c}\text { Coefficient } \\
\text { of variation } \\
(\%)\end{array}$ \\
\hline$n=1$ & $(45 / 90 /-45 / 0)_{\mathrm{s}}$ & 30 & 8 & 11 & 842 & 7.6 \\
\hline$n=2$ & $(45 / 90 /-45 / 0)_{2 \mathrm{~s}}$ & 60 & 16 & 6 & 911 & 2.0 \\
\hline$n=4$ & $(45 / 90 /-45 / 0)_{4 \mathrm{~s}}$ & 120 & 32 & 10 & 929 & 3.9 \\
\hline
\end{tabular}

\footnotetext{
${ }^{3}$ Reprinted from Composite Structures, 84(1), Wisnom MR, Khan B, Hallett SR, Size effects in unnotched tensile strength of unidirectional and quasi-isotropic carbon/epoxy composites, pp. 21-28, Copyright (2007), with permission from Elsevier.
} 
Table 2.2 Static tensile test results for ply level scaled specimens (recreated from [64])3

\begin{tabular}{|c|c|c|c|c|c|c|}
\hline Case & Lay-up & $\begin{array}{c}\text { Gauge } \\
\text { length } \\
(\mathrm{mm})\end{array}$ & $\begin{array}{c}\text { Width } \\
(\mathrm{mm})\end{array}$ & $\begin{array}{c}\text { No. of } \\
\text { specimens }\end{array}$ & $\begin{array}{c}\text { Failure } \\
\text { stress } \\
(\mathrm{MPa})\end{array}$ & $\begin{array}{c}\text { Coefficient } \\
\text { of variation } \\
(\%)\end{array}$ \\
\hline$m=1$ & $(45 / 90 /-45 / 0)_{\mathrm{s}}$ & 30 & 8 & 11 & 842 & 7.6 \\
\hline$m=2$ & $\left(45_{2} / 90_{2} /-45_{2} / 0_{2}\right)_{\mathrm{s}}$ & 60 & 16 & 8 & 660 & 3.3 \\
\hline$m=4$ & $\left(454 / 90_{4} /-45_{4} / 0_{4}\right)_{\mathrm{s}}$ & 120 & 32 & 11 & 458 & 5.8 \\
\hline$m=8$ & $\left(458 / 90_{8} /-45_{8} / 0_{8}\right)_{\mathrm{s}}$ & 240 & 64 & 10 & 321 & 2.9 \\
\hline
\end{tabular}

In the literature, several studies are found which document the tensile behaviour of thin-ply carbon fibre composites. However, the vast majority of these studies are conducted at room temperature, without any pre-test conditioning. Composite materials are being used far more in industries such as aerospace, construction, and marine in recent years $[4,7,8]$. Therefore, the performance of such materials in challenging environments, such as high temperature or exposure to moisture, should be investigated. Moon et al. [60] investigated the performance of carbon fibre composites during exposure to low earth orbit (LEO) conditions, for use in space applications. To do this they incorporated thin-ply prepregs and multi-wall carbon nanotubes into the material. Prior to testing the materials were conditioned for 20 hours in a typical space environment (high vacuum, UV radiation and thermal cycling). Quasi-isotropic conventional and thin-ply samples were produced with ply thicknesses of $0.125 \mathrm{~mm}$ and $0.06 \mathrm{~mm}$ respectively. Sub-laminate scaling was used to make coupons of the same dimensions. The UTS of the non-conditioned thin-ply laminates was, on average, $12.11 \%$ greater than the conventional ply thickness material. Moon et al. [60] attributed this to the high constraining effect between the individual laminas, which delayed delamination before fibre breakage. After exposure to LEO environmental conditions, the thin-ply material again had a higher UTS than the

\footnotetext{
${ }^{3}$ Reprinted from Composite Structures, 84(1), Wisnom MR, Khan B, Hallett SR, Size effects in unnotched tensile strength of unidirectional and quasi-isotropic carbon/epoxy composites, pp. 21-28, Copyright (2007), with permission from Elsevier.
} 
LEO conditioned, conventional ply thickness samples. When compared to the unconditioned thin-ply samples, the thin-ply LEO conditioned specimens had a $13 \%$ decrease in UTS, which was similar to the decrease seen with the exposed and non-exposed, conventional ply thickness samples. This suggests that the thin-ply samples had similar matrix damage to the conventional material after exposure to the LEO environment. Aside from tensile strength, tensile stiffness was also investigated. In contrast to the UTS results and to the tensile modulus results of Sihn et al. [16] the thin-ply laminate stiffness decreased compared to conventional thickness plies. This was for both the conditioned and the unconditioned samples. The reason for this was said to be due to a $7 \%$ lower fibre volume fraction of the thin-ply laminate. Moon et al. [60] stated that this occurred during prepreg manufacture due to the outflow of excess resin being hindered.

The current literature supports the fact that QI thin-ply laminates provide increased tensile strength when compared to thicker ply laminates of the same material, when unconditioned and tested at room temperature. Despite the work carried out by Moon et al. [60] there are still gaps in the literature regarding pre-testing conditioning of samples, or indeed non-ambient temperature testing. Moon et al. [60] conditioned samples for 20 hours and so a more long-term conditioning programme may present different results. Furthermore, investigations into the effect of moisture ingress and testing samples at non-ambient temperature would provide useful information into the performance of spread-tow prepreg materials.

\subsubsection{Quasi-static Open-hole Tensile Behaviour}

The performance of open-hole, or 'notched' composites is important information for design engineers. As well as simulating flaws, open-hole testing provides useful data for circumstances when fastener holes may be required in the end component. The presence of a hole weakens the laminate and causes a stress 
concentration within the material. This further complicates the already complex damage and failure mechanisms seen with composite materials $[69,70]$.

Wisnom et al. [71] investigated the effect of hole size and laminate thickness with respect to the open-hole tensile strength of QI laminates. Test coupons were scaled in three ways; thickness only (using both sub-laminate and ply block scaling), width, length, and hole diameter, and finally a combination of all four (width, length, hole diameter and thickness). The stacking sequence for each laminate was $\left[45^{\circ} \mathrm{m} / 90^{\circ} \mathrm{m} /-45^{\circ} \mathrm{m} / 0^{\circ} \mathrm{m}\right] \mathrm{ns}$. The subscripts $m$ and $n$ indicate the number of plies within the laminate, with $m$ changing for ply block scaled laminates and $n$ changing for sub-laminate scaled laminates. The work was not based on investigating the effect of spread-tow, thin-ply prepreg, although the effect of changing ply thickness can still be observed. Prepreg thickness was $0.125 \mathrm{~mm}$ for all coupons; the method of increasing ply thickness was via ply block scaling. The difference in open-hole tensile strength for the two ways of increasing laminate thickness (and effective ply thickness) are of particular interest. These results are shown graphically in Figure 2.10. To note, the hole size for all specimens in Figure 2.10 was $3.125 \mathrm{~mm}$, width-to-hole ratio was five and length-to-hole ratio was 20 [71].

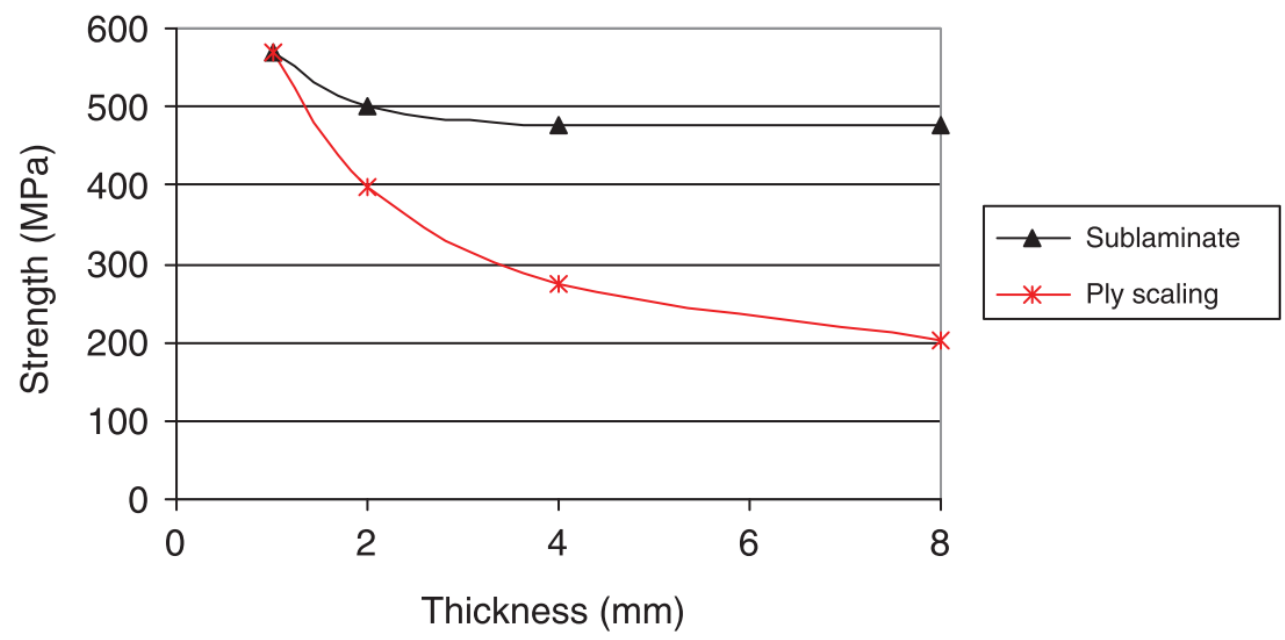

Figure 2.10 Impact of laminate thickness (and effective ply thickness) on open-hole tensile strength (3.175 mm hole) [71] 
The results from Wisnom et al. [71] differ from that found by both Sihn et al. [16] and Amacher et al. [14]. Using a ply block scaled QI laminate, Sihn et al. [16] found that the laminates with thicker ply blocks gave a $10 \%$ increased open-hole tensile strength compared to the thin-ply laminates. As before, the thick-ply laminates refer to a group of five thinner plies blocked together. The reason given for the increased strength is due to a stress relaxation which occurs near the edge of the hole after the initial failure. As the thin-ply laminates are known to suppress damage until very close to failure, these stresses become more concentrated and cause a more sudden failure compared to the thick-ply material. Acoustic emission and X-ray imaging was used to support this statement [16]. Similarly to the findings of Amacher et al. [14] for unnotched tensile samples (discussed earlier), the acoustic emission analysis showed that very little damage occurred in the thin-ply laminate prior to failure, which was not the case with the thicker ply material [16]. X-ray imaging (as seen in Figure 2.11) showed a large number of microcracks in the thick-ply laminate, which was not seen with the thin-ply laminate. This further supports the hypothesis of damage suppression of thin-ply material. Sihn et al. [16] found that the mode of damage for thick and thin-ply laminates was the same as Wisnom et al. [71]. A brittle type failure for thin-ply open-hole tensile coupons was also witnessed by Amacher et al. [14].

Amacher et al. [14] saw a similar trend relating quasi-static open-hole tensile strength and ply thickness to that shown by Sihn et al. [16]. Sub-laminate stacking of two prepregs ( $30 \mathrm{~g} / \mathrm{m}^{2}$ and $300 \mathrm{~g} / \mathrm{m}^{2}$ ) was used to produce QI thin and thick-ply coupons of equal thickness and geometry. A $26 \%$ decrease in ultimate strength was seen for the thin-ply coupons, with damage initiation occurring close to ultimate failure. On the contrary, damage onset for the thick-ply specimens was approximately $50 \%$ of the failure strength. The same trend (decreasing open-hole tensile strength with decreasing ply thickness) was also found by Huang et al. [72] who investigated both QI and cross-ply laminates using three different thickness prepregs. 


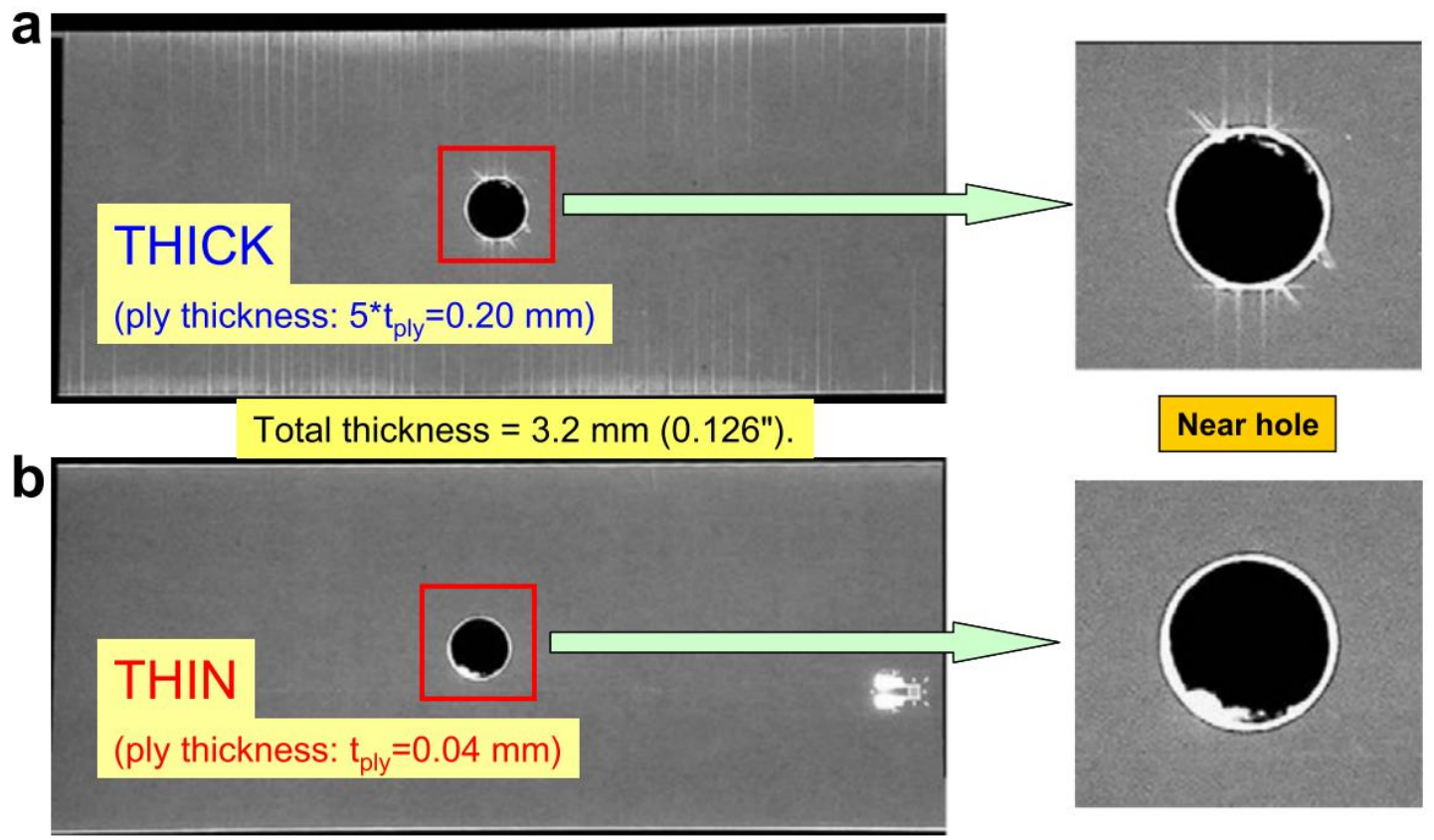

Figure 2.11 X-ray images of: a) thick-ply and b) thin-ply laminates after static open-hole tensile loading applied at $448 \mathrm{MPa}[16]^{1}$

\subsubsection{Tensile Fatigue Behaviour}

Over time, cyclic loading of in service materials can lead to strength reduction and ultimately material failure [37]. This makes fatigue testing a fundamental engineering process.

Sihn et al. [16] conducted unnotched tensile fatigue tests on the QI laminates described previously. A maximum stress of $\sim 60 \%$ of the static failure stress for thin-ply QI unnotched tensile specimens was used. The test was stopped at three intervals $(1,000,10,000$ and 50,000 cycles) to allow the strain near the free-edge to be measured. There was very little change in the free-edge strain after 50,000 cycles on the thin-ply laminate. The thick-ply laminate, however, showed an increase in strain after just 1,000 cycles. After 50,000 cycles of tension-tension fatigue loading, static load was applied to both materials, to determine the remaining residual strength and stiffness. Degradation of both properties was

\footnotetext{
${ }^{1}$ Reprinted from Composites Science and Technology, 67(6), Sihn S, Kim RY, Kawabe K, Tsai SW, Experimental studies of thin-ply laminated composites, pp. 996-1008, Copyright (2006), with permission from Elsevier.
} 
seen for the thick-ply specimen, but not for the thin-ply material. This indicates that the thin-ply specimen is more durable under fatigue loading. The stress-strain graphs for both the thick and the thin-ply specimens are shown in Figure 2.12. The graph, which displays the quasi-static stress/strain curves for samples before and after fatigue testing, highlights the degradation in strength of the thick-ply material after fatigue loading and the lack of degradation of the thin-ply laminate [16].

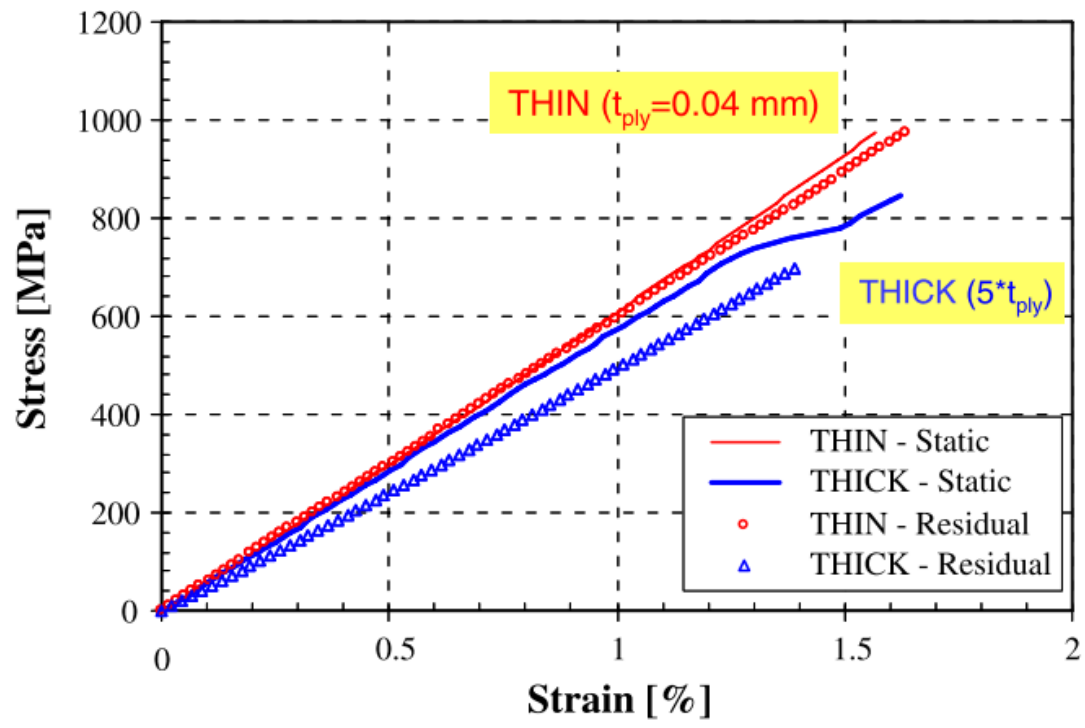

Figure 2.12 Unnotched tensile stress/strain curves for QI thin and thick-ply laminates before and after 50,000 cycles of fatigue loading at $483 \mathrm{MPa}[16]^{1}$

To investigate the differences in mechanical performance, $\mathrm{X}$-ray images of the two different laminate lay-ups were taken after the 50,000 cycles of fatigue loading (Figure 2.13). No visible damage was seen in the thin-ply specimen. However, with the thick-ply specimen, a large volume of micro-cracking and delamination starting from the edge of the specimen was observed [16]. This indicates high interlaminar stresses and is thought to explain why the thin and thick-ply coupons have different fatigue durability.

\footnotetext{
${ }^{1}$ Reprinted from Composites Science and Technology, 67(6), Sihn S, Kim RY, Kawabe K, Tsai SW, Experimental studies of thin-ply laminated composites, pp. 996-1008, Copyright (2006), with permission from Elsevier.
} 


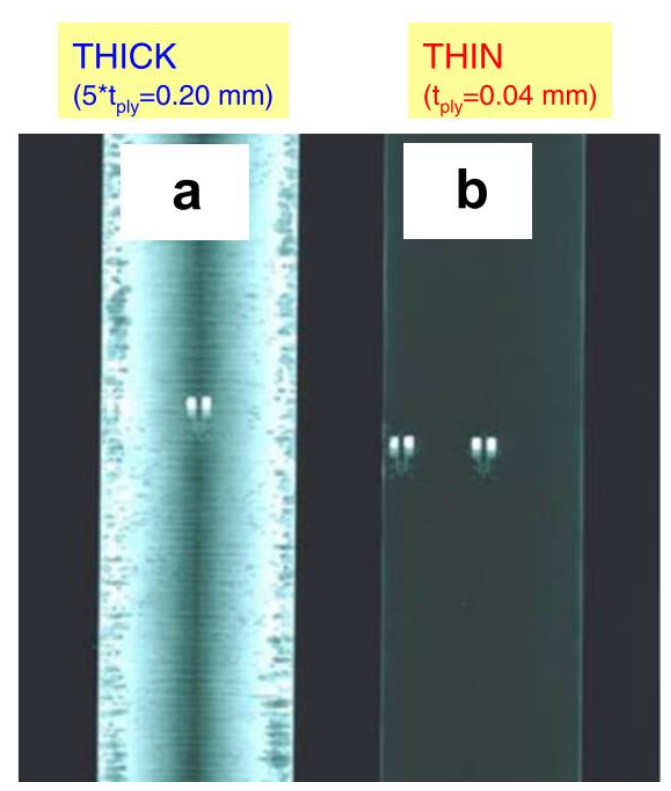

Figure 2.13 X-ray images of QI unnotched tensile fatigue samples after 50,000 cycles at $60 \%$ of ultimate quasi-static strength: a) thick-ply, b) thin-ply [16 $]^{1}$

Sihn et al. [16] also conducted open-hole tensile fatigue testing, with subsequent X-ray imaging. The difference in damage severity between the thin and thick-ply samples can be seen even more clearly during fatigue testing of open-hole tensile specimens, as shown in Figure 2.14 [16]. In this figure, the samples have been exposed to 100,000 cycles of fatigue loading. The stress is $70 \%$ of the ultimate strength for the quasi-static open-hole tensile specimens. The white areas correspond to delamination and microcracking.

Amacher et al. [14] also studied the effect of ply thickness on QI open-hole tensile fatigue properties. They found that the thick-ply samples $\left(300 \mathrm{~g} / \mathrm{m}^{2}\right)$ acquired damage via delamination and shear cracking of the off-axis plies and showed a trend for deceasing fatigue life with increasing load. The thin-ply samples $\left(30 \mathrm{~g} / \mathrm{m}^{2}\right)$ showed little fatigue damage at stresses lower than or equal to $83 \%$ of the corresponding, quasi-static ultimate strength. Ultimately, the thin-ply material was found to have superior fatigue properties; when both samples were

\footnotetext{
${ }^{1}$ Reprinted from Composites Science and Technology, 67(6), Sihn S, Kim RY, Kawabe K, Tsai SW, Experimental studies of thin-ply laminated composites, pp. 996-1008, Copyright (2006), with permission from Elsevier.
} 
fatigue tested at $316 \mathrm{MPa}$ the thick-ply sample failed before 20,000 cycles, whereas the thin-ply sample maintained load for the full 1,000,000 cycles.

Yokozeki et al. [15] found a similar trend for thin-ply laminates having a superior fatigue life, when tested in unnotched tension. This was attributed to the thinner ply material being less prone to the propagation of delamination from the free edge.

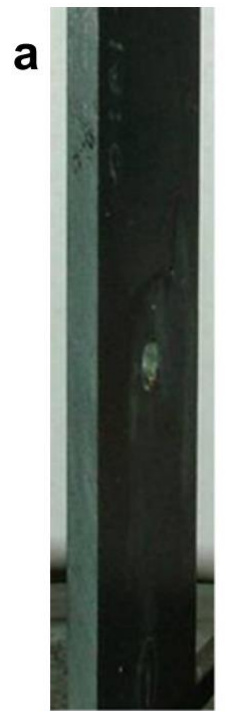

Side view

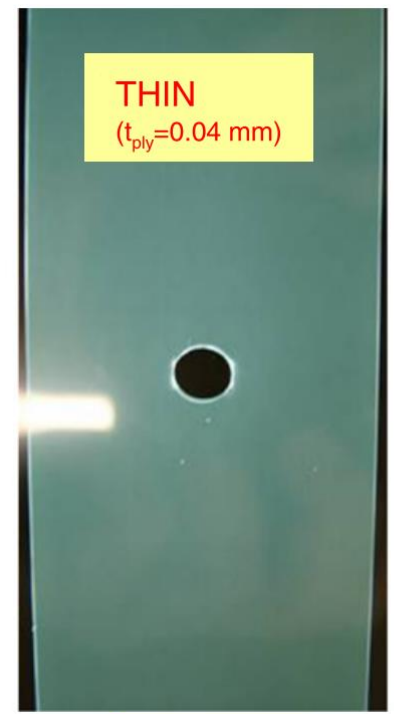

Front view

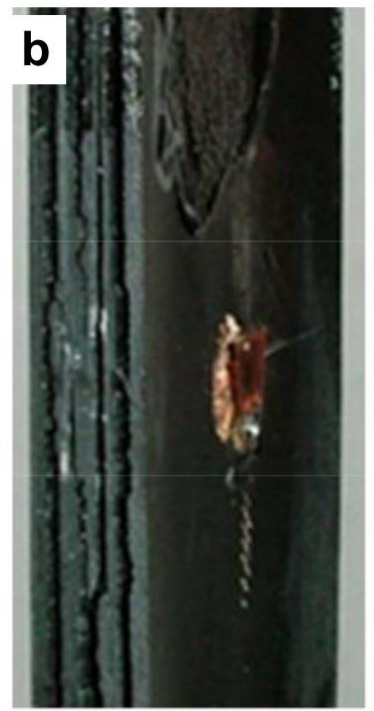

Side view

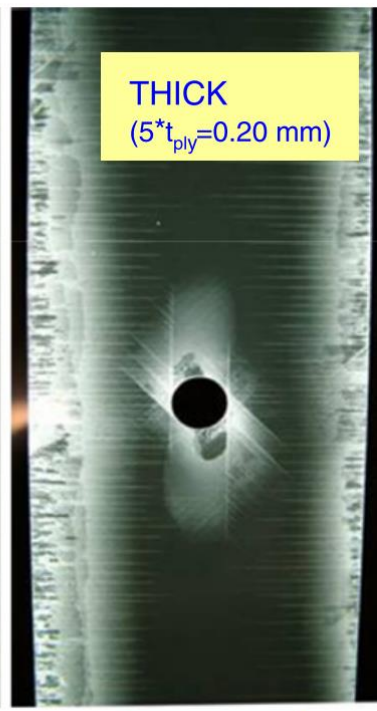

Front view

Figure 2.14 X-ray images of QI open-hole tensile fatigue specimens after 100,000 cycles at $70 \%$ of the ultimate quasi-static strength: a) thin-ply, b) thick-ply [16] ${ }^{1}$

\subsubsection{Compressive Behaviour}

Compressive properties are notoriously difficult to reliably test in a polymer composite material. This is due to issues such as buckling of the sample, or, as is the case with UD laminates, 'end-crushing'. End-crushing is when the sample crushes at the ends of the sample, instead of failing in the gauge length, and is caused by the high strength of the fibres. Despite the well-known challenges of compression testing, it is an important property to investigate, especially because

\footnotetext{
${ }^{1}$ Reprinted from Composites Science and Technology, 67(6), Sihn S, Kim RY, Kawabe K, Tsai SW, Experimental studies of thin-ply laminated composites, pp. 996-1008, Copyright (2006), with permission from Elsevier.
} 
the measured tensile and compressive strengths of FRPs are typically not equal. The compressive strengths of carbon fibre composites can be as low as $60 \%$ of the measured tensile strength [73]. This makes it a limiting factor of the material and thus should be investigated accordingly.

Using laminates prepared from two different ply thicknesses, $145 \mathrm{~g} / \mathrm{m}^{2}$ and $75 \mathrm{~g} / \mathrm{m}^{2}$, Yokozeki et al. [15] investigated the compressive properties of thick and thin-ply QI laminates. Back to back strain gauges were attached to the specimens to monitor for bending or buckling. This is important, as misalignment can largely affect compressive strength results. The thin-ply laminate was found to have a $16 \%$ increase in strength, over an average of five specimens, compared to the thick-ply material. No hypothesis was given as to why this strength increase was seen.

An increase in compressive strength for thin-ply laminates was also seen when compressive properties of UD laminates were investigated by Amacher et al. [14]. This data (shown in Figure 2.15) was highly scattered, however a general trend towards increased strength was observed for the thinner ply material. After looking at the microstructure of both the thin and thick-ply laminates, Amacher et al. [14] attributed the increased compressive strength to a more homogeneous microstructure, as seen in Figure 2.16. Resin rich regions are prone to fibre micro-buckling and therefore are prime sites for compressive instability [14]. Amacher et al. [14] found that thick-ply material was generally more inhomogeneous than the thin-ply prepreg materials. Using optical microscopy, the $300 \mathrm{~g} / \mathrm{m}^{2}$ laminate was found to have fibre volume fractions ranging between $42 \%$ to $64 \%$ in an area of $310 \times 230 \mu \mathrm{m}^{2}$ [14]. The thinnest ply was the most homogeneous. Amacher et al. [14] suggested that these findings could explain the increase in performance of the thinner ply laminates. It is well documented that fibre volume fraction impacts mechanical properties [68]. As such this is a 
variable that should be kept constant in order to fully understand differences between thin and thick-ply behaviour.

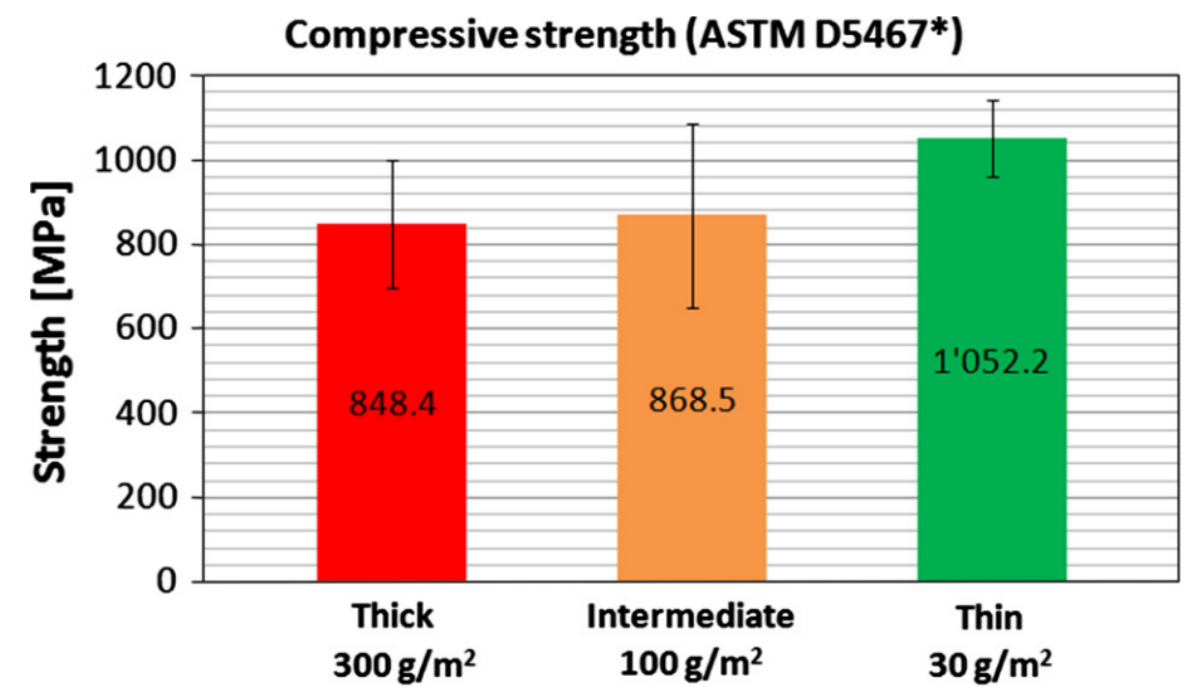

Figure 2.15 Compressive strength of UD samples produced using different prepreg thicknesses [14] $]^{2}$
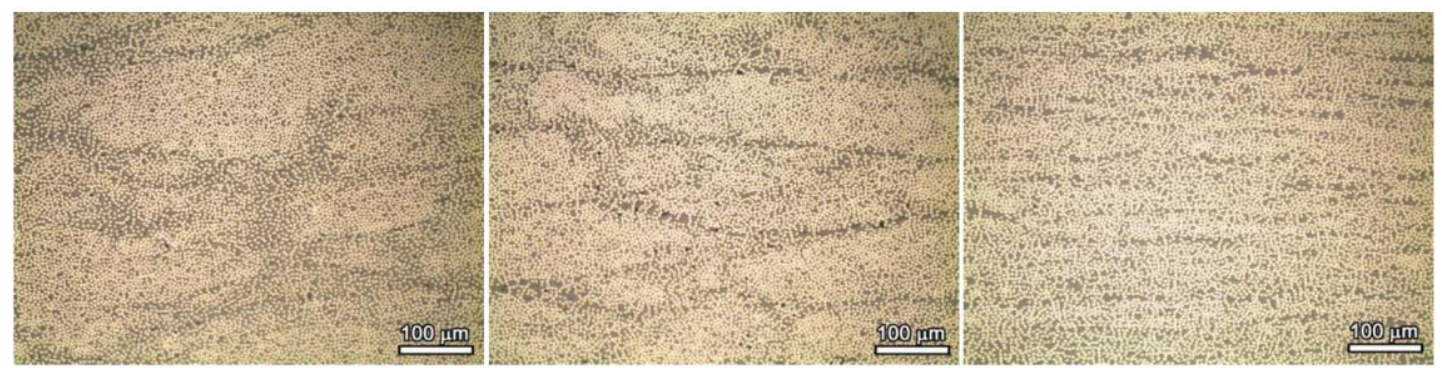

Figure 2.16 Micrographs of unidirectional laminates made from various thickness prepregs (left $300 \mathrm{~g} / \mathrm{m}^{2}$, middle $150 \mathrm{~g} / \mathrm{m}^{2}$, right $50 \mathrm{~g} / \mathrm{m}^{2}$ ) [74 ${ }^{4}$

Lee and Soutis [68] used both ply block and sub-laminate scaling to measure compressive properties of QI laminates made from a $0.125 \mathrm{~mm}$ thick prepreg. On average, compressive strength remained constant with increase in specimen thickness for the sub-laminate scaled coupons. However, for the ply block scaled ("thick-ply") coupons, the compressive strength decreased when the coupon

\footnotetext{
${ }^{2}$ Reprinted from Composites Science and Technology, 101, Amacher R, Cugnoni J, Botsis J, Sorensen L, Smith W, Dransfeld C, Thin ply composites: Experimental characterization and modeling of size-effects, pp. 121-132, Copyright (2014), with permission from Elsevier.

${ }^{4}$ Thin Ply: From Size-Effect Characterization to Real Life Design, Amacher R, Smith W, Dransfeld C, Botsis J, Cugnoni J. Reprinted by permission from the Society for the Advancement of Material and Process Engineering (SAMPE).
} 
thickness reached above $4 \mathrm{~mm}$. This is shown graphically in Figure 2.17. It should be noted that the $8 \mathrm{~mm}$ ply block laminate had a large difference in strength because a six-year-old, brittle prepreg was used, which caused a premature failure. The reason given for the lower strength of the ply block scaled coupons is because, once micro-buckling, or a crack, has initiated within plies of the same orientation the damage propagates across all of the block, promoting earlier failure [68]. This theory could not be applied to the results from Amacher et. al [14], as they investigated UD laminates and therefore all plies were in the same orientation.

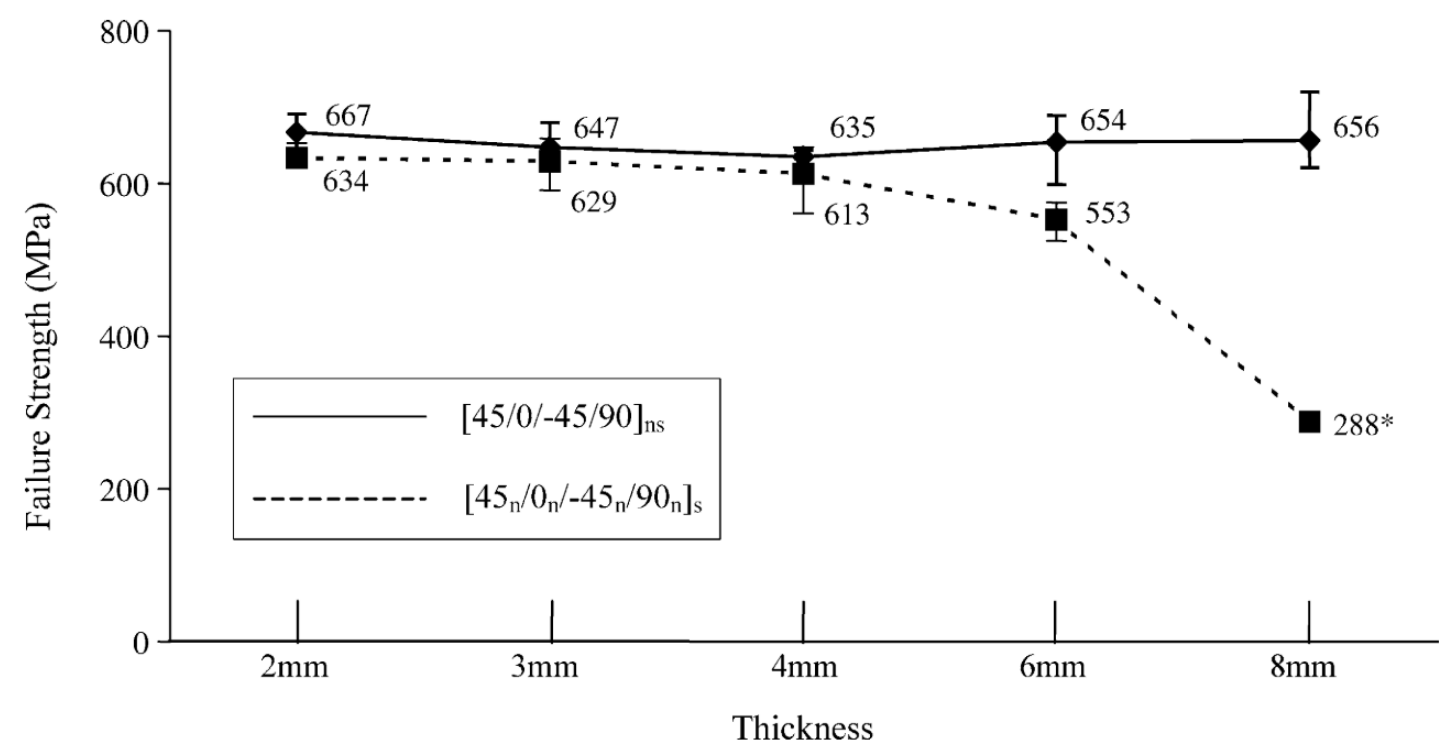

Figure 2.17 Compressive strength as a function of coupon thickness for sub-laminate scaled (solid line) and ply block scaled (dashed line) laminates [68 $]^{5}$

\subsubsection{Open-hole Compressive Behaviour}

As with open-hole tensile testing, open-hole compression testing provides useful information for situations were material defects may occur, or when fasteners are required. Due to the hole in the centre of the test coupon providing a large stress

\footnotetext{
${ }^{5}$ Reprinted from Composites Part A: Applied Science and Manufacturing, 36(2), Lee J, Soutis C, Thickness effect on the compressive strength of T800/924C carbon fibre-epoxy laminates, pp. 213-227, Copyright (2004), with permission from Elsevier.
} 
concentration, open-hole compression testing is a relatively straight forward test to carry out, especially when compared to unnotched compression testing.

Lee and Soutis [68] investigated open-hole compressive strength on ply block and sub-laminate scaled QI laminates produced from $0.125 \mathrm{~mm}$ thick prepreg. They reported different failure modes for the two different stacking methods. Sub-laminate ("thin-ply") scaled laminates showed delamination and fibre buckling along the fracture, with little damage further away from the hole. However, the ply block ("thick-ply") scaled laminates showed increased matrix cracks, delamination, fibre micro-buckling and fibre splitting. Similar failure modes were found by Amacher et al. [14]. For each thickness tested, the open-hole compressive strengths were very similar for both ply scaling methods used [68]. Conversely, Amacher et. al [14] observed an $18 \%$ increase in open-hole compressive strength for QI laminates manufactured from a $30 \mathrm{~g} / \mathrm{m}^{2}$ prepreg, compared to a $300 \mathrm{~g} / \mathrm{m}^{2}$ laminate. Acoustic emission analysis showed that onset of damage increased by $17.7 \%$ for thin-ply laminates, as was the case previously with different loading types. Interestingly, the supressed damage did not lead to a lower strength, as was the case with open-hole tensile strength. This is something that could be investigated further to understand more.

Based on five test samples, Yokozeki et al. [15] found that QI open-hole compression specimens manufactured using $75 \mathrm{~g} / \mathrm{m}^{2}$ prepreg had, on average, a $9 \%$ increase in strength compared to coupons, of the same geometry, made using $145 \mathrm{~g} / \mathrm{m}^{2}$ prepreg.

Wisnom et al. [71] conducted open-hole compression testing on laminates with equal prepreg thicknesses, but different 'effective' ply thicknesses (through the use of ply block scaling methods). As before, although the work was not conducted using spread-tow prepreg, comparisons between coupons with different overall ply thickness can be made. All QI sub-laminate scaled coupons displayed brittle failure, whereas the ply block scaled laminates displayed a 
delamination failure mode. The delamination failure mode was said to be due to the presence of non-critical damage prior to failure. On the other hand, in the sub-laminate scaled coupons, the $0^{\circ}$ plies were put under sufficient stress to initiate micro-buckling before critical damage, thus leading to a brittle failure [71].

\subsubsection{Shear Properties}

Fibre reinforced polymers often have low shear properties, particularly in material planes which are dominated by the matrix properties, and this can compromise the overall material performance [37]. In-plane and through-thickness strains can differ in polymer composites, therefore several different test methods for determination of shear properties are available [37]. One example of an in-plane shear test method is testing of a $\pm 45^{\circ}$ laminate in tension [75] and an example of a through-thickness shear test method is the short beam strength (apparent interlaminar shear strength) test [76]. Huang et al. [77] investigated the interlaminar shear strength of CFRPs manufactured using three different prepreg thicknesses, $20 \mathrm{~g} / \mathrm{m}^{2}, 54 \mathrm{~g} / \mathrm{m}^{2}$ and $125 \mathrm{~g} / \mathrm{m}^{2}$. Both unidirectional and quasi-isotropic properties were studied. The results showed a trend for increased interlaminar strength with decreasing ply thickness, for both UD and QI coupons. Upon observation of the failure modes, the thinner ply specimens showed a greater number of interlaminar shear failure cracks, whereas the thick-ply specimens showed the propagation of transverse ply cracking [77]. Huang et al. [77] attributed the increased strength to the more homogeneous microstructure of the thin-ply material, leading to a reduction in resin rich areas and fewer defects, thus increasing strength.

\subsubsection{Compression after Impact Behaviour}

Open-hole compression and tensile tests aim to study the mechanical properties of a material when deliberate holes (due to the insertion of fasteners, for example) are incorporated into the composite design. Taking this one step further, compression after impact (CAI) tests are used to determine the mechanical 
properties of the material when unexpected, or accidental damage occurs. This damage may be undetected during routine inspections; delamination, for example, is particularly difficult to detect visually. This is a potentially serious problem, given the extent at which delamination can diminish mechanical properties. For example, compressive properties can be reduced by $40 \%$ to $60 \%$ compared to that of the undamaged material [78]. As a result, it is important to factor in damage tolerance during the component design.

Sihn et al. [16] expected the compression after impact properties of thin-ply laminates to out-perform thick-ply laminates (manufactured using ply block scaling), because thin-ply laminates have been shown to supress the onset of damage (micro cracks and delamination). Only two duplicate compression after impact samples for both the thick and thin-ply material were tested. The initial results showed that the thicker ply laminates buckled at lower stresses compared to the thin-ply samples. This is demonstrated in the stress/strain curve shown in Figure 2.18. The gradient of the stress/strain curve represents stiffness; the thin-ply samples were therefore stiffer after impact damage, which suggests less damage has occurred. Two stress/strain curves for each sample are shown, because back-to-back strain gauges were attached to the samples, to monitor instability during the compressive loading. The earlier bifurcation seen with the thick-ply samples also indicates that severe damage occurred at a lower stress.

Yokozeki et al. [15] also performed CAI tests on samples made from QI thick and thin-ply prepregs (145 g/m² and $75 \mathrm{~g} / \mathrm{m}^{2}$ respectively). As with Sihn et al. [16] only two specimens of each were tested. The results showed an $8 \%$ increase in strength for the thinner ply laminate which was attributed to the increased resistance to delamination growth. Despite this, ultrasonic C-scans of the specimens, post impact, showed similar projected delamination areas for both materials. The delamination areas were more circular in the standard laminate compared to a more elliptical shape with the thin-ply laminate. As with the findings from 
Sihn et al. [16] the limited sample size demands for further tests to be carried out in order to fully understand any differences in mechanical properties.

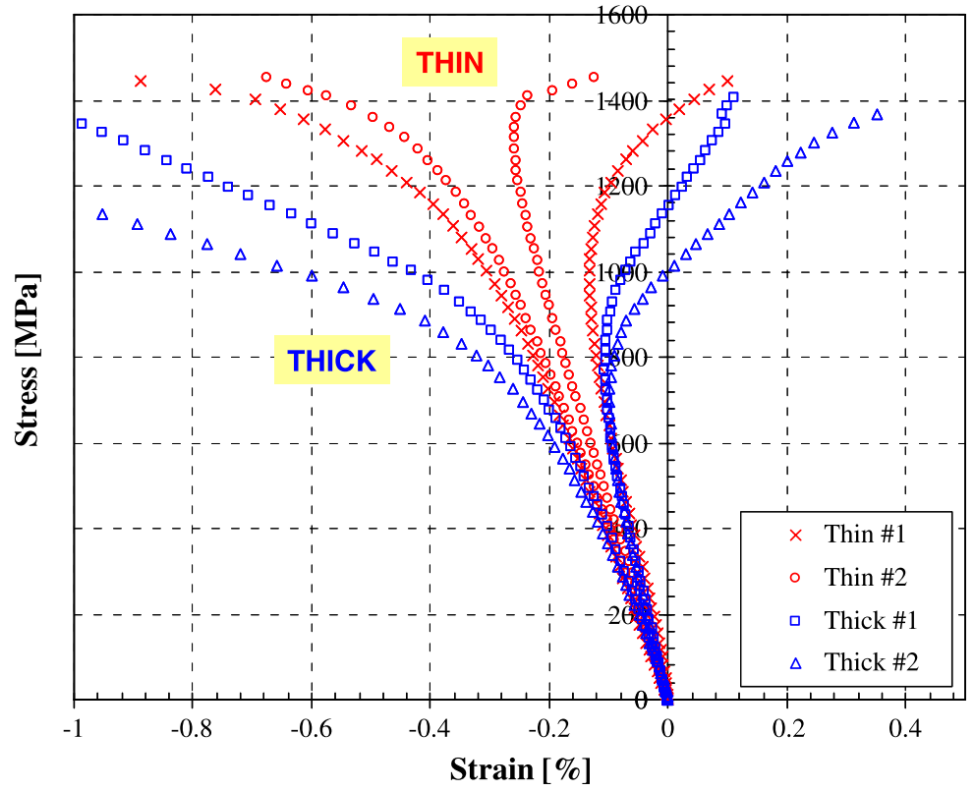

Figure 2.18 CAI stress/strain curves of QI thick and thin-ply laminates [16] ${ }^{1}$

Saito et al. [61] conducted a comprehensive investigation into the effect of ply thickness on impact damage. They used thin prepregs $(38 \mu \mathrm{m})$ and standard prepregs $(147 \mu \mathrm{m})$ to manufacture QI laminates with 96 and 24 plies respectively. Contrary to the findings by Yokozeki et al. [15], Saito et al. [61] found the delamination area in the thin-ply specimens to be larger than those seen in the thick-ply. That said, there was a large variability in the delamination area for thin-ply coupons and the error bars overlapped with the results of the thick-ply coupons. Despite the differences in delamination area, the compression after impact strength results were $23 \%$ higher for the thin-ply specimens, as shown in Figure 2.19. Stress/strain curves from strain gauges bonded to both the front and back of the specimen indicated that buckling of the samples did not occur. Cross-sectional examination of the specimens showed transverse cracks in every $\pm 45^{\circ}$ layer when located above a $0^{\circ}$ layer in the thick-ply specimens (shown in

\footnotetext{
${ }^{1}$ Reprinted from Composites Science and Technology, 67(6), Sihn S, Kim RY, Kawabe K, Tsai SW, Experimental studies of thin-ply laminated composites, pp. 996-1008, Copyright (2006), with permission from Elsevier.
} 
Figure 2.20). These cracks connected to interlaminar delamination that extended across the $0^{\circ}$ ply. This was not the case with the thin-ply specimens, where only one transverse crack was observed. This crack was located in the mid-plane, where two $90^{\circ}$ plies were stacked together, essentially forming a thicker ply. This is a potential reason for the formation of this crack. The supressed microcracking in the thin-ply laminates is thought to be the reason for their increased strength.

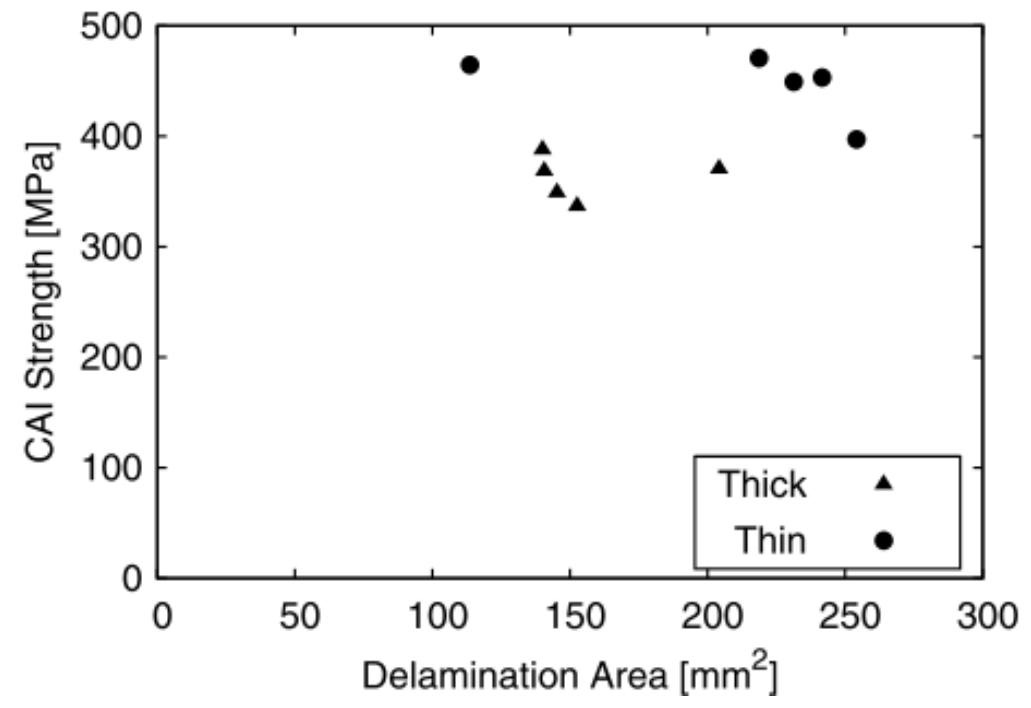

Figure 2.19 Correlation between delamination area and CAI strength [61]
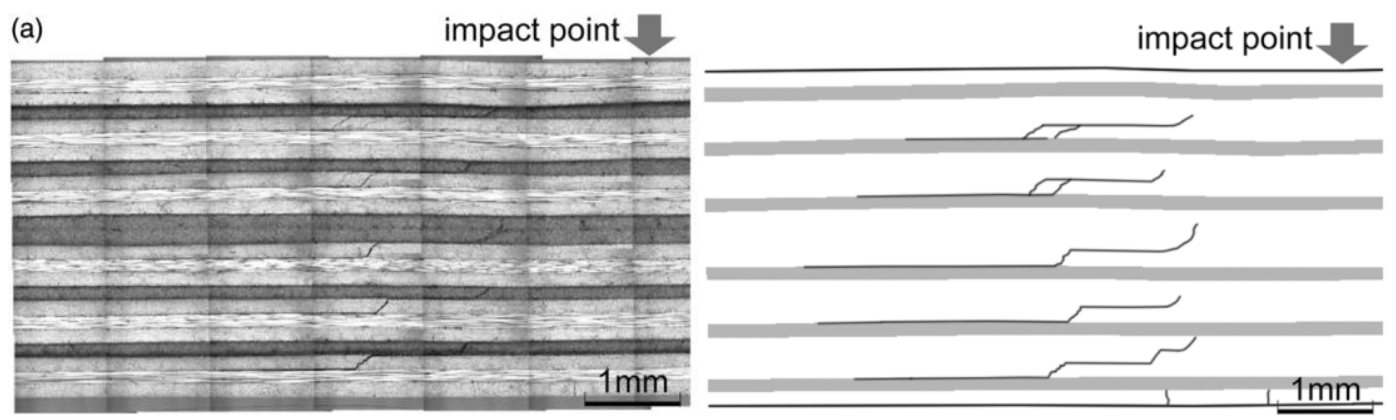

(b) impact point
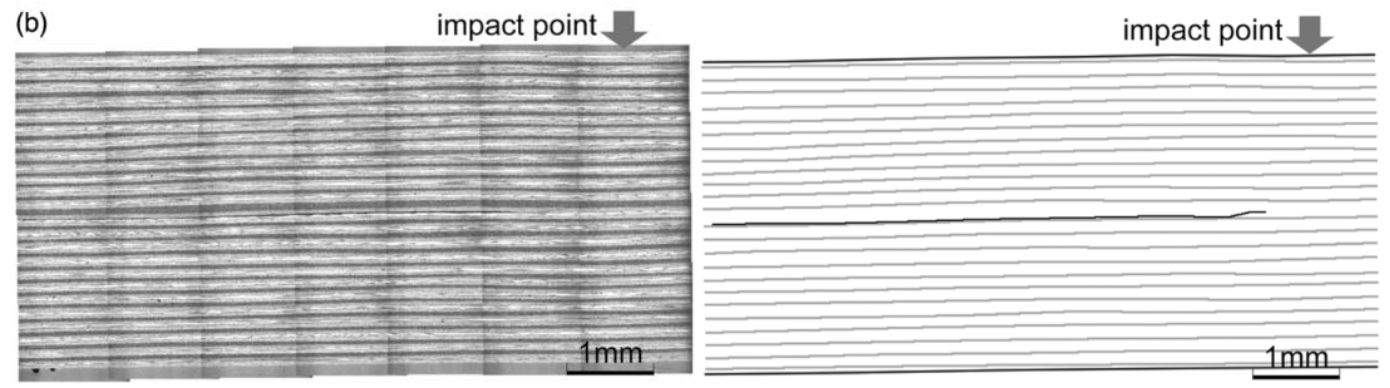

Figure 2.20 Cross sectional images of: a) thick-ply and b) thin-ply specimens after CAI testing. Grey areas represent the $0^{\circ}$ layers, bold black lines represent the transverse cracks and delamination areas (figure adapted from original) [61] 


\subsubsection{Mechanical Behaviour Summary}

A review of the current literature on the mechanical properties of carbon fibre composites with varying ply thicknesses has been conducted. The literature generally suggests that thin-ply laminates have enhanced mechanical properties but are more negatively affected by large stress concentrating features (such as holes). This has been shown to be the case particularly for open-hole tensile properties $[14,16]$.

Several mechanisms have been proposed for the enhanced performance of thin-ply materials. One such example is the delayed onset of damage which they exhibit. The delayed damage onset has been shown to occur through a use of acoustic emission analysis and X-ray imaging [14-16]. Delayed damage onset was often seen to produce a more brittle failure mode, whereas the thicker ply samples generally displayed more damage, in the form of delamination $[14,16,71]$. The reason for this delamination is the high interlaminar shear stresses seen with the thicker ply material [16]. Damage suppression was shown to give varying results in terms of mechanical performance. For example, without the presence of a hole, damage suppression led to enhanced tensile strengths. On the contrary, with notched tensile, the damage suppression of thin-ply materials was detrimental to strength $[14,16]$.

Furthermore, the spread-tow procedure is thought to enhance the uniformity of fibre distribution within each layer, allowing for more uniform properties and reducing local stress peaks [14,77]. In addition, there may be more resin rich areas and fibre defects, such as kinks and bending, with thick-ply materials, due to the fact that the size of the ply is larger. This could lead to reduced properties.

A review of the current literature has highlighted that numerous studies can be found which use the method of ply block scaling to compare the properties of "thick" and "thin" ply laminates. Research into the behaviour of carbon fibre laminates manufactured using spread-tow fibre prepregs is more limited. This is 
something that could be expanded on, in order to truly understand whether the differences in mechanical performance are due to the use of thinner plies or stacking sequence. To do this, laminates manufactured from various ply thicknesses should be investigated. The hypothesis regarding the increased homogeneity of thin-ply laminates causing an increase in strength [14] could then be investigated further. This is not possible when plies of the same thickness are used to make ply-block and sub-laminate scaled materials. Furthermore, the fibre/matrix interface in thin-ply laminates could also be investigated. A poor interface can lead to the propagation of cracks along the fibre length, therefore it would be interesting to see if this is improved in thin-ply laminates.

In addition to unconditioned and ambient temperature testing of specimens, an investigation into the behaviour of thin-ply laminates after environmental conditioning, and at varying temperatures would be of interest. With the exception of Moon et al. [60] environmental conditioning of thin-ply specimens has not been extensively researched. This is something that could be particularly useful in the marine or aerospace industries.

\subsection{Influence of Moisture and High Temperature on the Behaviour of Polymer Composites}

Polymer composites are widely used in industries where exposure to harsh or changeable environmental conditions is inevitable. Examples of these include, but are not limited to, moisture, high/low temperature, acidic/alkaline solutions and ultraviolet radiation $[44,79]$. The long-term effect of such conditions on the behaviour of the material is an important design consideration. This section will focus on the impact of moisture and high temperature on both the mechanical and thermal properties of CFRPs.

Most polymer composites will be exposed to moisture in some form throughout their service life [80]. Despite this, it is well documented that the mechanical and 
thermal properties of polymer composites are often negatively affected by moisture absorption $[29,79-85]$. As such, understanding the long-term effect of moisture on novel composites is an important consideration.

Water absorption can occur via diffusion and capillary action $[29,44,79]$. The process is dependent on many variables, such as: fibre volume fraction [86], fibre orientation [87], material thickness [88], resin type [89], temperature and humidity [86]. Both the amount of moisture absorption (maximum saturation) and the rate of water absorption through a polymer composite (diffusion rate) have been shown to be dependent on temperature [86,90]. A possible mechanism for this increased moisture absorption this is that the free volume of the resin increases with temperature, providing more volume for the water to diffuse into. In addition, a high temperature environment can cause cracking within the matrix, enabling more water to diffuse inward [86]. Maximum moisture content has also been shown to be strongly dependent on relative humidity, with increasing humidity leading to increased moisture content [86].

Saturation level is also dependent on fibre volume fraction [86]. This is because the polymer matrix is more susceptible to moisture ingress than the reinforcement $[82,86]$, thus larger volumes of resin allow for more moisture to be absorbed. Furthermore, fibre arrangement and fibre volume fraction have been shown to strongly impact rate of diffusion, due to changes in the diffusion path length and the amount of resin present between neighbouring fibres [91]. Modelling of diffusion using a random fibre arrangement (such is the case with a lower fibre volume fraction) predicts lower diffusivity than that of a more ordered fibre arrangement, due to the longer diffusion path [91]. Polymer composite materials are typically anisotropic, thus the diffusion of water is also anisotropic [87]. Diffusion is typically faster along the fibres and slower through the thickness of the material [87]. Arnold et al. [87] found that diffusion through the thickness of a UD carbon fibre/epoxy composite was approximately $13 \%$ of the diffusion 
along the fibres. Furthermore, diffusion across fibres (within a pre-preg layer) was found to be approximately $40 \%$ of the diffusion along the fibres. As such, exposure of component edges (for example at holes or sites of damage) enables an easier route for moisture ingress via diffusion along the fibres [87]. This means that if the thickness of a material is large in comparison to the other dimensions, moisture ingress via the edges should be considered [88]. Moisture diffusion into thick components is generally a slow process; water absorption begins immediately upon contact with the material surface, but it can take several years before the material becomes saturated [88]. Korkees et al. [88] investigated the effect of thickness on diffusion rate using carbon fibre epoxy composite materials. They found that thinner samples had a faster weight uptake compared to thicker samples.

Typically, diffusion rate is determined based on a Fickian diffusion process, where a fixed saturation point is reached. That said, it has been shown that some epoxy and bismaleimide resins do not reach a fixed saturation point and instead continue to slowly absorb water beyond the typical Fickian saturation stage $[44,84,90,92,93]$. Proposed reasons for this continued absorption include molecular relaxation of the polymer [90,93], micro-cracking (which enables increased water ingress), chemical degradation of the matrix, and water absorption into toughening particles [84]. Moisture ingress can occur by wicking of water along a deboned fibre/matrix interface and through voids and microcracks in the matrix $[29,90]$. Arnold et al. [84] investigated the long-term moisture ingress of materials which exhibited an initial Fickian diffusion followed by slower, more gradual water absorption thereafter. No microcracking in the material was found, despite the use of optical microscopy, and Fourier-transform infrared spectroscopy (FTIR) showed no significant chemical degradation. Therefore the mechanism for long-term water absorption was attributed to molecular relaxation [84]. Research conducted by Korkees et al. [86] suggests that for carbon fibre epoxy composites that continue to steadily absorb water after the 
initial Fickian behaviour, the long-term element of moisture absorption is more dependent on temperature than the initial phase. The dependence on relative humidity was found to occur for both the initial Fickian component and the long-term behaviour.

Moisture ingress can lead to both reversible and irreversible changes in polymer composites. Reversible changes typically recover when the material is dried. Irreversible damage, such as chemical degradation, leads to changes in properties of the fibre, the matrix and the fibre/matrix interface [94]. Irreversible damage can also occur in the form of coalescence of microcracks and voids into larger cracks, which, in turn, enables further diffusion and wicking of water via new routes [90]. This degradation is enhanced with high temperatures [90]. Water can be present in two states in an epoxy matrix, unbonded and hydrogen bonded. The unbonded water fills nanovoids and does not cause swelling, whereas hydrogen-bonded water does [44]. Swelling of the matrix is an issue, because, as the fibres are generally unaffected, expansion of the matrix is greater than the expansion of the fibres. This causes residual stresses to develop, which degrades the fibre/matrix interface [95]. A weak interface can limit the efficiency of stress transfer from the matrix to the fibre, which consequently results in a reduced strength and modulus [44]. Despite carbon fibres being less susceptible to moisture ingress, the presence of microcracks on fibres can lead to fibre rupture [79].

Selzer and Friedrich investigated the effect of water on carbon fibre composites with both thermoset (epoxy) and thermoplastic matrices [80]. They found that moisture most negatively impacted the properties of epoxy-based CFRPs when the fibres were orientated perpendicularly to the direction of the load. The thermoset matrix materials were more negatively impacted by water ingress compared to the thermoplastic matrix. This was said to be because the epoxy materials had a higher moisture saturation level. Genna et al. [95] researched the effect of moisture ingress on an epoxy matrix CFRP and found that short-beam 
shear strength was highly influenced by moisture absorption, with shear strength decreasing linearly with increasing moisture immersion time. Kafodya et al. [96] recorded similar interlaminar shear strength behaviour with UD CFRP material. The degradation of interlaminar shear strength was said to be a result of matrix plasticisation and debonding of the fibre/matrix interface. Ray [82] studied the impact of moisture ingress at different temperatures on the ILSS properties of UD epoxy carbon fibre composites. Not only did they find that ILSS decreased with increasing moisture content, but that ILSS also decreased with increasing temperature, even when the moisture content was similar for the two temperatures observed. This was thought to be a result of thermal stresses promoting crack initiation/propagation. Humeau et al. [89] also investigated the effect of moisture on the shear behaviour of epoxy carbon fibre laminates. They found that in-plane shear strength (tested using a $\pm 45^{\circ}$ woven laminate) was negatively impacted after aging in water, due to plasticisation of the matrix. They also studied the impact of moisture on the tensile behaviour of a QI laminate. This was found to be less susceptible to moisture degradation, due to the presence of the fibres orientated in the load direction. Kumar et al. [97] investigated the tensile properties of UD (in both the longitudinal and transverse directions) and $\pm 45^{\circ}$ carbon fibre prepreg laminates after moisture absorption. Longitudinal tensile strength was found to decrease during the first month of exposure to water, but then remained constant thereafter. The transverse tensile properties were found to continue to degrade for the entire immersion period of 168 days. An increasing-decreasing trend was also observed for in-plane shear strength.

Water ingress has been shown by many to lower the glass transition temperature of epoxy based composites $[80,90]$. High temperature is often used to accelerate the effect of water, but high temperature alone can also impact polymer composite properties [79]. As discussed previously, the upper service temperature of a composite material is governed by the glass transition temperature [46], due to the degradation of mechanical properties at 
temperatures above this point [98]. Above the $\mathrm{T}_{\mathrm{g}}$ the matrix softens and the efficiency of the stress transfer between the fibres and the resin is reduced. As such, the failure mode of FRPs at high temperature is fibre dominated [79]. High temperature can also lead to microcracking at the fibre/matrix interface, as a result of the different thermal expansions of the two constituents causing thermal stresses [44].

As mentioned previously, the quantity of water that can be absorbed varies for different resin systems [99], meaning it is useful to investigate the effect of water on the properties of different fibre and matrix systems. This, combined with the fact that fibre arrangement and fibre volume fraction impact strongly on moisture ingress, is of significance when examining the effect of moisture on spread-tow prepreg materials. Thin-ply composites have been shown to have a more homogeneous microstructure than the respective thicker-ply materials [14]. Thus, it is possible that the more uniform fibre distribution may impact the water absorption for the thin-ply material, when compared to conventional ply thickness materials.

A study into moisture ingress of thin-ply materials is something that, to the author's knowledge, is not found in the literature. As such, the aim of this research is to further the knowledge in the field of thin-ply technology by investigating the mechanical behaviour of thin-ply carbon fibre composites after exposure to differing environmental conditions. 


\section{Experimental Procedures}




\subsection{Materials}

The carbon fibre composite materials used throughout the project were manufactured by North Thin-ply Technology and consisted of T800SC-24000-10E carbon fibres (Toray) and TP135-4 epoxy resin, in prepreg form. Laminate curing followed conventional vacuum bagging and autoclave methods. An autoclave pressure of 6 bar with a cure cycle of two hours at $130{ }^{\circ} \mathrm{C}$, followed by four hours at $165^{\circ} \mathrm{C}$ was used. The heating and cooling ramps were both $1{ }^{\circ} \mathrm{C} / \mathrm{min}$. An impregnated peel ply was applied to both faces of the material. The same peel ply was used for all of the manufactured material.

Carbon fibre laminates were manufactured using three different prepreg thicknesses:

- $50 \mathrm{~g} / \mathrm{m}^{2}$, which had a nominal thickness of $0.05 \mathrm{~mm}$ and is referred to as "thin-ply"

- $150 \mathrm{~g} / \mathrm{m}^{2}$, which had a nominal thickness of $0.15 \mathrm{~mm}$ and is referred to as "intermediate-ply"

- $\quad 300 \mathrm{~g} / \mathrm{m}^{2}$, which had a nominal thickness of $0.30 \mathrm{~mm}$ and is referred to as "thick-ply" (these laminates consisted of two $150 \mathrm{~g} / \mathrm{m}^{2}$ plies stacked together)

Laminates with different ply orientations were manufactured for each of the three prepregs used. These consisted of unidirectional (UD), quasi-isotropic (QI) and $\pm 45^{\circ}$.

Despite varying ply thicknesses, all laminates used for ply thickness comparisons were manufactured to have the same overall thickness. For example, a laminate with overall thickness of $2 \mathrm{~mm} \pm 0.3 \mathrm{~mm}$ would contain 48 thin plies $\left(50 \mathrm{~g} / \mathrm{m}^{2}\right), 16$ intermediate plies $\left(150 \mathrm{~g} / \mathrm{m}^{2}\right)$ or 8 thick plies $\left(300 \mathrm{~g} / \mathrm{m}^{2}\right)$. After manufacture each panel was numbered to allow for traceability of the material throughout the testing process. Details of each panel (including stacking sequence, ply thickness 
and panel dimensions) are shown in Table 3.1. The mean thickness for each panel was based on a minimum of twelve measurements taken across the panel, using a round end micrometer with a $4 \mathrm{~mm}$ radius and an accuracy of $0.01 \mathrm{~mm}$. Panels 261 and 281 are the exceptions to this; the thicknesses of these panels are based on nine measurements for panel 261 and six measurements for 281 .

After manufacture the material was delivered to R-Tech Services. Once on site the panels were sealed in plastic bags and stored in a freezer at $-30{ }^{\circ} \mathrm{C}$, to slow down the moisture ingress process. During the production of test coupons, the laminates were stored at room temperature.

Table 3.1 List of T800 TP135 carbon fibre composite panels, including panel stacking sequence, panel number, ply thickness and panel dimensions (Page 1 of 2)

\begin{tabular}{|c|c|c|c|c|c|}
\hline Panel \# & Stacking Sequence & $\begin{array}{l}\text { Ply } \\
\text { thickness } \\
\left(\mathrm{g} / \mathrm{m}^{2}\right)\end{array}$ & $\begin{array}{l}\text { Length } \\
(\mathrm{mm})\end{array}$ & $\begin{array}{c}\text { Width } \\
(\mathrm{mm})\end{array}$ & $\begin{array}{c}\text { Mean } \\
\text { thickness } \\
(\mathrm{mm})\end{array}$ \\
\hline 251 & QI $[-45 / 90 /+45 / 0]_{6 s}$ & 50 & 300 & 400 & 2.22 \\
\hline 252 & QI $[-45 / 90 /+45 / 0]_{6 s}$ & 50 & 300 & 400 & 2.24 \\
\hline 253 & QI $[-45 / 90 /+45 / 0]_{6 s}$ & 50 & 300 & 400 & 2.22 \\
\hline 254 & QI $[-45 / 90 /+45 / 0]_{6 s}$ & 50 & 300 & 400 & 2.26 \\
\hline 255 & QI $[-45 / 90 /+45 / 0] 6 \mathrm{~s}$ & 50 & 300 & 400 & 2.25 \\
\hline 256 & QI $[-45 / 90 /+45 / 0]_{6 s}$ & 50 & 300 & 400 & 2.24 \\
\hline 257 & QI $[-45 / 90 /+45 / 0]_{6 s}$ & 50 & 300 & 400 & 2.24 \\
\hline 258 & QI $[-45 / 90 /+45 / 0]_{2 \mathrm{~s}}$ & 150 & 300 & 400 & 2.10 \\
\hline 259 & QI $[-45 / 90 /+45 / 0]_{2 \mathrm{~s}}$ & 150 & 300 & 400 & 2.10 \\
\hline 260 & QI $[-45 / 90 /+45 / 0]_{2 \mathrm{~s}}$ & 150 & 300 & 400 & 2.10 \\
\hline 261 & QI $[-45 / 90 /+45 / 0]_{2 \mathrm{~s}}$ & 150 & 300 & 400 & 2.06 \\
\hline 262 & QI $[-45 / 90 /+45 / 0]_{2 \mathrm{~s}}$ & 150 & 300 & 400 & 2.09 \\
\hline 263 & QI $[-45 / 90 /+45 / 0]_{2 \mathrm{~s}}$ & 150 & 300 & 400 & 2.12 \\
\hline 264 & QI $[-45 / 90 /+45 / 0]_{2 \mathrm{~s}}$ & 150 & 300 & 400 & 2.09 \\
\hline 265 & QI $[-45 / 90 /+45 / 0]_{1 \mathrm{~s}}$ & $300(2 \times 150)$ & 300 & 400 & 2.12 \\
\hline 266 & QI $[-45 / 90 /+45 / 0]_{1 \mathrm{~s}}$ & $300(2 \times 150)$ & 300 & 400 & 2.10 \\
\hline 267 & QI $[-45 / 90 /+45 / 0]_{1 \mathrm{~s}}$ & $300(2 \times 150)$ & 300 & 400 & 2.10 \\
\hline 268 & QI $[-45 / 90 /+45 / 0]_{1 \mathrm{~s}}$ & $300(2 \times 150)$ & 300 & 400 & 2.12 \\
\hline 269 & QI $[-45 / 90 /+45 / 0]_{1 \mathrm{~s}}$ & $300(2 \times 150)$ & 300 & 400 & 2.06 \\
\hline 270 & QI $[-45 / 90 /+45 / 0]_{1 \mathrm{~s}}$ & $300(2 \times 150)$ & 300 & 400 & 2.11 \\
\hline 271 & QI $[-45 / 90 /+45 / 0]_{1 s}$ & $300(2 \times 150)$ & 300 & 400 & 2.13 \\
\hline 272 & $\mathrm{UD}[0]_{24}$ & 50 & 300 & 400 & 0.94 \\
\hline
\end{tabular}




\begin{tabular}{|c|c|c|c|c|c|}
\hline Panel \# & Stacking Sequence & $\begin{array}{c}\text { Ply } \\
\text { thickness } \\
\left(\mathrm{g} / \mathrm{m}^{2}\right)\end{array}$ & $\begin{array}{c}\text { Length } \\
(\mathrm{mm})\end{array}$ & $\begin{array}{l}\text { Width } \\
(\mathrm{mm})\end{array}$ & $\begin{array}{c}\text { Mean } \\
\text { thickness } \\
(\mathrm{mm})\end{array}$ \\
\hline 273 & $\mathrm{UD}[0]_{48}$ & 50 & 300 & 400 & 1.83 \\
\hline 274 & $\mathrm{UD}[0]_{48}$ & 50 & 300 & 400 & 1.83 \\
\hline 275 & UD $[0]_{16}$ & 150 & 300 & 400 & 2.17 \\
\hline 276 & UD [0] $]_{16}$ & 150 & 300 & 400 & 2.14 \\
\hline 277 & $\mathrm{UD}[0]_{8}$ & 150 & 300 & 400 & 1.04 \\
\hline 278 & QI $[-45 / 90 /+45 / 0]_{6 s}$ & 50 & 300 & 400 & 2.22 \\
\hline 279 & QI $[-45 / 90 /+45 / 0]_{6 s}$ & 50 & 300 & 400 & 2.21 \\
\hline 281 & QI $[-45 / 90 /+45 / 0]_{6 s}$ & 50 & 300 & 400 & 2.19 \\
\hline 283 & QI $[-45 / 90 /+45 / 0]_{6 s}$ & 50 & 300 & 400 & 2.20 \\
\hline 285 & QI $[-45 / 90 /+45 / 0]_{6 s}$ & 50 & 300 & 400 & 2.21 \\
\hline 286 & QI $[-45 / 90 /+45 / 0]_{2 \mathrm{~s}}$ & 150 & 300 & 400 & 2.18 \\
\hline 288 & QI $[-45 / 90 /+45 / 0]_{2 \mathrm{~s}}$ & 150 & 300 & 400 & 2.23 \\
\hline 289 & QI $[-45 / 90 /+45 / 0]_{2 \mathrm{~s}}$ & 150 & 300 & 400 & 2.09 \\
\hline 290 & QI $[-45 / 90 /+45 / 0]_{2 \mathrm{~s}}$ & 150 & 300 & 400 & 2.24 \\
\hline 293 & QI $[-45 / 90 /+45 / 0]_{1 \mathrm{~s}}$ & $300(2 \times 150)$ & 300 & 400 & 2.04 \\
\hline 294 & QI $[-45 / 90 /+45 / 0]_{1 \mathrm{~s}}$ & $300(2 \times 150)$ & 300 & 400 & 2.08 \\
\hline 296 & QI $[-45 / 90 /+45 / 0]_{1 \mathrm{~s}}$ & $300(2 \times 150)$ & 300 & 400 & 2.19 \\
\hline 297 & QI $[-45 / 90 /+45 / 0]_{1 \mathrm{~s}}$ & $300(2 \times 150)$ & 300 & 400 & 2.00 \\
\hline 301 & $\mathrm{UD}[0]_{48}$ & 50 & 300 & 400 & 1.78 \\
\hline 302 & $\mathrm{UD}[0]_{48}$ & 50 & 300 & 400 & 1.79 \\
\hline 304 & UD [0] $]_{16}$ & 150 & 300 & 400 & 2.07 \\
\hline 305 & UD [0] $]_{16}$ & 150 & 300 & 400 & 1.95 \\
\hline 306 & {$[+45 /-45]_{24}$} & 50 & 600 & 400 & 2.24 \\
\hline 307 & {$[+45 /-45] 8$} & 150 & 600 & 400 & 2.09 \\
\hline 308 & {$[+45 /-45]_{4}$} & $300(2 \times 150)$ & 600 & 400 & 2.04 \\
\hline
\end{tabular}

\subsection{Material Quality Control}

To reliably compare the properties of carbon fibre laminates made from different prepreg thicknesses, several material quality checks were conducted. Ideally prepreg thickness would be the only variable in the investigation, however factors such as curing schedules and fibre spreading allow for other variables to arise. In addition, the use of multiple panels for each ply thickness created an element of variation to the investigation. 
To limit the influence of factors other than prepreg thickness, certain quality control tests were performed on each laminate. These included:

- Optical microscopy

- Fibre volume fraction $\left(v_{f}\right)$ determination

- Determination of glass transition temperature $\left(\mathrm{T}_{\mathrm{g}}\right)$

\subsubsection{Optical Microscopy}

Microscope analysis was used to check for the presence of voids and significant differences in microstructure. Multiple samples from different areas of the carbon fibre laminate were analysed. Samples were cut using a Struers Secotom-1 table saw, with a diamond cut-off wheel (E1D20) and then mounted in a 2-part cold mount resin (Vari-Set 20 powder and Vari-Set 10/20 liquid from MetPrep), so that the cut edge could be examined. The samples were ground and polished to a $1 \mu \mathrm{m}$ finish and then images were taken using a Hirox-KH-1300 digital microscope at $140 \times$ magnification .

\subsubsection{Fibre Volume Fraction}

Calculation of fibre volume fraction was conducted using the thickness measurement method described in BS ISO 14127, method B [100]. The equation used was:

$$
v_{f}=\frac{n w_{a f}}{t p_{f}}
$$

Where $v_{f}=$ fibre volume fraction, $t=$ cured specimen thickness, $n=$ total number of plies, $w_{a f}=$ fibre areal weight of one ply and $p_{f}=$ density of the fibres [14].

To ensure the mechanical testing results were not influenced by differences in fibre volume fraction, the results of each fibre dominated test were normalised to $60 \% v_{f}$ using the equation: 


$$
\sigma_{60 \%}=\left(\frac{60 \%}{v_{f}}\right) \sigma_{v f}
$$

Where $\sigma=$ stress in $\mathrm{MPa}$ and $v_{f}=$ fibre volume fraction [14].

The thickness of each sample was determined as described in Section 3.1. Fibre areal weight and density of the fibres were obtained from the laminate manufacturer.

The prospect of verifying the calculated fibre volume fraction results with a second methodology (BS ISO 14127, method A, procedure A3 [100]) was also considered. This method involves resin digestion in a mixture of sulphuric acid and hydrogen peroxide. Ultimately the decision was taken not to calculate $\mathrm{v}_{\mathrm{f}}$ in this way, for several reasons. Firstly, the method is more time consuming and, given the fact that the method involves heating concentrated sulphuric acid, has greater risks associated with it compared to using Equation 5. Furthermore, given the inaccuracies associated with both methods it was thought that conducting these extra checks would not be necessary.

\subsubsection{Determination of $\mathrm{T}_{\mathrm{g}}$}

Dynamic mechanical analysis was used to determine the $T_{g}$ of 'as received' laminates. At least one sample from each panel was tested using a Perkin Elmer DMA 8000 in single cantilever bending deformation mode. The DMA samples were cut to size using a Struers table saw with a diamond cut off wheel. All samples were tested with the middle $0^{\circ}$ fibres in the length direction. The samples were tested at a ramp rate of $5^{\circ} \mathrm{C} / \mathrm{min}$, from room temperature to $250{ }^{\circ} \mathrm{C}$, using a single frequency of $1 \mathrm{~Hz}$. Due to the high stiffness of the material, different strain values and span lengths were experimented with to ensure the best DMA results were achieved. Experimental analysis showed that changing the span length or strain value did not influence the tan delta or $\mathrm{T}_{\mathrm{g}}$ (onset of storage modulus) 
results. The specific method used for each specimen is outlined in Table 4.2 to Table 4.4. Sample dimensions were as follows:

- Span length: $10 \mathrm{~mm}$ or $15 \mathrm{~mm}$ (see Table 4.2 to Table 4.4 )

- Width: $9.5 \mathrm{~mm} \pm 1 \mathrm{~mm}$

- Thickness: see Table 4.2 to Table 4.4

In Table 4.2 to Table 4.4 , the sample ID relates to the carbon fibre composite panel number.

\subsection{Production of Test Samples}

\subsubsection{End-tab Procedure}

End-tabs were bonded to the surface of test specimens, as required, to increase the thickness at the point where the coupon is gripped by the testing machine. The tabbing material used was Tufnol 10G/42, with a thickness of $2.0 \mathrm{~mm}$. This was supplied by Tufnol Composites Limited in $1.2 \mathrm{~m}^{2}$ sheets. The use of end-tabs protects the test specimen from grip damage and promotes failure of the sample within the gauge length. The edge of the tab which is in contact with the gauge length is often tapered at an angle of $7^{\circ}$ to $15^{\circ}$ to reduce the stress concentration at this point [101]. For test coupons where a tapered edge was required, a $10^{\circ}$ angle was machined onto the edge of the Tufnol sheet prior to adhesion onto the carbon fibre composite. This was achieved using a Jones \& Shipman 1400 AR surface grinder, with a 46 grit size abrasive grinding wheel.

A two-part epoxy paste adhesive, Araldite AW4858/Hardener HW4858, was used to bond the end-tab to the carbon fibre composite. The adhesive cures at room temperature. This was preferable to the use of film adhesive, because no unnecessary heating of the carbon fibre composite was required. The adhesive was also chosen due to its high lap shear and peel strength properties. The method used for adhesion was as follows: 
- The composite panel and Tufnol 10G/42 were cut to the desired length using a Struers Secotom-1 table saw, with a diamond cut-off wheel

- To promote adhesion, the Tufnol 10G/42 was sanded using a P600 grit paper, washed in water and dried using paper towels, before being washed using acetone

- Abrasion of the carbon fibre composite panel was not necessary, due to the presence of peel ply on both outer surfaces, however the samples were washed using acetone prior to adhesion

- The resin/hardener mix was applied to both the specimen and the Tufnol using a spatula

- The end-tab was positioned in place and weighed down until fully cured

\subsubsection{Production of Test Coupons}

Several different test standards were used for the determination of mechanical properties. Test coupon specification (for example length, width and use of end-tab) differed depending on which test standard was used. Table 3.2 specifies which standard was followed for each test method and the geometry and machining method used to produce each test coupon. A minimum of $15 \mathrm{~mm}$ was removed from the edge of each laminate, to avoid areas of material where the plies may not finish at exactly the same position.

The dimensions of each test sample were measured to ensure compliance with the relevant standard used. Sample widths were measured using a digital caliper with a resolution of $0.01 \mathrm{~mm}$ for dimensions greater than $20 \mathrm{~mm}$. Dimensions less than $20 \mathrm{~mm}$ were measured using a micrometer with a resolution of $0.01 \mathrm{~mm}$. A round end micrometer was used for uneven surfaces (such as the peel ply face) and a flat end micrometer was used for smooth surfaces. All measuring equipment used was UKAS calibrated and therefore traceable to national standards. 
Table 3.2 Test coupon specification (Page 1 of 2)

\begin{tabular}{|l|l|l|l|}
\hline Test method & $\begin{array}{l}\text { Nominal coupon geometry } \\
(\mathrm{mm}) \\
{[\text { length } \times \text { width } \times \text { thickness }]}\end{array}$ & $\begin{array}{l}\text { End-tab } \\
\text { dimensions }\end{array}$ & Machining method \\
\hline $\begin{array}{l}\text { Unnotched Tensile }\left(0^{\circ}\right) \\
\text { ASTM D3039M [101] }\end{array}$ & $250 \times 15 \times 1.2$ & $\begin{array}{l}45 \mathrm{~mm} \\
10 \mathrm{~mm} \text { chamfer }\end{array}$ & $\begin{array}{l}\text { Struers Secotom-1 table saw with a diamond cut-off } \\
\text { wheel E1D20 }\end{array}$ \\
$\begin{array}{l}\text { Unnotched Tensile }\left(90^{\circ}\right) \\
\text { ASTM D3039M [101] }\end{array}$ & $175 \times 25 \times 2.4$ & $\begin{array}{l}25 \mathrm{~mm} \\
\text { No chamfer }\end{array}$ & $\begin{array}{l}\text { Struers Secotom-1 table saw with a diamond cut-off } \\
\text { wheel E1D20 }\end{array}$ \\
\hline $\begin{array}{l}\text { Unnotched Tensile (QI) } \\
\text { ASTM D3039M [101] }\end{array}$ & $250 \times 25 \times 2.4$ & $\begin{array}{l}45 \mathrm{~mm} \\
10 \mathrm{~mm} \text { chamfer }\end{array}$ & $\begin{array}{l}\text { Coupon length machined using a Struers Secotom-1 } \\
\text { table saw with a diamond cut-off wheel E1D20 } \\
\text { Coupon width machined using a Jones \& Shipman } \\
1400 \text { AR surface grinder with a 46 grit size abrasive } \\
\text { grinding wheel }\end{array}$ \\
\hline $\begin{array}{l}\text { Unnotched Compression } \\
\text { ASTM D6641M [102] }\end{array}$ & $140 \times 13 \times 2.4$ & $63.5 \mathrm{~mm}$ & $\begin{array}{l}\text { Coupon length and width machined using a Struers } \\
\text { Secotom-1 table saw with a diamond cut-off wheel } \\
\text { E1D20 } \\
\text { Parallelism of the sample achieved using a Jones \& } \\
\text { Shipman 1400 AR surface grinder with a 46 grit size } \\
\text { abrasive grinding wheel }\end{array}$ \\
\hline
\end{tabular}




\begin{tabular}{|c|c|c|c|}
\hline Test method & $\begin{array}{l}\text { Nominal coupon geometry } \\
(\mathrm{mm}) \\
\text { [length } \mathrm{x} \text { width } \mathrm{x} \text { thickness] }\end{array}$ & $\begin{array}{l}\text { End-tab } \\
\text { dimensions }\end{array}$ & Machining method \\
\hline $\begin{array}{l}\text { In Plane Shear Strength } \\
\text { ASTM D3518M [75] }\end{array}$ & $250 \times 25 \times 2.4$ & $\begin{array}{l}45 \mathrm{~mm} \\
10 \mathrm{~mm} \text { chamfer }\end{array}$ & $\begin{array}{l}\text { Coupon length machined using a Struers Secotom- } 1 \\
\text { table saw with a diamond cut-off wheel E1D20 } \\
\text { Coupon width machined using a Jones \& Shipman } \\
1400 \text { AR surface grinder with a } 46 \text { grit size abrasive } \\
\text { grinding wheel }\end{array}$ \\
\hline $\begin{array}{l}\text { Interlaminar Shear } \\
\text { Strength } \\
\text { BS EN ISO } 14130[76]\end{array}$ & $\begin{array}{l}\text { Width }=5 \times \text { thickness } \\
\text { Length }=10 \times \text { thickness }\end{array}$ & None & $\begin{array}{l}\text { Struers Secotom-1 table saw with a diamond cut-off } \\
\text { wheel E1D20 }\end{array}$ \\
\hline $\begin{array}{l}\text { Open-hole Tensile } \\
\text { ASTM D5766M [103] }\end{array}$ & $\begin{array}{l}250 \times 36 \times 2.4 \\
\text { Hole diameter: } 6.0\end{array}$ & None & $\begin{array}{l}\text { Coupon length and width machined using a Struers } \\
\text { Secotom-1 table saw with a diamond cut-off wheel } \\
\text { E1D20 } \\
\text { Hole milled using a Schaublin } 22 \text { milling machine }\end{array}$ \\
\hline $\begin{array}{l}\text { Open-hole Compression } \\
\text { BS ISO 12817-13 Method I } \\
{[104]}\end{array}$ & $\begin{array}{l}118 \times 36 \times 2.4 \\
\text { Hole diameter: } 6.0\end{array}$ & $\begin{array}{l}50 \mathrm{~g} / \mathrm{m}^{2}, \text { no end-tab } \\
150 \mathrm{~g} / \mathrm{m}^{2} \text {, no end-tab } \\
300 \mathrm{~g} / \mathrm{m}^{2}, 50 \mathrm{~mm}\end{array}$ & $\begin{array}{l}\text { Coupon length and width machined using a Struers } \\
\text { Secotom- } 1 \text { table saw with a diamond cut-off wheel } \\
\text { E1D20 } \\
\text { Parallelism of the sample achieved using a Jones \& } \\
\text { Shipman } 1400 \text { AR surface grinder with a } 46 \text { grit size } \\
\text { abrasive grinding wheel } \\
\text { Hole milled using a Schaublin } 22 \text { milling machine }\end{array}$ \\
\hline
\end{tabular}




\subsection{Mechanical Testing Procedures}

To compare the mechanical properties of thin and thick-ply carbon fibre composites, a large testing matrix was designed. Table 3.3 provides details of this test matrix, including the number of samples tested, the environmental test conditions, ply orientation and the stacking sequence of the laminates used. Details about the particular standard used for each test were outlined previously, in Table 3.2. Further information, regarding the specific parameters used for each test (test speed, strain measurement device and modulus determination region), is provided in Table 3.4.

The test machines used for each test were as follows:

- Zwick $250 \mathrm{kN}$ machine with wedge screw grips, load cell calibrated to class 0.5 (meaning within $0.5 \%$ ) down to $0.5 \mathrm{kN}$ and alignment calibrated to within $8 \%$ bending, in accordance with ASTM E1012 [105]

$\circ$ Unnotched tensile $0^{\circ}, \mathrm{QI}$

○ Open-hole tensile QI

- Open-hole compression QI

○ Unnotched compression UD

- In plane shear

- Zwick $10 \mathrm{kN}$ machine, load cell calibrated to class 0.5 down to $40 \mathrm{~N}$

○ Unnotched tensile $90^{\circ}$

- Interlaminar shear stress

- SiPlan $100 \mathrm{kN}$ servo-hydraulic fatigue machine, load cell calibrated to class 1 (within $1 \%$ ) down to $2 \mathrm{kN}$

○ Open-hole tension-tension fatigue, QI

Strain measurements for each sample tested in tension (except unnotched tensile $90^{\circ}$ ) were obtained using a Zwick biaxial extensometer with a $25 \mathrm{~mm}$ gauge length, calibrated to class 0.5 between $0.012 \mathrm{~mm}$ and $1.200 \mathrm{~mm}$. The unnotched 
tensile $90^{\circ}$ strain was measured using an Epsilon uniaxial extensometer with a $50 \mathrm{~mm}$ gauge length, calibrated to class 0.5 down to $0.01 \mathrm{~mm}$. For the unnotched compression samples modulus values were determined using $350 \Omega$ foil strain gauges. The author attended a Vishay strain gauge course to become trained in the correct installation of strain gauges. No strain measurements were obtained for the QI unnotched or open-hole compression tests. 
Table 3.3 Mechanical testing programme (Page 1 of 2). Shaded numbers refer to the number of samples tested. Numbers in brackets denote the number of samples tested with valid failures (applicable if invalid tests or failure modes occurred)

\begin{tabular}{|c|c|c|c|c|c|c|c|}
\hline \multirow[b]{2}{*}{ Test } & \multirow[b]{2}{*}{ Stacking } & \multicolumn{3}{|c|}{ Test Temperature } & \multicolumn{3}{|c|}{ Conditioning Environment } \\
\hline & & $23^{\circ} \mathrm{C}$ & $120^{\circ} \mathrm{C}$ & $150^{\circ} \mathrm{C}$ & $\begin{array}{c}70{ }^{\circ} \mathrm{Cl} \\
45 \% \mathrm{RH}\end{array}$ & $\begin{array}{c}70{ }^{\circ} \mathrm{Cl} \\
65 \% \mathrm{RH}\end{array}$ & $\begin{array}{c}70{ }^{\circ} \mathrm{Cl} \\
85 \% \mathrm{RH}\end{array}$ \\
\hline \multirow{2}{*}{ Unnotched tensile $\left(0^{\circ}\right)$} & UD [0] $]_{24}$ THIN & 6 & & & & & \\
\hline & UD [0]8 INTERMEDIATE & 6 & & & & & \\
\hline \multirow{2}{*}{ Unnotched compressive test $\left(0^{\circ}\right)$} & UD [0] $]_{48}$ THIN & 6 & & & & & \\
\hline & UD [0]16 INTERMEDIATE & 5 & & & & & \\
\hline \multirow{2}{*}{ Unnotched tensile $\left(90^{\circ}\right)$} & UD [0] $]_{48}$ THIN & 8 & & & 7 & 8 & 8 \\
\hline & UD [0]16 INTERMEDIATE & 8 & & & 5 & 7 & 8 \\
\hline \multirow{3}{*}{ In plane shear strength } & {$\left[+45^{\circ} /-45\right]_{24}$ THIN } & $10(5)$ & & & & $5(4)$ & 5 \\
\hline & [+45\%-45]8 INTERMEDIATE & $9(6)$ & & & & $5(4)$ & $5(3)$ \\
\hline & {$\left[+45^{\circ} /-45\right] 4$ THICK } & 6 & & & & 5 & $5(3)$ \\
\hline \multirow{2}{*}{ Interlaminar shear strength $\left(0^{\circ}\right)$} & UD [0] $]_{48}$ THIN & 6 & & & 6 & 6 & 6 \\
\hline & UD [0]16 INTERMEDIATE & 6 & & & 6 & 6 & 6 \\
\hline \multirow{3}{*}{ Unnotched tensile (QI) } & QI, $[-45 / 90 /+45 / 0]_{6 s}$ THIN & 6 & 6 & 5 & & & \\
\hline & QI, [-45/90/+45/0] $]_{2 \mathrm{~S}}$ INTERMEDIATE & 6 & $6(5)$ & 5 & & & \\
\hline & QI, $[-45 / 90 /+45 / 0]_{1 \mathrm{~s}}$ THICK & 6 & $6(5)$ & $6(5)$ & & & \\
\hline
\end{tabular}




\begin{tabular}{|c|c|c|c|c|c|c|c|}
\hline \multirow[b]{2}{*}{ Test } & \multirow[b]{2}{*}{ Stacking } & \multicolumn{3}{|c|}{ Test Temperature } & \multicolumn{3}{|c|}{ Conditioning Environment } \\
\hline & & $23^{\circ} \mathrm{C}$ & $120^{\circ} \mathrm{C}$ & $150^{\circ} \mathrm{C}$ & $\begin{array}{c}70^{\circ} \mathrm{C} / \\
45 \% \mathrm{RH}\end{array}$ & $\begin{array}{c}70^{\circ} \mathrm{Cl} \\
65 \% \mathrm{RH}\end{array}$ & $\begin{array}{c}70^{\circ} \mathrm{C} / \\
85 \% \mathrm{RH}\end{array}$ \\
\hline \multirow{3}{*}{ Open-hole tensile (QI) } & QI, $[-45 / 90 /+45 / 0]_{6 s}$ THIN & 6 & 6 & 6 & & & \\
\hline & QI, [-45/90/+45/0]2s INTERMEDIATE & 6 & 6 & 6 & & & \\
\hline & QI, $[-45 / 90 /+45 / 0] 1 s$ THICK & 6 & 6 & 6 & & & \\
\hline \multirow{2}{*}{ Unnotched compressive test (QI) } & QI, $[-45 / 90 /+45 / 0]_{6 s}$ THIN & 5 & & & & & \\
\hline & QI, [-45/90/+45/0]2s INTERMEDIATE & 5 & & & & & \\
\hline \multirow{3}{*}{ Open-hole compression (QI) } & QI, $[-45 / 90 /+45 / 0]_{6 s}$ THIN & 6 & 8 & 6 & 6 & 6 & 6 \\
\hline & QI, [-45/90/+45/0] $]_{2 \mathrm{~S}}$ INTERMEDIATE & 6 & $7(6)$ & 6 & 6 & 6 & $6(5)$ \\
\hline & QI, $[-45 / 90 /+45 / 0] 1 s$ THICK & $6(5)$ & - & - & 6 & 6 & 6 \\
\hline \multirow{2}{*}{ Interlaminar shear strength (QI) } & QI, $[-45 / 90 /+45 / 0]_{6 s}$ THIN & 6 & & & & & \\
\hline & QI, [-45/90/+45/0] $]_{2 \mathrm{~s}}$ INTERMEDIATE & 6 & & & & & \\
\hline \multirow{2}{*}{$\begin{array}{l}\text { Open-hole tensile-tensile fatigue } \\
\text { (QI) }\end{array}$} & QI, $[-45 / 90 /+45 / 0]_{6 s}$ THIN & 15 & & & & & \\
\hline & QI, [-45/90/+45/0]2s INTERMEDIATE & $15(13)$ & & & & & \\
\hline
\end{tabular}


Table 3.4 Mechanical testing parameters (quasi-static loading)

\begin{tabular}{|c|c|c|c|c|}
\hline \multirow{2}{*}{ Test } & \multirow{2}{*}{$\begin{array}{c}\text { Test } \\
\text { speed } \\
(\mathrm{mm} / \mathrm{min})\end{array}$} & \multirow{2}{*}{$\begin{array}{c}\text { Strain } \\
\text { measurement }\end{array}$} & \multicolumn{2}{|c|}{$\begin{array}{l}\text { Modulus determination } \\
\text { region (\% strain) }\end{array}$} \\
\hline & & & Start & End \\
\hline $\begin{array}{l}\text { Unnotched tensile } \\
\qquad\left(0^{\circ}\right)\end{array}$ & 2.0 & $\begin{array}{l}\text { Zwick biaxial } \\
\text { extensometer }\end{array}$ & 0.05 & 0.20 \\
\hline $\begin{array}{c}\text { Unnotched } \\
\text { compressive }\left(0^{\circ}\right)\end{array}$ & 1.0 & $\begin{array}{l}350 \Omega \text { strain } \\
\text { gauge }\end{array}$ & 0.10 & 0.30 \\
\hline $\begin{array}{l}\text { Unnotched tensile } \\
\qquad\left(90^{\circ}\right)\end{array}$ & 2.0 & $\begin{array}{c}\text { Epsilon } \\
\text { extensometer }\end{array}$ & 0.10 & 0.30 \\
\hline $\begin{array}{l}\text { In-plane shear } \\
\text { strength }\end{array}$ & 2.0 & $\begin{array}{l}\text { Zwick biaxial } \\
\text { extensometer }\end{array}$ & 0.10 & 0.50 \\
\hline $\begin{array}{l}\text { Interlaminar shear } \\
\text { strength }\left(0^{\circ}\right)\end{array}$ & 1.0 & N/A & N/A & N/A \\
\hline $\begin{array}{l}\text { Unnotched tensile } \\
\text { (QI) }\end{array}$ & 2.0 & $\begin{array}{l}\text { Zwick biaxial } \\
\text { extensometer }\end{array}$ & 0.05 & 0.20 \\
\hline $\begin{array}{l}\text { Open-hole tensile } \\
\text { (QI) }\end{array}$ & 2.0 & $\begin{array}{l}\text { Zwick biaxial } \\
\text { extensometer }\end{array}$ & 0.05 & 0.20 \\
\hline $\begin{array}{c}\text { Unnotched } \\
\text { compressive (QI) }\end{array}$ & 1.3 & N/A & N/A & N/A \\
\hline $\begin{array}{c}\text { Open-hole } \\
\text { compression (QI) }\end{array}$ & 1.0 & N/A & N/A & N/A \\
\hline $\begin{array}{l}\text { Interlaminar shear } \\
\text { strength }(\mathrm{QI})\end{array}$ & 1.0 & N/A & N/A & N/A \\
\hline
\end{tabular}

\subsubsection{Mechanical Behaviour of Unconditioned Samples at Ambient Temperature}

For the unconditioned, ambient temperature tests the coupons were stored in a freezer at $-30{ }^{\circ} \mathrm{C}$ prior to testing. During the production process the test samples were stored at room temperature. The samples were not oven dried prior to testing, to avoid possible effects of post curing. However, for a sub-set of tests, traveller samples were used to retrospectively calculate an estimate of the moisture content of the tested material. The traveller specimens were the same size as the test specimens, minus the tabbed region. After testing a minimum of five samples (according the standard outlined in Table 3.2) two travellers were 
placed in an oven at $70{ }^{\circ} \mathrm{C}$. Samples masses were measured immediately prior to insertion into the oven and periodically from then onwards until a constant mass was obtained over three consecutive measurements. At this point the sample was assumed to be dry. Sample masses were measured using a Sartorius CP64 balance with a resolution of $0.1 \mathrm{mg}$. Traveller samples were taken from the same laminate as the test samples and were subjected to the same environmental conditions prior to testing. For tests where samples were produced from more than one carbon fibre composite panel, a sample from each different panel was used as a traveller specimen. This procedure was conducted on the following tests: UD unnotched tension, UD ILSS, QI unnotched tension, QI open-hole tension and QI open-hole compression.

\subsubsection{Tension-tension Fatigue Behaviour of Unconditioned Samples at Ambient Temperature}

Panels used for fatigue testing were stored in a freezer at $-30{ }^{\circ} \mathrm{C}$ prior to coupon production. After production, samples were stored at room temperature. No determination of moisture content was conducted, and samples were not dried prior to testing, to avoid effects of post curing. All fatigue testing was carried out open-hole tensile samples at $5 \mathrm{~Hz}$ frequency and an R-ratio (stress ratio) of 0.1. The maximum number of cycles was set to 1,000,000. The loads chosen for testing were percentages (ranging between $95 \%$ and $60 \%$ ) of the mean, quasi-static ultimate open-hole tensile stress for each ply thickness material. These stress values were converted into specific load values for each individual test coupon, based on the cross-sectional area of the specimen. 


\subsubsection{Mechanical Behaviour of Unconditioned Samples at High Temperature}

For the unconditioned high temperature tests, the coupons were stored in a freezer at $-30{ }^{\circ} \mathrm{C}$ prior to testing. During the production process the test samples were stored at room temperature.

A UKAS calibrated Severn Thermal Solutions Eurotherm EC2275 thermal chamber was used to heat the sample during testing. Two different test temperatures were used, $+120^{\circ} \mathrm{C}$ and $+150{ }^{\circ} \mathrm{C}$. The temperatures were chosen based on the glass transition temperature of the material (discussed further in Chapter 4). After pre-heating the oven to the desired temperature, the samples were loaded into the test machine. Once loaded, the thermal chamber was then allowed to reach the required test temperature again. A UKAS calibrated PTFE coated Type K thermocouple, with an RS 1384 Data Logging Thermometer was used to monitor temperature. The thermocouple was placed on the centre of the test specimen. Once the required temperature was reached, a hold time of two minutes was maintained before load was applied. Given the thin size of the test samples (nominally $2 \mathrm{~mm}$ ) this time period was considered adequate. In a review by Bai et al. [106] the through-thickness temperature profile of a $3 \mathrm{~mm}$ thick glass fibre reinforced polymer tube was investigated. Temperature sensors were embedded into the specimen at various through-thickness positions. The temperature at said positions was shown to increase at the same rate as the test chamber. The nominal thickness of the specimens used in this project was $2 \mathrm{~mm}$, therefore a hold time of two minutes at the required temperature was thought adequate to achieve equilibrium. An international standard for elevated temperature testing of composite materials is not known to the author. 


\subsubsection{Mechanical Behaviour of Conditioned Samples at Ambient Temperature}

To determine the effect of moisture on mechanical properties, test coupons were conditioned until saturation in three different environments:

- $85 \%$ relative humidity $(\mathrm{RH}), 70{ }^{\circ} \mathrm{C}$

- $65 \% \mathrm{RH}, 70{ }^{\circ} \mathrm{C}$

- $45 \% \mathrm{RH}, 70{ }^{\circ} \mathrm{C}$

Two traveller samples from each set of tests were used to monitor moisture ingress via the change in sample mass. Sample masses were measured using an A \& D GH-252 balance with a resolution of $0.01 \mathrm{mg}$. The material used for the travellers was exactly the same as that used for the mechanical tests and was subjected to the same environmental conditions prior to insertion into the conditioning chamber. The travellers were weighed before conditioning commenced and periodically from then onwards. The temperature and humidity of the environmental chambers were checked with a calibrated probe every two weeks. Conditioned samples were tested at room temperature to maintain the moisture content within the samples.

\subsection{Investigating the Effect of Ply Thickness on Moisture Ingress}

\subsubsection{Sample Preparation}

Samples of the material described in Section 3.1 were used to compare moisture ingress for thin, intermediate and thick-ply materials. Both UD and QI panels were analysed.

Using a Struers Secotom-1 table saw with a diamond cut-off wheel E1D20, $50 \mathrm{~mm}$ square samples were produced as follows:

- 9 x QI $50 \mathrm{~g} / \mathrm{m}^{2} 2.1 \mathrm{~mm} \pm 0.2$ thickness 
- 9 x QI $150 \mathrm{~g} / \mathrm{m}^{2} 2.1 \mathrm{~mm} \pm 0.2$ thickness

- 9 x QI $300 \mathrm{~g} / \mathrm{m}^{2} 2.1 \mathrm{~mm} \pm 0.2$ thickness

- 9 x UD $50 \mathrm{~g} / \mathrm{m}^{2} 2.0 \mathrm{~mm} \pm 0.3$ thickness

- $9 \times \mathrm{UD} 150 \mathrm{~g} / \mathrm{m}^{2} 2.0 \mathrm{~mm} \pm 0.3$ thickness

\subsubsection{Vacuum Drying of Samples}

Prior to conditioning, samples were dried in a vacuum oven to ensure a consistent initial moisture content. Samples were taken from several different panels for each ply thickness and fibre orientation. One traveller sample from each panel used was weighed periodically, until a constant mass, over three consecutive readings, was reached. An A \& D GH-252 balance with a resolution of $0.01 \mathrm{mg}$ was used. If more than one panel was used to produce test specimens (per laminate type) a sample from each panel was weighed.

The percentage mass loss was calculated as follows:

$$
\frac{\left(M_{1}-M_{0}\right)}{M_{0} \times 100}
$$

Where $M_{1}$ is the current mass of the sample and $M_{0}$ is the original mass of the sample (before drying).

\subsubsection{Sample Conditioning}

Three $50 \mathrm{~mm} \times 50 \mathrm{~mm}$ (length $\times$ width) samples from each laminate type were conditioned in each of the following environments:

- $85 \%$ relative humidity $(\mathrm{RH}), 70{ }^{\circ} \mathrm{C}$

- $65 \% \mathrm{RH}, 70{ }^{\circ} \mathrm{C}$

- $\quad 45 \% \mathrm{RH}, 70{ }^{\circ} \mathrm{C}$ 
Mass measurements were taken regularly, with the interval of each measurement gradually decreasing over time. An A \& D GH-252 balance, with a resolution of $0.01 \mathrm{mg}$ was used to measure the change in mass.

The conditioning chambers were monitored twice-weekly to ensure that the correct environment was being provided.

To calculate diffusion coefficients the following equation was used:

$$
D=\pi\left(\frac{h}{4 M_{\max }}\right)^{2}\left(\frac{M_{2}-M_{1}}{\sqrt{t_{2}}-\sqrt{t_{1}}}\right)^{2}
$$

Where $h$ is the thickness of the sample in metres, $M_{\max }$ is the measured Fickian saturation value (wt \%) and $M_{1}$ and $M_{2}$ are the moisture content (wt \%) at times $t_{1}$ and $t_{2}$ (seconds) [107].

\subsection{High Speed Camera Imaging Coupled with Digital Image Correlation}

High speed camera video recording coupled with post-processing digital image correlation was used to understand more about the failure modes of samples when tested in quasi-static tension. Digital image correlation is a method of obtaining full-field strain data. The method involves applying a speckle pattern to the sample surface and then monitoring changes to this pattern as load is applied [108].

High speed camera videos were obtained using a PHOTRON SA4 model $500 \mathrm{~K}-\mathrm{M} 1$ camera at a frame rate of 8,000 frames per second and a resolution of $384 \times 1024$ pixels. This frame rate was the highest possible for the chosen resolution. Using these settings, the camera's maximum useable memory enabled 1.8 seconds of recording to be saved. A continuous lighting set up was used to illuminate the sample. Recording of the failure mode was obtained using the "End Mode" function on the Photron FASTCAM Viewer software. This mode was 
useful when recording high speed, unpredictable events, because a trigger was pressed immediately after the action had occurred (sample failure) and then the previous 1.8 seconds of footage was saved. The software was also capable of photographing still images throughout the mechanical test. Still shots were taken at different intervals throughout the test, firstly once the sample had been placed into the grips (one photo with one grip tightened and a second photo once both grips were tightened) and then periodically throughout the mechanical test.

Prior to testing, a speckle pattern was generated on the front surface of the sample using white spray paint. The deformation of this speckle pattern was used to obtain the in-plain strain field. This was performed using GOM Correlate 2017 software.

\subsection{Field Emission Gun Scanning Electron Microscopy}

A Jeol 7800F field emission gun scanning electron microscope (FEG-SEM) was used for high magnification imaging of polished carbon fibre composite samples. Prior to imaging, samples were prepared using the methodology described in Section 3.2.1 and subsequently sputter coated to improve the electrical conductivity. This was conducted using an Agar high resolution sputter coater, fitted with a platinum target. The thickness of the coating was $4 \mathrm{~nm}$.

\subsection{Atomic Force Microscopy}

Atomic force microscopy (AFM) was performed using a JPK Instruments NanoWizard 3 with NanoWorld FM-50 cantilever tips. In addition to topography, the instrument was used in both force modulation and force mapping mode, to obtain data relating to the stiffness of the material. Force mapping is similar to force spectroscopy, except that multiple force measurements are taken in a grid pattern over a specified area. An image is then produced by the software, using the force curves generated at each point across the grid. In this mode the 
cantilever is moved vertically towards the sample surface using the piezo. It is then retracted and the deflection of the cantilever measured [109].

To obtain quantitative force measurements the instrument was calibrated. Two types of calibrations were conducted, sensitivity calibration and spring constant calibration. Sensitivity calibration enables the deflection of the cantilever (vertical deflection) to be converted from Volts into nanometres. Next, the spring constant was measured, to enable this distance value to be converted into a force value. The spring constant is often supplied with the cantilever datasheet, however this is an approximation, so the actual spring constant should be measured when absolute measurements are required. The deflection force of the cantilever is calculated using the equation:

$$
F=-k x
$$

Where $F=$ deflection force, $k=$ spring constant and $x=$ cantilever deflection (units of distance) [109].

The calibrations were conducted as per the JPK NanoWizard 3 user manual, version $4.2[110]$. 
4 Investigation into the effect of Ambient and High Temperature on the Behaviour of Carbon Fibre Composites 


\subsection{Introduction}

The basis of this research was to investigate the effect of ply thickness on the mechanical properties of carbon fibre composite materials when tested under various environmental conditions. This chapter outlines the mechanical testing results for samples tested in the unconditioned, 'as received' state and the results of the high temperature testing. The chapter also explains the various material quality assessments which were carried out. Finally, the results are summarised and discussed. A more comprehensive discussion of the results is found in Chapter 6, where the results are also compared to the mechanical performance of thin-ply CFRP after exposure to humid environments.

\subsection{Material Quality Control Assessment}

Many parameters can influence the mechanical properties of composite materials and test coupons. These include:

- The level of sample cure

- Fibre volume fraction

- The presence of voids

- Fibre alignment

- Ply orientation

- Sample dimensions

- Test machine alignment

It was important to ensure that these variables were kept constant for all specimens, as far as reasonably possible. As such, several techniques were utilised to assess the quality of the material used.

During manufacture laminates were constructed so that the overall panel thickness was nominally equal for each of the three fibre areal weights (FAW). The overall mean coupon thicknesses, and the number of plies used to achieve this thickness, for each test type are noted in Table 3.2 and Table 3.3 respectively. 
Similarly, the test coupons for each FAW were produced using the same dimensions and tolerances (as shown in Table 3.2). This was to remove any influence of sample dimensions.

Test coupons were produced with particular attention to the fibre alignment. For UD samples, the fibre direction was taken as a datum edge for each sample, to ensure consistency. For the QI samples, the $45^{\circ}$ layer was on the outer surface, so a set square was used to draw a $0^{\circ}$ line on the samples, to ensure that the fibres were aligned as required.

Due to the size of autoclave used and the volume of material required, multiple carbon fibre composite panels were manufactured. These are shown in Table 3.1. Several quality control tests were conducted on each carbon fibre laminate used in the project, including optical microscopy (to examine the laminate quality) determination of fibre volume fraction and determination of the glass transition temperature.

\subsubsection{Optical Microscopy Analysis}

Optical microscopy images were taken from each laminate, as described in Section 3.2.1. Various sections from each laminate were inspected for the presence of defects, such as voids. If such defects were found, that particular laminate would not be used.

Due to the large volume of material used in this project, it was deemed unnecessary to show the microscopy images from each panel. Instead, images from one panel for each FAW and orientation are included as examples (see Figure 4.1). 

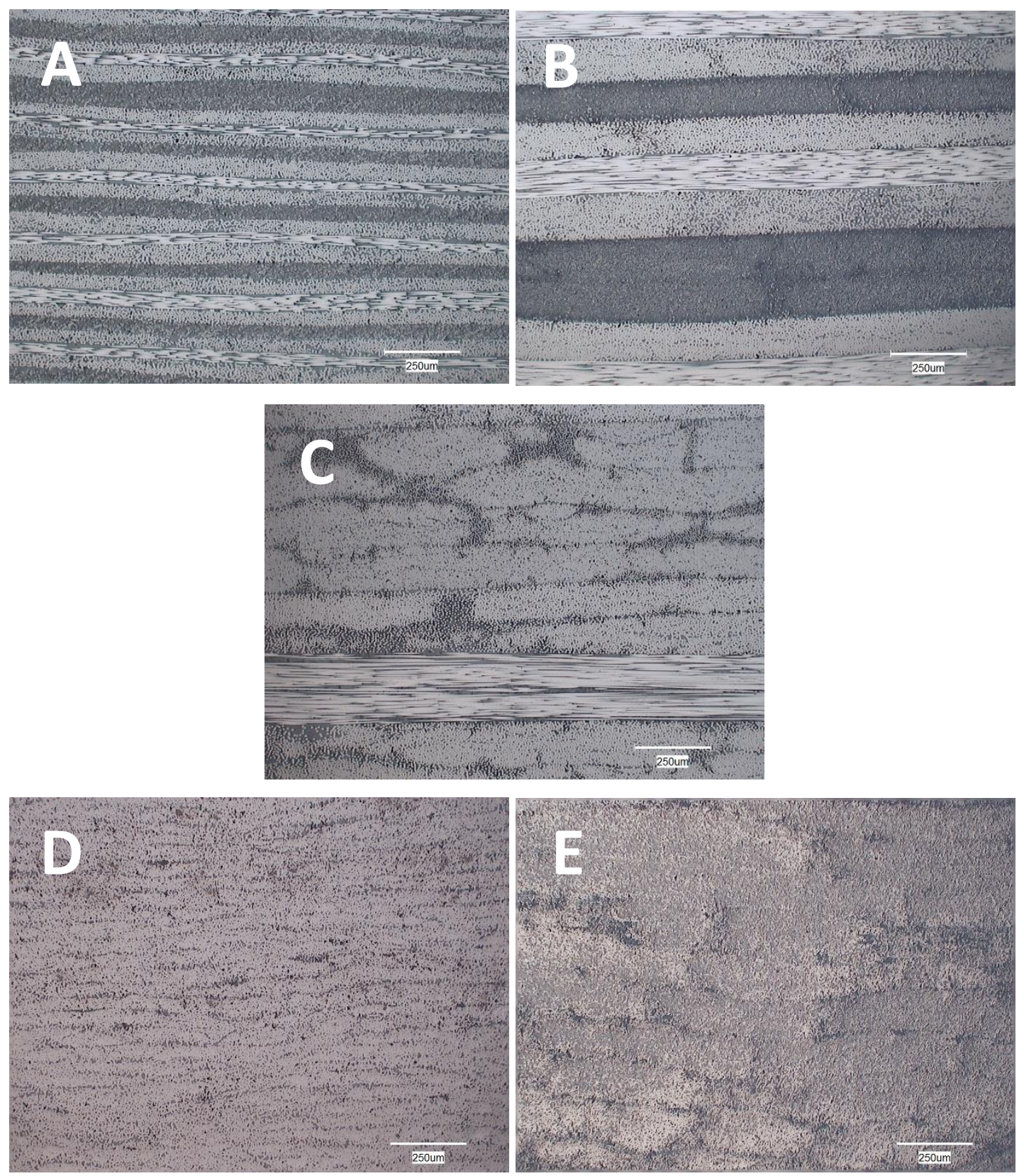

Figure 4.1 Microscopy images (140× magnification) to assess laminate quality: a) panel 251 $\left.\left(\mathrm{QI}, 50 \mathrm{~g} / \mathrm{m}^{2}\right), \mathrm{b}\right)$ panel $\left.258\left(\mathrm{QI}, 150 \mathrm{~g} / \mathrm{m}^{2}\right), \mathrm{c}\right)$ panel $\left.265\left(\mathrm{QI}, 300 \mathrm{~g} / \mathrm{m}^{2}\right), d\right)$ panel $274(\mathrm{UD}$, $\left.50 \mathrm{~g} / \mathrm{m}^{2}\right)$, e) panel $276\left(\mathrm{UD}, 150 \mathrm{~g} / \mathrm{m}^{2}\right)$

It is acknowledged that although optical microscopy can be used to check for the presence of voids [111,112], it is not a definitive check. The volume of material under inspection is small, so voids present in other sections of the laminate may go undetected, as will very small voids [112]. On the other hand, microscopy has the benefit of void morphology detection, which is not possible with some techniques. An alternative method would be to conduct X-ray computed 
tomography on the panel as a whole, however it was not feasible to use this technique in this project.

\subsubsection{Fibre Volume Fraction}

The fibre volume fraction of each carbon fibre panel was determined, as described in Section 3.2.2. The mean results for each ply thickness are shown in Table 4.1.

Table 4.1 Mean fibre volume fraction for each ply thickness and ply orientation

\begin{tabular}{|c|c|c|c|}
\hline $\begin{array}{c}\text { Ply thickness } \\
\left(\mathrm{g} / \mathrm{m}^{2}\right)\end{array}$ & $\begin{array}{c}\text { Panel } \\
\text { orientation }\end{array}$ & \multicolumn{2}{|c|}{ Fibre volume fraction (\%) } \\
\hline 50 & QI & 60.0 & $\begin{array}{c}\text { Standard } \\
\text { deviation }\end{array}$ \\
\hline 150 & QI & 63.1 & 0.01 \\
\hline 300 & QI & 62.9 & 0.01 \\
\hline 50 & UD & 61.4 & 0.02 \\
\hline 150 & UD & 63.7 & 0.01 \\
\hline 50 & $\pm 45^{\circ}$ & 60.0 & 0.03 \\
\hline 150 & $\pm 45^{\circ}$ & 66.0 & - \\
\hline 300 & $\pm 45^{\circ}$ & 66.3 & - \\
\hline
\end{tabular}

For both the QI and the UD laminates the mean fibre volume fraction was between $60.0 \%$ and $63.5 \%$, for all of the ply thicknesses. As shown in Table 4.1, the mean fibre volume fraction was lower for the $50 \mathrm{~g} / \mathrm{m}^{2}$ laminates compared to the $150 \mathrm{~g} / \mathrm{m}^{2}$ and $300 \mathrm{~g} / \mathrm{m}^{2}$ laminates. This difference is even more pronounced with the $\pm 45^{\circ}$ laminates. The nominal total fibre area weight is consistent for each ply thickness, because the $50 \mathrm{~g} / \mathrm{m}^{2}$ panels have three times as many plies compared to the $150 \mathrm{~g} / \mathrm{m}^{2}$ (for example 48 plies compared to 16 plies) and six times as many plies when compared to the $300 \mathrm{~g} / \mathrm{m}^{2}$ laminate (for example 48 plies versus 8 plies). The difference in fibre volume fraction can be explained by the fact that the thin-ply laminates are generally thicker than the $150 \mathrm{~g} / \mathrm{m}^{2}$ and 
$300 \mathrm{~g} / \mathrm{m}^{2}$ panels, as shown in Table 3.1. It is thought that the $150 \mathrm{~g} / \mathrm{m}^{2}$ and the $300 \mathrm{~g} / \mathrm{m}^{2}$ laminates bled more resin during manufacture, compared to the $50 \mathrm{~g} / \mathrm{m}^{2}$, which would explain the difference in thickness. It is not understood why the difference in resin bleed occurred, although a similar effect $(7 \%$ decrease in fibre volume fraction for thin ply material) was found by Moon et al. [60]. A further explanation for the difference in fibre volume fraction is the presence of resin rich areas at ply boundaries. These areas tend to be greater with larger ply-angle changes. Thus, given that the $50 \mathrm{~g} / \mathrm{m}^{2}$ samples have the greatest number of plies, this may lead to the lower fibre content. This hypothesis is particularly relevant for the $\pm 45^{\circ}$ laminates, as these have the most abrupt ply orientation. This is also where the largest difference in fibre volume fraction was found. Further research could be conducted to understand why the thin-ply material had a lower fibre volume fraction and to ascertain if this is a common occurrence with spread tow prepregs.

Although there is a difference in fibre volume fraction for the thin and thicker ply materials, this difference is within $3 \%$ for the UD and QI samples, which are used for the majority of the testing. Furthermore, it is the $150 \mathrm{~g} / \mathrm{m}^{2}$ and $300 \mathrm{~g} / \mathrm{m}^{2}$ samples which have the greater fibre volume fraction, hence any mechanical benefits shown by the thin-ply material cannot be explained by an increased fibre content. Because of this, the differences in fibre volume fraction were thought to be acceptable.

\subsubsection{Determination of Glass Transition Temperature}

As discussed in Section 2.3, the glass transition temperature refers to the temperature range where a polymer transitions from its "glassy" state, where it is brittle and hard, to a more "rubbery" state, where the material is more flexible [45]. The $\mathrm{T}_{\mathrm{g}}$ therefore determines the useable service temperature of the polymer [46]. 
The glass transition temperature of each panel used for testing was determined, to check that the level of cure was consistent. Glass transition temperature was determined for at least one sample from every carbon fibre composite panel that was used for testing, using the method described in Section 3.2.3. The carbon fibre composites used throughout this project were made using the same fibre and resin matrix, the only difference was ply thickness. With this in mind, it was hypothesised that the glass transition temperature of each panel would be similar.

The glass transition temperature and testing parameters for each QI panel are shown in Table 4.2, for each UD panel in Table 4.3 and for each $\pm 45^{\circ}$ panel in Table 4.4. Interestingly, the DMA traces for some samples showed a 'double' tan delta peak, hence the column labelled "Tan Delta [Peak II]". The presence and significance of this peak will be discussed further in Chapter 6. 
Table 4.2 DMA results and the specific testing parameters for all QI carbon fibre panels used for testing. All panels have the same overall thickness of $2.1 \mathrm{~mm}$ $\pm 0.3 \mathrm{~mm}$ (page 1 of 2 )

\begin{tabular}{|c|c|c|c|c|c|c|c|c|c|}
\hline \multirow[b]{2}{*}{$\begin{array}{c}\text { Panel } \\
\text { number }\end{array}$} & \multirow[b]{2}{*}{$\begin{array}{c}\text { Ply } \\
\text { thickness } \\
\left(\mathrm{g} / \mathrm{m}^{2}\right)\end{array}$} & \multirow[b]{2}{*}{$\begin{array}{c}\text { Panel } \\
\text { orientation }\end{array}$} & \multicolumn{2}{|c|}{ Storage modulus onset } & \multicolumn{4}{|c|}{ Tan delta peak } & \multirow[b]{2}{*}{ Test parameters } \\
\hline & & & $\begin{array}{c}\text { Temperature } \\
\left({ }^{\circ} \mathrm{C}\right)\end{array}$ & $\begin{array}{l}\text { Storage } \\
\text { Modulus } \\
(\mathrm{GPa})\end{array}$ & $\begin{array}{l}\text { Temperature } \\
\left({ }^{\circ} \mathrm{C}\right)[\text { Peak I] }\end{array}$ & $\begin{array}{c}\text { Tan delta } \\
{[\text { Peak I] }}\end{array}$ & $\begin{array}{l}\text { Temperature } \\
\left({ }^{\circ} \mathrm{C}\right)[\text { Peak II }]\end{array}$ & $\begin{array}{c}\text { Tan delta } \\
\text { [Peak II] }\end{array}$ & \\
\hline 250 & 50 & QI & 168.2 & 3.06 & 200.5 & 0.13 & N/A & N/A & $10 \mathrm{~mm}$ length, $0.05 \mathrm{~mm}$ strain, $0^{\circ}$ direction \\
\hline 251 & 50 & QI & 168.1 & 3.51 & 200.4 & 0.12 & N/A & N/A & $10 \mathrm{~mm}$ length, $0.05 \mathrm{~mm}$ strain, $0^{\circ}$ direction \\
\hline 252 & 50 & QI & 168.2 & 3.53 & 201.5 & 0.13 & $\mathrm{~N} / \mathrm{A}$ & N/A & $10 \mathrm{~mm}$ length, $0.05 \mathrm{~mm}$ strain, $0^{\circ}$ direction \\
\hline 253 & 50 & QI & 169.7 & 4.08 & 200.2 & 0.12 & N/A & N/A & $10 \mathrm{~mm}$ length, $0.05 \mathrm{~mm}$ strain, $0^{\circ}$ direction \\
\hline 254 & 50 & QI & 166.8 & 3.61 & 199.7 & 0.13 & N/A & N/A & $10 \mathrm{~mm}$ length, $0.05 \mathrm{~mm}$ strain, $0^{\circ}$ direction \\
\hline 255 & 50 & QI & 167.9 & 3.17 & 199.4 & 0.14 & N/A & N/A & $10 \mathrm{~mm}$ length, $0.05 \mathrm{~mm}$ strain, $0^{\circ}$ direction \\
\hline 256 & 50 & QI & 172.0 & 3.68 & 201.2 & 0.13 & N/A & N/A & $10 \mathrm{~mm}$ length, $0.05 \mathrm{~mm}$ strain, $0^{\circ}$ direction \\
\hline 257 & 50 & QI & 168.8 & 2.88 & 201.3 & 0.13 & N/A & N/A & $10 \mathrm{~mm}$ length, $0.05 \mathrm{~mm}$ strain, $0^{\circ}$ direction \\
\hline 258 & 150 & QI & 149.8 & 4.45 & 184.7 & 0.11 & N/A & N/A & $10 \mathrm{~mm}$ length, $0.05 \mathrm{~mm}$ strain, $0^{\circ}$ direction \\
\hline 259 & 150 & QI & 149.2 & 3.84 & 177.0 & 0.112 & N/A & N/A & $10 \mathrm{~mm}$ length, $0.05 \mathrm{~mm}$ strain, $0^{\circ}$ direction \\
\hline 260 & 150 & QI & 153.2 & 4.01 & 187.7 & 0.11 & N/A & N/A & $10 \mathrm{~mm}$ length, $0.05 \mathrm{~mm}$ strain, $0^{\circ}$ direction \\
\hline 261 & 150 & QI & 145.1 & 4.48 & 176.0 & 0.12 & 192.1 & 0.11 & $10 \mathrm{~mm}$ length, $0.05 \mathrm{~mm}$ strain, $0^{\circ}$ direction \\
\hline 262 & 150 & QI & 148.8 & 4.80 & 182.0 & 0.11 & N/A & N/A & $10 \mathrm{~mm}$ length, $0.05 \mathrm{~mm}$ strain, $0^{\circ}$ direction \\
\hline 263 & 150 & QI & 153.8 & 3.83 & 183.5 & 0.11 & N/A & N/A & $10 \mathrm{~mm}$ length, $0.05 \mathrm{~mm}$ strain, $0^{\circ}$ direction \\
\hline 264 & 150 & QI & 151.7 & 3.30 & 178.2 & 0.11 & N/A & $\mathrm{N} / \mathrm{A}$ & $10 \mathrm{~mm}$ length, $0.05 \mathrm{~mm}$ strain, $0^{\circ}$ direction \\
\hline
\end{tabular}




\begin{tabular}{|c|c|c|c|c|c|c|c|c|c|}
\hline \multirow[b]{2}{*}{$\begin{array}{c}\text { Panel } \\
\text { number }\end{array}$} & \multirow[b]{2}{*}{$\begin{array}{l}\text { Ply } \\
\text { thickness } \\
\left(\mathrm{g} / \mathrm{m}^{2}\right)\end{array}$} & \multirow[b]{2}{*}{$\begin{array}{c}\text { Panel } \\
\text { orientation }\end{array}$} & \multicolumn{2}{|c|}{ Storage modulus onset } & \multicolumn{4}{|c|}{ Tan delta peak } & \multirow[b]{2}{*}{ Test parameters } \\
\hline & & & $\begin{array}{c}\text { Temperature } \\
\left({ }^{\circ} \mathrm{C}\right)\end{array}$ & $\begin{array}{c}\text { Storage } \\
\text { Modulus } \\
(\mathrm{GPa})\end{array}$ & $\begin{array}{l}\text { Temperature } \\
\left({ }^{\circ} \mathrm{C}\right)[\text { Peak I] }\end{array}$ & $\begin{array}{l}\text { Tan delta } \\
{[\text { Peak I] }}\end{array}$ & $\begin{array}{l}\text { Temperature } \\
\left({ }^{\circ} \mathrm{C}\right)[\text { Peak II }]\end{array}$ & $\begin{array}{l}\text { Tan delta } \\
\text { [Peak II] }\end{array}$ & \\
\hline 265 & 300 & QI & 150.7 & 3.73 & 178.6 & 0.12 & $\mathrm{~N} / \mathrm{A}$ & N/A & $10 \mathrm{~mm}$ length, $0.05 \mathrm{~mm}$ strain, $0^{\circ}$ direction \\
\hline 266 & 300 & QI & 119.6 & 5.16 & 151.5 & 0.10 & $\mathrm{~N} / \mathrm{A}$ & N/A & $15 \mathrm{~mm}$ length, $0.03 \mathrm{~mm}$ strain, $0^{\circ}$ direction \\
\hline 267 & 300 & QI & 150.1 & 3.33 & 186.4 & 0.11 & N/A & $\mathrm{N} / \mathrm{A}$ & $10 \mathrm{~mm}$ length, $0.02 \mathrm{~mm}$ strain, $0^{\circ}$ direction \\
\hline 268 & 300 & QI & 149.7 & 2.95 & 186.6 & 0.11 & N/A & N/A & $10 \mathrm{~mm}$ length, $0.02 \mathrm{~mm}$ strain, $0^{\circ}$ direction \\
\hline 269 & 300 & QI & 145.5 & 4.13 & 176.5 & 0.10 & N/A & N/A & $10 \mathrm{~mm}$ length, $0.02 \mathrm{~mm}$ strain, $0^{\circ}$ direction \\
\hline 270 & 300 & QI & 147.2 & 4.83 & 174.3 & 0.12 & 194.0 & 0.11 & $10 \mathrm{~mm}$ length, $0.05 \mathrm{~mm}$ strain, $0^{\circ}$ direction \\
\hline 271 & 300 & QI & 144.1 & 3.17 & 183.6 & 0.11 & N/A & N/A & $10 \mathrm{~mm}$ length, $0.02 \mathrm{~mm}$ strain, $0^{\circ}$ direction \\
\hline 278 & 50 & QI & 153.6 & 3.81 & 199.7 & 0.10 & N/A & N/A & $10 \mathrm{~mm}$ length, $0.02 \mathrm{~mm}$ strain, $0^{\circ}$ direction \\
\hline 279 & 50 & QI & 156.7 & 6.83 & 192.7 & 0.10 & $\mathrm{~N} / \mathrm{A}$ & N/A & $15 \mathrm{~mm}$ length, $0.03 \mathrm{~mm}$ strain, $0^{\circ}$ direction \\
\hline 280 & 50 & QI & 140.0 & 6.94 & 174.5 & 0.09 & N/A & N/A & $15 \mathrm{~mm}$ length, $0.03 \mathrm{~mm}$ strain, $0^{\circ}$ direction \\
\hline 281 & 50 & QI & 140.0 & 7.58 & 173.7 & 0.08 & N/A & N/A & $15 \mathrm{~mm}$ length, $0.03 \mathrm{~mm}$ strain, $0^{\circ}$ direction \\
\hline 283 & 50 & QI & 153.1 & 7.38 & 193.9 & 0.09 & N/A & N/A & $15 \mathrm{~mm}$ length, $0.03 \mathrm{~mm}$ strain, $0^{\circ}$ direction \\
\hline 285 & 50 & QI & 132.14 & 5.89 & 159.0 & 0.10 & 188.46 & N/A & $15 \mathrm{~mm}$ length, $0.03 \mathrm{~mm}$ strain, $0^{\circ}$ direction \\
\hline 286 & 150 & QI & 152.1 & 4.00 & 176.0 & 0.12 & 198.8 & 0.10 & $10 \mathrm{~mm}$ length, $0.02 \mathrm{~mm}$ strain, $0^{\circ}$ direction \\
\hline 288 & 150 & QI & 132.3 & 6.63 & 158.3 & 0.12 & 184.8 & 0.08 & $15 \mathrm{~mm}$ length, $0.03 \mathrm{~mm}$ strain, $0^{\circ}$ direction \\
\hline 289 & 150 & QI & 151.4 & 6.40 & 175.9 & 0.13 & 196.5 & 0.10 & $15 \mathrm{~mm}$ length, $0.03 \mathrm{~mm}$ strain, $0^{\circ}$ direction \\
\hline 290 & 150 & QI & 126.7 & 7.50 & 160.7 & 0.10 & 187.6 & 0.08 & $15 \mathrm{~mm}$ length, $0.03 \mathrm{~mm}$ strain, $0^{\circ}$ direction \\
\hline 293 & 300 & QI & 124.9 & 6.13 & 162.1 & 0.10 & $\mathrm{~N} / \mathrm{A}$ & N/A & $15 \mathrm{~mm}$ length, $0.03 \mathrm{~mm}$ strain, $0^{\circ}$ direction \\
\hline 294 & 300 & QI & 138.0 & 6.68 & 166.9 & 0.12 & 194.6 & 0.08 & $15 \mathrm{~mm}$ length, $0.03 \mathrm{~mm}$ strain, $0^{\circ}$ direction \\
\hline 296 & 300 & QI & 133.5 & 4.68 & 164.8 & 0.11 & 192.6 & 0.08 & $15 \mathrm{~mm}$ length, $0.03 \mathrm{~mm}$ strain, $0^{\circ}$ direction \\
\hline 297 & 300 & QI & 127.9 & 6.02 & 161.3 & 0.1 & N/A & N/A & $15 \mathrm{~mm}$ length, $0.03 \mathrm{~mm}$ strain, $0^{\circ}$ direction \\
\hline
\end{tabular}


Table 4.3 DMA results and the specific testing parameters for all UD carbon fibre panels used for testing. All panels have an overall thickness of $2.0 \mathrm{~mm} \pm 0.3 \mathrm{~mm}$, except for the panels shaded in green. The panels shaded in green have an overall thickness of $1.0 \mathrm{~mm} \pm 0.15 \mathrm{~mm}$

\begin{tabular}{|c|c|c|c|c|c|c|c|c|c|}
\hline \multirow{2}{*}{$\begin{array}{c}\text { Panel } \\
\text { number }\end{array}$} & \multirow{2}{*}{$\begin{array}{l}\text { Ply } \\
\text { thickness } \\
\left(\mathrm{g} / \mathrm{m}^{2}\right)\end{array}$} & \multirow{2}{*}{$\begin{array}{c}\text { Panel } \\
\text { orientation }\end{array}$} & \multicolumn{2}{|c|}{ Storage modulus onset } & \multicolumn{4}{|c|}{ Tan delta peak } & \multirow[b]{2}{*}{ Test parameters } \\
\hline & & & $\begin{array}{c}\text { Temperature } \\
\left({ }^{\circ} \mathrm{C}\right)\end{array}$ & $\begin{array}{c}\text { Storage } \\
\text { Modulus } \\
(\mathrm{GPa})\end{array}$ & $\begin{array}{l}\text { Temperature } \\
\left({ }^{\circ} \mathrm{C}\right)[\text { Peak I] }\end{array}$ & $\begin{array}{l}\text { Tan delta } \\
\text { [Peak I] }\end{array}$ & $\begin{array}{l}\text { Temperature } \\
\left({ }^{\circ} \mathrm{C}\right) \text { [Peak II] }\end{array}$ & $\begin{array}{l}\text { Tan delta } \\
\text { [Peak II] }\end{array}$ & \\
\hline 272 & 50 & 0 & 157.5 & 23.8 & 189.4 & 0.13 & N/A & N/A & $10 \mathrm{~mm}$ length, $0.05 \mathrm{~mm}$ strain, $0^{\circ}$ direction \\
\hline 273 & 50 & 0 & 145.0 & 11.4 & 175.1 & 0.10 & N/A & N/A & $15 \mathrm{~mm}$ length, $0.03 \mathrm{~mm}$ strain, $0^{\circ}$ direction \\
\hline 274 & 50 & 0 & 147.7 & 9.26 & 174.8 & 0.10 & N/A & N/A & $15 \mathrm{~mm}$ length, $0.03 \mathrm{~mm}$ strain, $0^{\circ}$ direction \\
\hline 275 & 150 & 0 & 149.2 & 9.6 & 182.9 & 0.11 & N/A & N/A & $15 \mathrm{~mm}$ length, $0.03 \mathrm{~mm}$ strain, $0^{\circ}$ direction \\
\hline 276 & 150 & 0 & 130.8 & 9.3 & 159.5 & 0.10 & N/A & N/A & $15 \mathrm{~mm}$ length, $0.03 \mathrm{~mm}$ strain, $0^{\circ}$ direction \\
\hline 277 & 150 & 0 & 121.46 & 24.4 & 154.1 & 0.09 & N/A & N/A & $15 \mathrm{~mm}$ length, $0.03 \mathrm{~mm}$ strain, $0^{\circ}$ direction \\
\hline 301 & 50 & 0 & 134.7 & 10.6 & 175.0 & 0.093 & N/A & N/A & $15 \mathrm{~mm}$ length, $0.03 \mathrm{~mm}$ strain, $0^{\circ}$ direction \\
\hline 302 & 50 & 0 & 135.9 & 10.5 & 169.6 & 0.101 & N/A & N/A & $15 \mathrm{~mm}$ length, $0.03 \mathrm{~mm}$ strain, $0^{\circ}$ direction \\
\hline 304 & 150 & 0 & 142.3 & 10.5 & 168.3 & 0.153 & 198.0 & 0.082 & $15 \mathrm{~mm}$ length, $0.03 \mathrm{~mm}$ strain, $0^{\circ}$ direction \\
\hline 305 & 150 & 0 & 124.2 & 11.6 & 152.0 & 0.1 & 184.9 & 0.073 & $15 \mathrm{~mm}$ length, $0.03 \mathrm{~mm}$ strain, $0^{\circ}$ direction \\
\hline
\end{tabular}


Table 4.4 DMA results and the specific testing parameters for all $\pm 45^{\circ}$ carbon fibre panels used for testing. All panels have an overall thickness of $2.1 \mathrm{~mm} \pm 0.25 \mathrm{~mm}$

\begin{tabular}{|c|c|c|c|c|c|c|c|c|c|}
\hline \multirow{2}{*}{$\begin{array}{c}\text { Panel } \\
\text { number }\end{array}$} & \multirow{2}{*}{$\begin{array}{l}\text { Ply } \\
\text { thickness } \\
\left(\mathrm{g} / \mathrm{m}^{2}\right)\end{array}$} & \multirow{2}{*}{$\begin{array}{c}\text { Panel } \\
\text { orientation }\end{array}$} & \multicolumn{2}{|c|}{ Storage modulus onset } & \multicolumn{4}{|c|}{ Tan delta peak } & \multirow{2}{*}{ Test parameters } \\
\hline & & & $\begin{array}{c}\text { Temperature } \\
\left({ }^{\circ} \mathrm{C}\right)\end{array}$ & $\begin{array}{l}\text { Storage } \\
\text { Modulus } \\
(\mathrm{GPa})\end{array}$ & $\begin{array}{l}\text { Temperature } \\
\left({ }^{\circ} \mathrm{C}\right)[\text { Peak I] }\end{array}$ & $\begin{array}{c}\text { Tan delta } \\
{[\text { Peak I] }}\end{array}$ & $\begin{array}{l}\text { Temperature } \\
\left({ }^{\circ} \mathrm{C}\right)[\text { Peak II] }\end{array}$ & $\begin{array}{c}\text { Tan delta } \\
\text { [Peak II] }\end{array}$ & \\
\hline 306 & 50 & \pm 45 & 146.8 & 5.20 & 172.7 & 0.095 & 195.0 & 0.115 & $15 \mathrm{~mm}$ length, $0.03 \mathrm{~mm}$ strain \\
\hline 307 & 150 & \pm 45 & 136.4 & 6.25 & 163.3 & 0.131 & 191.9 & 0.097 & $15 \mathrm{~mm}$ length, $0.03 \mathrm{~mm}$ strain \\
\hline 308 & 300 & \pm 45 & 128.7 & 6.27 & 159.6 & 0.104 & N/A & N/A & $15 \mathrm{~mm}$ length, $0.03 \mathrm{~mm}$ strain \\
\hline
\end{tabular}


The mean glass transition temperatures of all the laminates are shown in Table 4.5. The values for the $\pm 45^{\circ}$ panels are based on one sample, hence no standard deviation is given. The results of the QI, UD and $\pm 45^{\circ}$ panels are also displayed graphically in Figure 4.2 and Figure 4.3.

Table 4.5 Mean glass transition temperature values

\begin{tabular}{|c|c|c|c|}
\hline $\begin{array}{c}\text { Ply thickness } \\
\left(\mathrm{g} / \mathrm{m}^{2}\right)\end{array}$ & $\begin{array}{c}\text { Panel } \\
\text { orientation }\end{array}$ & Mean & $\begin{array}{c}\text { Glass transition temperature }\left({ }^{\circ} \mathrm{C}\right) \\
\text { deviation }\end{array}$ \\
\hline 50 & QI & 158.9 & 3.5 \\
\hline 150 & QI & 146.7 & 2.8 \\
\hline 300 & QI & 139.2 & 3.5 \\
\hline 50 & UD & 144.2 & 4.2 \\
\hline 150 & UD & 133.6 & - \\
\hline 50 & $\pm 45^{\circ}$ & 146.8 & - \\
\hline 150 & $\pm 45^{\circ}$ & 136.4 & - \\
\hline 300 & $\pm 45^{\circ}$ & 128.7 & \\
\hline
\end{tabular}

The results show an interesting trend; the glass transition temperatures of the thin-ply materials were consistently higher than both the intermediate and thick-ply laminates. On average the $\mathrm{T}_{\mathrm{g}}$ of the QI $50 \mathrm{~g} / \mathrm{m}^{2}$ samples was $12{ }^{\circ} \mathrm{C}$ higher than the $150 \mathrm{~g} / \mathrm{m}^{2}$ samples and $20{ }^{\circ} \mathrm{C}$ higher than the $300 \mathrm{~g} / \mathrm{m}^{2}$ samples. For the UD panels the mean $50 \mathrm{~g} / \mathrm{m}^{2} \mathrm{~T}_{\mathrm{g}}$ was $11^{\circ} \mathrm{C}$ higher than the $150 \mathrm{~g} / \mathrm{m}^{2}$ material.

Possible reasons for the difference in glass transition temperature were considered and are discussed in detail in Section 6.2. In summary, the proposed explanations include: changes to the DMA method used (such as changes to the applied strain and the single-cantilever span length), changes to storage conditions leading to differing moisture content, and the presence of poly-ether-sulfone toughening particles leading to differing levels of phase separation, depending on ply thickness. A further possible reason for the 
difference was varying levels of cure, because, due to the large volume of material used, the laminates were not all cured in the autoclave at the same time. Therefore, it could be proposed that the difference in $\mathrm{T}_{\mathrm{g}}$ was a result of the thin-ply laminates being subjected to a slightly longer cure time, or a higher cure temperature. However, there are several reasons which suggest that this was not the case. Firstly, all samples were cured for two hours at $130^{\circ} \mathrm{C}$ followed by four hours at $165^{\circ} \mathrm{C}$. Furthermore, panels 250 to 277 were cured in the same autoclave, at the same time and therefore all experienced the same cure schedule. Despite this, the discussed differences between the thin and thicker ply samples were still found. Lastly, no correlation between autoclave batch and $T_{g}$ was seen. This strengthens the argument that the difference in $\mathrm{T}_{\mathrm{g}}$ cannot be explained by a difference in cure time or temperature (assuming the temperature distribution in the oven is uniform).

Furthermore, variations in the glass transition temperature of panels manufactured using the same prepreg thickness were also found. Subsequent analysis indicted this was due to storage conditions of the samples and is discussed in detail in Section 6.2. Ideally all panels would have the same $T_{g}$, to ensure that the effect of cure did not influence the mechanical testing results. However, given that the $T_{g}$ was consistently different for the thinner ply samples, independent of when the samples were cured, this was not possible. As alluded to earlier, additional DMA analysis was conducted on the samples in order to understand the results further and is discussed in Chapter 6. 


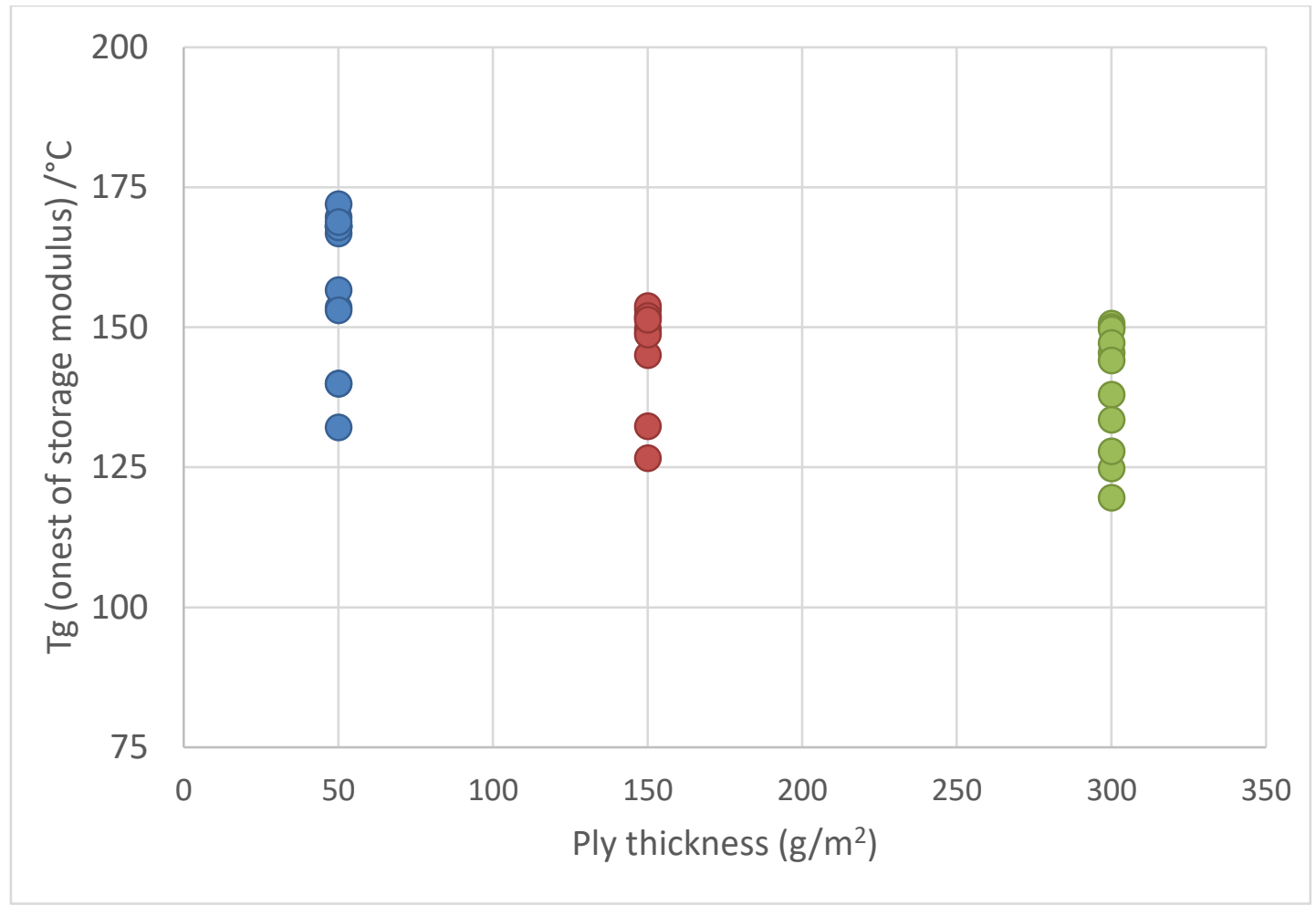

Figure 4.2 Scatter graph to show the glass transition temperature of all QI panels ( $T_{8}$ determined via onset of storage modulus)

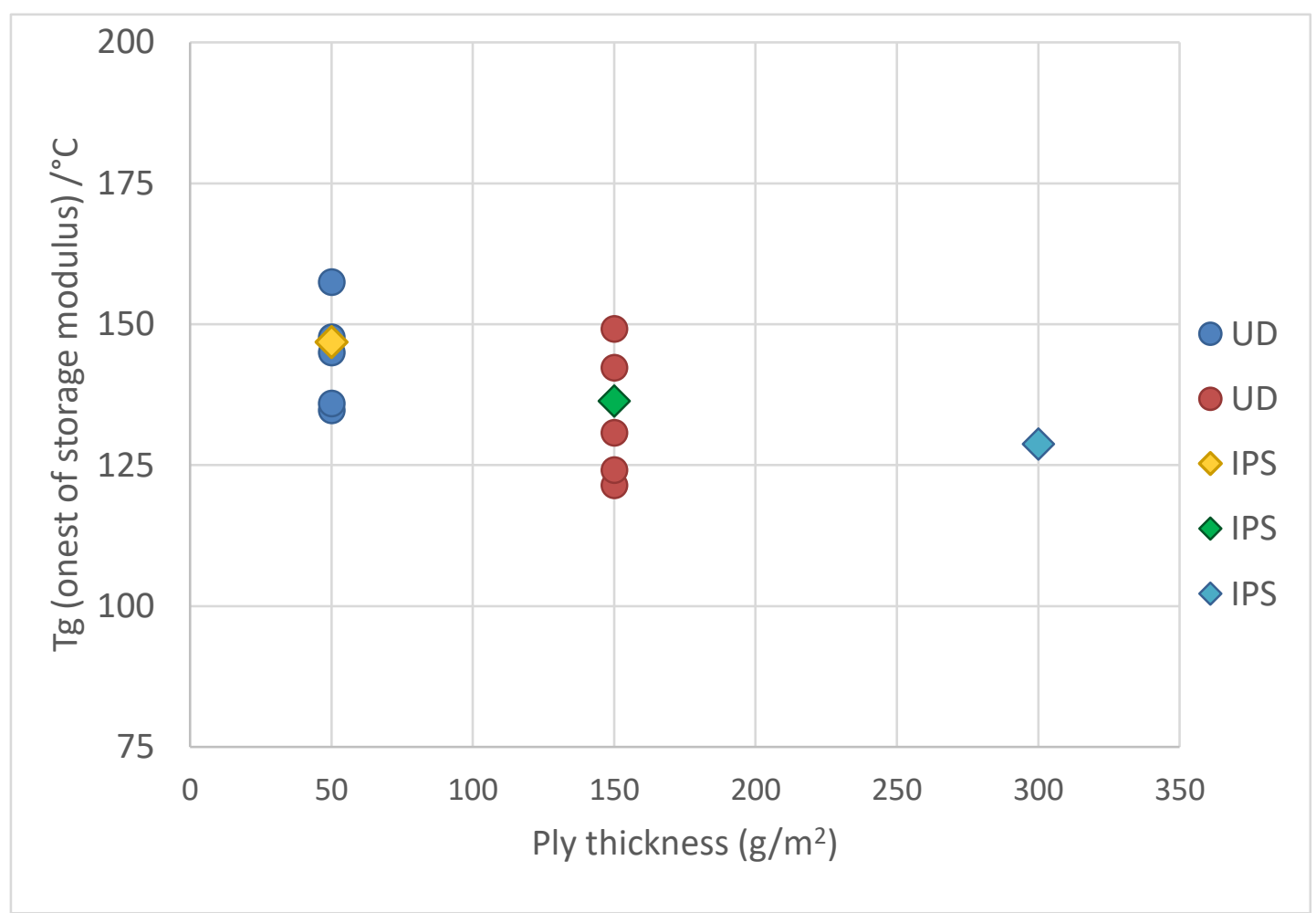

Figure 4.3 Scatter graph to show the glass transition temperature of all UD and IPS panels ( $T_{g}$ determined via onset of storage modulus) 


\subsection{Mechanical Behaviour of Unconditioned Samples at Ambient Temperature}

As outlined in Table 3.3, a detailed testing programme was developed to determine the effect of laminate ply thickness on mechanical properties, when tested in different environmental conditions. The first stage of this programme was to understand the material behaviour at room temperature, in the unconditioned state. The results of these tests are detailed below.

\subsubsection{Unidirectional $0^{\circ}$ Unnotched Tensile}

The results of the unidirectional, $0^{\circ}$ tensile tests are shown in Figure 4.4. As the load increased the stress/strain curve for the intermediate-ply samples became increasingly non-linear, compared to the thinner ply coupons. A similar event was seen in the work by Bhudolia et al. [113] and could be linked to the start of unrecoverable damage, such as microcracks and delamination. All samples exhibited widespread fracture and generation of debris (as demonstrated in Figure 4.5) however the intermediate-ply samples failed more progressively than the thin-ply coupons. This explains why the stress/strain curve continues after maximum load was reached.

The mean results for each set of samples are shown in Table 4.6 and Figure 4.6. The results have been normalised to a $v_{f}$ of $60 \%$, using the equation described in Section 3.2.2. There was no significant difference in the UTS or tensile modulus for the UD $0^{\circ}$ thin and intermediate-ply samples, which corroborates with the work carried out by Amacher et al. [14]. There was an increase in tensile strain for the thin-ply samples, compared to the intermediate thickness coupons (1.8\% $\pm 0.04 \%$ compared to $1.6 \% \pm 0.08 \%)$. 

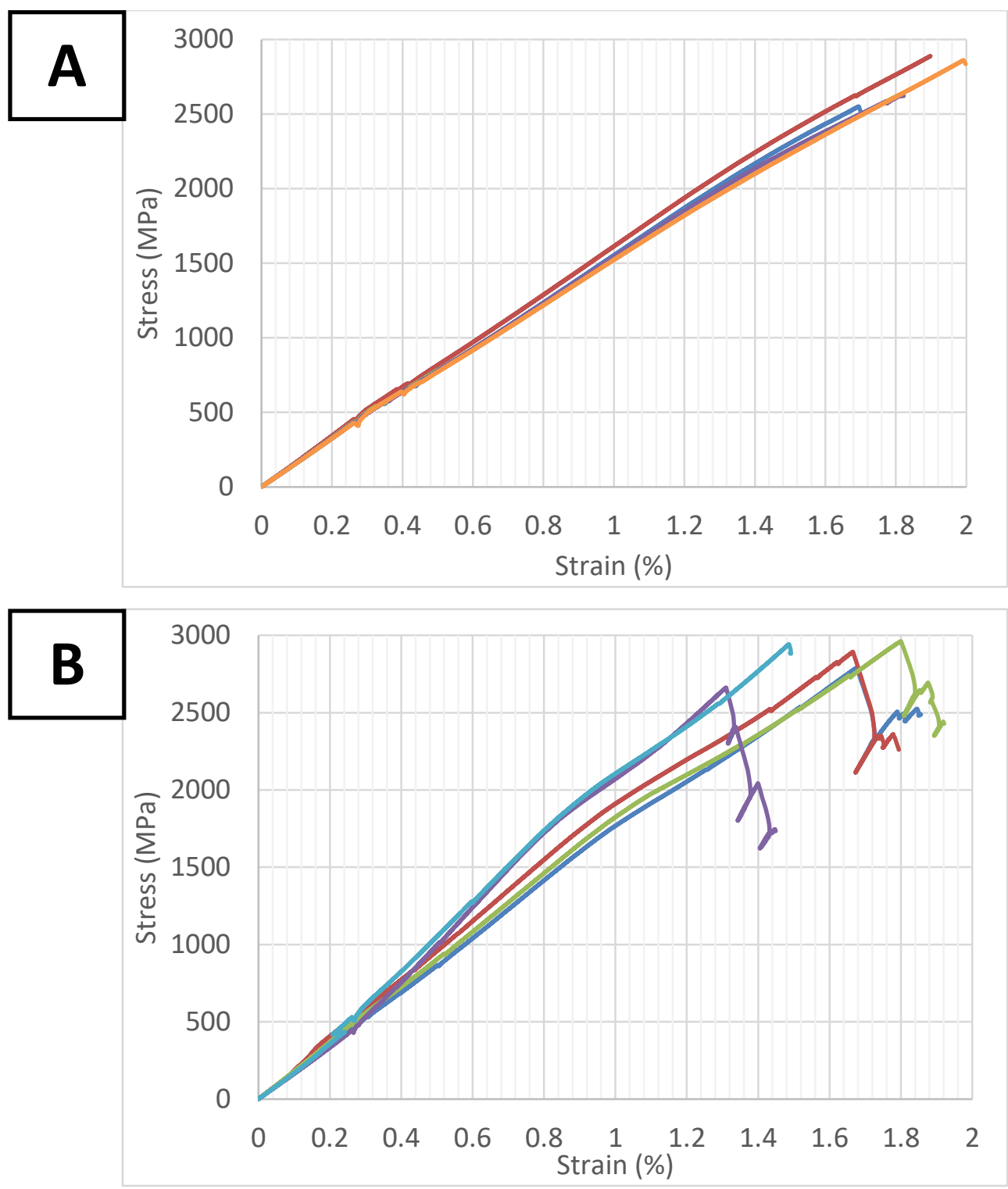

Figure 4.4 Stress/strain curves for $0^{\circ}$ unnotched tensile specimens: a) $50 \mathrm{~g} / \mathrm{m}^{2}$, b) $150 \mathrm{~g} / \mathrm{m}^{2}$ 

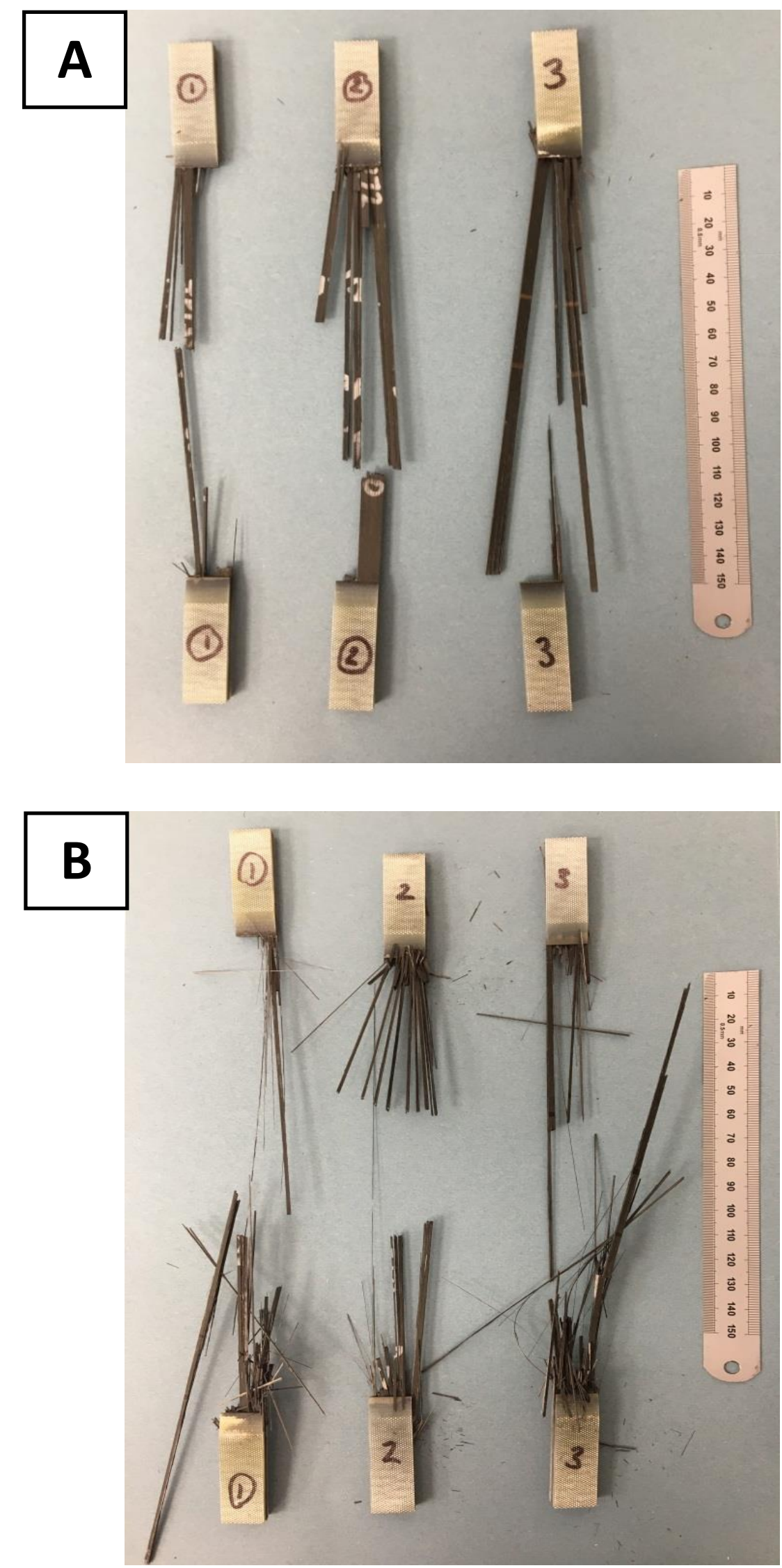

Figure $4.50^{\circ}$ unnotched tensile failure modes: a) $50 \mathrm{~g} / \mathrm{m}^{2}$, b) $150 \mathrm{~g} / \mathrm{m}^{2}$ 
Table 4.6 Mean $0^{\circ}$ unnotched tensile stress, strain and modulus values (normalised) [set of six samples per material]

\begin{tabular}{|c|c|c|c|c|c|c|}
\hline \multirow{2}{*}{ Prepreg } & \multicolumn{2}{|c|}{ Max Stress (MPa) } & \multicolumn{2}{c|}{ Strain at break (\%) } & \multicolumn{2}{c|}{ Modulus (GPa) } \\
& Mean & $\begin{array}{c}\text { Standard } \\
\text { error }\end{array}$ & Mean & $\begin{array}{c}\text { Standard } \\
\text { error }\end{array}$ & Mean & $\begin{array}{c}\text { Standard } \\
\text { error }\end{array}$ \\
\hline $50 \mathrm{~g} / \mathrm{m}^{2}$ & 2705 & 48.6 & 1.8 & 0.04 & 167 & 2.0 \\
\hline $150 \mathrm{~g} / \mathrm{m}^{2}$ & 2706 & 40.4 & 1.6 & 0.07 & 173 & 6.3 \\
\hline
\end{tabular}

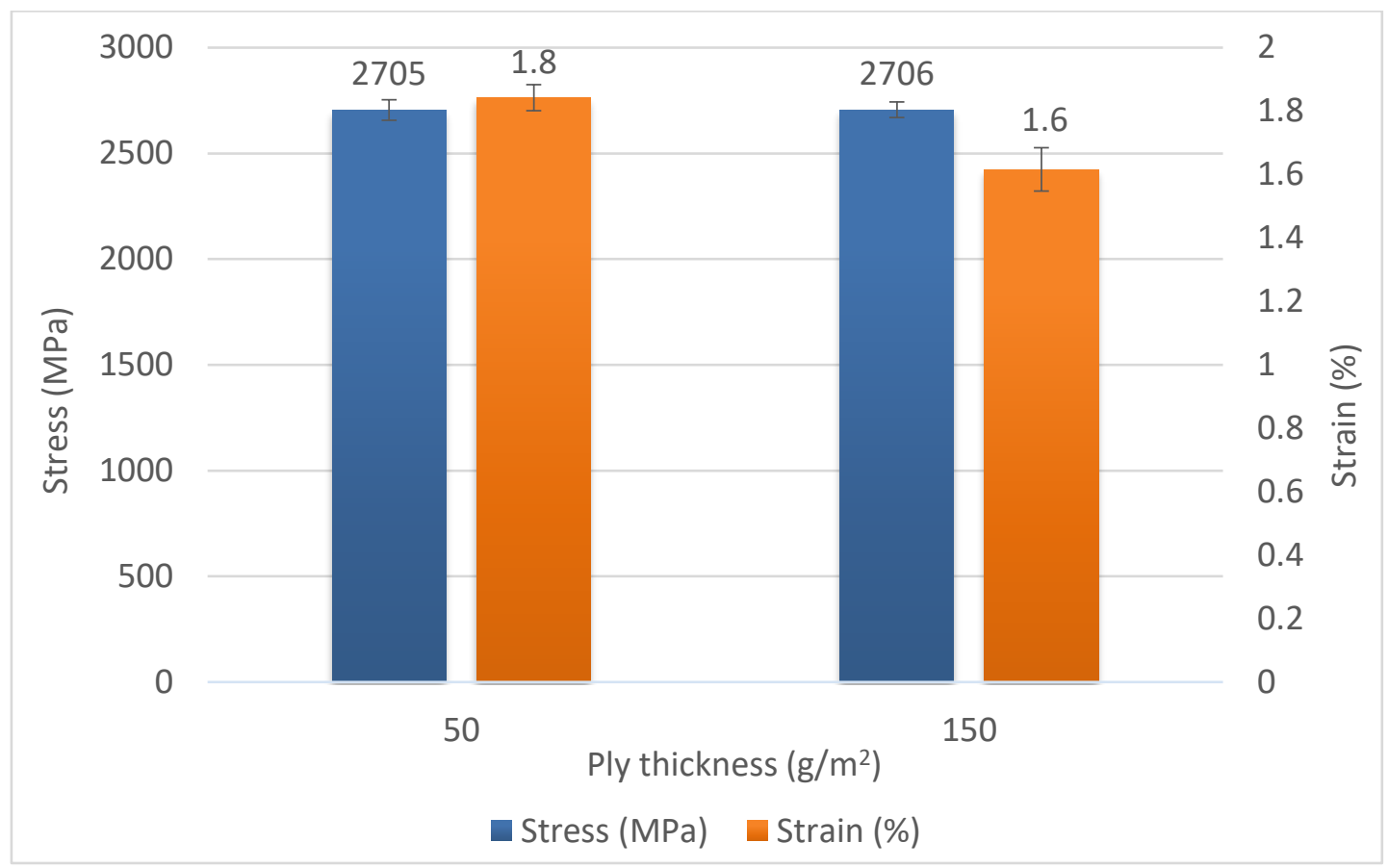

Figure 4.6 Mean $0^{\circ}$ unnotched tensile stress and strain data (normalised) [set of six samples per material]

\subsubsection{Unidirectional $90^{\circ}$ Unnotched Tensile}

The stress/strain curves for the unidirectional, $90^{\circ}$ tensile tests were linear throughout for both the $50 \mathrm{~g} / \mathrm{m}^{2}$ and the $150 \mathrm{~g} / \mathrm{m}^{2}$ materials. A lateral failure type was seen for all specimens, as expected for a $90^{\circ}$ tensile test. Failures in both the gauge length and at the tab region were observed, as demonstrated in Figure 4.7.

There were no significant differences in the $90^{\circ}$ tensile strength, strain or modulus values for $50 \mathrm{~g} / \mathrm{m}^{2}$ and $150 \mathrm{~g} / \mathrm{m}^{2}$ test coupons, as shown in Table 4.7 and Figure 4.8. The results have not been normalised, due to the fact that the test is resin, not fibre, dominated. 

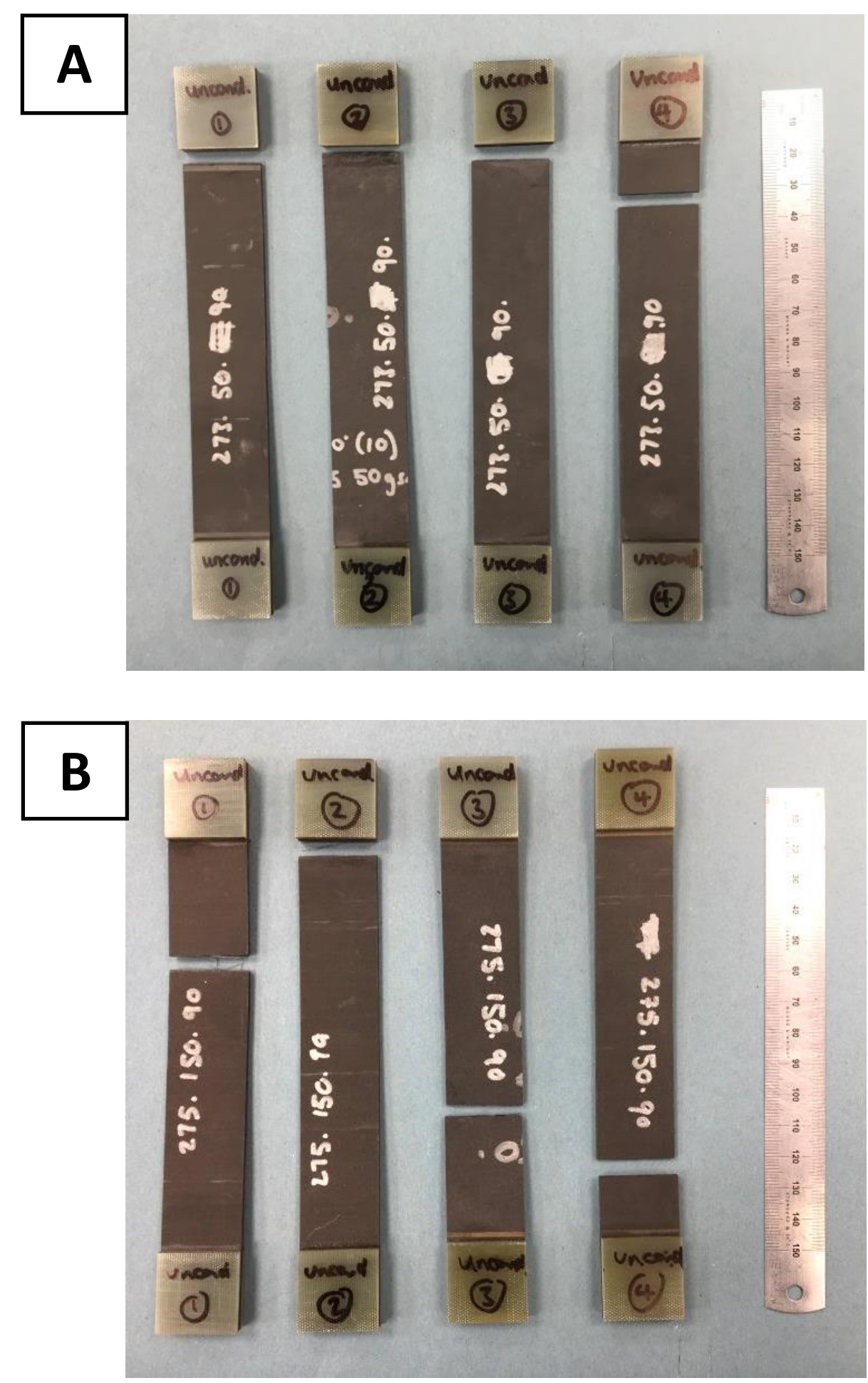

Figure $4.790^{\circ}$ unnotched tensile failure modes: a) $50 \mathrm{~g} / \mathrm{m}^{2}$, b) $150 \mathrm{~g} / \mathrm{m}^{2}$ 
Table 4.7 Mean $90^{\circ}$ unnotched tensile stress, strain and modulus values (not normalised) [set of eight samples per material]

\begin{tabular}{|c|c|c|c|c|c|c|}
\hline & \multicolumn{2}{|c|}{ Max Stress (MPa) } & \multicolumn{2}{c|}{ Strain at break (\%) } & \multicolumn{2}{|c|}{ Modulus (GPa) } \\
\hline & Mrepreg & $\begin{array}{c}\text { Standard } \\
\text { error }\end{array}$ & Mean & $\begin{array}{c}\text { Standard } \\
\text { error }\end{array}$ & Mean & $\begin{array}{c}\text { Standard } \\
\text { error }\end{array}$ \\
\hline $50 \mathrm{~g} / \mathrm{m}^{2}$ & 53.9 & 4.75 & 0.61 & 0.05 & 9.13 & 0.08 \\
\hline $150 \mathrm{~g} / \mathrm{m}^{2}$ & 49.8 & 3.32 & 0.54 & 0.04 & 9.34 & 0.07 \\
\hline
\end{tabular}

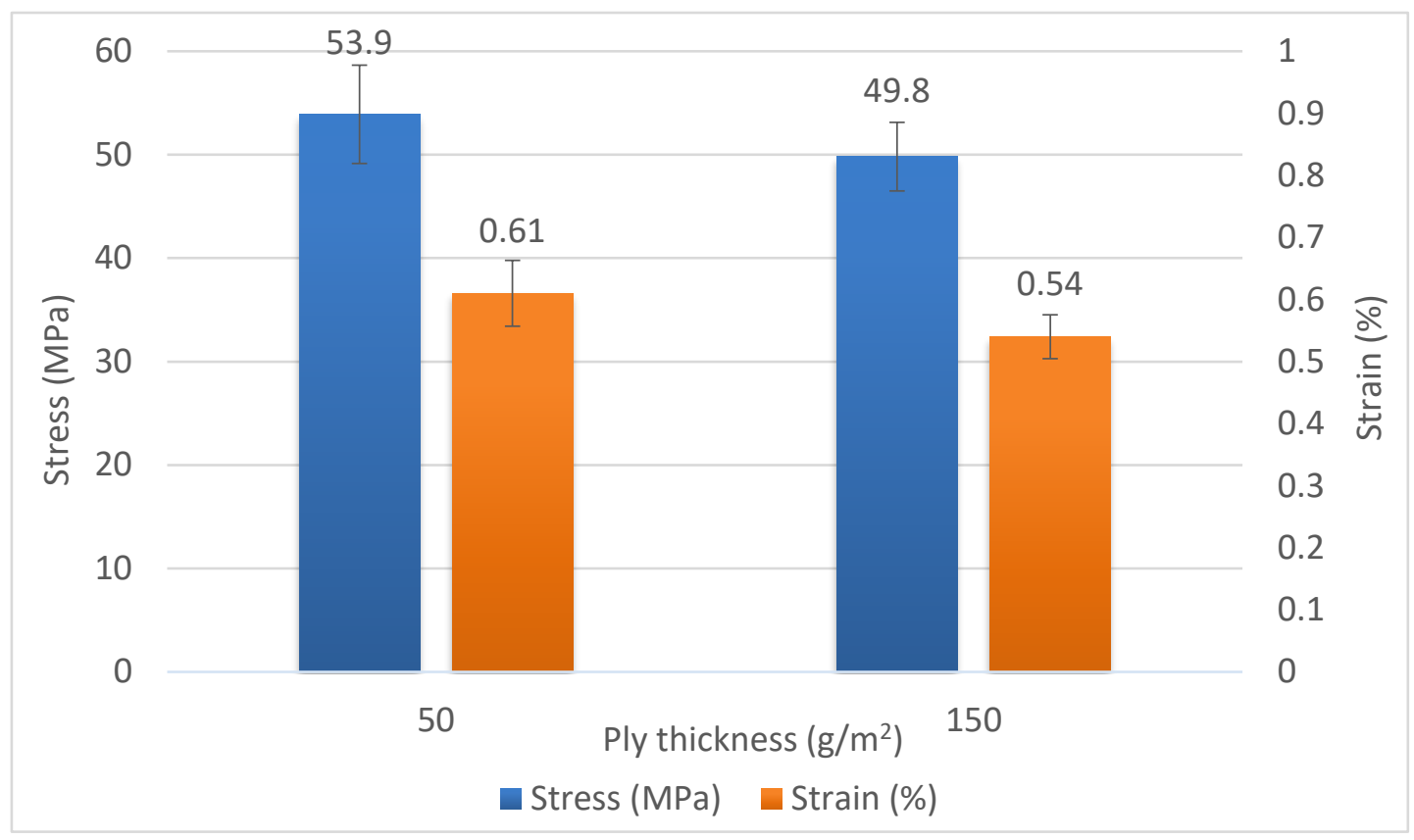

Figure 4.8 Mean $90^{\circ}$ unnotched tensile stress and strain data (not normalised) [set of eight samples per material]

\subsubsection{Quasi-isotropic Unnotched Tensile}

Six unnotched tensile samples for each ply thickness were tested at ambient temperature. Different failure modes were seen with laminates manufactured from different ply thicknesses. Evidence of this can be seen in both the stress/strain curves (Figure 4.9) and the failure mode images (Figure 4.10). Unlike the $50 \mathrm{~g} / \mathrm{m}^{2}$ and the $150 \mathrm{~g} / \mathrm{m}^{2}$ samples, the thick-ply specimens did not fail suddenly at the maximum stress. Instead, individual plies within the sample continued to hold a reduced load until final failure of the sample occurred. This is why the $300 \mathrm{~g} / \mathrm{m}^{2}$ stress/strain curve differs from the rest. The two anomalous results for the $150 \mathrm{~g} / \mathrm{m}^{2}$ samples are thought to be due to fibre breaks. The 
unnotched $300 \mathrm{~g} / \mathrm{m}^{2}$ coupons generally failed in a far more progressive manor (distinct, individual ply failure, before final coupon failure) compared to the $50 \mathrm{~g} / \mathrm{m}^{2}$ and $150 \mathrm{~g} / \mathrm{m}^{2}$ samples. A large amount of delamination was seen along the entire length of the thick-ply samples. The thin-ply coupons had a more brittle failure mode.

Figure 4.11 and Table 4.8 show the mean results for each material. The data shows that there is a significant difference in the ultimate tensile stress for the three sets of specimens, with the thinnest plies $\left(50 \mathrm{~g} / \mathrm{m}^{2}\right)$ giving the greatest mean strength value. The $50 \mathrm{~g} / \mathrm{m}^{2}$ ply samples had a $45 \%$ and an $8 \%$ increase in normalised tensile strength compared to the $300 \mathrm{~g} / \mathrm{m}^{2}$ and the $150 \mathrm{~g} / \mathrm{m}^{2}$ samples respectively. The $50 \mathrm{~g} / \mathrm{m}^{2}$ coupons also gave greater strain values compared to $300 \mathrm{~g} / \mathrm{m}^{2}$. The strain values for thin and intermediate-ply coupons were not significantly different. The two anomalous $150 \mathrm{~g} / \mathrm{m}^{2}$ results were removed from the mean strain calculation. The results have not been removed from the mean modulus calculations, as the effects occur after the modulus determination region. No difference was found between the modulus values of the three sets of laminates. 

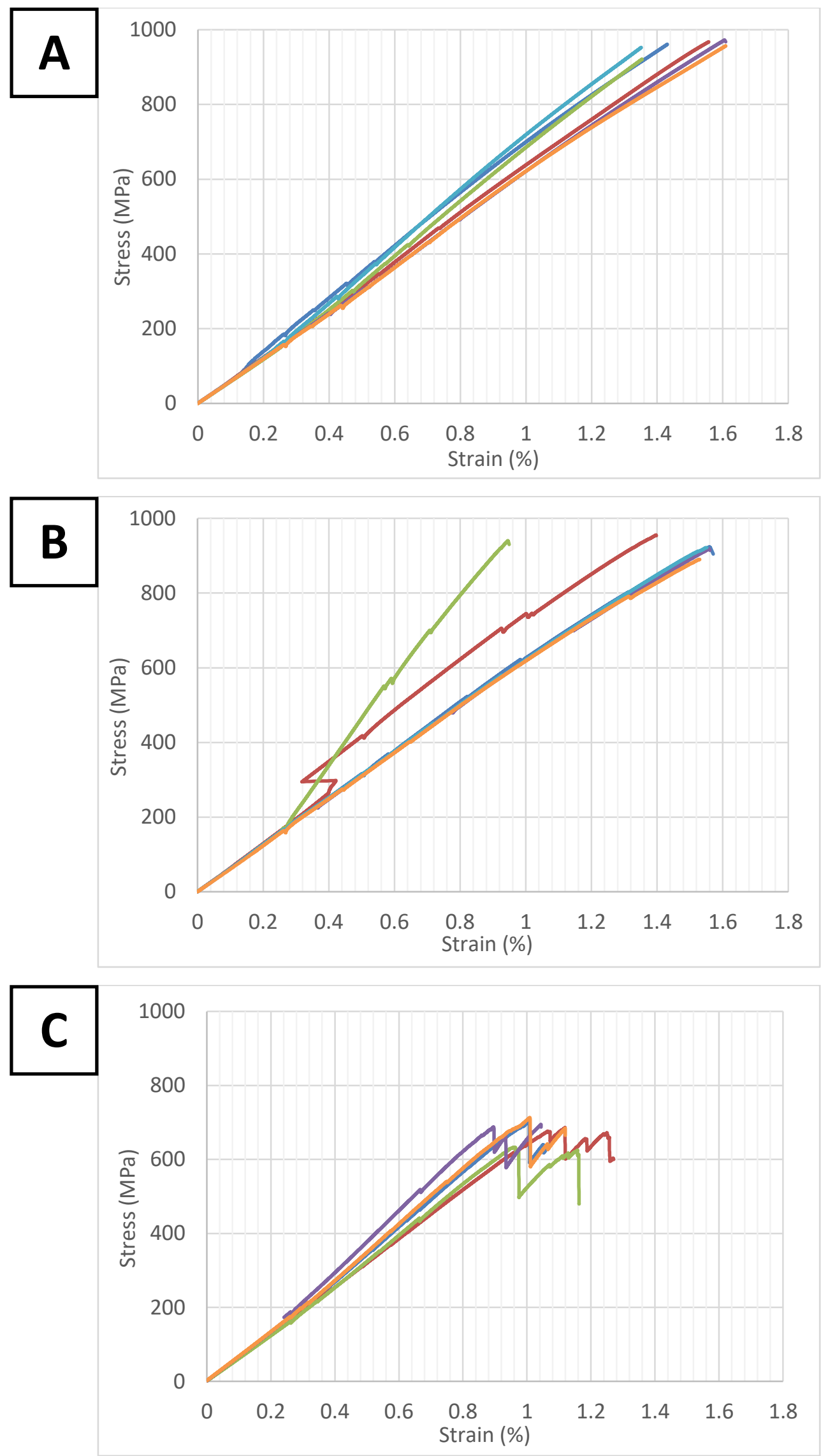

Figure 4.9 Stress/strain curves for QI unnotched tensile specimens: a) $50 \mathrm{~g} / \mathrm{m}^{2}$, b) $150 \mathrm{~g} / \mathrm{m}^{2}$, c) $300 \mathrm{~g} / \mathrm{m}^{2}$ 


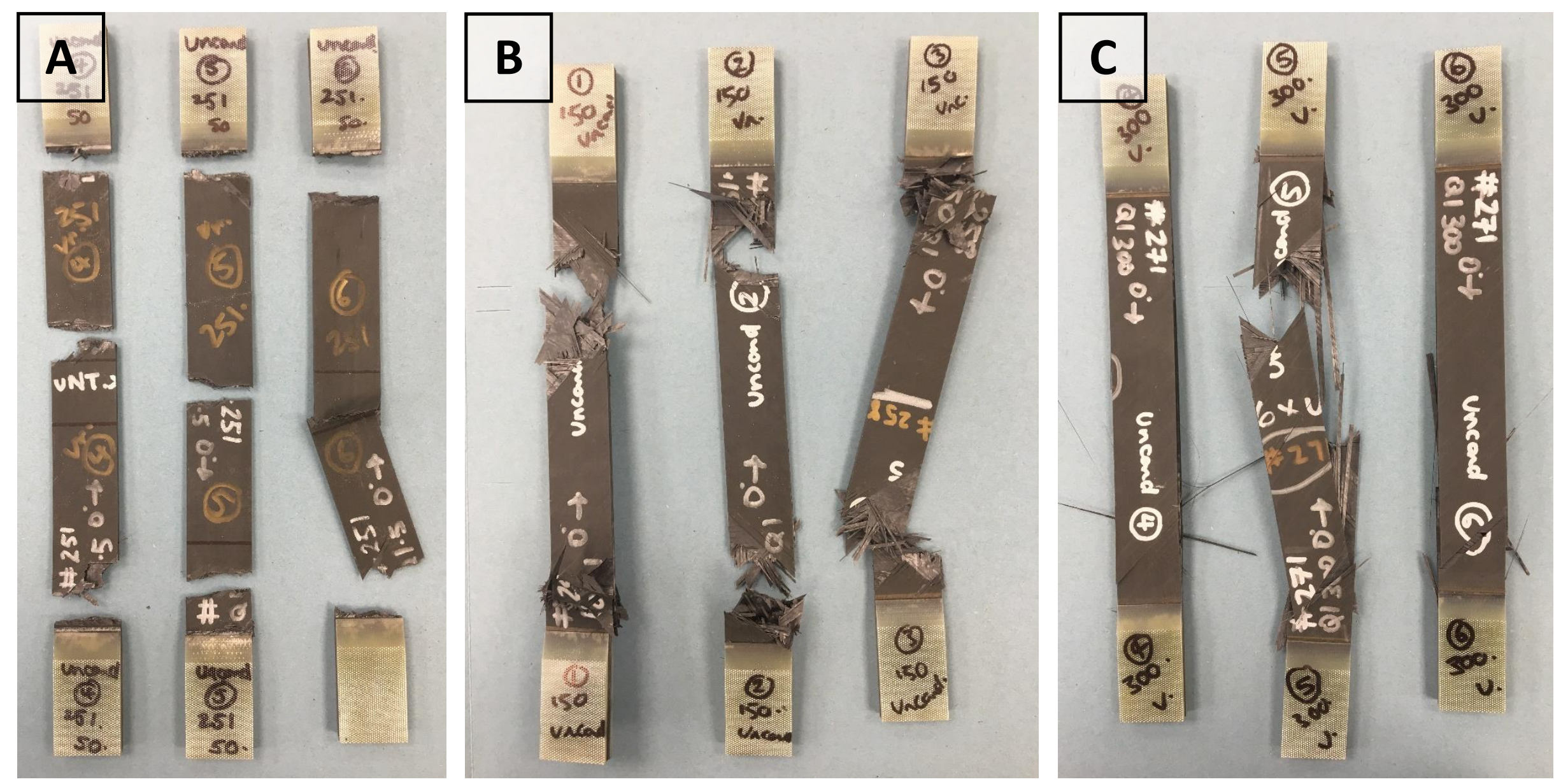

Figure 4.10 QI unnotched tensile failure modes: a) $50 \mathrm{~g} / \mathrm{m}^{2}$, b) $150 \mathrm{~g} / \mathrm{m}^{2}$, c) $300 \mathrm{~g} / \mathrm{m}^{2}$ 
Table 4.8 Mean QI unnotched tensile stress, strain and modulus values (normalised) [set of six samples per material]

\begin{tabular}{|c|c|c|c|c|c|c|}
\hline \multirow{2}{*}{ Prepreg } & \multicolumn{2}{|c|}{ Max Stress (MPa) } & \multicolumn{2}{c|}{ Strain at break (\%) } & \multicolumn{2}{c|}{ Modulus (GPa) } \\
\cline { 2 - 5 } & Mean & $\begin{array}{c}\text { Standard } \\
\text { error }\end{array}$ & Mean & $\begin{array}{c}\text { Standard } \\
\text { error }\end{array}$ & Mean & $\begin{array}{c}\text { Standard } \\
\text { error }\end{array}$ \\
\hline $50 \mathrm{~g} / \mathrm{m}^{2}$ & 951 & 7.4 & 1.5 & 0.05 & 62.5 & 2.0 \\
\hline $150 \mathrm{~g} / \mathrm{m}^{2}$ & 878 & 9.9 & $* 1.5$ & ${ }^{*} 0.02$ & 60.1 & 0.5 \\
\hline $300 \mathrm{~g} / \mathrm{m}^{2}$ & 658 & 12.0 & 1.1 & 0.05 & 62.2 & 1.0 \\
\hline
\end{tabular}

*Anomalous results removed from calculation of mean

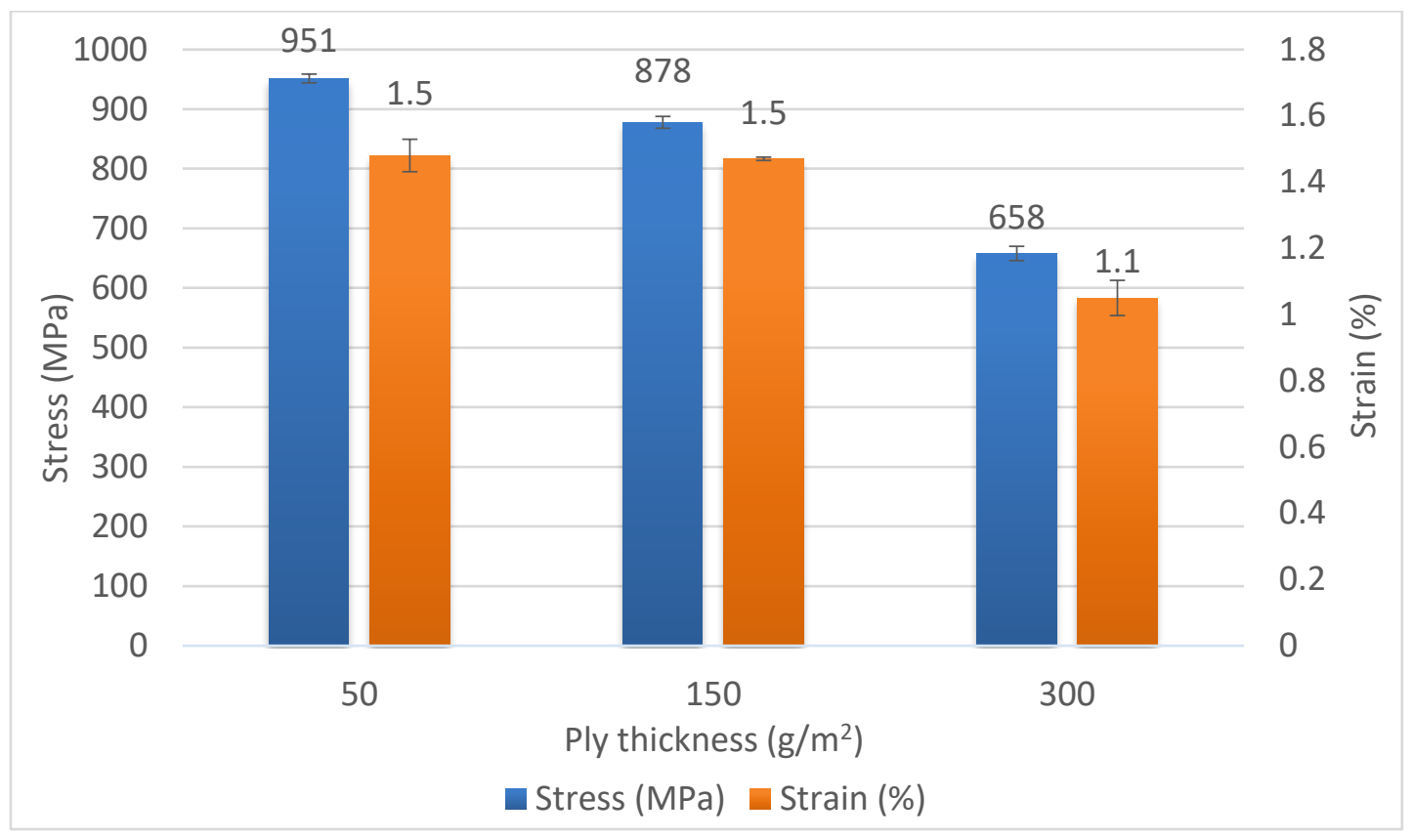

Figure 4.11 Mean QI unnotched tensile stress and strain data (normalised) [set of six samples per material]

\subsubsection{Quasi-isotropic Open-hole Tensile}

Six open-hole tensile samples for each ply thickness were tested at ambient temperature. The failure modes and stress/strain curves for the tests are shown in Figure 4.12 and Figure 4.13. As was the case with the unnotched tensile samples, the stress/strain curves for the three different ply thickness materials varied greatly. The progressive failure of the $300 \mathrm{~g} / \mathrm{m}^{2}$ specimens is evident in graph C in Figure 4.12. Unlike the $50 \mathrm{~g} / \mathrm{m}^{2}$ and $150 \mathrm{~g} / \mathrm{m}^{2}$ samples, the thick-ply specimens did not completely fail at the maximum stress. After the maximum load was 
reached, individual plies progressively failed until the final failure of the sample occurred. The $300 \mathrm{~g} / \mathrm{m}^{2}$ open-hole tensile coupons failed more progressively than the $50 \mathrm{~g} / \mathrm{m}^{2}$ and the $150 \mathrm{~g} / \mathrm{m}^{2}$ samples. Extensive delamination was seen along the entire length of the thick-ply samples. The thin-ply coupons had a very lateral, brittle failure mode which was very different to the more widespread failures of the intermediate and thick-ply specimens. This behaviour was similar to that of the unnotched tensile coupons.

In contrast to the unnotched tensile test results, the thin-ply specimens had the lowest mean ultimate tensile strength. This corroborates with the work carried out by Amacher et al. [14]. The mean UTS for $150 \mathrm{~g} / \mathrm{m}^{2}$ and $300 \mathrm{~g} / \mathrm{m}^{2}$ did not differ significantly. Similarly, the modulus values did not differ significantly with change in ply thickness. Table 4.9 and Figure 4.14 show the mean test results. Six samples were tested for each ply thickness. 

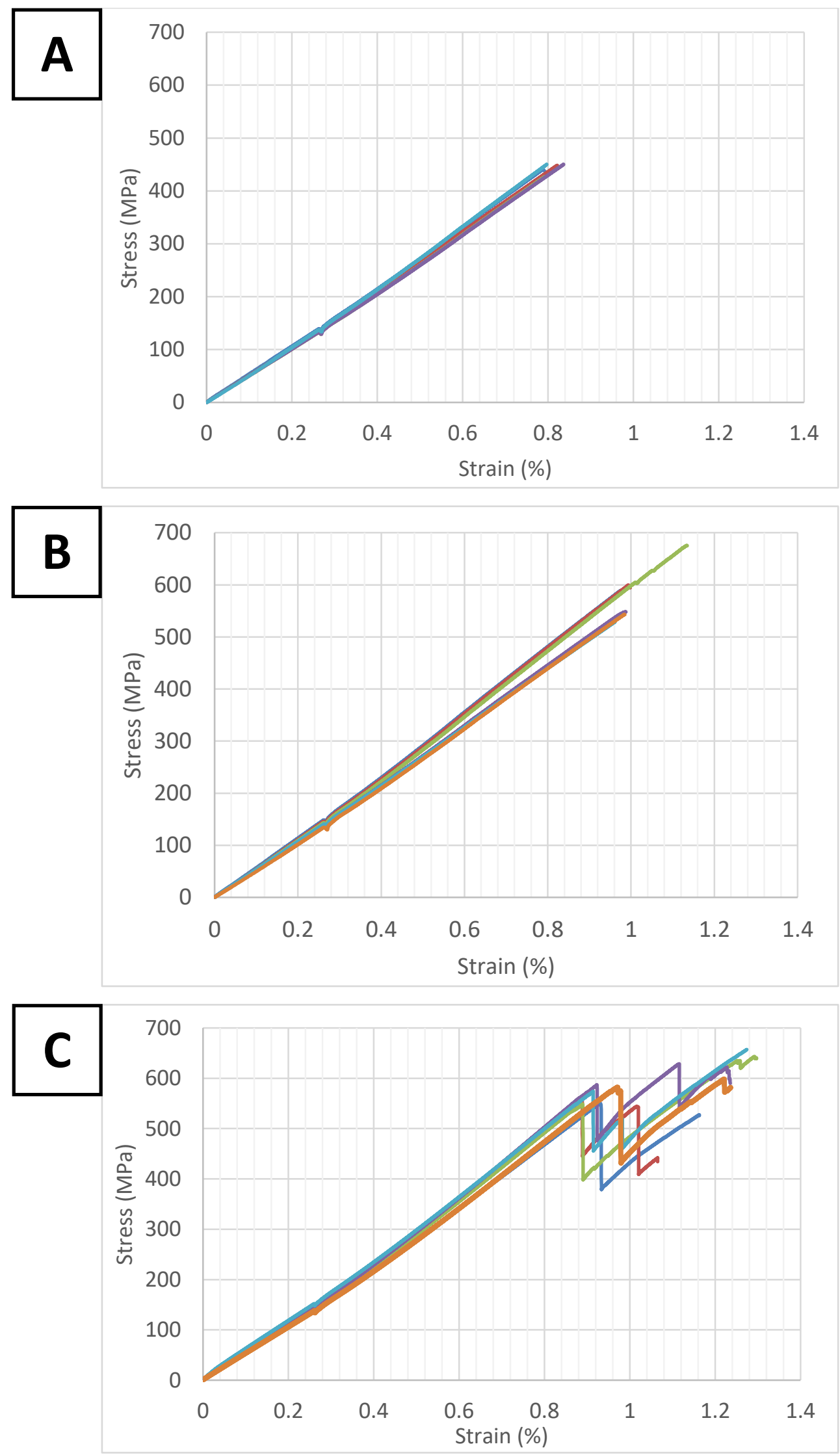

Figure 4.12 Stress/strain curves for QI open-hole tensile specimens: a) $50 \mathrm{~g} / \mathrm{m}^{2}$, b) $150 \mathrm{~g} / \mathrm{m}^{2}$, c) $300 \mathrm{~g} / \mathrm{m}^{2}$ 


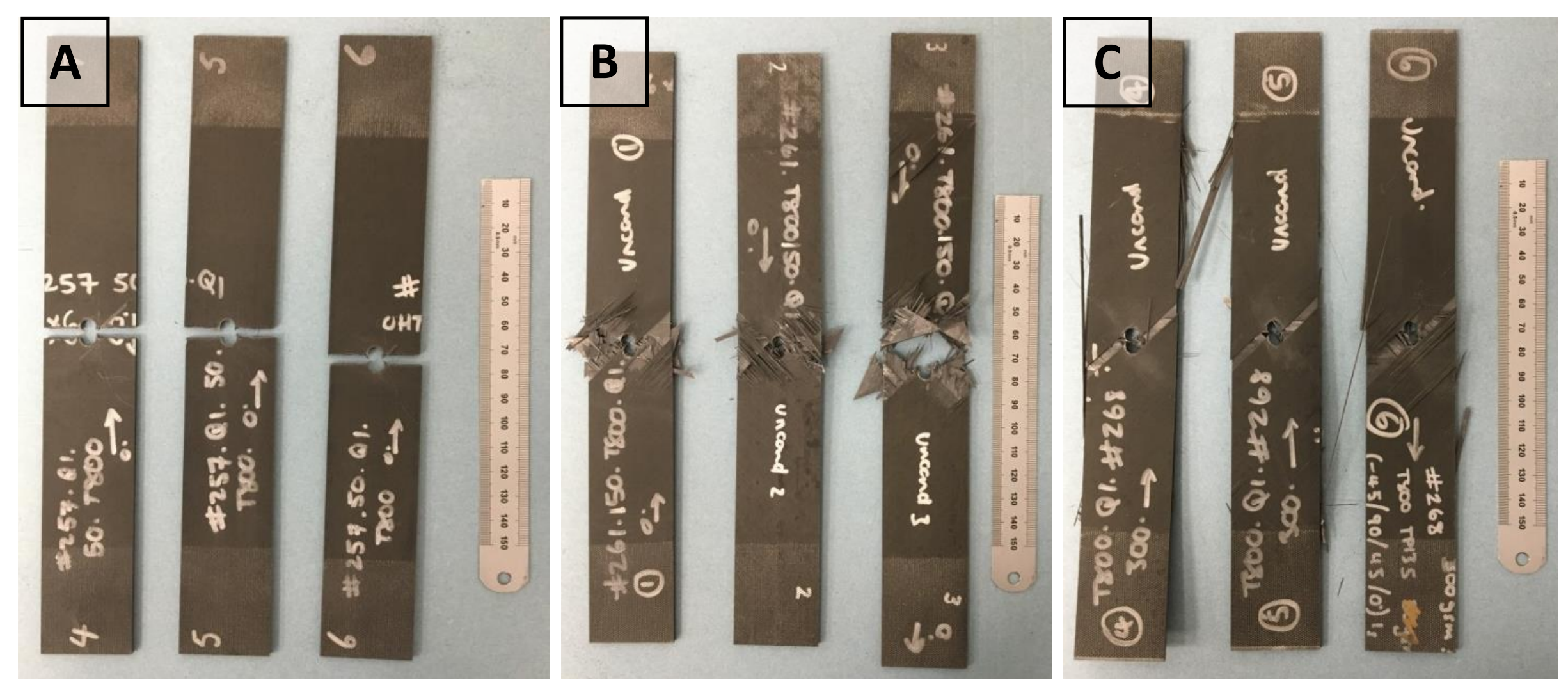

Figure 4.13 QI open-hole tensile failure modes: a) $50 \mathrm{~g} / \mathrm{m}^{2}$, b) $\left.150 \mathrm{~g} / \mathrm{m}^{2}, \mathrm{c}\right) 300 \mathrm{~g} / \mathrm{m}^{2}$ 
Table 4.9 Mean QI open-hole tensile stress, strain and modulus values (normalised) [set of six samples per material]

\begin{tabular}{|c|c|c|c|c|c|c|}
\hline & \multicolumn{2}{|c|}{ Max Stress (MPa) } & \multicolumn{2}{c|}{ Strain at break (\%) } & \multicolumn{2}{c|}{ Modulus (GPa) } \\
\hline Prepreg & Mean & $\begin{array}{c}\text { Standard } \\
\text { error }\end{array}$ & Mean & $\begin{array}{c}\text { Standard } \\
\text { error }\end{array}$ & Mean & $\begin{array}{c}\text { Standard } \\
\text { error }\end{array}$ \\
\hline $50 \mathrm{~g} / \mathrm{m}^{2}$ & 447 & 3.4 & 0.80 & 0.00 & 51.7 & 0.41 \\
\hline $150 \mathrm{~g} / \mathrm{m}^{2}$ & 551 & 17.0 & 1.0 & 0.01 & 51.5 & 0.53 \\
\hline $300 \mathrm{~g} / \mathrm{m}^{2}$ & 565 & 12.1 & 1.1 & 0.02 & 50.9 & 1.30 \\
\hline
\end{tabular}

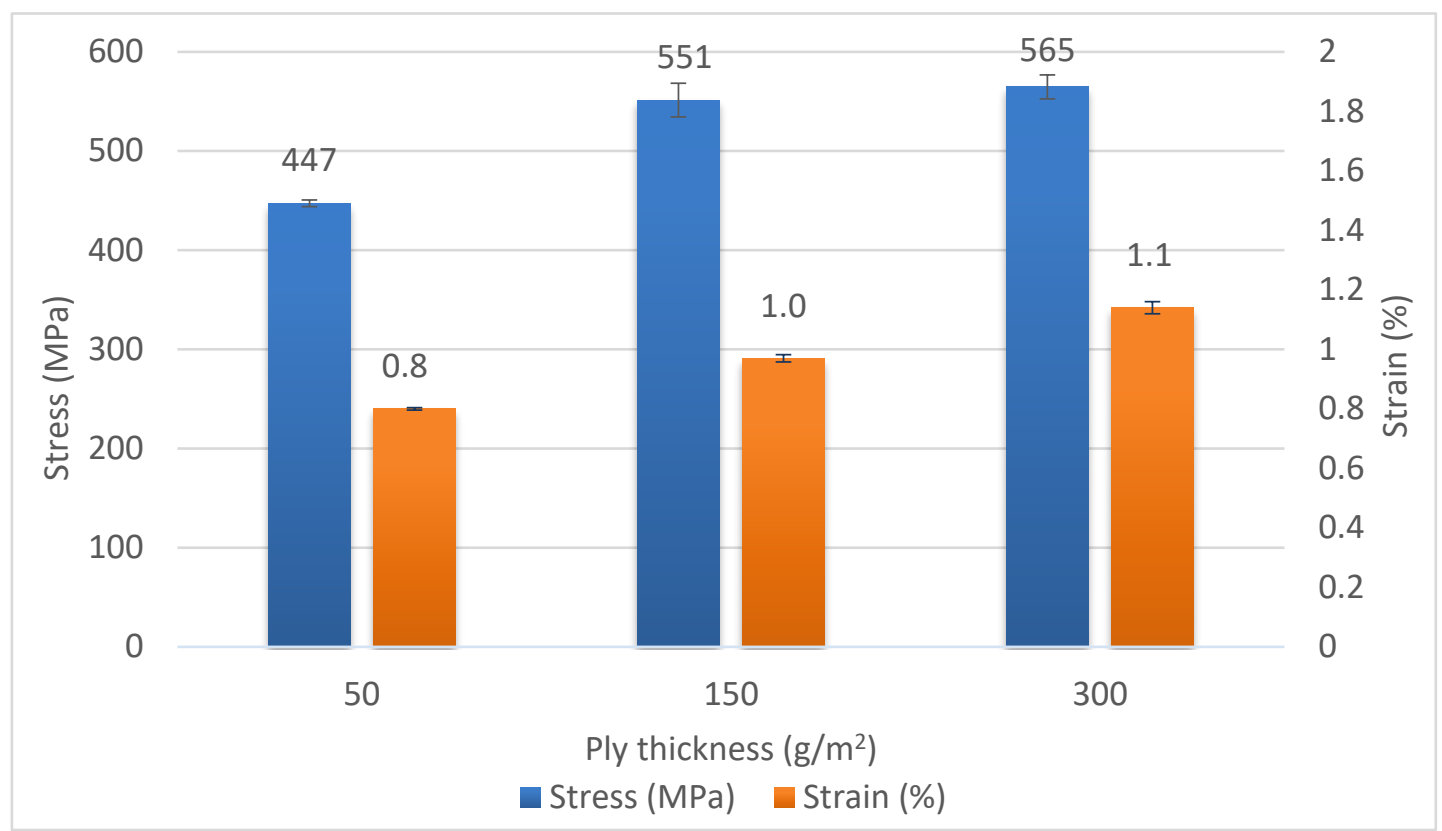

Figure 4.14 Mean QI open-hole stress and strain data (normalised) [set of six samples per material]

\subsubsection{Unidirectional Unnotched Compression (Combined Loading)}

Unidirectional samples $\left(50 \mathrm{~g} / \mathrm{m}^{2}\right.$ and $\left.150 \mathrm{~g} / \mathrm{m}^{2}\right)$ were tested in compression according to ASTM D6641M [102], which is a combined end and side loading compression test. The stress/strain curves are shown in Figure 4.15 and example failure modes are shown in Figure 4.16. The stress/strain curves display deformation based on crosshead displacement, not strain gauge data, due to issues with strain gauge bonding on a small number of samples. Modulus values were calculated using strain gauges on both faces of the test coupon. These values are based on four thin-ply samples and three intermediate-ply samples, due to 
the aforementioned issues with strain gauge bonding. The mean, normalised results are shown in Table 4.10. On average the thin-ply samples had a $9 \%$ lower compressive strength. This is the opposite trend to the results published by Amacher et al. [14]. The modulus results were found to be the same for the two materials.
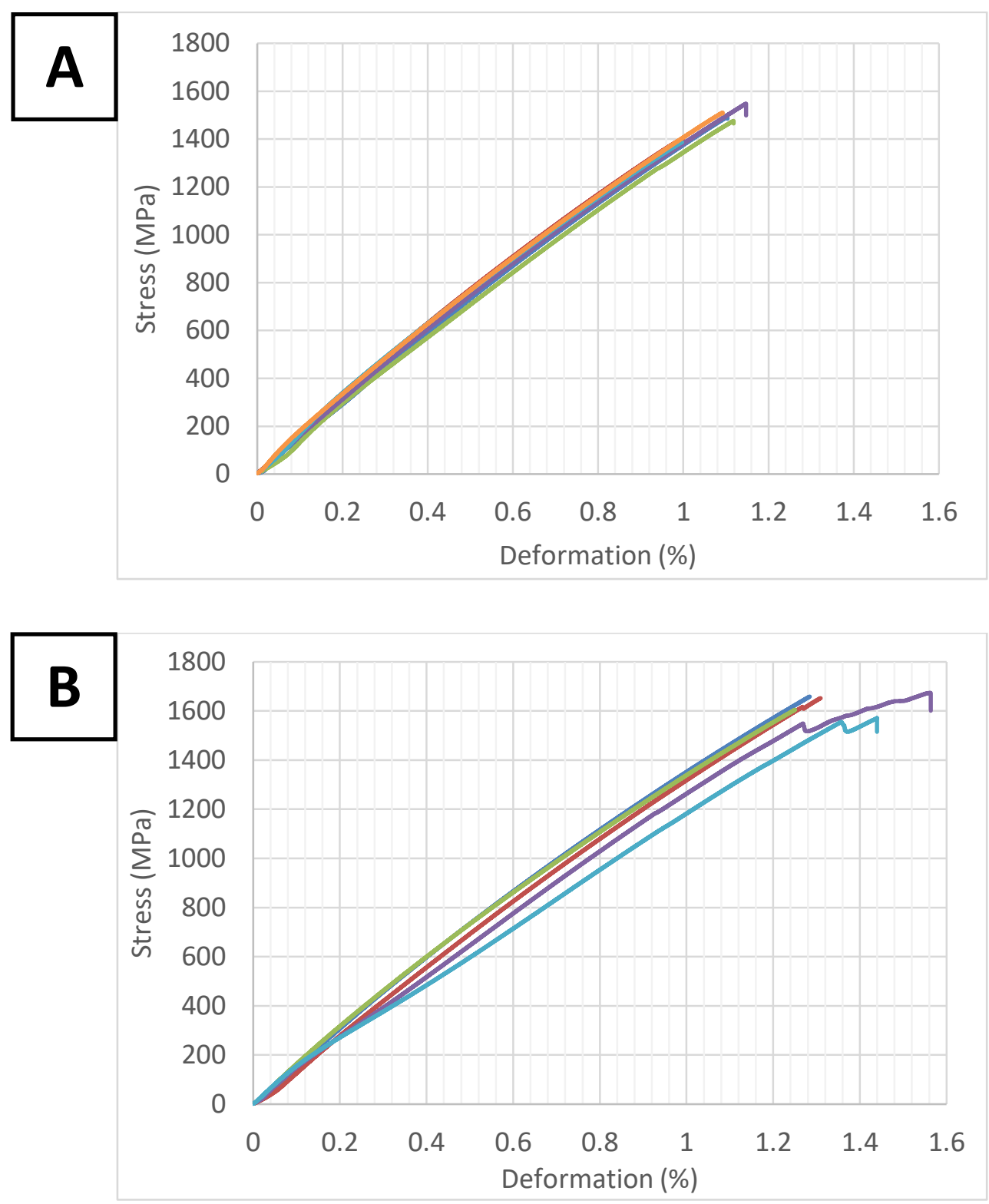

Figure 4.15 Stress/strain curves for $0^{\circ}$ unnotched compression specimens: a) $50 \mathrm{~g} / \mathrm{m}^{2}, b$ ) $150 \mathrm{~g} / \mathrm{m}^{2}$ (note: deformation based on crosshead displacement, not strain gauge data) 

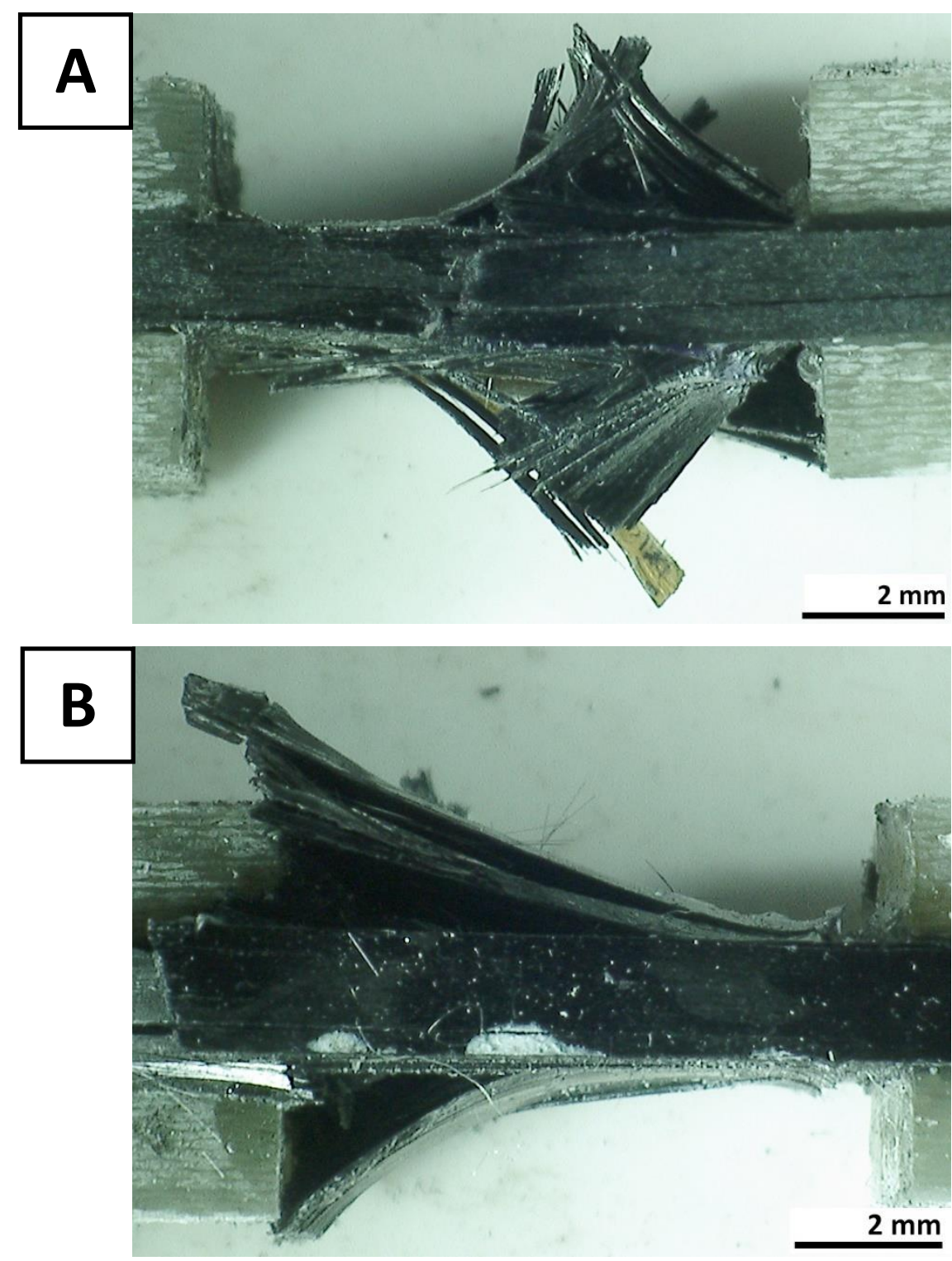

Figure $4.160^{\circ}$ unnotched compression failure modes: a) $50 \mathrm{~g} / \mathrm{m}^{2}$, b) $150 \mathrm{~g} / \mathrm{m}^{2}$

Table 4.10 Mean $0^{\circ}$ unnotched compressive stress and modulus values (normalised)

\begin{tabular}{|c|c|c|c|c|}
\hline \multirow{2}{*}{ Prepreg } & \multicolumn{2}{|c|}{ Max Stress (MPa) } & \multicolumn{2}{c|}{ Modulus (GPa) } \\
\cline { 2 - 5 } & Mean & $\begin{array}{c}\text { Standard } \\
\text { error }\end{array}$ & Mean & $\begin{array}{c}\text { Standard } \\
\text { error }\end{array}$ \\
\hline $50 \mathrm{~g} / \mathrm{m}^{2}$ & 1393 & 30.8 & 145.6 & 4.5 \\
\hline $150 \mathrm{~g} / \mathrm{m}^{2}$ & 1525 & 21.7 & 145.9 & 5.7 \\
\hline
\end{tabular}




\subsubsection{Quasi-isotropic Unnotched Compression (Combined Loading)}

Using the method described in ASTM D6641M [102], the compressive strength of QI thin-ply and intermediate-ply materials was tested. Strain gauges were not bonded to the samples, so only compressive strength values were obtained. Strain measurement from the crosshead movement was avoided, to mitigate the impact of system compliance (deformation of the load frame, load cell, and grips, as load is applied). If crosshead travel is used to calculate the deformation of the material, the deformation of the machine is also included, which can lead to errors [114].

In contrast to the unidirectional unnotched compressive results, the thin-ply material had a significantly greater compressive strength (an increase of $7 \%$ ). The normalised results are shown in Table 4.11. Images of example failure modes are shown in Figure 4.17.

Table 4.11 Mean QI unnotched compressive stress values (normalised) [set of five samples

\begin{tabular}{|c|c|c|}
\hline & per mater & \\
\hline \multirow{2}{*}{ Prepreg } & \multicolumn{2}{|c|}{ Compressive Strength (MPa) } \\
\hline & Mean & Standard error \\
\hline $50 \mathrm{~g} / \mathrm{m}^{2}$ & 769 & 10.4 \\
\hline $150 \mathrm{~g} / \mathrm{m}^{2}$ & 719 & 26.3 \\
\hline
\end{tabular}



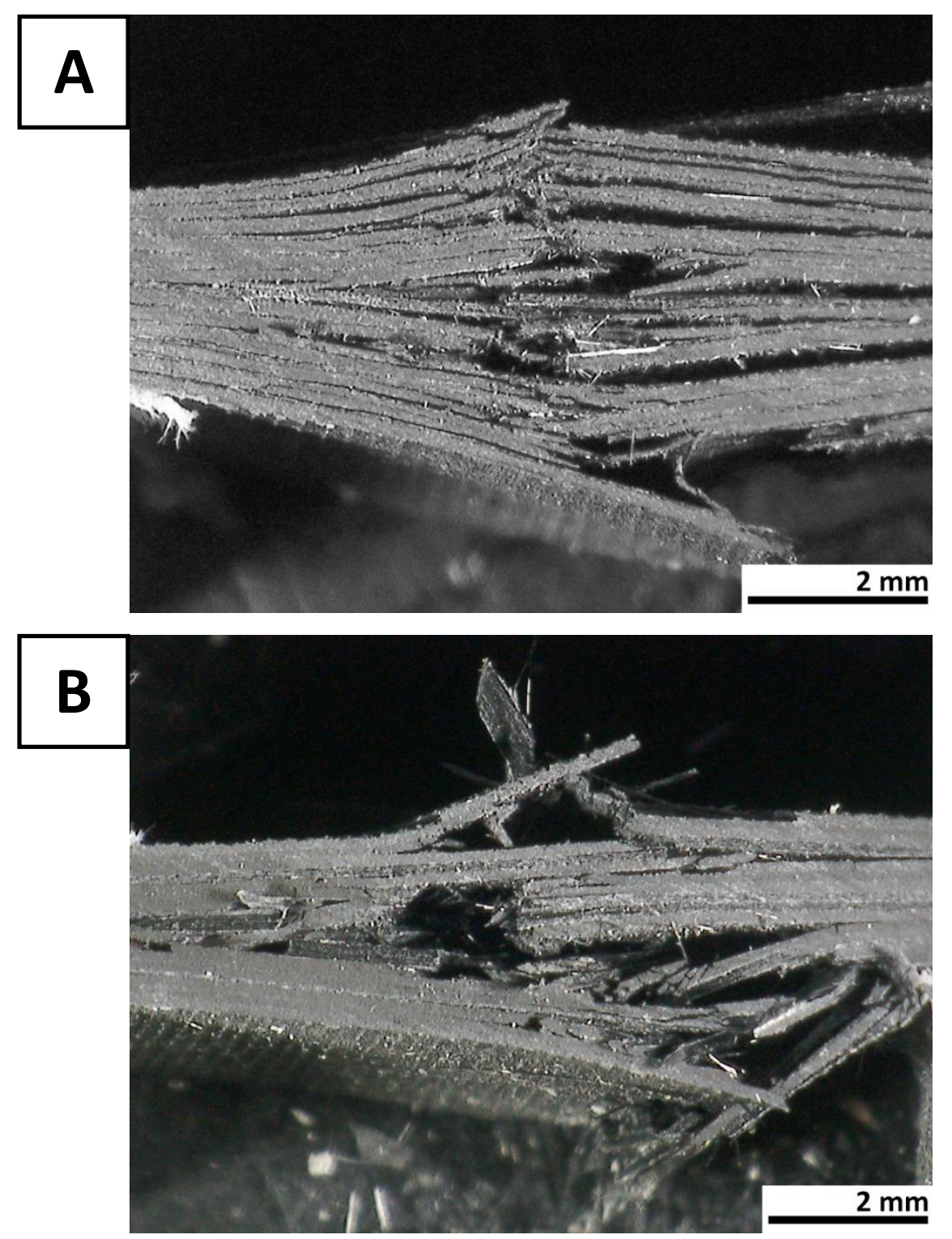

Figure 4.17 QI unnotched compression failure modes: a) $50 \mathrm{~g} / \mathrm{m}^{2}$, b) $150 \mathrm{~g} / \mathrm{m}^{2}$ 


\subsubsection{Quasi-isotropic Open-hole Compression}

The open-hole compressive properties of QI laminates made from the three different ply thicknesses was studied. Strain gauges were not bonded to the samples, so only compressive strength values were obtained. Figure 4.18 shows the typical failure modes for each material. The images, which refer to the sides of the specimens, display extensive delamination, particularly for the thicker ply samples. The $50 \mathrm{~g} / \mathrm{m}^{2}$ and the $150 \mathrm{~g} / \mathrm{m}^{2}$ samples produced valid failure modes (failure at the hole) without the need for end-tabs, however the $300 \mathrm{~g} / \mathrm{m}^{2}$ samples required end-tabbing to achieve valid results.

The mean results for the data are shown in Table 4.12. The results show a trend for increased open-hole compressive strength as laminate ply thickness decreases. The thinnest ply laminate had an increased strength of $13 \%$ and $33 \%$ compared to the intermediate and thick-ply laminates respectively. As was the case with the unnotched and open-hole tensile behaviour, the observed open-hole and unnotched compressive behaviour differ from each other. This time the trend is reversed - thin-ply performed better than the thicker ply material in open-hole compression than unnotched compression.

Table 4.12 Mean QI open-hole compressive stress values (normalised) [set of six samples per material]

\begin{tabular}{|c|c|c|}
\hline \multirow{2}{*}{ Prepreg } & \multicolumn{2}{|c|}{ Max Stress (MPa) } \\
\hline $50 \mathrm{~g} / \mathrm{m}^{2}$ & Mean & Standard error \\
\hline $150 \mathrm{~g} / \mathrm{m}^{2}$ & 304 & 6.8 \\
\hline $300 \mathrm{~g} / \mathrm{m}^{2}$ & 270 & 9.4 \\
\hline
\end{tabular}



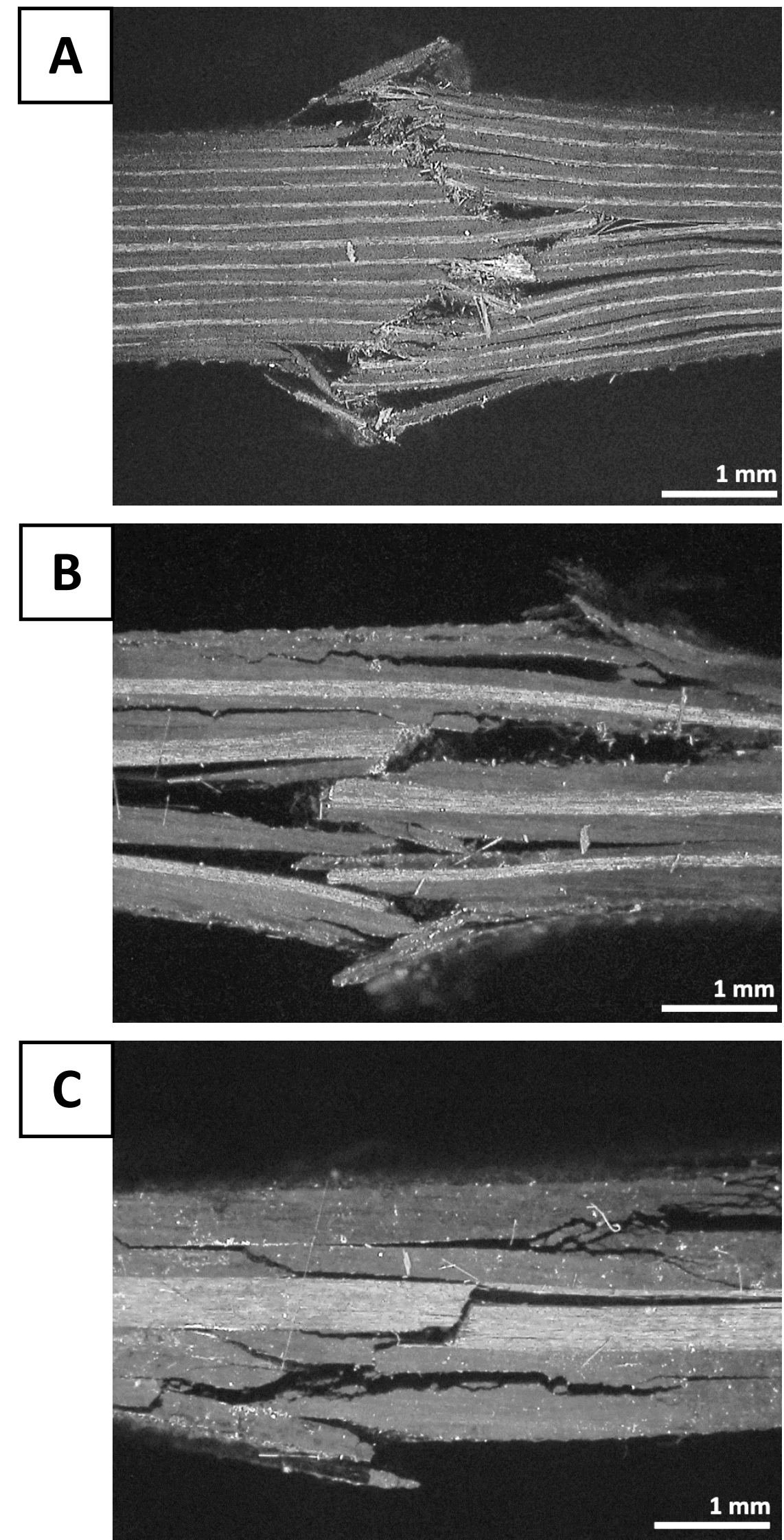

Figure 4.18 QI open-hole compression failure modes: a) $50 \mathrm{~g} / \mathrm{m}^{2}$, b) $150 \mathrm{~g} / \mathrm{m}^{2}$, c) $300 \mathrm{~g} / \mathrm{m}^{2}$ (note: images refer to the sides of the specimens) 


\subsubsection{Interlaminar Shear Stress (Unidirectional and Quasi-Isotropic)}

Interlaminar shear stress values for $0^{\circ}$ unidirectional and quasi-isotropic, thin-ply and intermediate-ply laminates were investigated. Interestingly, no interlaminar cracks were seen in any of the samples tested, even when examined under the microscope. Despite this, an obvious reduction in load was observed on the force/displacement graphs (Figure 4.19). It should be noted that only the unidirectional force/displacement curves are shown; the quasi-isotropic graphs show a very similar trend. A possible reason for the lack of visible cracks may be due to the matrix having a high toughness, meaning that the cracks cannot propagate. The mean results for the sets of six samples are shown in Table 4.13 and Figure 4.20. The results have not been normalised, due to the fact that the test is resin, not fibre, dominated. The unidirectional ILSS results were almost identical for the two prepreg thicknesses tested. On the contrary, the $50 \mathrm{~g} / \mathrm{m}^{2} \mathrm{QI}$ laminate had a $30 \%$ increase in interlaminar shear strength compared to the QI intermediate-ply specimens. 

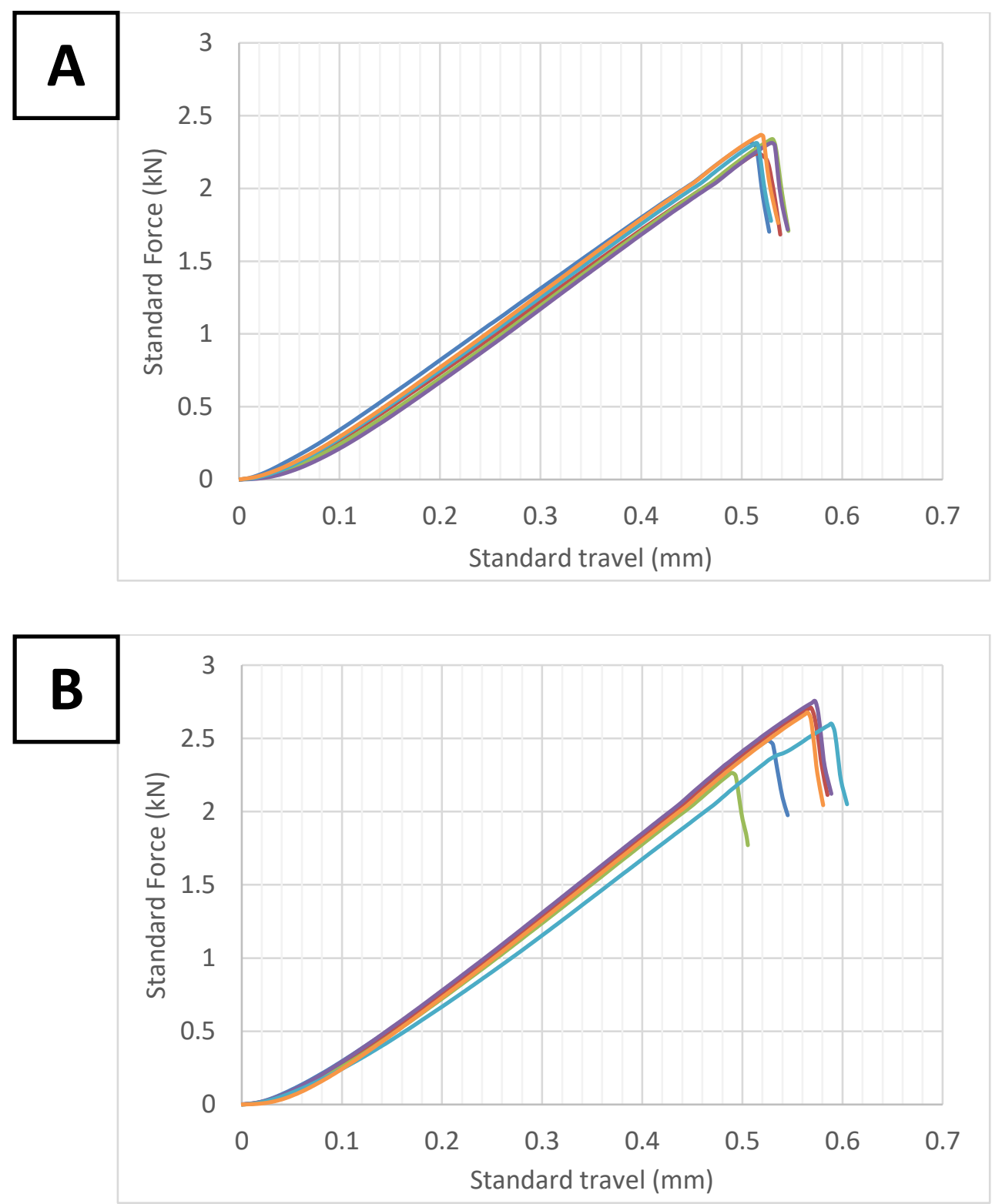

Figure 4.19 Forceldisplacement curves for $0^{\circ}$ ILSS specimens: a) $50 \mathrm{~g} / \mathrm{m}^{2}$, b) $150 \mathrm{~g} / \mathrm{m}^{2}$

Table 4.13 Mean $0^{\circ}$ and QI ILSS values (not normalised) [set of six samples per material]

\begin{tabular}{|c|c|c|c|c|}
\hline \multirow{2}{*}{ Prepreg } & \multicolumn{2}{|c|}{ UD ILSS (MPa) } & \multicolumn{2}{c|}{ QI ILSS (MPa) } \\
& Mean & $\begin{array}{c}\text { Standard } \\
\text { error }\end{array}$ & Mean & $\begin{array}{c}\text { Standard } \\
\text { error }\end{array}$ \\
\hline $50 \mathrm{~g} / \mathrm{m}^{2}$ & 105 & 1.0 & 87.3 & 1.3 \\
\hline $150 \mathrm{~g} / \mathrm{m}^{2}$ & 105 & 2.0 & 67.3 & 2.8 \\
\hline
\end{tabular}




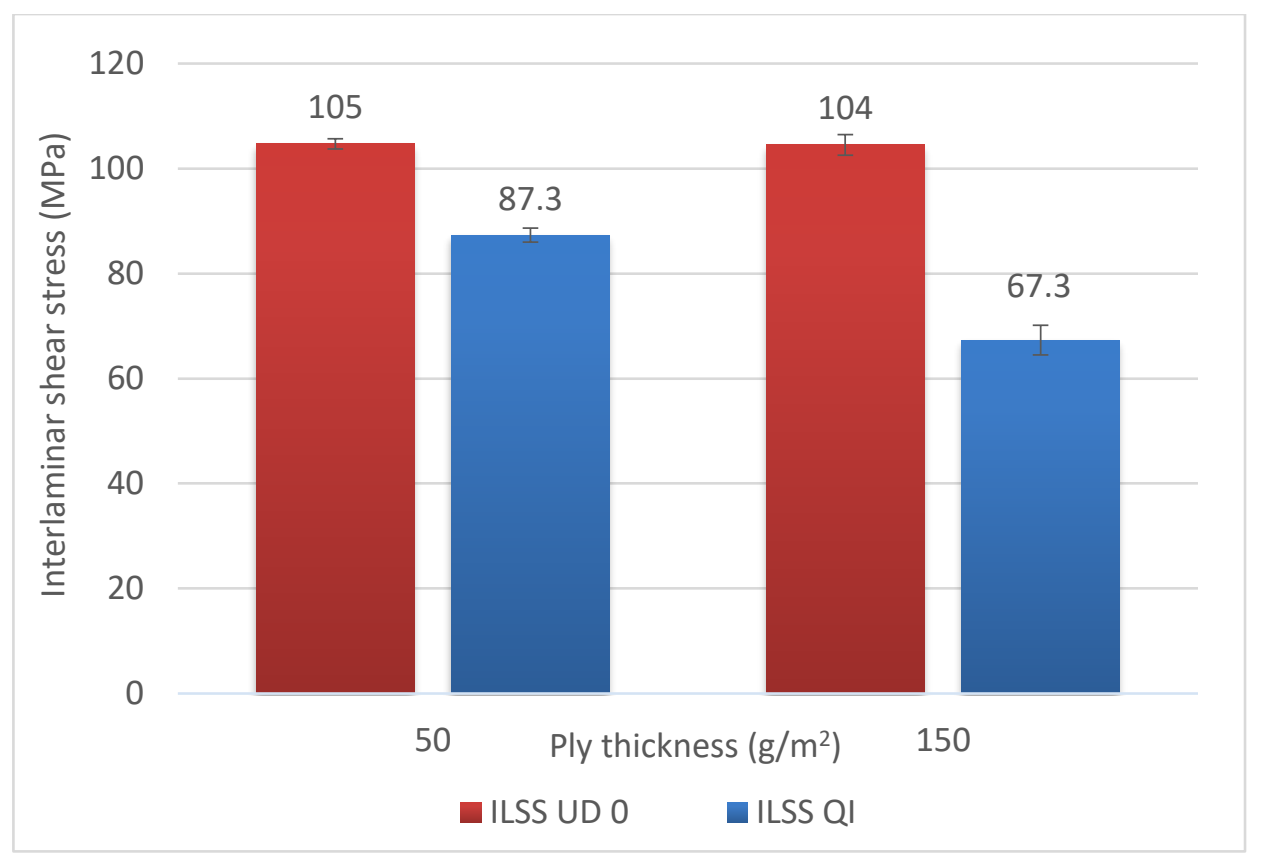

Figure 4.20 Mean $0^{\circ}$ and QI ILSS data (not normalised) [set of six samples per material]

\subsubsection{In-plane Shear $\left( \pm 45^{\circ}\right)$}

In-plane shear tests were performed on laminates with $\pm 45^{\circ}$ orientation in tension. A minimum of six coupons per ply thickness were tested. For the $50 \mathrm{~g} / \mathrm{m}^{2}$ and $150 \mathrm{~g} / \mathrm{m}^{2}$ samples, slipping of the bi-axial extensometer occurred on a number of samples. To overcome this, extra samples were tested, and the bi-axial extensometer was secured tighter onto the samples to avoid slips.

Some interesting differences occurred with changes to ply thickness. Firstly, the thin-ply specimens had a greater mean shear stress $(20 \%$ greater than the $300 \mathrm{~g} / \mathrm{m}^{2}$ coupons) and secondly the thick-ply coupons failed at a far lower strain compared to the thin-ply coupons. This is demonstrated in Figure 4.21, where it shows that the thick-ply coupons failed before reaching $5 \%$ strain. Only one sample for each FAW has been shown in this graph, to ensure the differences could be seen easily. 
Table 4.14 Mean in-plane shear stress and modulus values (not normalised)

\begin{tabular}{|c|c|c|c|c|}
\hline \multirow{2}{*}{ Prepreg } & \multicolumn{2}{|c|}{ Shear Stress (MPa) } & \multicolumn{2}{|c|}{ Shear Modulus (GPa) } \\
\cline { 2 - 5 } & Mean & $\begin{array}{c}\text { Standard } \\
\text { error }\end{array}$ & Mean & $\begin{array}{c}\text { Standard } \\
\text { error }\end{array}$ \\
\hline $50 \mathrm{~g} / \mathrm{m}^{2}$ & 97.2 & 1.0 & 5.98 & 0.22 \\
\hline $150 \mathrm{~g} / \mathrm{m}^{2}$ & 84.1 & 0.4 & 6.51 & 0.08 \\
\hline $300 \mathrm{~g} / \mathrm{m}^{2}$ & 80.9 & 2.0 & 7.27 & 0.09 \\
\hline
\end{tabular}

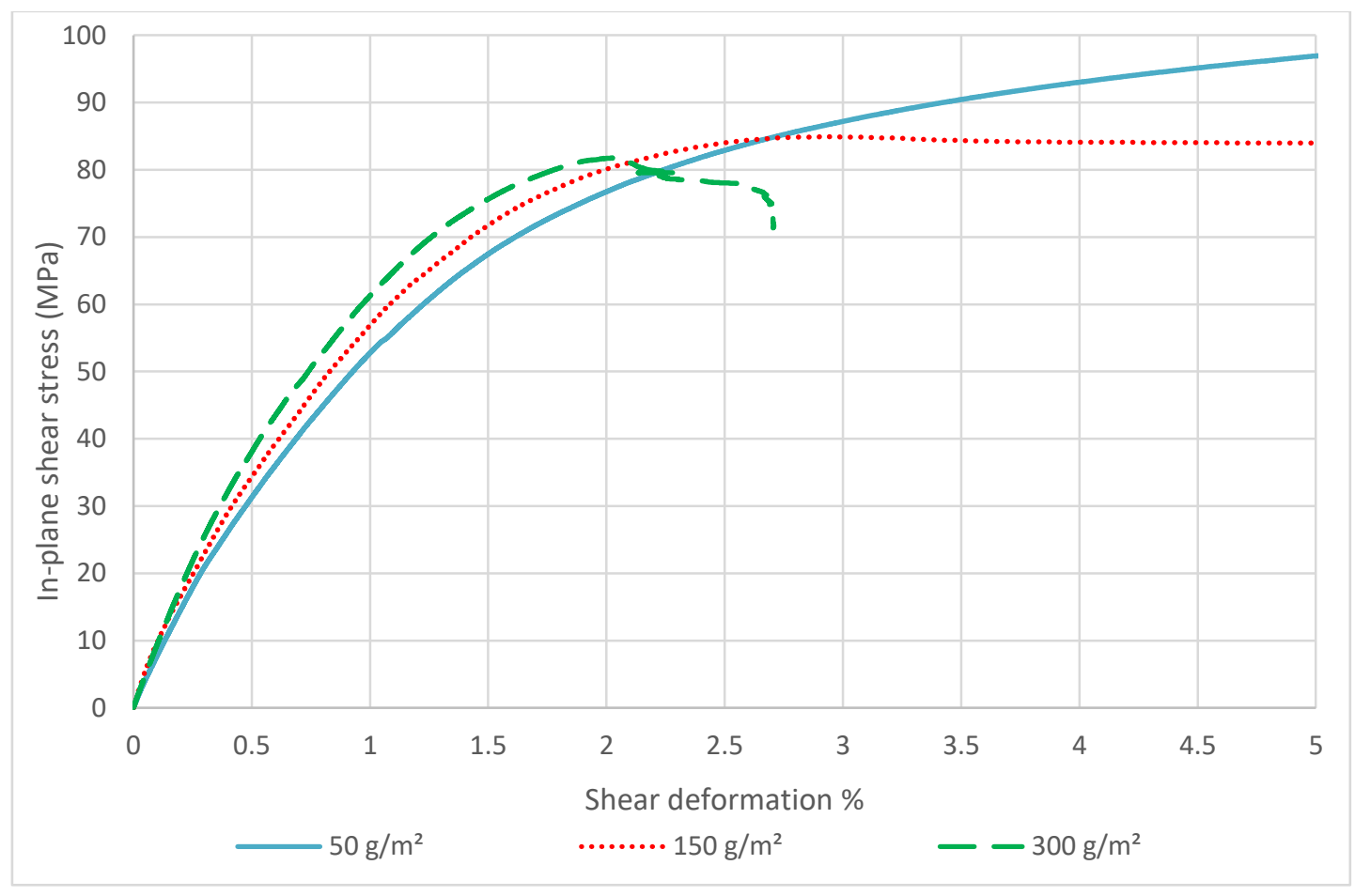

Figure 4.21 Example in-plane shear stress $/$ strain curves for $50 \mathrm{~g} / \mathrm{m}^{2}, 150 \mathrm{~g} / \mathrm{m}^{2}$ and $300 \mathrm{~g} / \mathrm{m}^{2}$ test coupons

\subsection{Tension-tension Fatigue Behaviour of Unconditioned Samples at Ambient Temperature}

Open-hole, tension-tension fatigue tests were conducted on the thin-ply and intermediate-ply material. The results of the tests were quite varied. For example, six $50 \mathrm{~g} / \mathrm{m}^{2}$ samples were tested at a maximum stress value of $400 \mathrm{MPa}$. Of these six tests, one sample reached the full 1,000,000 cycles, another reached 83,789, a third reached 454,524 cycles, a fourth reached 5,109 and the remaining two failed after less than 2,500 cycles. Hence, to produce a more reliable S-N curve, more 
data points would be needed. However, trends in the data can be observed in the S-N curves shown in Figure 4.22. The trend line for the thin-ply material has a lower gradient compared to the intermediate-ply samples, which suggests that the fatigue properties are maintained with increasing stress. The loads chosen for fatigue testing were based on the mean, quasi-static, open-hole tensile strengths for each material. The thin-ply material generally had a lower ultimate strength in quasi-static open-hole tension, hence the maximum applied fatigue stresses were lower. Figure 4.23 shows the same data, but on the $\mathrm{Y}$-axis the percentage of the mean, quasi-static, open-hole tensile stress has been plotted, instead of the maximum applied stress. This gives an indication of the fatigue properties for each material, in comparison to the quasi-static properties. Again, the trend line for the thin-ply material is shallower. In addition, it can be seen that the thin-ply material possibly has enhanced fatigue life at loads close to the quasi-static ultimate stress. More data points would be useful to confirm this. The failure mechanisms for the thin and intermediate-ply specimens were very similar to those seen with quasi-static testing; thin-ply had a brittle failure, whereas the intermediate-ply samples showed far more delamination damage.

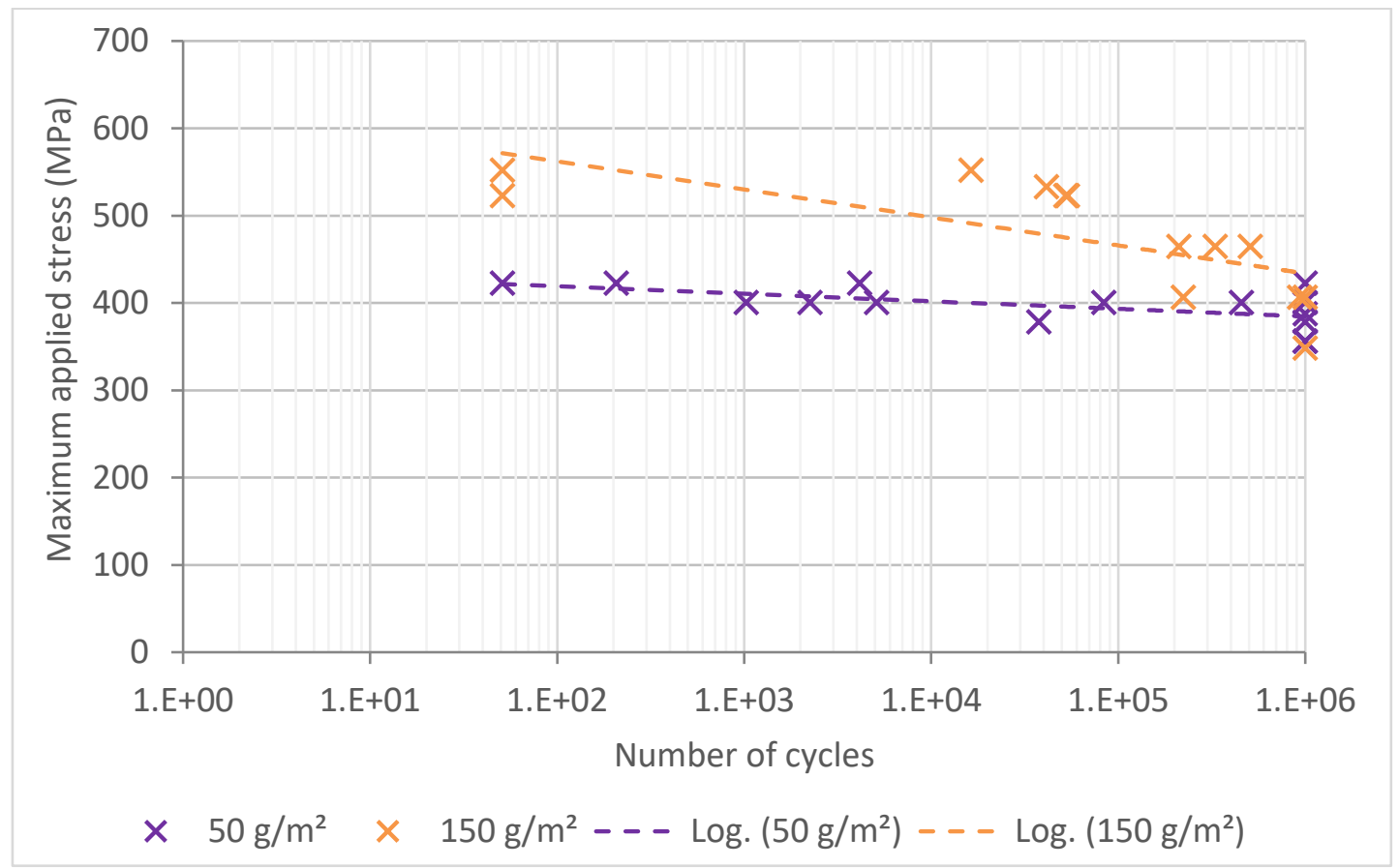

Figure $4.22 \mathrm{~S}-\mathrm{N}$ curve for $50 \mathrm{~g} / \mathrm{m}^{2}$ and $150 \mathrm{~g} / \mathrm{m}^{2}$ open-hole tension-tension fatigue samples 


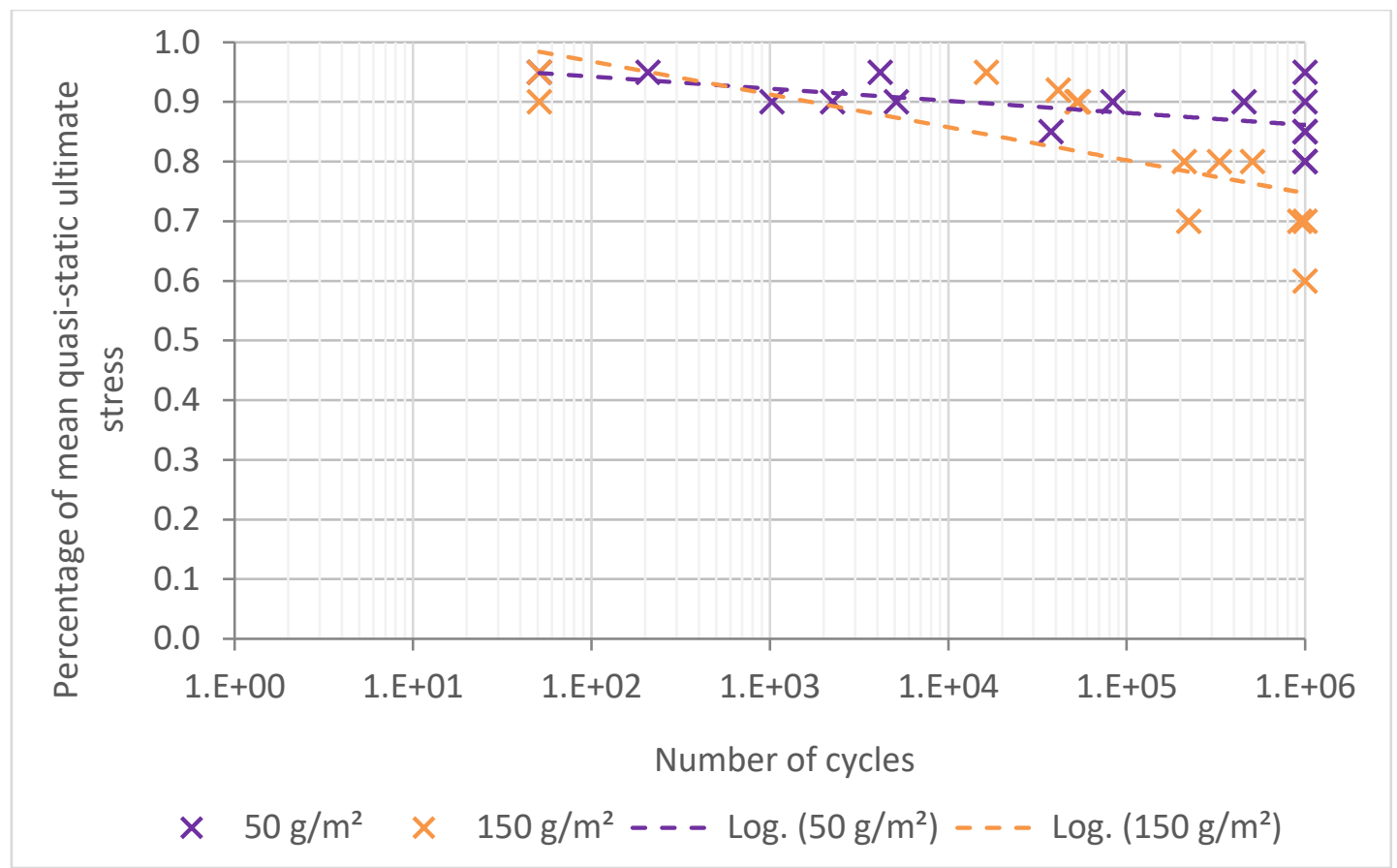

Figure 4.23 Percentage of mean, quasi-static, open-hole tensile stress verses number of cycles for $50 \mathrm{~g} / \mathrm{m}^{2}$ and $150 \mathrm{~g} / \mathrm{m}^{2}$ open-hole tension-tension fatigue samples

\subsection{Mechanical Behaviour of Unconditioned Samples at High Temperature}

It is known that the performance of polymer composites can deteriorate at high temperatures [98]. However, until now there has been little research into the effect of temperatures on materials made using thin-ply technology. Given the popularity of thin-ply materials, and the fact that thick and thin-ply materials have been shown to behave differently at room temperature, an investigation into the mechanical performance of thin-ply carbon fibre composites at high temperatures was conducted.

Two test temperatures were chosen, $+120^{\circ} \mathrm{C}$ and $+150{ }^{\circ} \mathrm{C}$. These were chosen due to the different glass transition temperatures for the thin, intermediate and thick-ply material (as discussed in Section 4.2.3). The $\mathrm{T}_{\mathrm{g}}$ for the thin-ply material was consistently higher, with a mean of $159^{\circ} \mathrm{C}$, compared to the intermediate and thick-ply panels where the mean $\mathrm{T}_{\mathrm{g}}$ was $147^{\circ} \mathrm{C}$ and $139{ }^{\circ} \mathrm{C}$ respectively. Therefore, it was hypothesised that the thin-ply samples would perform better 
than the thicker-ply samples at higher temperatures. Test methods where local stress transfer is important were used to investigate this, such as open-hole tension and unnotched tension tests. Methods which are too resin dominated were avoided, as this would dominate the effect of temperature.

\subsubsection{Quasi-isotropic Unnotched Tensile}

Figure 4.24 shows the mean tensile strength values for samples produced from the three different ply thicknesses, at three different test temperatures. There was no clear trend relating UTS and temperature for this data set. The $50 \mathrm{~g} / \mathrm{m}^{2}$ coupons increased in strength when tested at $120^{\circ} \mathrm{C}$, but decreased in strength at $150{ }^{\circ} \mathrm{C}$. The $150 \mathrm{~g} / \mathrm{m}^{2}$ and $300 \mathrm{~g} / \mathrm{m}^{2}$ samples followed different trends. The $150 \mathrm{~g} / \mathrm{m}^{2}$ coupons got progressively weaker as temperature increased, with a $9 \%$ decrease in strength between ambient and $150{ }^{\circ} \mathrm{C}$. On the other hand, the $300 \mathrm{~g} / \mathrm{m}^{2}$ samples increased in strength with increasing temperature. An increase of $23 \%$ was seen in UTS between the $300 \mathrm{~g} / \mathrm{m}^{2}$ unconditioned samples and those tested at $150{ }^{\circ} \mathrm{C}$.

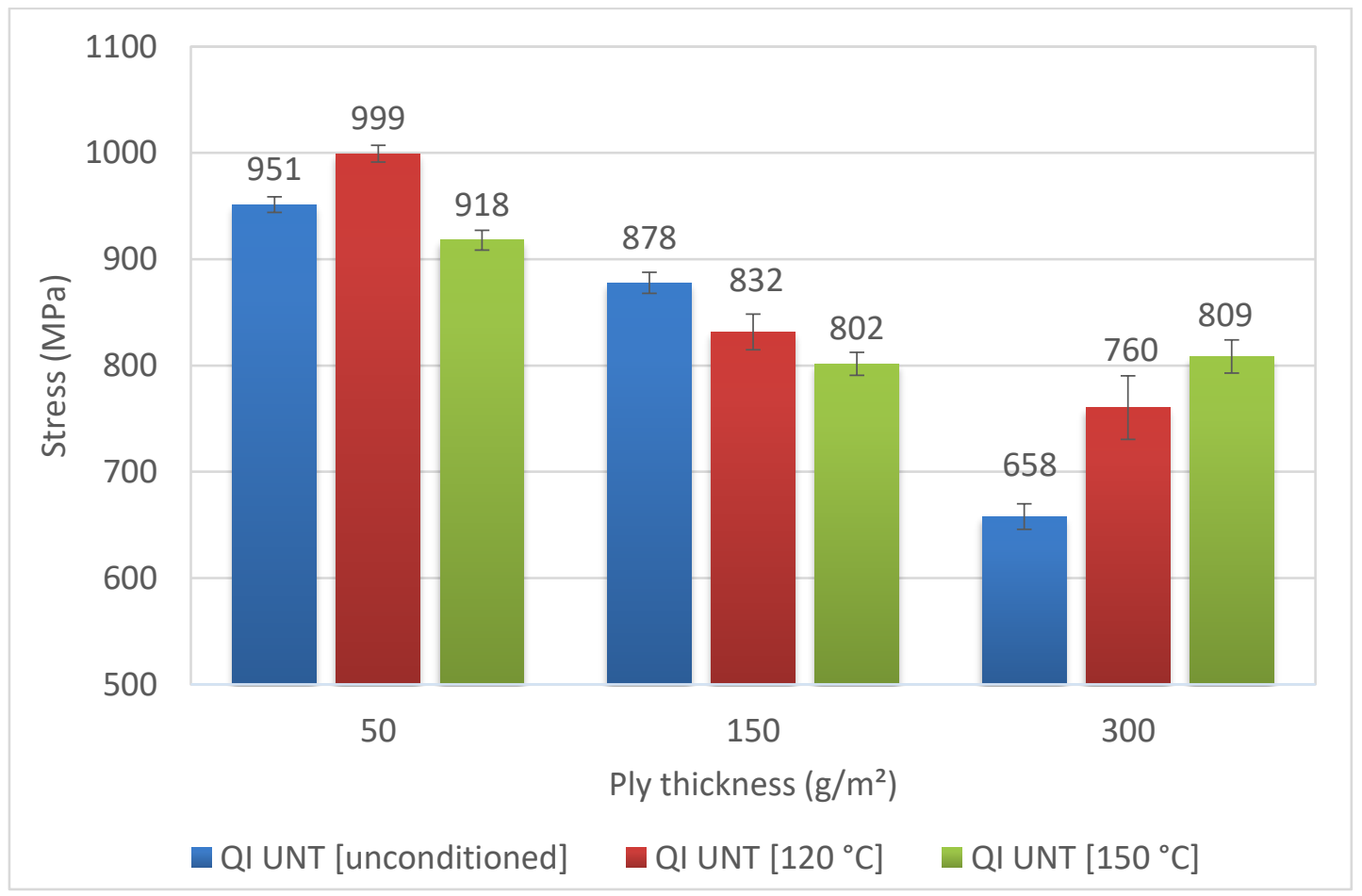

Figure 4.24 Mean QI unnotched tensile (UNT) stress data at various test temperatures (normalised) [minimum of 5 samples per test] 


\subsubsection{Quasi-isotropic Open-hole Tensile}

Figure 4.25 displays the mean tensile strength values for samples produced from varying ply thicknesses and tested at various temperatures. For this data set, there is a trend of increased UTS with increased temperature. The tensile strength of the $300 \mathrm{~g} / \mathrm{m}^{2}$ samples increased by $11 \%$ when tested at $150{ }^{\circ} \mathrm{C}$ compared to ambient temperature. The $150 \mathrm{~g} / \mathrm{m}^{2}$ samples also showed increased strength $(8 \%$ and $7 \%$ increase when tested at $150{ }^{\circ} \mathrm{C}$ and $120^{\circ} \mathrm{C}$ respectively). The tensile strength of the thin-ply samples only increased when tested at $150{ }^{\circ} \mathrm{C}(9 \%$ increase compared to ambient temperature). No significant increase was seen when tested at $120^{\circ} \mathrm{C}$.

The failure modes for the open-hole tensile tests at high temperatures were very similar to those at ambient temperature (see Section 4.3.4). As before, extensive delamination was seen along the entire length of the thick-ply samples, whereas the thinner ply samples failed in a far more brittle manner.

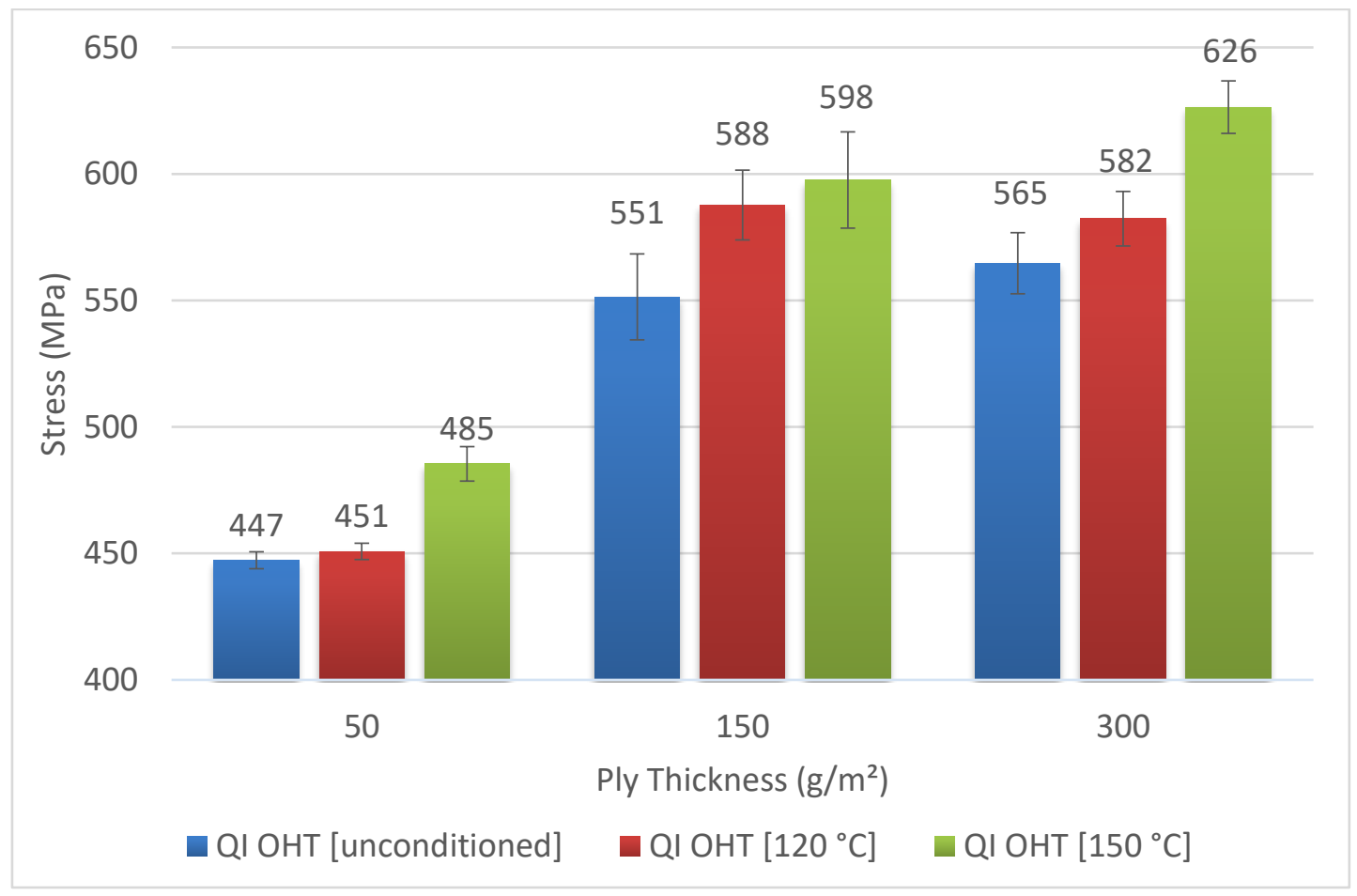

Figure 4.25 Mean QI open-hole tensile (OHT) stress data at various test temperatures (normalised) [minimum of 5 samples per test] 


\subsubsection{Quasi-isotropic Open-hole Compression}

Open-hole compression tests were performed on coupons made from $50 \mathrm{~g} / \mathrm{m}^{2}$ plies and $150 \mathrm{~g} / \mathrm{m}^{2}$ plies, at $120^{\circ} \mathrm{C}$ and $150{ }^{\circ} \mathrm{C}$. The mean results are shown in Figure 4.26. A minimum of five samples for each condition and ply thickness were tested. The results showed a clear trend of decreased compressive strength with increasing ply thickness, coupled with decreased strength with increasing test temperature. This behaviour is in contrast to the open-hole tensile performance (shown in Section 4.5.2). In tension, the strength of the QI open-hole coupons (for all of the ply thicknesses) increased with increasing ply thickness and increased with increasing test temperature.

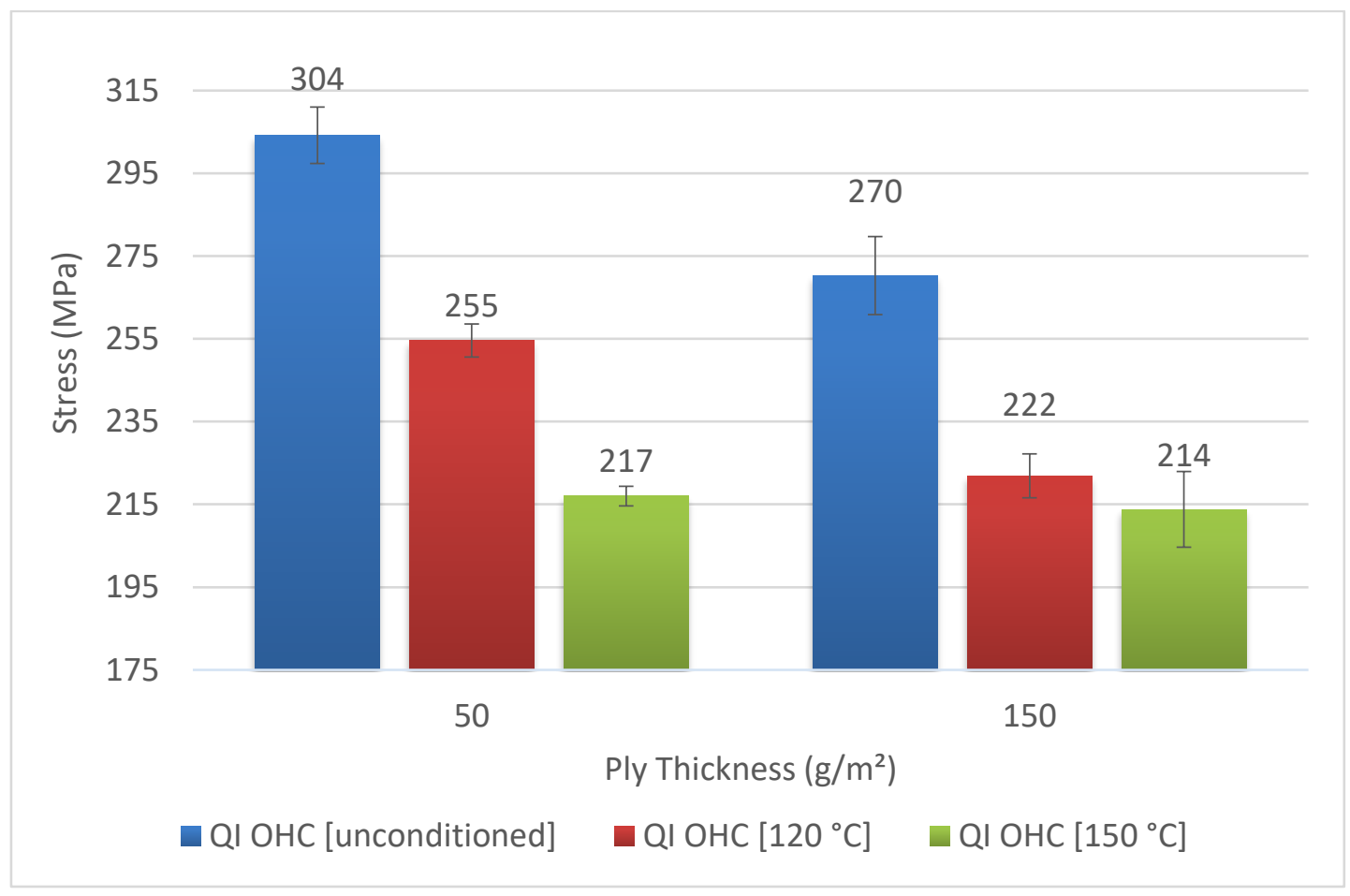

Figure 4.26 Mean QI open-hole compressive (OHC) stress values at various test temperatures (normalised) [minimum of five samples per test]

\subsection{Summary of Results}

The results discussed in this chapter have demonstrated the differences in mechanical properties for carbon fibre composites manufactured using different ply thicknesses. These results will now be summarised, to allow for a clear 
comparison of the results from different testing environments. A comprehensive discussion of the results is given in Chapter 6.

Table 4.15 to Table 4.17 collate the mean stress, strain and modulus values, for each ply thickness, test type and test environment. Numbers highlighted in pink are the values which are significantly greater for that particular test and condition. 
Table 4.15 Summary of maximum stress values for all unconditioned and high temperature tested samples (numbers highlighted in pink denote the values which are significantly greater for that particular test and condition). Fibre dominated test results have been normalised, as described in Section 3.2.2

\begin{tabular}{|c|c|c|c|c|c|c|c|}
\hline \multirow{3}{*}{ Test } & \multirow{3}{*}{ Condition } & \multicolumn{6}{|c|}{ Max stress (MPa) } \\
\hline & & \multicolumn{2}{|c|}{$50 \mathrm{~g} / \mathrm{m}^{2}$} & \multicolumn{2}{|c|}{$150 \mathrm{~g} / \mathrm{m}^{2}$} & \multicolumn{2}{|c|}{$300 \mathrm{~g} / \mathrm{m}^{2}$} \\
\hline & & Mean & $\begin{array}{c}\text { Standard } \\
\text { error }\end{array}$ & Mean & $\begin{array}{c}\text { Standard } \\
\text { error }\end{array}$ & Mean & $\begin{array}{c}\text { Standard } \\
\text { error }\end{array}$ \\
\hline Unnotched tensile $0^{\circ}$ & Unconditioned & 2705 & 48.6 & 2706 & 40.4 & - & - \\
\hline Unnotched tensile $90^{\circ}$ & Unconditioned & 53.9 & 4.75 & 49.8 & 3.32 & - & - \\
\hline \multirow{3}{*}{ Unnotched tensile QI } & Unconditioned & 951 & 7.4 & 878 & 9.9 & 658 & 12.0 \\
\hline & $+120^{\circ} \mathrm{C}$ & 999 & 7.9 & 832 & 16.8 & 760 & 29.9 \\
\hline & $+150{ }^{\circ} \mathrm{C}$ & 918 & 9.3 & 802 & 10.8 & 809 & 15.6 \\
\hline \multirow{3}{*}{ Open-hole tensile QI } & Unconditioned & 447 & 3.4 & 551 & 17.0 & 565 & 12.1 \\
\hline & $+120^{\circ} \mathrm{C}$ & 451 & 3.2 & 588 & 13.8 & 582 & 10.8 \\
\hline & $+150{ }^{\circ} \mathrm{C}$ & 485 & 6.8 & 598 & 19.0 & 626 & 10.4 \\
\hline \multirow{3}{*}{ Open-hole compression QI } & Unconditioned & 304 & 6.8 & 270 & 9.4 & 229 & 9.6 \\
\hline & $+120^{\circ} \mathrm{C}$ & 255 & 4.0 & 223 & 5.3 & - & - \\
\hline & $+150^{\circ} \mathrm{C}$ & 217 & 2.4 & 214 & 9.1 & - & - \\
\hline Unnotched compression $0^{\circ}$ & Unconditioned & 1393 & 30.8 & 1525 & 21.7 & - & - \\
\hline Unnotched compression QI & Unconditioned & 769 & 10.4 & 719 & 26.3 & - & - \\
\hline $\operatorname{ILSS} 0^{\circ}$ & Unconditioned & 105 & 1.0 & 105 & 2.0 & - & - \\
\hline ILSS QI & & 87.3 & 1.3 & 67.3 & 2.8 & - & - \\
\hline In-plane shear & Unconditioned & 97.2 & 1.0 & 84.1 & 0.4 & 80.9 & 2.0 \\
\hline
\end{tabular}


Table 4.16 Summary of strain at break values for all unconditioned and high temperature tested samples (numbers highlighted in pink denote the values which are significantly greater for that particular test and condition)

\begin{tabular}{|c|c|c|c|c|c|c|c|}
\hline \multirow{3}{*}{ Test } & \multirow{3}{*}{ Condition } & \multicolumn{6}{|c|}{ Strain at break (\%) } \\
\hline & & \multicolumn{2}{|c|}{$50 \mathrm{~g} / \mathrm{m}^{2}$} & \multicolumn{2}{|c|}{$150 \mathrm{~g} / \mathrm{m}^{2}$} & \multicolumn{2}{|c|}{$300 \mathrm{~g} / \mathrm{m}^{2}$} \\
\hline & & Mean & $\begin{array}{c}\text { Standard } \\
\text { error }\end{array}$ & Mean & $\begin{array}{c}\text { Standard } \\
\text { error }\end{array}$ & Mean & $\begin{array}{c}\text { Standard } \\
\text { error }\end{array}$ \\
\hline Unnotched tensile $0^{\circ}$ & Unconditioned & 1.8 & 0.04 & 1.6 & 0.07 & - & - \\
\hline Unnotched tensile $90^{\circ}$ & Unconditioned & 0.61 & 0.05 & 0.54 & 0.04 & - & - \\
\hline \multirow{3}{*}{ Unnotched tensile QI } & Unconditioned & 1.5 & 0.05 & 1.5 & 0.02 & 1.1 & 0.05 \\
\hline & $+120^{\circ} \mathrm{C}$ & 1.3 & 0.04 & 1.2 & 0.08 & 1.1 & 0.06 \\
\hline & $+150{ }^{\circ} \mathrm{C}$ & 1.4 & 0.08 & 1.1 & 0.07 & 1.1 & 0.02 \\
\hline \multirow{3}{*}{ Open-hole tensile QI } & Unconditioned & 0.80 & 0.00 & 0.97 & 0.01 & 1.1 & 0.02 \\
\hline & $+120^{\circ} \mathrm{C}$ & 0.84 & 0.02 & 1.1 & 0.02 & 1.7 & 0.03 \\
\hline & $+150{ }^{\circ} \mathrm{C}$ & 0.89 & 0.02 & 1.1 & 0.05 & 1.6 & 0.03 \\
\hline
\end{tabular}


Table 4.17 Summary of modulus values for all unconditioned and high temperature tested samples (numbers highlighted in pink denote the values which are significantly greater for that particular test and condition)

\begin{tabular}{|c|c|c|c|c|c|c|c|}
\hline \multirow{3}{*}{ Test } & \multirow{3}{*}{ Condition } & \multicolumn{6}{|c|}{ Modulus (GPa) } \\
\hline & & \multicolumn{2}{|c|}{$50 \mathrm{~g} / \mathrm{m}^{2}$} & \multicolumn{2}{|c|}{$150 \mathrm{~g} / \mathrm{m}^{2}$} & \multicolumn{2}{|c|}{$300 \mathrm{~g} / \mathrm{m}^{2}$} \\
\hline & & Mean & $\begin{array}{l}\text { Standard } \\
\text { error }\end{array}$ & Mean & $\begin{array}{c}\text { Standard } \\
\text { error }\end{array}$ & Mean & $\begin{array}{c}\text { Standard } \\
\text { error }\end{array}$ \\
\hline Unnotched tensile $0^{\circ}$ & Unconditioned & 167 & 2.0 & 173 & 6.3 & - & - \\
\hline Unnotched tensile $90^{\circ}$ & Unconditioned & 9.13 & 0.08 & 9.34 & 0.07 & - & - \\
\hline \multirow{3}{*}{ Unnotched tensile QI } & Unconditioned & 62.5 & 2.0 & 60.1 & 0.5 & 62.2 & 1.0 \\
\hline & $+120^{\circ} \mathrm{C}$ & 61.0 & 1.27 & 57.3 & 1.22 & 60.3 & 3.62 \\
\hline & $+150^{\circ} \mathrm{C}$ & 61.7 & 8.36 & 57.1 & 2.24 & 56.2 & 1.57 \\
\hline \multirow{3}{*}{ Open-hole tensile QI } & Unconditioned & 51.7 & 0.41 & 51.5 & 0.53 & 50.9 & 1.30 \\
\hline & $+120^{\circ} \mathrm{C}$ & 50.5 & 1.10 & 48.9 & 0.78 & 46.7 & 0.57 \\
\hline & $+150{ }^{\circ} \mathrm{C}$ & 51.2 & 0.82 & 48.4 & 1.55 & 44.7 & 1.02 \\
\hline Unnotched compression $0^{\circ}$ & Unconditioned & 145.6 & 4.5 & 145.9 & 5.7 & - & - \\
\hline In-plane Shear & Unconditioned & 5.98 & 0.22 & 6.51 & 0.08 & 7.27 & 0.09 \\
\hline
\end{tabular}


5 Investigation into the Effect of Moisture on the Behaviour of Thin-ply Carbon Fibre Composites 


\subsection{Introduction}

Epoxy resins are well known to be affected by moisture ingress during their lifetime. Water absorption can lead to plasticisation of the matrix which, in turn, can cause a reduction of mechanical properties [84],[92]. There is little documented research into the effect of moisture ingress on thin-ply materials. It has been shown previously that thin-ply materials have a more uniform microstructure than composites made from thicker plies [14]. This more uniform layout of fibre and resin could affect the process of moisture ingress. The resin matrix within the composite is the component which absorbs most of the water (the fibre will absorb very little in comparison). Therefore, having less resin rich areas could help reduce the rate of ingress of water.

An investigation into the effect of ply thickness on both moisture diffusion rate and mechanical properties was conducted, to try and understand the behaviour of thin-ply materials when exposed to water.

\subsection{Investigation into the Effect of Ply Thickness on Moisture Ingress}

To begin the investigation into the effect of moisture on thin-ply carbon fibre composites, a comprehensive moisture ingress study was conducted. The purpose of this study was to monitor the moisture content of samples made from different ply thicknesses when exposed to different humidity. This enabled diffusion coefficients to be calculated, and thus an assessment of the effect of ply thickness on moisture ingress.

An outline of the materials used and the experimental procedure is provided in Section 3.5. 


\subsubsection{Vacuum Drying}

As described in Section 3.5, before analysing moisture ingress it is important to ensure that all of the samples start at the same level of moisture content. To achieve this the samples were placed in a vacuum oven until dry. Figure 5.1 shows a graph of the percentage mass loss over time.

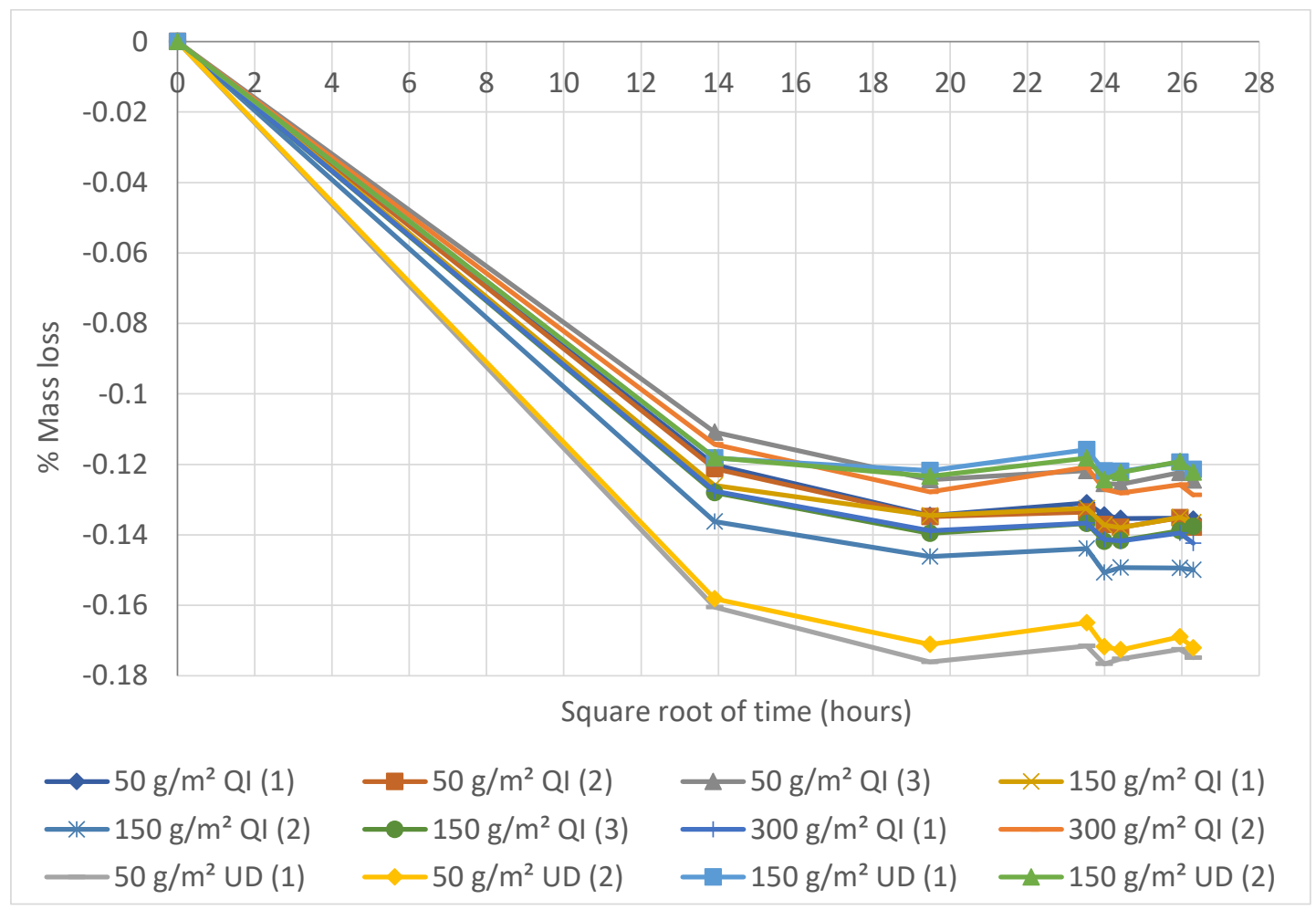

Figure 5.1 Vacuum oven drying of T800 TP135 to a constant mass

After approximately 28 days of vacuum drying, sample masses were found to be consistent over three consecutive readings. At this point the samples were deemed ready to begin conditioning. Figure 5.1 shows that most samples had a mass loss of between $0.12 \%$ and $0.15 \%$. Panels 273 and 274 had a greater percentage mass loss compared to the rest of the samples. These panels were slightly thinner than the rest, so it is likely that they absorbed more moisture at ambient conditions and therefore had a greater percentage mass loss. The slight mass increase seen at 23.5 square root hours is due to a loss of vacuum in the oven. 


\subsubsection{Monitoring the Effect of Ply Thickness on Moisture Ingress}

After drying, the samples were placed into environmental chambers to begin conditioning. Three different conditioning environments were used, $85 \% \mathrm{RH} / 70{ }^{\circ} \mathrm{C}, 65 \% \mathrm{RH} / 70{ }^{\circ} \mathrm{C}$ and $45 \% \mathrm{RH} / 70{ }^{\circ} \mathrm{C}$. The aim was to investigate the effect of ply thickness on moisture ingress, using different levels of moisture content. A conditioning temperature of $70^{\circ} \mathrm{C}$ was used to speed up the moisture ingress process.

Each sample was weighed periodically. The graph in Figure 5.2 displays the mean results for each QI material and conditioning environment; Figure 5.3 shows the equivalent data for the UD panels. The percentage mass gain has been plotted against the square root of time divided by the mean thickness of the samples. Dividing the square root of time elapsed by thickness removes the influence of sample thickness from the data. The reduction in percentage mass loss seen on the $45 \%$ RH results is due to a technical issue with the environmental chamber, which resulted in the relative humidity of the chamber dropping below $45 \%$ for a maximum of four days.

The graphs show several different trends. Firstly, the samples display an initial Fickian diffusion behaviour. Following this, instead of maintaining a maximum saturation level, the samples continue to slowly absorb water. Similar behaviour has been noted before and has been attributed to polymer relaxation $[84,87,91]$. Furthermore, the thin-ply material absorbed a higher moisture content compared to the thicker-ply materials. This is most noticeable for the quasi-isotropic samples, but also occurs with the unidirectional laminates. For the UD laminates, the increased moisture content may be related to differences in fibre volume fraction. As shown in Table 4.1, the mean fibre volume fraction for the $50 \mathrm{~g} / \mathrm{m}^{2}$ UD material was $61.4 \%$, compared to $63.7 \%$ for the $150 \mathrm{~g} / \mathrm{m}^{2}$ material. Thus, the greater proportion of resin in the thin-ply samples may account for this difference. The difference in moisture absorption for the QI laminates is greater than that 
seen for the UD laminates. Again, the QI laminates differed in fibre volume fraction $(60.0 \%$ for thin-ply, $63.1 \%$ for intermediate-ply and $62.9 \%$ for thick-ply), however it is thought that the moisture absorption difference is greater than would be expected for the differences in fibre volume fraction. It is not known why this larger water increase occurred. 


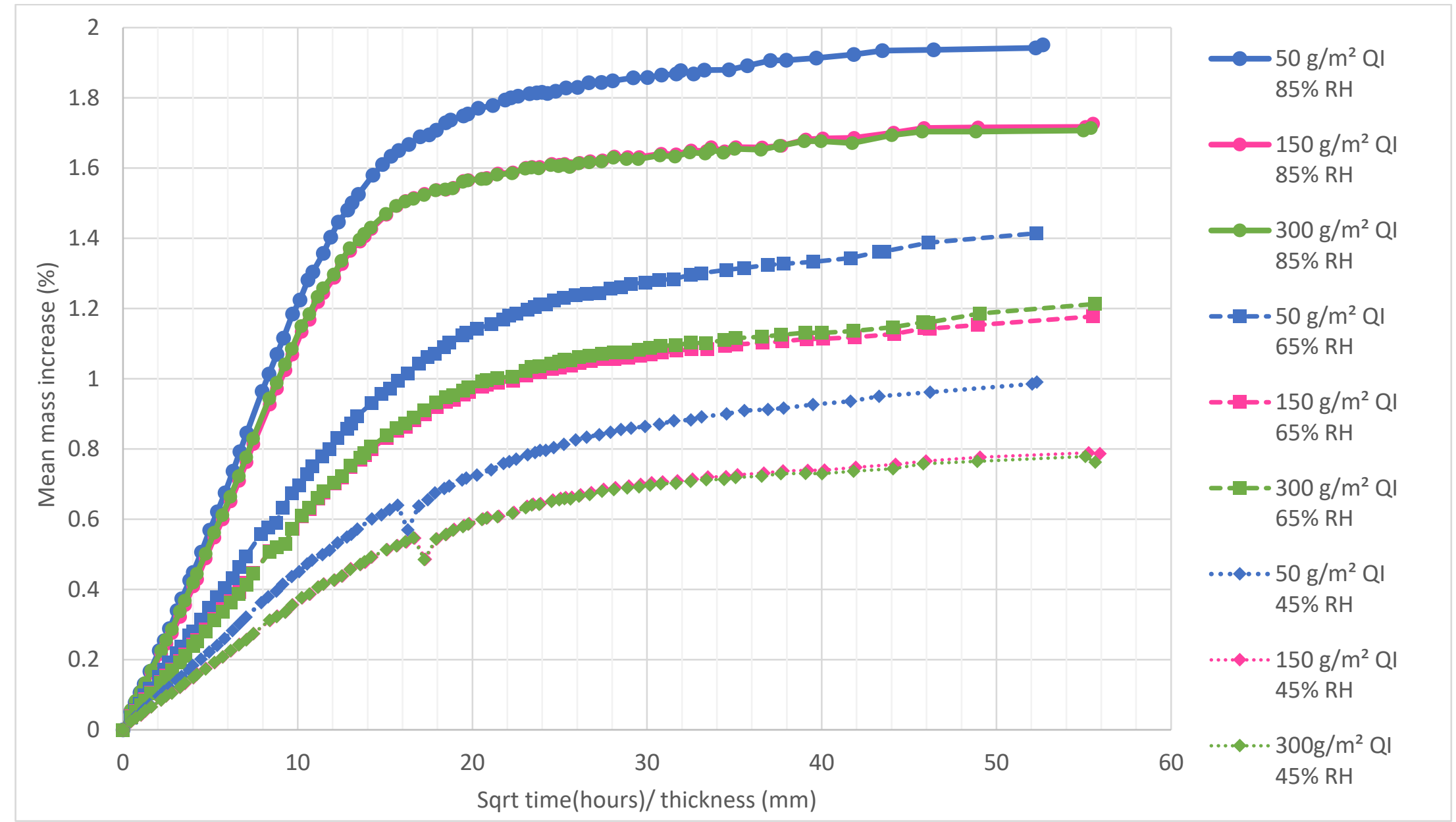

Figure 5.2 Mean percentage mass increase for QI T800 TP135 material manufactured using varying ply thicknesses and conditioned at $70{ }^{\circ} \mathrm{C}$ with different relative humidity environments 


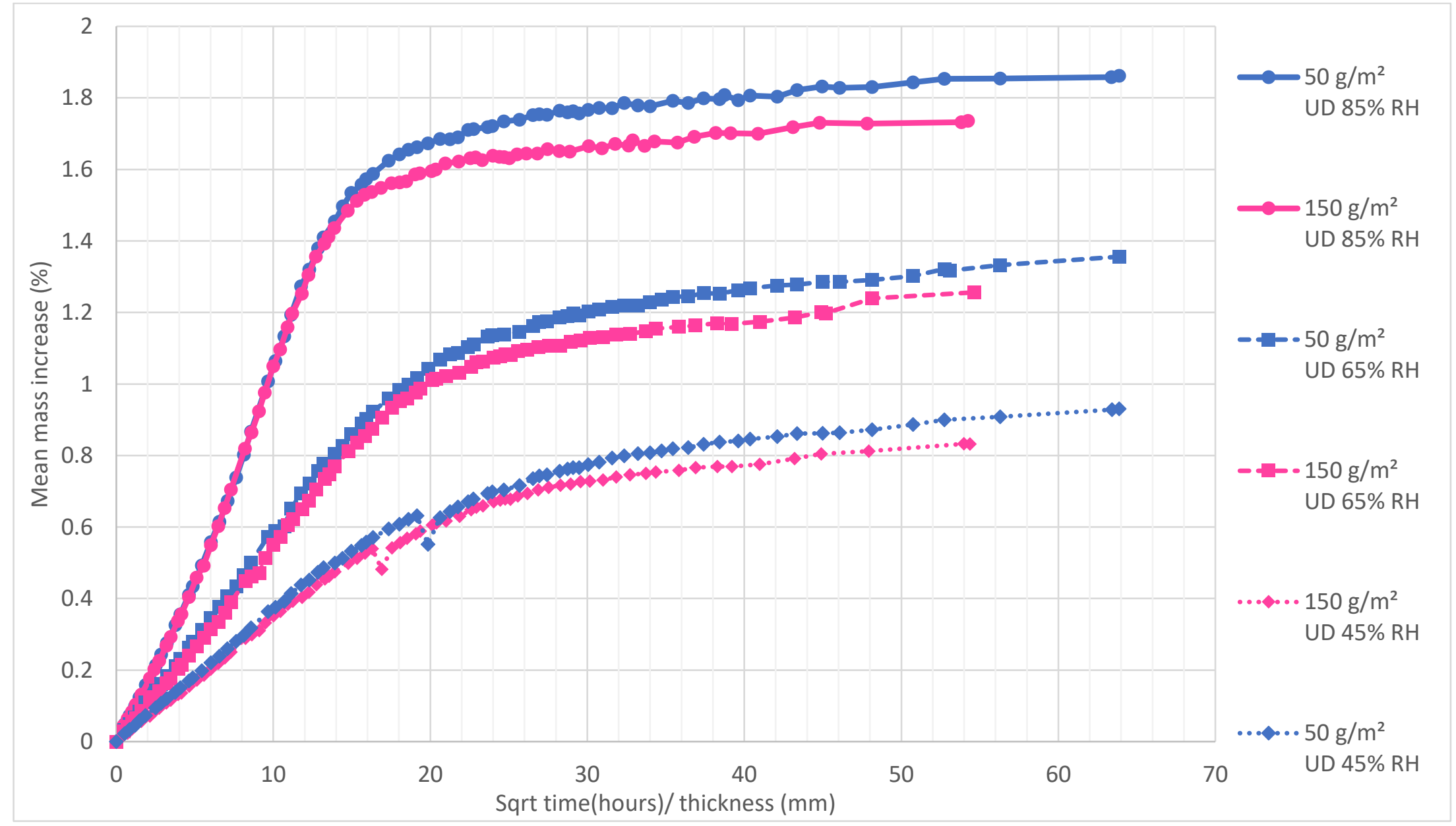

Figure 5.3 Mean percentage mass increase for UD T800 TP135 material, manufactured using varying ply thicknesses and conditioned at $70{ }^{\circ} \mathrm{C}$ with different relative humidity environments 


\subsubsection{Assessing the Effect of Ply Thickness on Diffusion Coefficient}

To calculate the diffusion coefficient (the rate of moisture ingress) using the method described in Section 3.5.3, a Fickian diffusion is assumed. However, as is reported in the literature, the moisture content of epoxy resins can continue to increase beyond the Fickian behaviour $[84,87,91]$. As shown in Figure 5.2 and Figure 5.3 this was the case for the samples in this study. The materials continued to slowly absorb water beyond the Fickian saturation point. To analyse the Fickian diffusion, the long-term, slower, moisture absorption section must be removed [87]. To do this, the gradient of a tangent to this section of the graph was calculated and then subtracted from the raw data, to provide an estimated Fickian graph [91]. An example of this is shown in Figure 5.4.

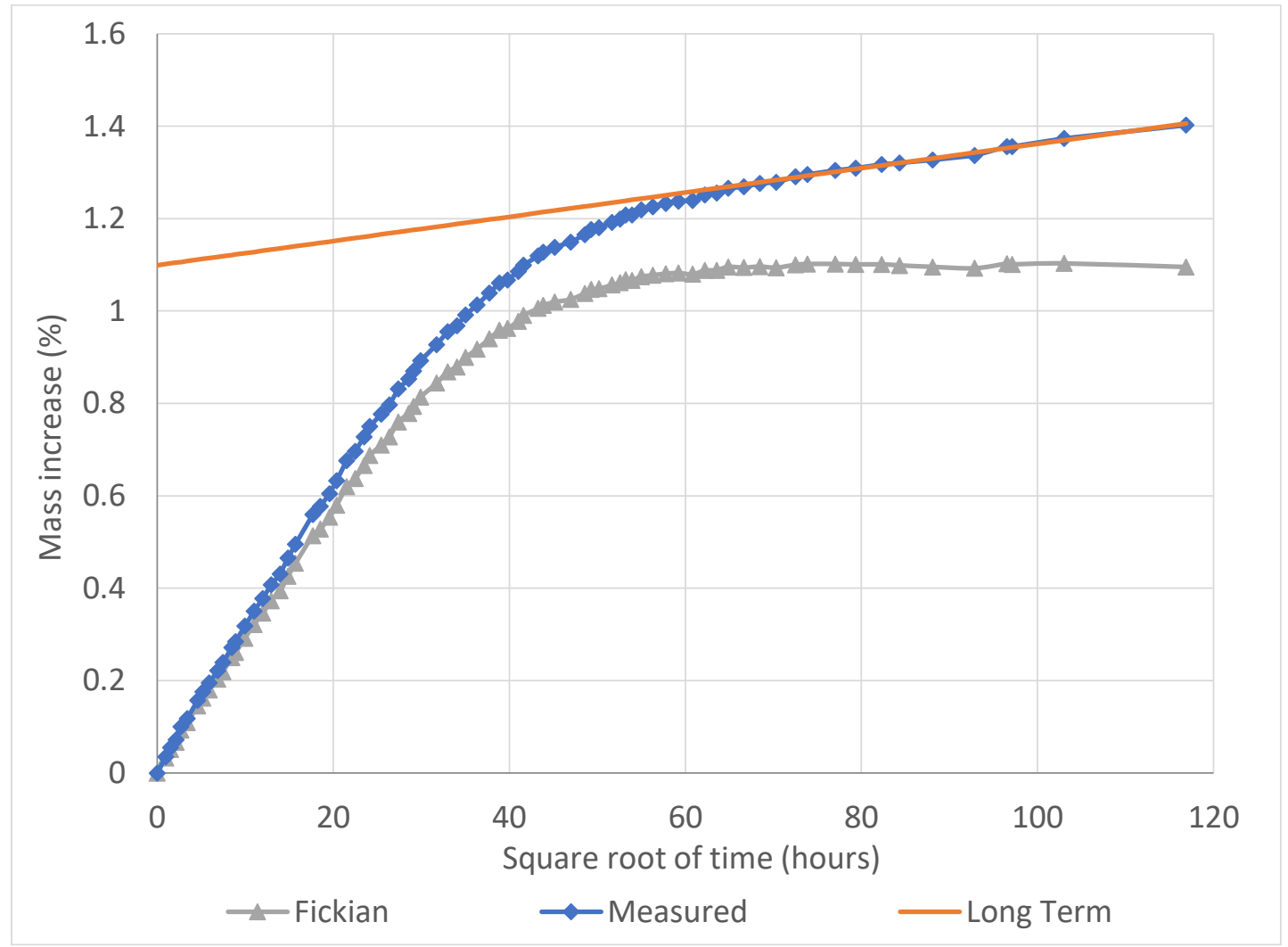

Figure 5.4 Removal of long-term moisture absorption to give an estimation of Fickian behaviour 
Once the maximum estimated Fickian saturation, and the estimated initial gradient of the Fickian curve were obtained for each sample, Equation 8 in Section 3.5.3 was used to determine the diffusion coefficient of each specimen. Three replicate samples for each ply thickness and moisture environment were studied. The means of these results are shown in Table 5.1 and Figure 5.5.

Overall, the results show no significant differences in the diffusion coefficients for materials with different ply thicknesses. The largest difference in diffusion coefficient was the result of changing relative humidity. The diffusion coefficient was higher for the $85 \%$ RH conditioned samples, in comparison to both the $65 \%$ and $45 \%$ RH conditioned specimens. This could be related to plasticisation of the matrix. If the matrix becomes more plasticised, the resin is more flexible and therefore moisture ingress can occur at a faster rate (because the polymer chains are more flexible). This would explain the higher diffusion rate at higher humidity.

Table 5.1 Mean diffusion coefficient values for $50 \mathrm{~g} / \mathrm{m}^{2}, 150 \mathrm{~g} / \mathrm{m}^{2}$ and $300 \mathrm{~g} / \mathrm{m}^{2}$ material, conditioned in different relative humidity environments (three replicate samples per material)

\begin{tabular}{|c|c|c|c|c|c|c|}
\hline \multirow[t]{2}{*}{ Prepreg } & \multicolumn{2}{|c|}{$\begin{array}{c}45 \% \mathrm{RH}, 70{ }^{\circ} \mathrm{C} \\
\text { diffusion coefficient } \\
\left(\mathrm{m}^{2} / \mathrm{s}\right)\end{array}$} & \multicolumn{2}{|c|}{$\begin{array}{c}65 \% \mathrm{RH}, 70{ }^{\circ} \mathrm{C} \\
\text { diffusion coefficient } \\
\left(\mathrm{m}^{2} / \mathrm{s}\right)\end{array}$} & \multicolumn{2}{|c|}{$\begin{array}{c}85 \% \mathrm{RH}, 70{ }^{\circ} \mathrm{C} \\
\text { diffusion coefficient } \\
\left(\mathrm{m}^{2} / \mathrm{s}\right)\end{array}$} \\
\hline & Mean & $\begin{array}{c}\text { Standard } \\
\text { error }\end{array}$ & Mean & $\begin{array}{c}\text { Standard } \\
\text { error }\end{array}$ & Mean & $\begin{array}{c}\text { Standard } \\
\text { error }\end{array}$ \\
\hline $\begin{array}{c}50 \mathrm{~g} / \mathrm{m}^{2} \\
\text { QI }\end{array}$ & $1.50 \mathrm{E}-13$ & $3.62 \mathrm{E}-15$ & $1.74 \mathrm{E}-13$ & 3.20E-15 & 2.72 E-13 & $9.44 \mathrm{E}-15$ \\
\hline $\begin{array}{c}150 \mathrm{~g} / \mathrm{m}^{2} \\
\mathrm{QI}\end{array}$ & $1.41 \mathrm{E}-13$ & $1.20 \mathrm{E}-14$ & $1.81 \mathrm{E}-13$ & $4.88 \mathrm{E}-15$ & 2.91 E-13 & 8.95E-15 \\
\hline $\begin{array}{c}300 \mathrm{~g} / \mathrm{m}^{2} \\
\mathrm{QI}\end{array}$ & $1.44 \mathrm{E}-13$ & $6.83 \mathrm{E}-15$ & $1.75 \mathrm{E}-13$ & $3.70 \mathrm{E}-15$ & $3.00 \mathrm{E}-13$ & $1.46 \mathrm{E}-14$ \\
\hline $\begin{array}{c}50 \mathrm{~g} / \mathrm{m}^{2} \\
\mathrm{UD}\end{array}$ & $1.12 \mathrm{E}-13$ & $2.59 \mathrm{E}-15$ & 1.33E-13 & $4.09 \mathrm{E}-15$ & $2.16 \mathrm{E}-13$ & $1.52 \mathrm{E}-14$ \\
\hline $\begin{array}{c}150 \mathrm{~g} / \mathrm{m}^{2} \\
\mathrm{UD}\end{array}$ & 1.19E-13 & $1.63 \mathrm{E}-15$ & $1.39 \mathrm{E}-13$ & $1.18 \mathrm{E}-14$ & 2.32 E-13 & $2.16 \mathrm{E}-15$ \\
\hline
\end{tabular}




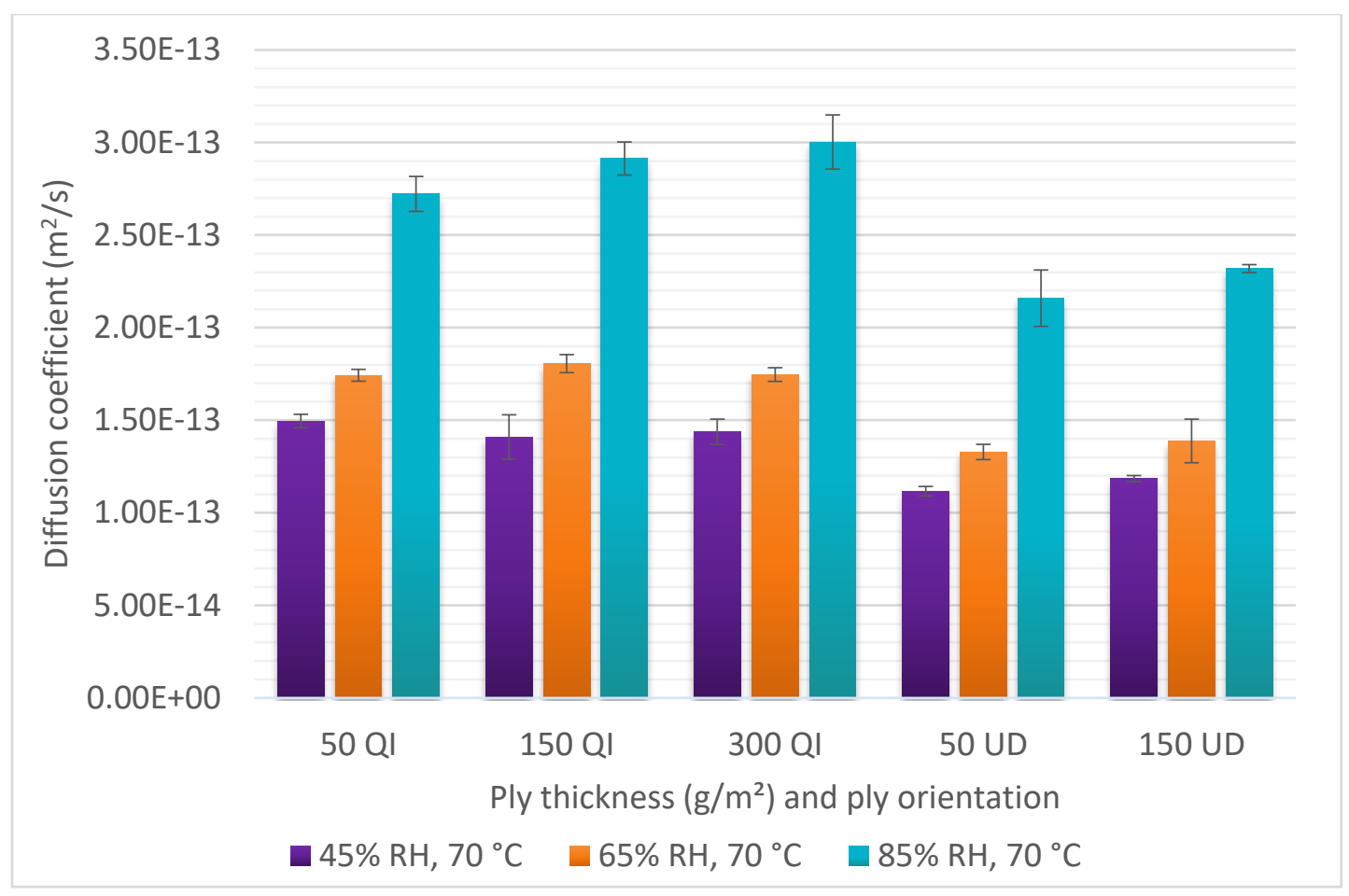

Figure 5.5 Mean diffusion coefficient values for $50 \mathrm{~g} / \mathrm{m}^{2}, 150 \mathrm{~g} / \mathrm{m}^{2}$ and $300 \mathrm{~g} / \mathrm{m}^{2}$ material, conditioned in different relative humidity environments (three replicate samples per material)

\subsection{Investigation into the Effect of Moisture on Mechanical Properties}

To determine the effect of moisture on mechanical properties, test coupons were conditioned until saturation in three different environments: $70{ }^{\circ} \mathrm{C}$ and $85 \% \mathrm{RH}$, $70{ }^{\circ} \mathrm{C}$ and $65 \% \mathrm{RH}$ and finally $70{ }^{\circ} \mathrm{C}$ and $45 \% \mathrm{RH}$. Once the samples reached saturation they were tested (at ambient temperature) using test methods that are resin dominated and where there is some influence of local stress transfer. Unnotched tensile $\left(90^{\circ}\right)$, interlaminar shear and open-hole compression tests are examples of such methods.

\subsubsection{Interlaminar Shear Stress (ILSS)}

Interlaminar shear stress tests were performed on UD samples after conditioning until saturation in three different environments: a) $85 \% \mathrm{RH}, 70{ }^{\circ} \mathrm{C}$ b) $65 \% \mathrm{RH}, 70{ }^{\circ} \mathrm{C}$ and c) $45 \% \mathrm{RH}, 70^{\circ} \mathrm{C}$. The results are shown in Figure 5.6. The results have not been normalised, because the test is resin, not fibre, dominated. 
Being a resin dominated property, it was expected that the interlaminar shear strength would decrease as the humidity in the conditioning environment increased. The results corroborated with this hypothesis. No significant differences were seen between the thin and intermediate-ply coupons, except for the samples which were conditioned at $85 \% \mathrm{RH}, 70{ }^{\circ} \mathrm{C}$. For these samples the interlaminar shear strength of the $150 \mathrm{~g} / \mathrm{m}^{2}$ coupons deteriorated more than the $50 \mathrm{~g} / \mathrm{m}^{2}$ coupons. For example, the ILSS of the $85 \% \mathrm{RH}, 70{ }^{\circ} \mathrm{C}$ conditioned $50 \mathrm{~g} / \mathrm{m}^{2}$ sample was $18 \%$ lower than the $50 \mathrm{~g} / \mathrm{m}^{2}$ unconditioned sample, whereas the $85 \% \mathrm{RH}, 70{ }^{\circ} \mathrm{C}$ conditioned $150 \mathrm{~g} / \mathrm{m}^{2}$ sample was $28 \%$ lower compared to the unconditioned state. This may suggest that the ILSS of thin-ply coupons are not as affected by moisture as the intermediate-ply coupons. However, this is only the case for one of the conditioning environments. Additional testing would need to be carried out to confirm this result. An important point to note is that, generally, the results do not differ with changes to ply thickness. This was also the case for the unconditioned, ambient temperature tests which were performed on UD coupons. The differences with respect to ply thickness tend to generally occur when the samples are not UD.

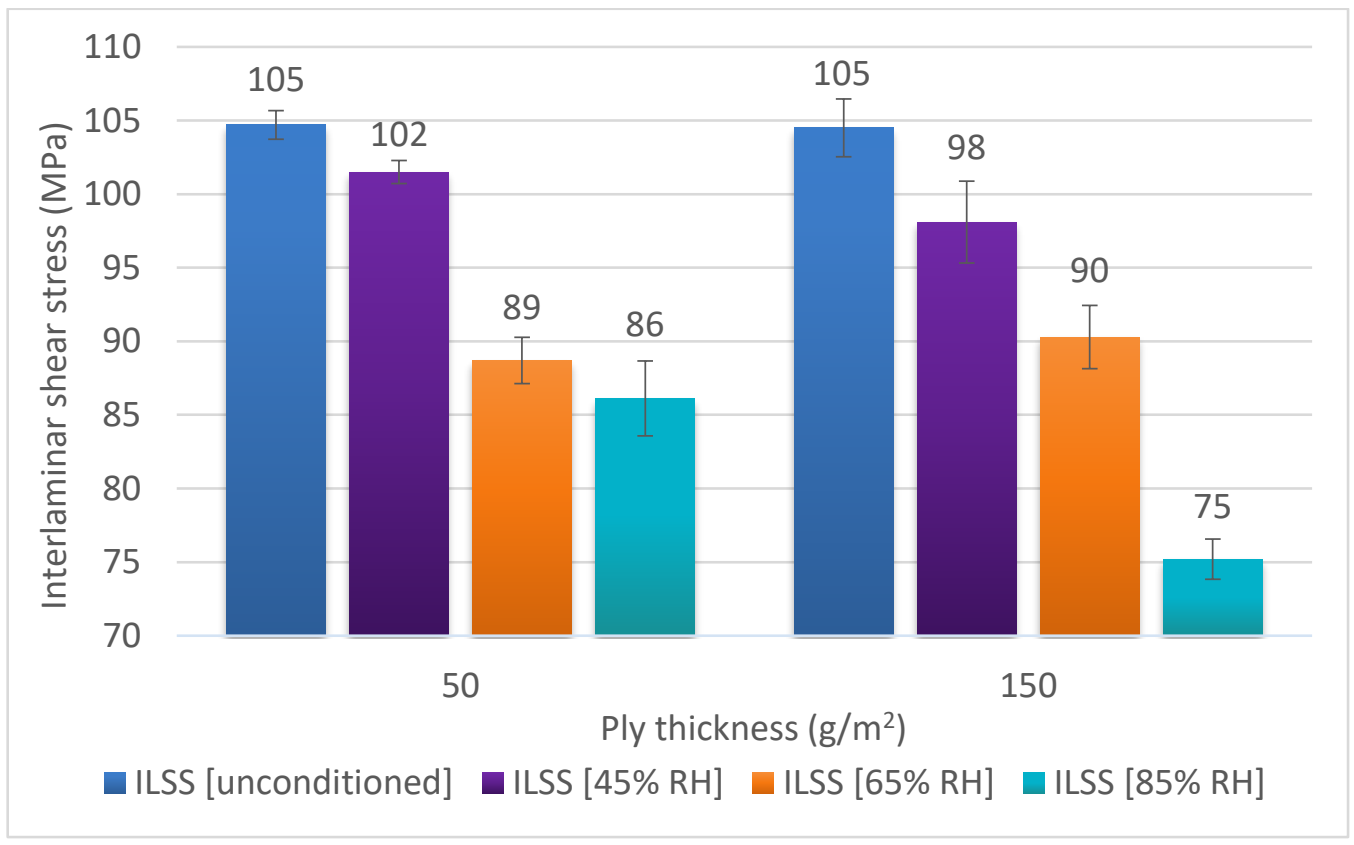

Figure 5.6 Mean $0^{\circ}$ ILSS data after conditioning in different relative humidity environments (not normalised) [minimum of five samples per test] 


\subsubsection{Unidirectional $90^{\circ}$ Unnotched Tension}

Unidirectional $90^{\circ}$ tensile samples were conditioned, until saturation, in the same three environmental conditions as described above (85\%, $65 \%$ and $45 \% \mathrm{RH}$, all at $70{ }^{\circ} \mathrm{C}$ ). During testing of these samples, it was noted that the results, even within the same batch of samples, were very variable. This is thought to be a result of uneven gripping of the samples. The geometry of the test coupons was $175 \mathrm{~mm}$ in length, by $25 \mathrm{~mm}$ width, with a tabbed region of $25 \mathrm{~mm}$. The very small length of gripping region is thought to have impacted the results, leading to a high scatter. In addition, UD $90^{\circ}$ test coupons have very low strength, which makes them prone to damage in handling, or due to slightly misaligned gripping.

The mean results are shown in Figure 5.7. Despite the issues with sample gripping, a general trend for decreased UTS with increased moisture content is observed, which is as to be expected for a resin dominated test. As with the unidirectional ILSS samples, the thin-ply materials appear to perform better at high humidity, however, due to the large error associated with this data, the significance of this result is questioned.

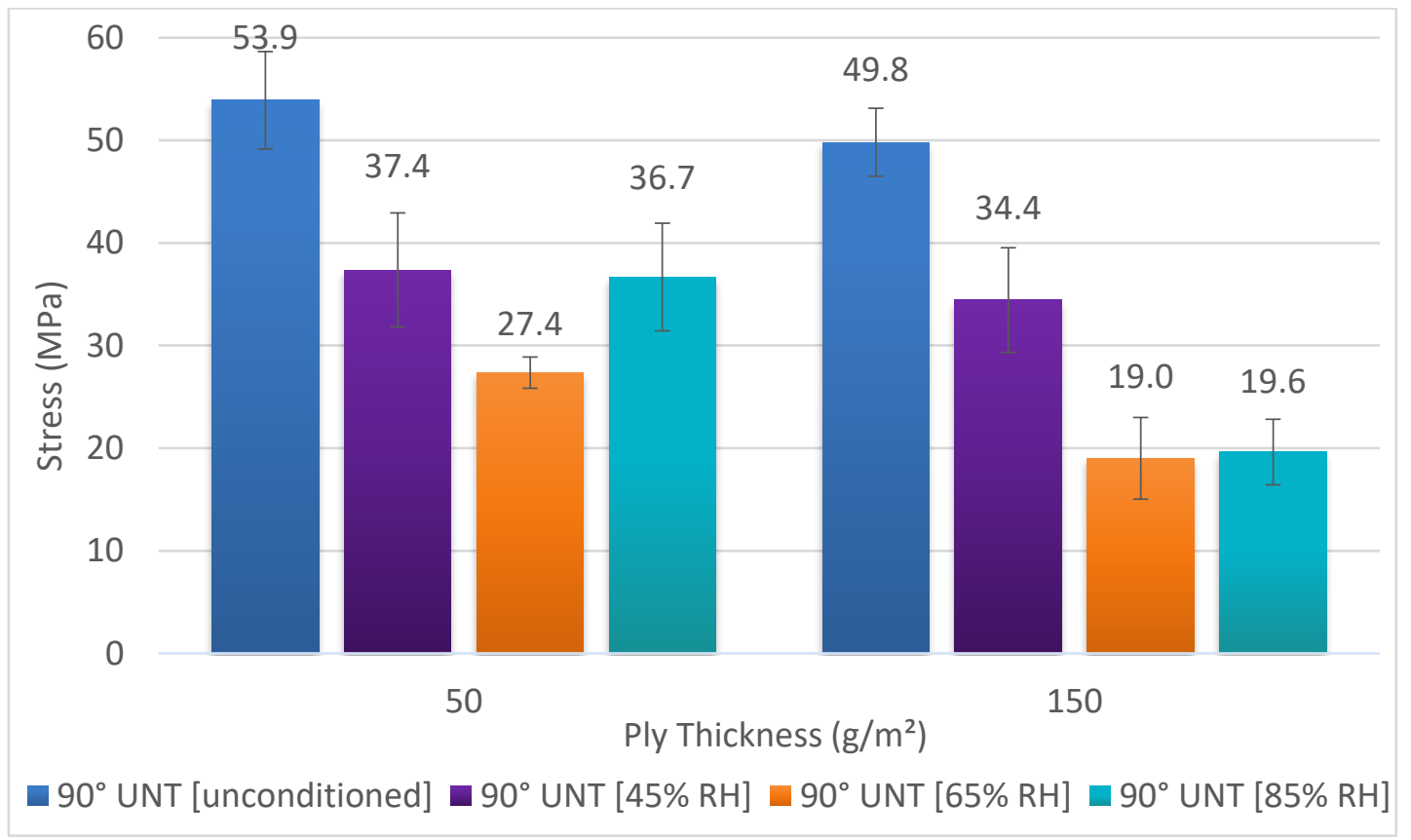

Figure 5.7 Mean $90^{\circ}$ unnotched tensile (UNT) stress data, after conditioning in different relative humidity environments (not normalised) [minimum of five samples per test] 


\subsubsection{Quasi-isotropic Open-hole Compression}

Open-hole compression tests were performed on conditioned samples made from the three different ply thicknesses. The results are shown in Figure 5.8. The thin-ply samples had greater strength values compared to the thicker ply samples, which was expected due to the unconditioned sample results. The greatest differences in strength were between the $50 \mathrm{~g} / \mathrm{m}^{2}$ and $300 \mathrm{~g} / \mathrm{m}^{2}$ samples; after conditioning at $85 \% \mathrm{RH}$ and $70{ }^{\circ} \mathrm{C}$, the thin-ply coupons had, on average, $39 \%$ increased strength compared to the thicker ply material.

Unlike the ILSS results, there was no great deterioration in open-hole compressive strength after conditioning in the humid environments. It is interesting to see that both the $45 \% \mathrm{RH}$ and the $65 \% \mathrm{RH}$ conditioned samples have increased open-hole compressive strength compared to the unconditioned coupons. These results were unexpected, because, typically, increased moisture content leads to a deterioration in strength. It is possible that the samples benefited from extra curing during the conditioning process. During conditioning the samples were held at the required relative humidity and $70{ }^{\circ} \mathrm{C}$ for the length of time needed for saturation to occur. This was 54 days, 77 days and 131 days for the $85 \% \mathrm{RH}, 65 \% \mathrm{RH}$ and $45 \% \mathrm{RH}$ samples respectively. The greater length of time at $70{ }^{\circ} \mathrm{C}$, coupled with the lower relative humidity, could explain why the $45 \% \mathrm{RH}$ and the $65 \% \mathrm{RH}$ samples increased in strength more than the $85 \% \mathrm{RH}$ samples. However, given that the laminate cure cycle was two hours at $130^{\circ} \mathrm{C}$ followed by four hours at $165^{\circ} \mathrm{C}$, it is unexpected that much curing would realistically be taking place at $70^{\circ} \mathrm{C}$. A second hypothesis is that water ingress led to plasticisation of the matrix, causing the matrix to toughen and become more flexible, thus leading to increased strength.

To determine whether the extra curing at $70^{\circ} \mathrm{C}$ was the reason for the increased strength of the $45 \%$ and $65 \%$ samples, open-hole compression coupons were placed in an oven for drying. The samples were in the oven for the same length 
of time as the $45 \%$ RH conditioned samples (approximately 131 days). After this, the samples were compression tested and the results where compared to the 'as received' ambient temperature results. An increase in strength for the oven dried samples would suggest that further post curing of the material was the cause of the increased strength. The results of the experiment are shown and discussed in Chapter 6.

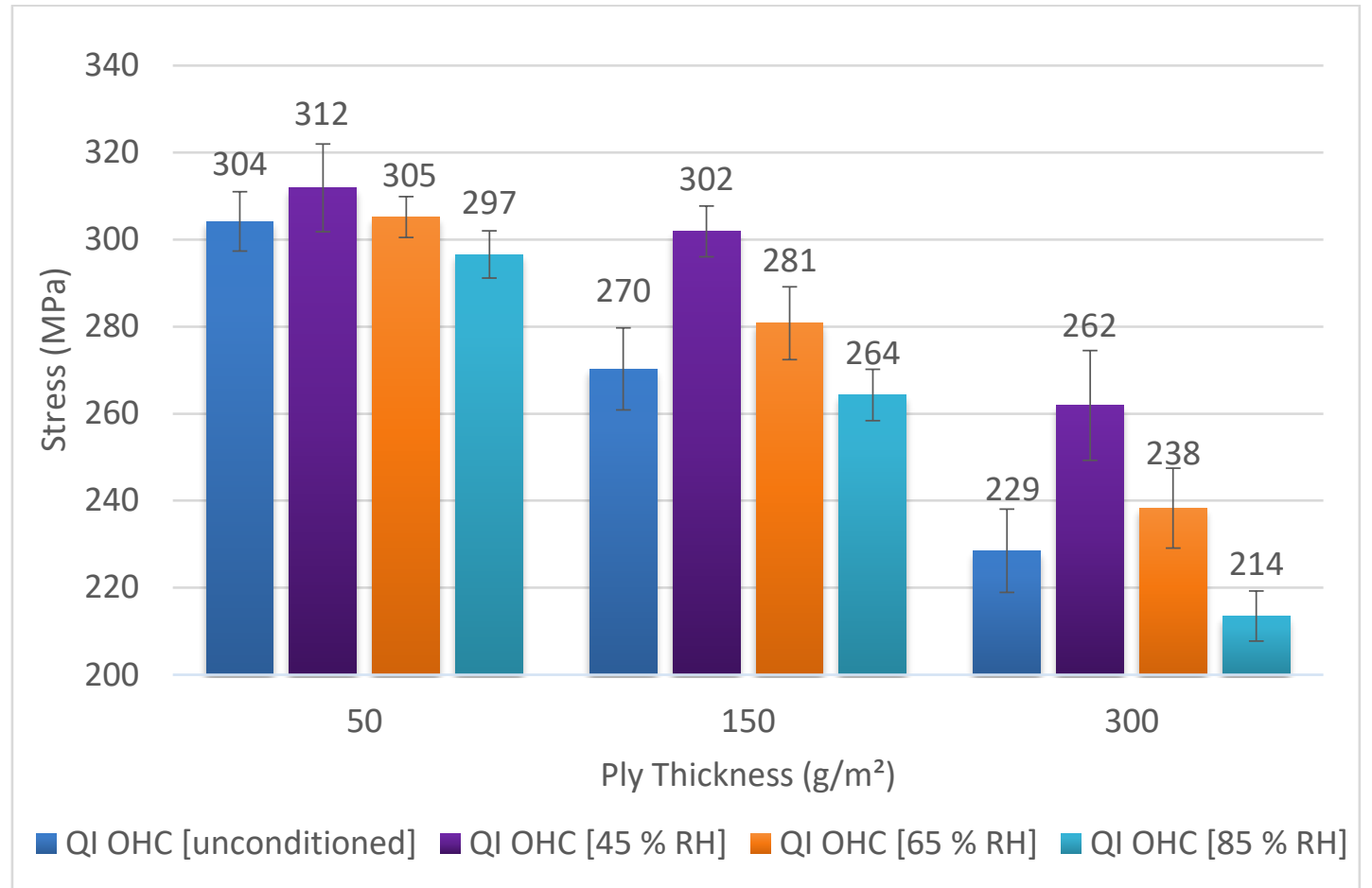

Figure 5.8 Mean QI open-hole compressive (OHC) stress data, after conditioning in different relative humidity environments (normalised) [minimum of five samples per test]

\subsubsection{In-plane Shear $\left( \pm 45^{\circ}\right)$}

Production of in-plane shear test coupons was undertaken with samples of each ply thickness material. The samples were then conditioned, until saturation, at $85 \% \mathrm{RH}, 70{ }^{\circ} \mathrm{C}$ and $65 \% \mathrm{RH}, 70{ }^{\circ} \mathrm{C}$, to investigate the effect of moisture ingress. As with the unconditioned samples, the $50 \mathrm{~g} / \mathrm{m}^{2}$ coupons had the highest in-plane shear strength for each conditioning environment (see Figure 5.9). Each material saw a deterioration in in-plane shear strength with increasing humidity. Interestingly, the unconditioned $300 \mathrm{~g} / \mathrm{m}^{2}$ failed before $5 \%$ strain, which is the standard test-end point. However, despite having a lower shear stress, the 
conditioned thick-ply samples reached higher strain values and did not fail before $5 \%$ strain. An example of this behaviour is shown in Figure 5.9, where the blue dashed curve represents the typical unconditioned behaviour and the orange and green dashed curves represent the $65 \%$ RH and the $85 \%$ RH conditioned samples respectively.

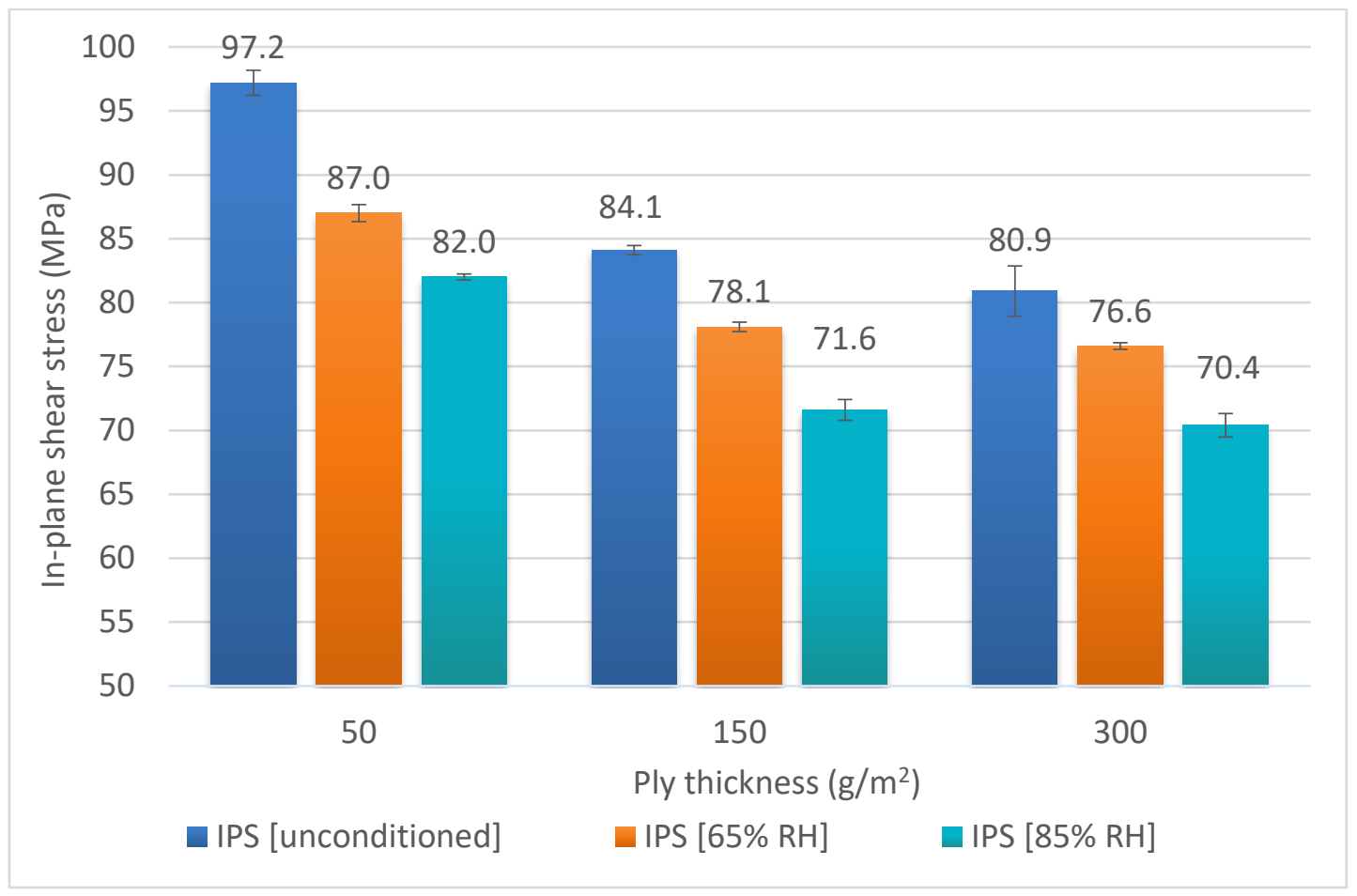

Figure 5.9 Mean in-plane shear (IPS) stress data, after conditioning in different relative humidity environments (not normalised) [minimum of four samples per test] 


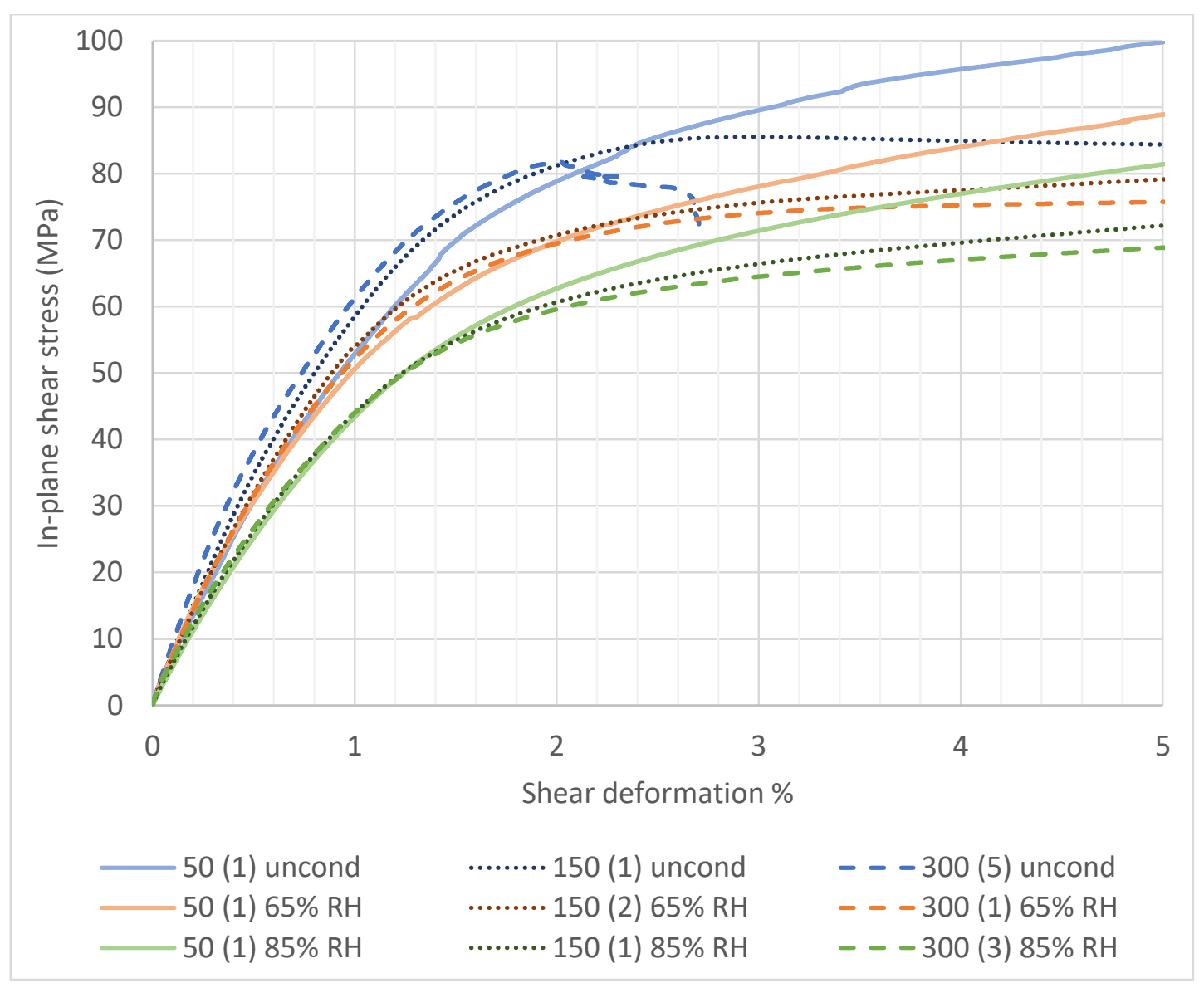

Figure 5.10 Example in-plane shear stress/strain curves for, $50 \mathrm{~g} / \mathrm{m}^{2}, 150 \mathrm{~g} / \mathrm{m}^{2}$ and $300 \mathrm{~g} / \mathrm{m}^{2}$ samples, tested after conditioning in different humid environments (blue curves: unconditioned, orange curves: $65 \%$ RH, green curves: $85 \%$ RH)

\subsubsection{Summary}

The aim of this chapter was to investigate the effect of moisture on thin-ply carbon fibre composite materials. Firstly, a study into the effect of ply thickness on moisture absorption and diffusion rate was conducted. The thin-ply material was found to have increased moisture absorption (particularly with QI laminates) compared to the thicker ply material. No significant differences in diffusion rate were found with changes to ply thickness. The $85 \% \mathrm{RH}$ conditioned samples were found to have a higher diffusion rate compared to the $65 \%$ and $45 \% \mathrm{RH}$ samples. This behaviour occurred for all samples investigated.

As expected, increased moisture content generally led to a deterioration in mechanical properties, for all ply thicknesses. Despite the increased moisture 
absorption for the thin-ply material, the effect of moisture on mechanical testing results remained consistent across all three materials. Therefore, it appears that the thin-ply material was not negatively affected by the extra moisture absorption. Interestingly, open-hole compressive properties for all FAW appeared to be positively affected by moisture content (for $45 \% \mathrm{RH}$ and $65 \%$ $\mathrm{RH})$. The effect of post curing on these samples was investigated further and is discussed in Chapter 6. 


\section{Effect of Ply Thickness on Mechanical Properties Discussion}




\subsection{Mechanical Testing Discussion}

The aim of this chapter is to discuss the mechanical testing results of the unconditioned, high temperature, and humidity conditioned samples. Due to the large volume of results presented thus far, the discussion has been divided into separate sections for tensile, compression and shear test methods. Within these sections is a discussion of all three testing conditions and all laminate orientations (UD, QI and $\pm 45^{\circ}$ ). In addition, the chapter will discuss various test methods used to understand more about the mechanical testing results. Methods such as high-speed camera video recording, DIC, DMA, FEG-SEM and AFM have all been used to investigate different hypotheses into why changes in material behaviour occurred with changes to ply thickness.

\subsubsection{Quasi-static Unnotched Tensile Behaviour}

This section will compare and discuss the tensile test results reported in Chapter 4 and Chapter 5. These tests include:

- Unnotched tensile $0^{\circ}, 90^{\circ}, \mathrm{QI}$ (tested 'as received')

- Unnotched tensile QI (tested at high temperature)

\subsubsection{Unidirectional Tensile Behaviour at Ambient Temperature}

Firstly, the effect of ply thickness on unnotched tensile samples with different laminate orientations was investigated. Room temperature quasi-static tensile tests were conducted on unidirectional specimens in both the $0^{\circ}$ and $90^{\circ}$ orientation. In UD laminates, each ply is orientated with the fibres in the same direction. This could suggest that maintaining an overall specimen thickness, but changing ply thickness, would have minimal impact on the mechanical properties of the material. This is because the microstructure of both the thin-ply and the standard ply materials would essentially be the same (that is, all fibres oriented in the same direction). An alternative view is that, as the thin-ply material has more ply boundaries, it has the potential for a greater number of resin rich 
interlaminar regions, which could lead to a lower tensile strength. On the contrary, the local microstructure of thin-ply materials has been shown to be more uniform than standard ply materials [14]. This was also found to be the case with the T800 TP135 material, as demonstrated in Figure 6.1. During thin-ply prepreg manufacture, the process of spreading the fibre tow generates a more homogeneous material, with less resin rich areas. It is possible that a more uniform microstructure could help to enhance tensile strength.
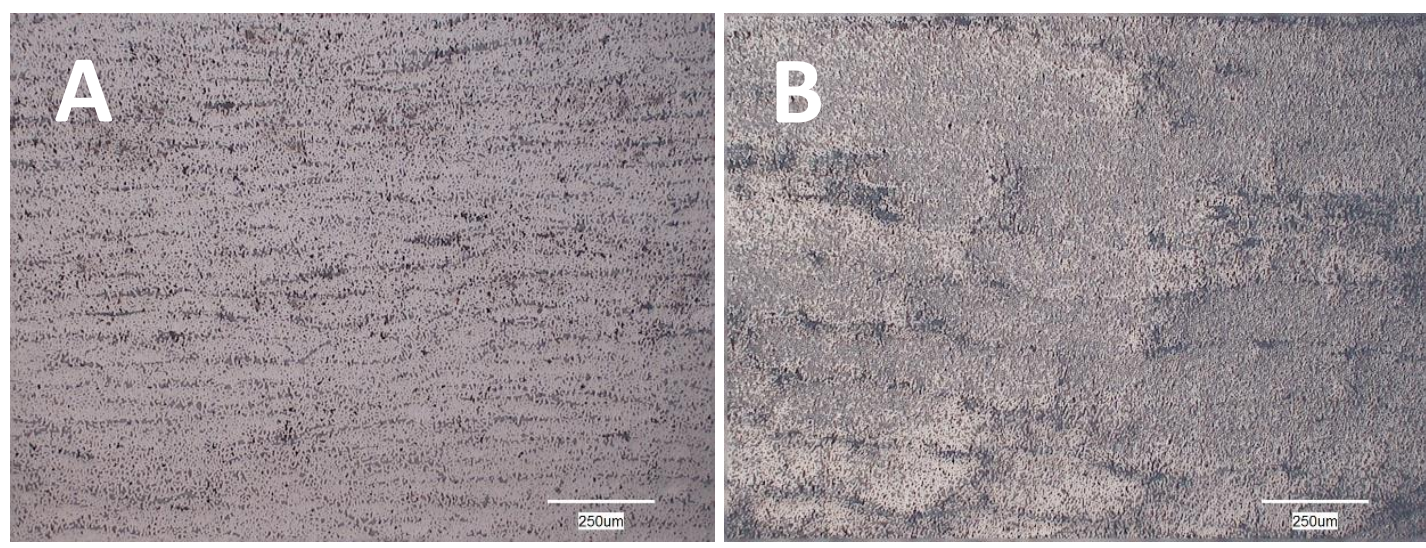

Figure 6.1 Microscopy images (140× magnification) of: a) UD, $\left.50 \mathrm{~g} / \mathrm{m}^{2}, b\right) U D, 150 \mathrm{~g} / \mathrm{m}^{2}$ laminates

Despite the thin-ply material having a more homogeneous microstructure, the results of the $0^{\circ}$ unidirectional tensile tests showed no significant difference in UTS for the different ply thicknesses tested. This corroborates with the work by Amacher et. al [14], who assessed the UD tensile behaviour of $30 \mathrm{~g} / \mathrm{m}^{2}, 100 \mathrm{~g} / \mathrm{m}^{2}$ and $300 \mathrm{~g} / \mathrm{m}^{2}$ laminates. It is possible that, because the $0^{\circ}$ tension test is so heavily dominated by fibre strength, the difference in local microstructure had little impact on the results. It is more likely that differences in fibre volume fraction would have a greater effect on $0^{\circ}$ tensile properties, with the laminate with a higher fibre content giving a greater UTS.

The $90^{\circ}$ UD tensile tests also showed no significant differences in UTS with changes to ply thickness. Therefore, despite being a largely resin dominated test, the more uniform microstructure seen with thin-ply laminates appeared to give little benefit. 


\subsubsection{Quasi-isotropic Unnotched Tensile Behaviour at Ambient Temperature}

In contrast to the unidirectional tensile tests, the QI laminates displayed very different tensile behaviour as a result of changes to ply thickness. The thin-ply materials had a $45 \%$ and an $8 \%$ increase in normalised tensile strength compared to the $300 \mathrm{~g} / \mathrm{m}^{2}$ and the $150 \mathrm{~g} / \mathrm{m}^{2}$ samples respectively, as shown in Section 4.3.3. This trend agrees with the current literature [14-16].

In addition to differences in ultimate strength, a very clear difference in failure mode was seen as a result of changing ply thickness. For example, the thin-ply coupons behaved like a homogeneous material, with a very brittle failure mode. As ply thickness increased, the failure mode became more progressive, with individual ply failure resulting in eventual sample failure. This behaviour has been reported with other thin-ply materials [14]. In literature it is also reported that first ply failure is delayed with thin-ply samples [14,15]. It was not possible to conduct acoustic emission testing in this project, however the observed failure modes tend to agree with this finding. To understand more about the progression of failure, a high-speed video camera was used to record the point of sample break. Figure 6.2 to Figure 6.4 show images, taken from the high-speed camera footage, of the unnotched tensile samples immediately prior to ultimate failure. It should be noted that the $300 \mathrm{~g} / \mathrm{m}^{2}$ sample failed so progressively that the entire failure mode could not be filmed within the maximum clip length of the camera, due to memory limitations. This is why the sample is fractured in the first picture of Figure 6.4. A frame rate of 8,000 fps was used for imaging the failure modes. This frame rate equates to each frame being $0.125 \mathrm{~ms}$ in length. This was the highest frame rate possible, whilst maintaining a high-quality resolution. In hindsight, reducing the resolution and using a higher frame rate may have given more insight into the point of failure, because, as shown in Figure 6.2 to Figure 6.4, the point of failure occurs so quickly that it is still difficult to see where failure initiates. 
As discussed, a clear difference in failure mode for thin and standard ply laminates has been shown previously, through the use of acoustic emission analysis and visual inspection of specimens [14]. The use of high-speed camera video recording has further added to this picture, as the visualisation of what happens at the point of failure provides further evidence as to why thin-ply materials behave so differently.

The reason why thin-ply QI laminates show an increase in strength, whereas UD thin-ply laminates do not, can be explained by the lack of interfacial stresses within UD specimens. Within a quasi-isotropic laminate, each ply is oriented differently to its neighbour (expect for the two centre symmetry-line plies). These orientation differences lead to a strain mismatch between each ply, which occurs in both the thin and standard ply specimens. However, the reason why the thin-ply specimens perform better, is because the thin-ply laminates have smaller interfacial stresses than standard ply laminates, due to the reduced thickness of the ply. The impact of these smaller interfacial stresses is demonstrated in the high-speed camera images (Figure 6.2 to Figure 6.4).

The $50 \mathrm{~g} / \mathrm{m}^{2}$ samples have relatively small interfacial stresses, thus ultimate failure of the sample occurs with failure of the $0^{\circ}$ fibres. The $0^{\circ}$ plies have the most strength when tested in tension and therefore hold the most load throughout the duration of the test. The plies orientated at different angles $\left( \pm 45^{\circ}\right.$ and $\left.90^{\circ}\right)$ do not carry much load in comparison. However, because of this, and the fact that thinner plies lead to lower interfacial stresses, the off-axis plies do not fail until the load bearing $0^{\circ}$ plies fail. When this happens, the rest of the plies fail immediately, as they cannot withstand the load. This is why the failure mode is very constrained. Figure 6.2 shows the point of failure for a $50 \mathrm{~g} / \mathrm{m}^{2}$ sample. Combined, all seven images capture just $1.0 \mathrm{~ms}$ of footage. Failure is shown to initiate at the middle of the sample. This is thought to generate a stress shock, which ricochets through the sample, causing it to then break at the tab region. The 
samples showed very little delamination (as shown in Chapter 4, Figure 4.10), which corroborates with the explanation that thinner ply laminates have lower interfacial stresses than the thicker ply samples.

Figure 6.3 shows the failure mode of a typical $150 \mathrm{~g} / \mathrm{m}^{2}$ sample. At $0.125 \mathrm{~ms}$ it is possible to see failure of the outer $45^{\circ}$ ply. This occurs because the larger interfacial stresses (caused by the thicker plies) trigger the weaker $45^{\circ}$ ply to fail first. The failure leads to more load being put on the remaining plies, which in turn causes ultimate sample failure. As with the $50 \mathrm{~g} / \mathrm{m}^{2}$ samples, the $150 \mathrm{~g} / \mathrm{m}^{2}$ specimens failed immediately after this ply failure. The $150 \mathrm{~g} / \mathrm{m}^{2}$ sample has more delamination compared to the thin-ply specimen, as demonstrated in Chapter 4, Figure 4.10.

Figure 6.4 shows the final failure of the $300 \mathrm{~g} / \mathrm{m}^{2}$ specimen. At the start of the pictures, the specimen already shows clear failure, in multiple locations, of the outer $45^{\circ}$ ply. The large amount of delamination is visible as the failure progresses. The failure mechanism of this specimen is similar to that of the $150 \mathrm{~g} / \mathrm{m}^{2}$ sample, however as the ply thickness is larger, the interfacial stresses are increased, which causes the off-axis plies fail at lower stress. As the $45^{\circ}$ plies failed at a relatively low load, the $0^{\circ}$ plies are capable of withstanding further load and therefore do no fail immediately after the initial ply failure. When the $0^{\circ}$ plies do eventually fail it causes catastrophic failure of the entire sample. 


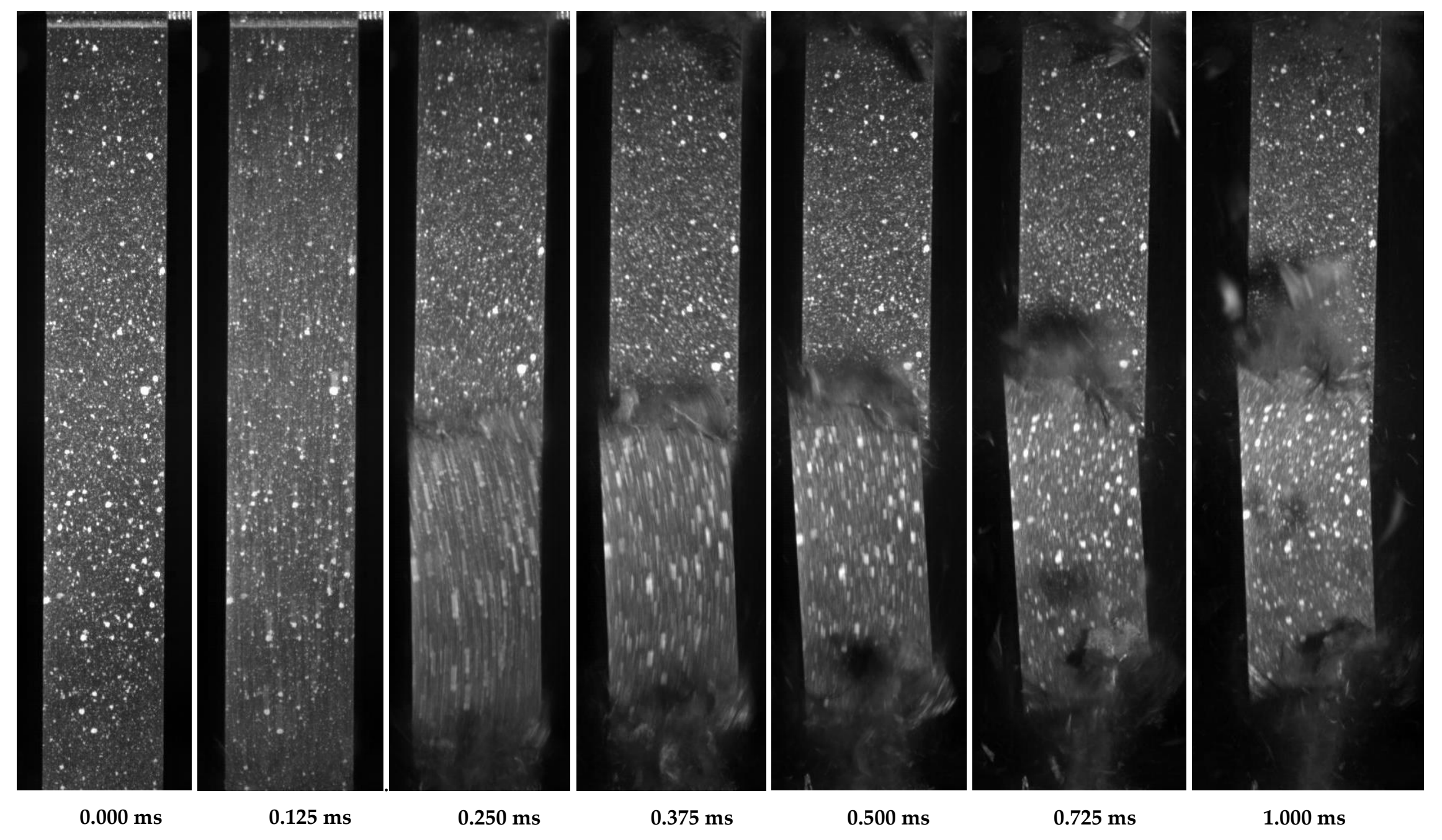

Figure 6.2 Stills from high speed camera video recording of a $50 \mathrm{~g} / \mathrm{m}^{2}$ unnotched tensile failure mechanism (shot at 8,000 fps) 


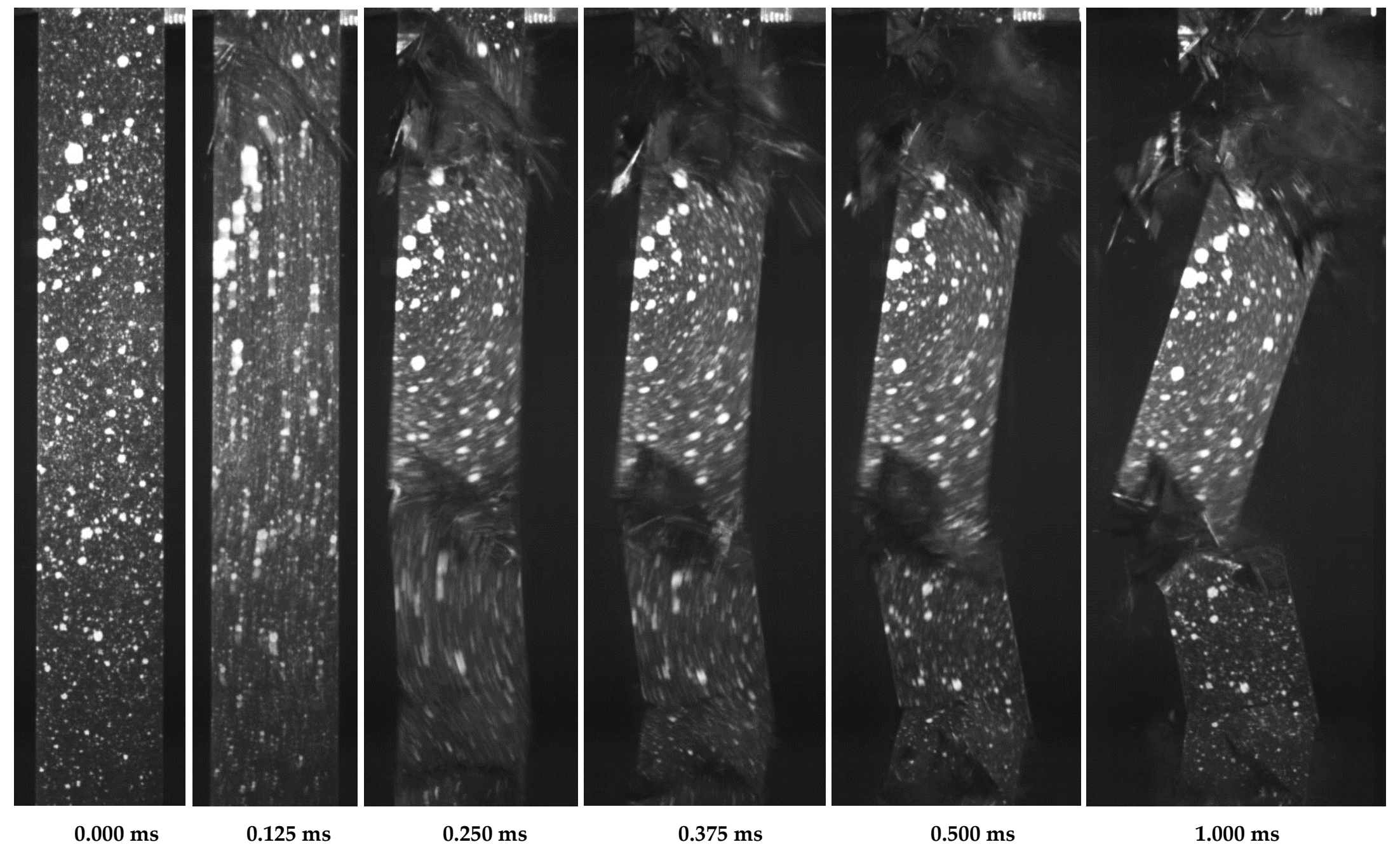

Figure 6.3 Stills from high speed camera video recording of a $150 \mathrm{~g} / \mathrm{m}^{2}$ unnotched tensile failure mechanism (shot at 8,000 fps) 


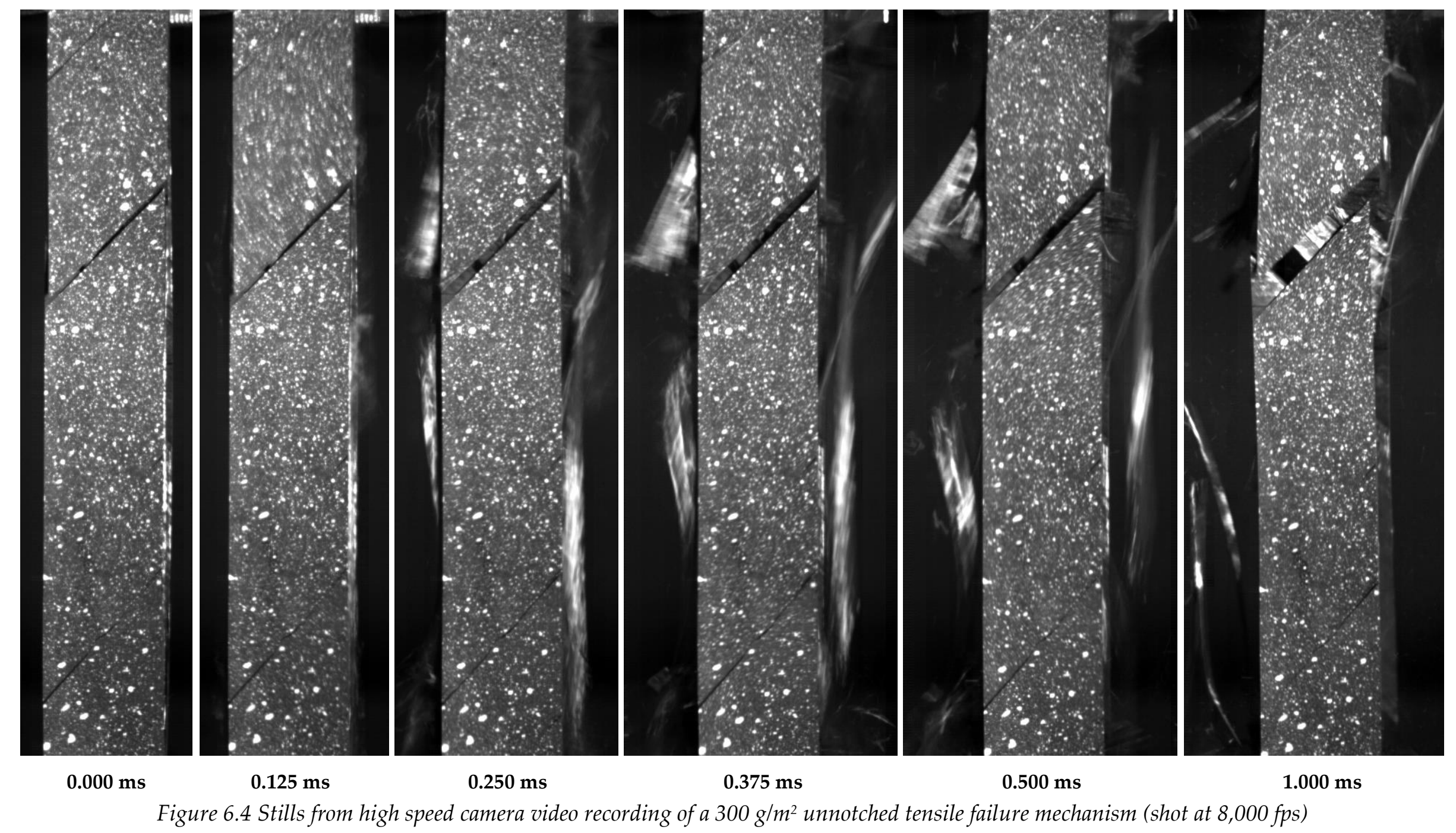


To understand more about the effect of ply thickness on tensile failure modes, DIC was conducted, in an attempt to map the local strains on the surface of the specimens. A description of the methodology used can be found in Section 3.6.

Initially, it was thought that the high-speed camera video footage would be required in order to perform digital image correlation (DIC). On the contrary, although viewing the failure mode at high speed provided interesting information, a high frame rate was not required for DIC. This is because DIC was being used to map the local strains on the sample prior to initiation of the ultimate failure. Indeed, upon analysis of the data, the high-speed camera videos did not provide enough information about the progressive failure of the sample, because the equipment was only capable of recording a short length of time (1.8 seconds). The solution to this issue was to use the high-speed camera to not only record the ultimate sample failure, but to also photograph still images periodically throughout the test. These images were then used in conjunction with stills from the high-speed camera video to map the strains on the sample. An alternative method would have been to increase the tensile test speed from $2 \mathrm{~mm}$ per minute, to ensure failure in a much shorter time frame. This method was not adopted, as it was not known how, or if, this would impact the failure type.

As described in Section 3.6, DIC was utilised to generate strain maps to understand how the localised strains on the sample differ with ply thickness. Changes in strain were measured by monitoring changes to the speckle pattern which was applied to the sample prior to testing. Still images were taken periodically throughout the test and these images, along with the four frames prior to sample break (taken from the high-speed camera video recording) were input into GOM Correlate software. A colour map depicting the strain on the sample at each of the images taken during the test was then generated. Digital image correlation was not performed on the $300 \mathrm{~g} / \mathrm{m}^{2}$ sample due to the very progressive nature of the failure. The first image of each sample was taken when 
the sample had been griped into the test machine, prior to any other load being applied. This gave an indication of the strain at the very beginning of the test. The final image, which can be seen in Figure 6.5, shows the specimen immediately prior to sample break. Scaling was used on each stage to remove outliers and to ensure the scale bars for each specimen were consistent. This allowed for a more direct comparison between samples. Furthermore, the option in the GOM Correlate software called "all visible stages" was selected, to ensure the strain legend remained constant for all stages throughout the test.

The use of DIC showed that the strain at each marker point (see Figure 6.5) increased throughout the test, for both ply thicknesses. However, the strains on the thin-ply material were much more uniform compared to the intermediate-ply sample. At marker point $\mathrm{H}$, the $150 \mathrm{~g} / \mathrm{m}^{2}$ sample had a sudden strain increase immediately prior to failure, which indicates the $45^{\circ}$ ply failure. The $50 \mathrm{~g} / \mathrm{m}^{2}$ sample had no significant strain increases at any one point across the surface. The specimen behaved like a homogenous material, without large stress concentrations. This is further evidence of the lower interfacial stresses present in thin-ply material. 


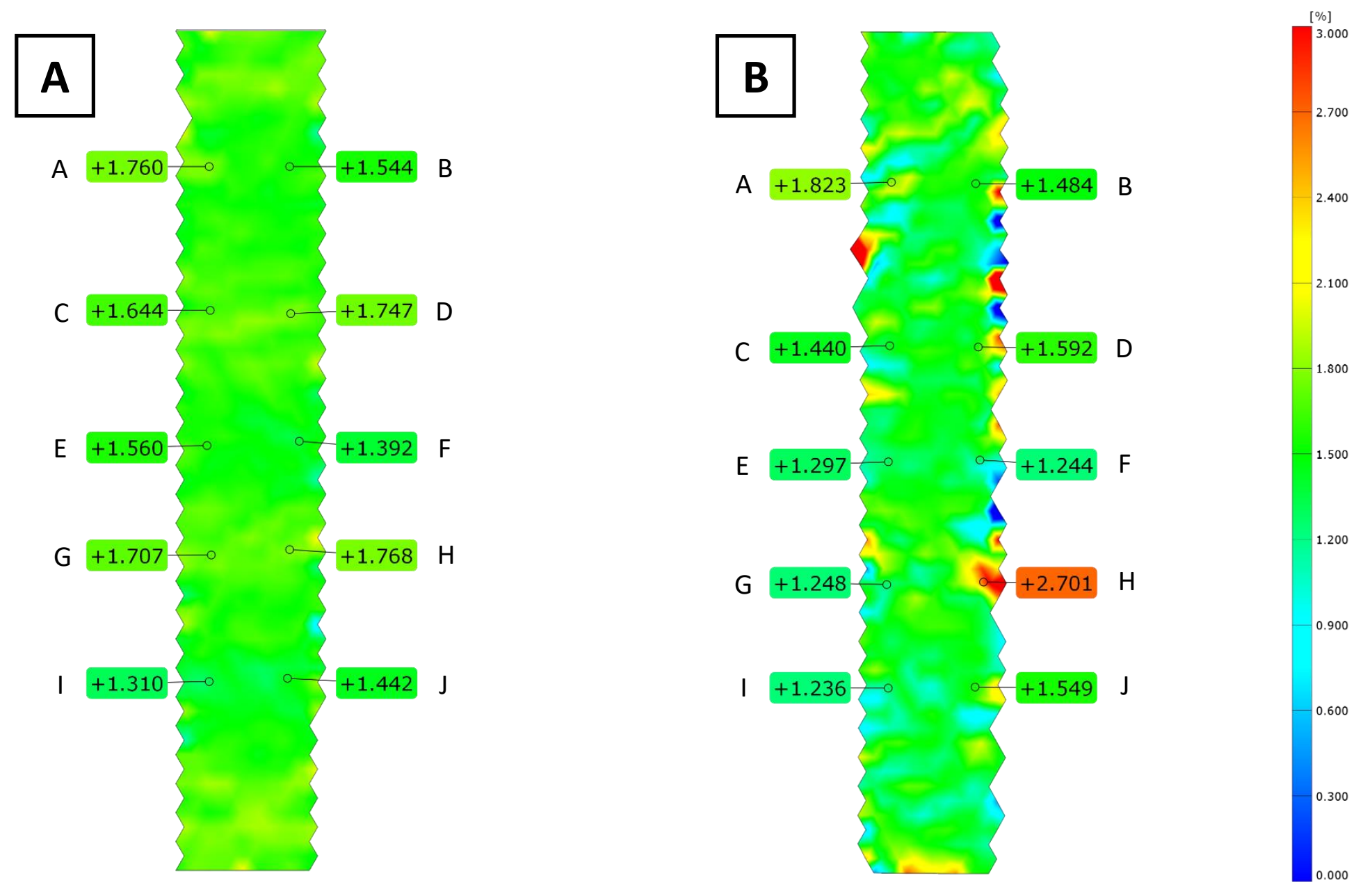

Figure 6.5 Change in strain (tensile load direction) during unnotched tensile tests: a) $50 \mathrm{~g} / \mathrm{m}^{2}$, b) $150 \mathrm{~g} / \mathrm{m}^{2}$. Images show strain maps immediately prior to sample break. 
In summary, the thin-ply material has an increased strength when tested at ambient temperature, compared to the $150 \mathrm{~g} / \mathrm{m}^{2}$ and $300 \mathrm{~g} / \mathrm{m}^{2}$ materials. This is due to a reduction in interfacial stresses causing higher strength, as demonstrated through the use of high-speed camera video recording and DIC.

\subsubsection{Quasi-isotropic Unnotched Tensile Behaviour at High Temperature}

The QI unnotched tensile samples tested at high temperature gave interesting results. The specimens were tested at two temperatures, $120^{\circ} \mathrm{C}$ and $150{ }^{\circ} \mathrm{C}$, based on the $\mathrm{T}_{\mathrm{g}}$ of the materials. The $\mathrm{T}_{\mathrm{g}}$ of the thin-ply panels was consistently higher, with a mean of $159^{\circ} \mathrm{C}$, compared to $147^{\circ} \mathrm{C}$ and $139^{\circ} \mathrm{C}$ for the intermediate and thick-ply panels (see Section 4.2.3). Therefore, it was hypothesised that the thin-ply samples would perform better than the thicker ply samples at higher temperatures. This is because testing at temperatures above the $\mathrm{T}_{\mathrm{g}}$ typically leads to a decrease in strength [52], as the material changes from its glassy state to a more rubbery state [48]. As the results in Table 6.1 show, the thin-ply material displayed higher strength in all three conditions, compared to the other materials. That said, the $50 \mathrm{~g} / \mathrm{m}^{2}$ samples increased in strength by $5 \%$ when tested at $120{ }^{\circ} \mathrm{C}$, but decreased by $3 \%$ when tested at $150{ }^{\circ} \mathrm{C}$, compared to the ambient temperature result. The $150 \mathrm{~g} / \mathrm{m}^{2}$ samples had a different trend, with the $120{ }^{\circ} \mathrm{C}$ and the $150{ }^{\circ} \mathrm{C}$ samples decreasing in strength by $5 \%$ and $9 \%$ respectively. On the contrary, the $300 \mathrm{~g} / \mathrm{m}^{2}$ samples increased by $16 \%$ when tested at $120{ }^{\circ} \mathrm{C}$, and by $23 \%$ when tested at $150{ }^{\circ} \mathrm{C}$. This was unexpected, due to the lower $\mathrm{T}_{\mathrm{g}}$ of the material. These results can also be seen in graphical form in Chapter 4, Figure 4.24 .

A possible mechanism for the increased tensile strength is that the resin became weaker, but tougher and therefore more flexible at high temperature. This reduces the interfacial stresses, because the plies can move more freely and therefore the stresses can be redistributed. This would perhaps explain why a greater increase in strength is seen with the thicker ply specimens, which have 
the largest interfacial stresses. A further possible mechanism for the increased strength is that the increased temperature allowed the resin matrix to cure further, making the material stronger. Thermosetting materials, such as epoxy resins, experience molecular cross-linking during the curing process [115]. If the resin matrix within the laminates was not fully cured during the manufacturing process, it is possible that the additional heat from the tensile test enabled more crosslinks to form. These additional crosslinks could lead to enhanced strength of the resin and thus increased strength of the composite. This is unlikely, given that the curing cycle for the laminates was two hours at $130{ }^{\circ} \mathrm{C}$, followed by four hours at $165^{\circ} \mathrm{C}$. It would be unusual for much additional curing to take place at the lower test temperature, especially in the short time period that the sample was exposed to the test environment for.

Table 6.1 Mean QI unnotched tensile stress values in MPa (normalised) [minimum of five samples per test]

\begin{tabular}{|c|c|c|c|c|c|c|}
\hline \multirow{2}{*}{ Prepreg } & \multicolumn{2}{|c|}{$50 \mathrm{~g} / \mathrm{m}^{2}$} & \multicolumn{2}{|c|}{$150 \mathrm{~g} / \mathrm{m}^{2}$} & \multicolumn{2}{|c|}{$300 \mathrm{~g} / \mathrm{m}^{2}$} \\
\cline { 2 - 7 } & Mean & $\begin{array}{c}\text { Standard } \\
\text { error }\end{array}$ & Mean & $\begin{array}{c}\text { Standard } \\
\text { error }\end{array}$ & Mean & $\begin{array}{c}\text { Standard } \\
\text { error }\end{array}$ \\
\hline Unconditioned & 951 & 7.4 & 878 & 9.9 & 658 & 12.0 \\
\hline$+120^{\circ} \mathrm{C}$ & 999 & 7.9 & 832 & 16.8 & 760 & 29.9 \\
\hline$+150^{\circ} \mathrm{C}$ & 918 & 9.3 & 802 & 10.8 & 809 & 15.6 \\
\hline
\end{tabular}

To test the two hypotheses, six additional $300 \mathrm{~g} / \mathrm{m}^{2}$ unnotched tensile samples, all from the same laminate, were tested. Three samples were tested in the 'as received' condition and three were placed into a Gallenkamp air and humidity oven, preheated to $150^{\circ} \mathrm{C}$, for five minutes. A UKAS calibrated PTFE coated Type K thermocouple, with an RS 1384 Data Logging Thermometer was used to monitor temperature. A time of five minutes was chosen in an attempt to replicate the level of cure the high temperature tested samples would have received during the tensile test. The samples were then allowed to cool before being tensile tested 
using the same methodology as the 'as received' samples. The results of the experiment are shown in Table 6.2.

Table 6.2 Comparison of ultimate tensile stress values for $300 \mathrm{~g} / \mathrm{m}^{2}$ samples tested after exposure to different environments

\begin{tabular}{|c|c|c|}
\hline & \multicolumn{2}{|c|}{ Max Stress (MPa) } \\
\hline Test material & Mean & Standard error \\
\hline $\begin{array}{c}300 \mathrm{~g} / \mathrm{m}^{2} \text { tested as received } \\
300 \mathrm{~g} / \mathrm{m}^{2} \text { tested after a five minute } \\
\text { cure at } 150^{\circ} \mathrm{C}\end{array}$ & 656 & 29.5 \\
\hline
\end{tabular}

No significant difference in UTS was seen between the two sets of test coupons. Furthermore, the $300 \mathrm{~g} / \mathrm{m}^{2}$ samples tested at a temperature of $150{ }^{\circ} \mathrm{C}$ had a UTS of $809 \mathrm{MPa}$ (as shown in Section 4.5.1), which is an increase of $15 \%$ compared to the sample which was cured at $150{ }^{\circ} \mathrm{C}$ for five minutes and then tested at ambient conditions. This suggests that the increase in strength is likely due to the resin becoming more flexible, rather than an increased level of cure.

Interestingly, a decrease in properties as temperature increases is likely to be a result of the high temperature causing the resin to decrease in strength. This leads to more stress being put onto the fibres, thus the composite fails earlier than it would at ambient temperature.

These two hypotheses would suggest that the intermediate-ply samples should increase in strength, similar to the $300 \mathrm{~g} / \mathrm{m}^{2}$ specimens. However, this was not the case. It is possible that changes in the $\mathrm{T}_{\mathrm{g}}$ of the panels influenced the results. To explain, the CFRP panels under investigation were received in two deliveries, with the laminates being cured on three separate occasions. The batches were all cured using the same conditions, however the $\mathrm{T}_{\mathrm{g}}$ of the second delivery of laminates was found to be approximately $10{ }^{\circ} \mathrm{C}$ to $15^{\circ} \mathrm{C}$ lower for all ply thicknesses. This is independent of the difference in $\mathrm{T}_{\mathrm{g}}$ between the thin and thick-ply panels, as discussed previously (see Section 4.2.3). A graph of the glass 
transition temperatures for each panel used in the QI unnotched tensile tests is presented in Figure 6.6. It is possible that the differences in $\mathrm{T}_{\mathrm{g}}$ influenced the results. A potential reason for this difference in $T_{g}$ was investigated and is discussed in Section 6.2.

In summary, the mechanical test results from the QI laminates showed clear differences between samples produced with different prepreg thicknesses. The thin-ply coupons out-performed both the $150 \mathrm{~g} / \mathrm{m}^{2}$ and the $300 \mathrm{~g} / \mathrm{m}^{2}$ samples when tested at both ambient and high temperatures. This is thought to be a result of the lower interfacial stresses associated with thinner plies.

The effect of ply thickness on UD samples conditioned in humid environments was not discussed in this chapter, due to the high scatter and uncertainty associated with the test data (as discussed in Section 5.3.2). In brief, the results for the $90^{\circ} \mathrm{UD}$ samples showed no significant differences as a result of changing ply thickness for the 'as received' samples, or those conditioned at $45 \% \mathrm{RH}$. For the samples exposed to both $65 \%$ and $85 \% \mathrm{RH}$ the thinner ply specimens showed enhanced UTS. However, as noted previously, the high scatter associated with this test data (attributed to the small tabbing region leading to uneven gripping of the samples) means that further work in this area would be preferable to ensure reliability. 


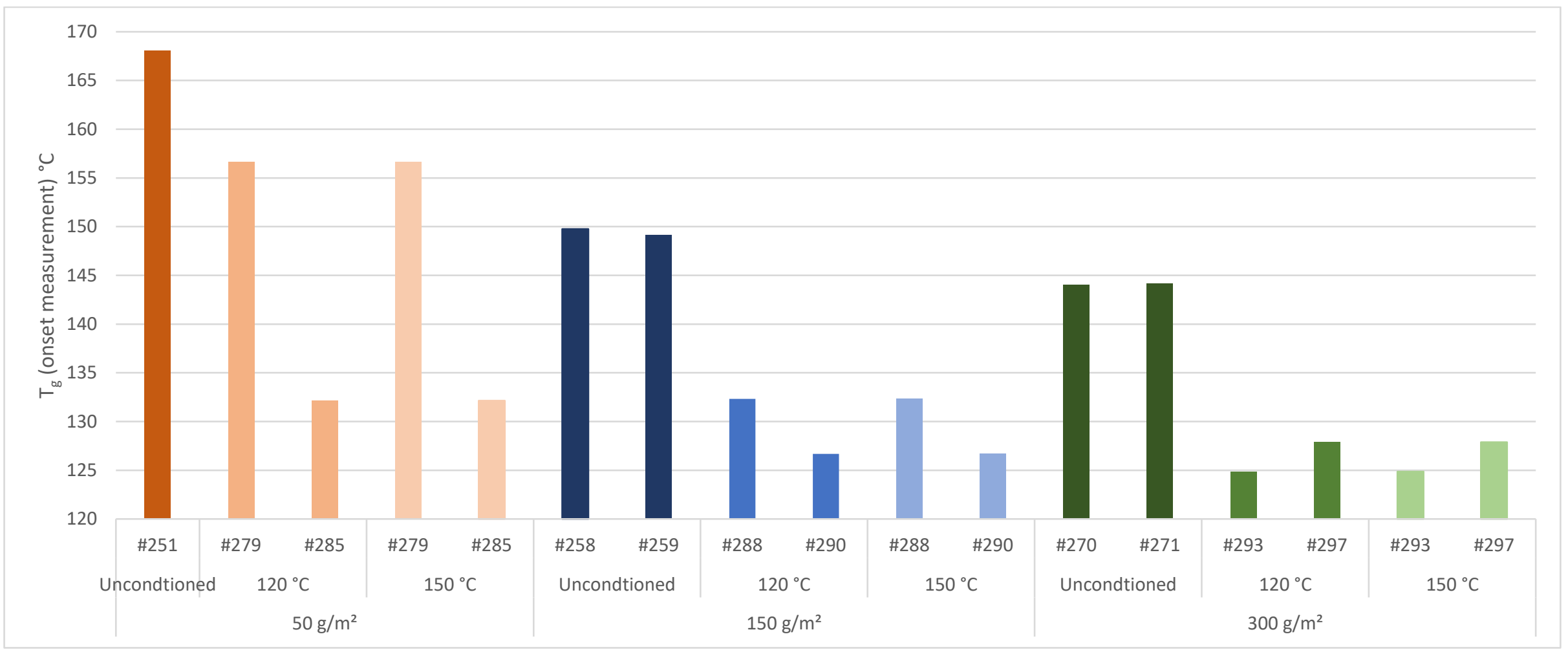

Figure 6.6 Graph to show the glass transition temperature of each panel used for the unnotched tensile samples under various test conditions (50 g/m ${ }^{2}$ samples: orange, $150 \mathrm{~g} / \mathrm{m}^{2}$ samples: blue, $300 \mathrm{~g} / \mathrm{m}^{2}$ samples: green) 


\subsubsection{Quasi-static Open-hole Tensile Behaviour}

\subsubsection{Quasi-isotropic Open-hole Tensile Behaviour at Ambient Temperature}

In contrast to the QI unnotched tensile results, the thin-ply material did not perform as well as the thicker ply laminates when open-hole tensile properties were tested. To recap, the mean UTS of the $50 \mathrm{~g} / \mathrm{m}^{2}, 150 \mathrm{~g} / \mathrm{m}^{2}$ and $300 \mathrm{~g} / \mathrm{m}^{2}$ samples were $447 \mathrm{MPa}$, $551 \mathrm{MPa}$ and $565 \mathrm{MPa}$ respectively, as shown in Section 4.3.4.

Despite the clear difference in performance between the unnotched and the open-hole tensile tests, it is thought that the samples failed via the same mechanisms. As before, the thin-ply specimens had lower interfacial stresses, however, due to the presence of the hole, the lower interfacial stresses did not lead to a higher ultimate stress. The $6 \mathrm{~mm}$ hole in the centre of the tensile sample creates a large stress concentration. The larger interfacial stresses that are present in the thicker ply samples tend to reduce reliance on this stress concentration. As with the QI unnotched tensile samples, the larger interfacial stresses lead to failure of the $45^{\circ}$ plies first. These ply failures help to redistribute stresses within the sample, which, in turn, enable the samples to reach a higher UTS. For the thin-ply samples, the smaller interfacial stresses cause the material to act like a more homogenous material, putting more reliance on the large stress concentration at the hole, thus causing failure at lower load.

High-speed camera video recording was used to learn more about the progression of failure of the open-hole tensile samples. As with the QI unnotched tensile samples, the $50 \mathrm{~g} / \mathrm{m}^{2}$ sample had a very localised, brittle failure mode with no visible delamination. Figure 6.7 shows the progression of this failure. Typically, open-hole tensile samples fail laterally across the hole. This is a result of the high stresses which are generated at the sides of the hole and the very low 
stresses generated immediately above and below the hole. DIC was used to demonstrate this; the results are discussed in more detail later in this section.

Figure 6.8 shows a typical failure of the $150 \mathrm{~g} / \mathrm{m}^{2}$ open-hole tensile sample. This specimen did not fail laterally along the hole. Instead, failure occurred along the $45^{\circ}$ plies, which in turn causes ultimate failure. As described previously, the larger interfacial stresses generated by the thicker prepreg allows the dependence of the stress concentration at the hole to be reduced, leading to a greater UTS.

The thickest ply sample follows the same pattern as the intermediate-ply laminate, but this time the interfacial stresses are larger, thus delamination occurs to a greater extent. Figure 6.9 and Figure 6.10 show the point of failure. It should be noted that due to the useable memory of the high-speed camera video recorder, it was not possible to record the entire failure of the sample, because of its very progressive nature. Consequently, Figure 6.9 and Figure 6.10 are images of different samples; both show the same failure mechanism, just at different stages of the failure. Figure 6.9 shows the initial failure of the outer $45^{\circ}$ ply and Figure 6.10 shows the ultimate failure of a second sample. The coupon does not fail immediately after the $45^{\circ}$ plies break, because the stresses within the sample redistribute with individual ply failure, and the stronger $0^{\circ}$ plies are capable of withstanding further load. For the $150 \mathrm{~g} / \mathrm{m}^{2}$ sample, the interfacial stresses are smaller, therefore less damage occurs within the sample prior to failure. Hence, when the outer $45^{\circ}$ plies fail, the rest of the sample fails too. For the $50 \mathrm{~g} / \mathrm{m}^{2}$ sample, the very small interfacial stresses mean that sample failure doesn't occur until the $0^{\circ}$ fibres break, causing a very localised, lateral failure. 


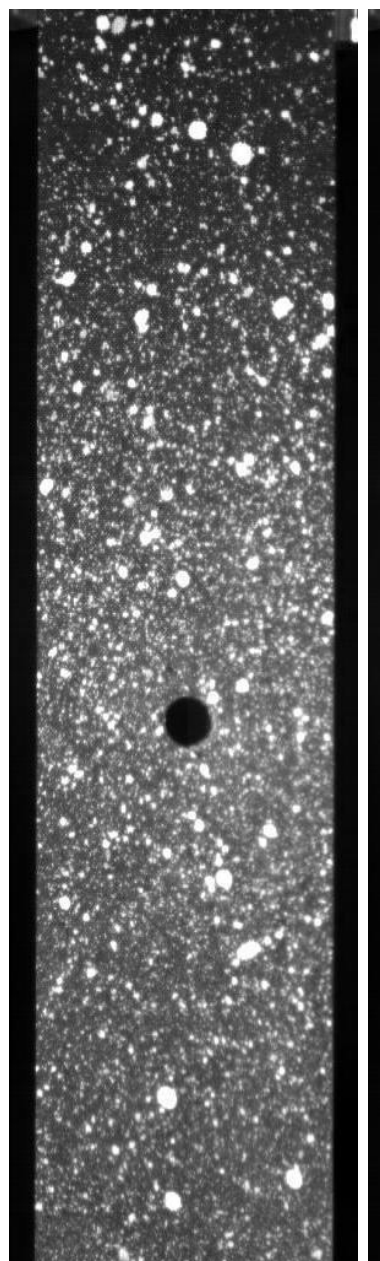

$0.000 \mathrm{~ms}$

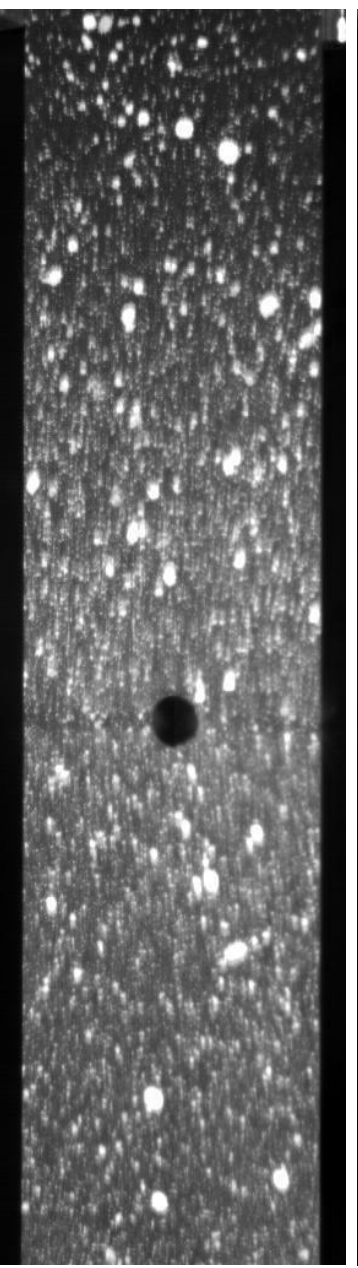

$0.125 \mathrm{~ms}$

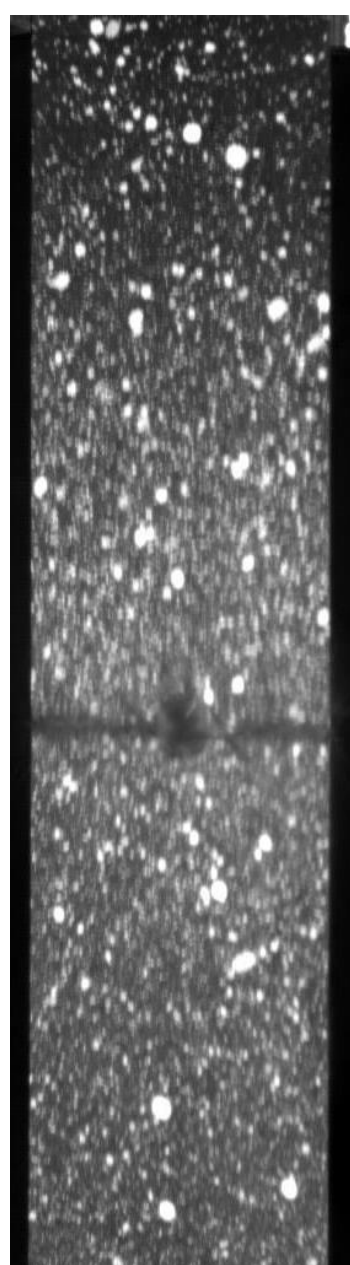

$0.250 \mathrm{~ms}$

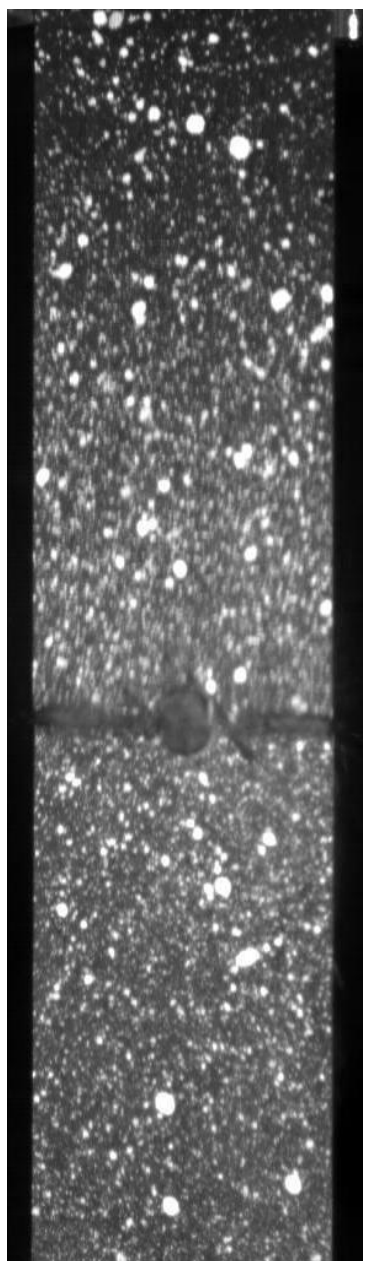

$0.500 \mathrm{~ms}$

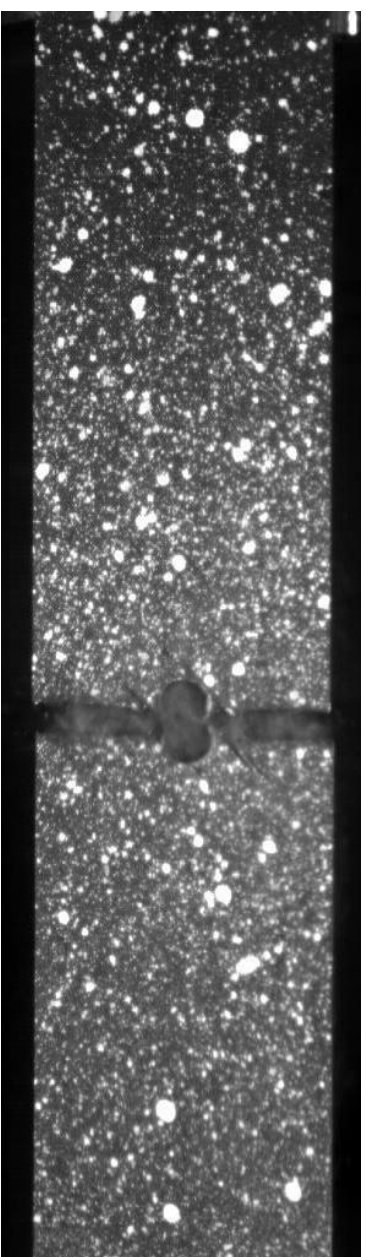

$1.000 \mathrm{~ms}$

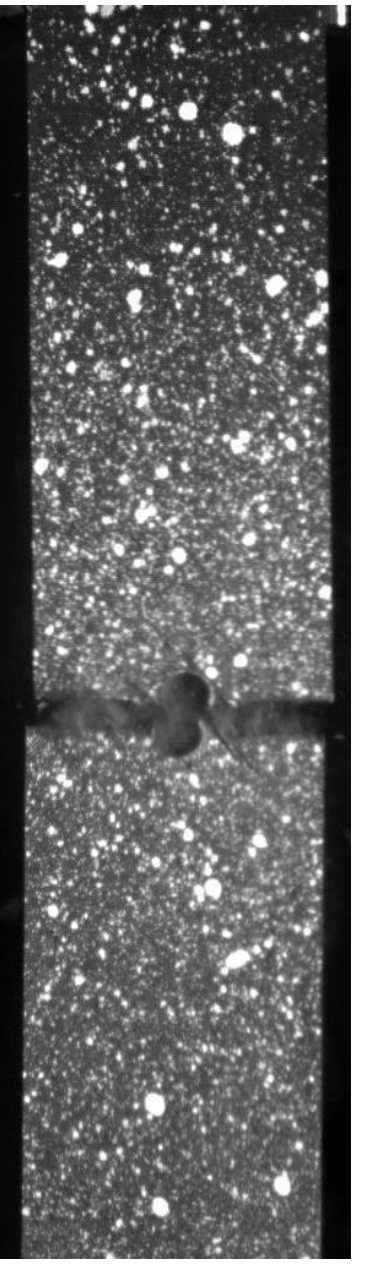

$1.750 \mathrm{~ms}$

Figure 6.7 Stills from high speed camera video recording of a $50 \mathrm{~g} / \mathrm{m}^{2}$ open-hole tensile failure mechanism (shot at 8,000 fps) 


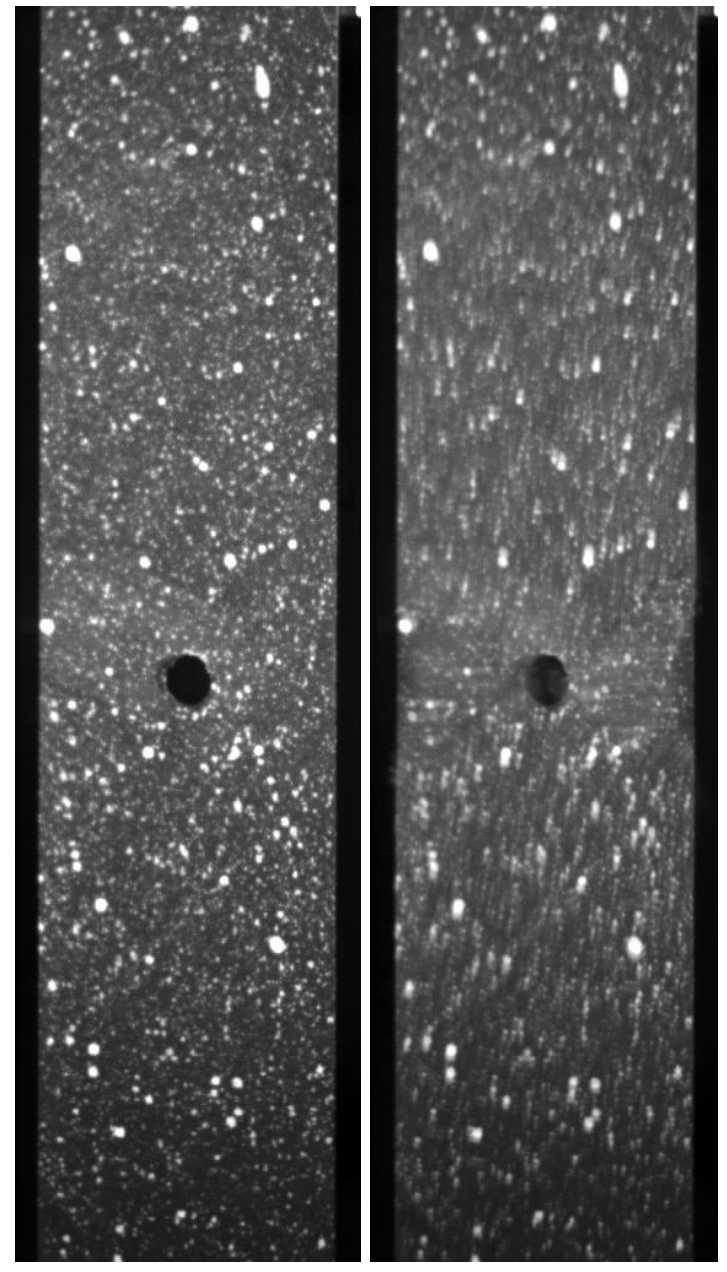

$0.000 \mathrm{~ms}$

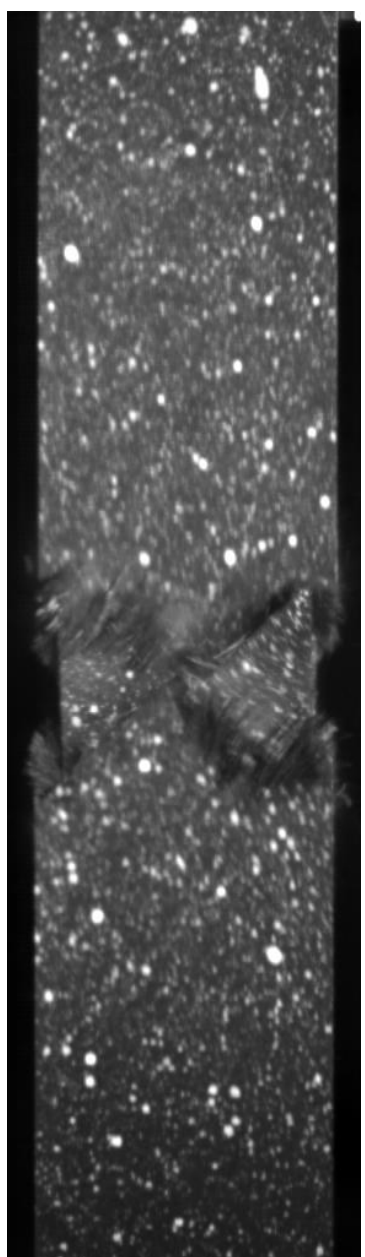

$0.250 \mathrm{~ms}$

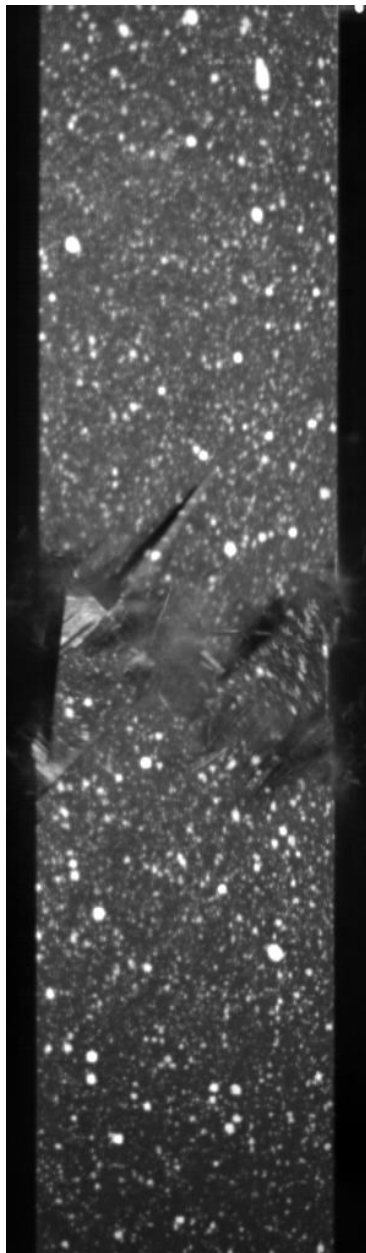

$0.500 \mathrm{~ms}$

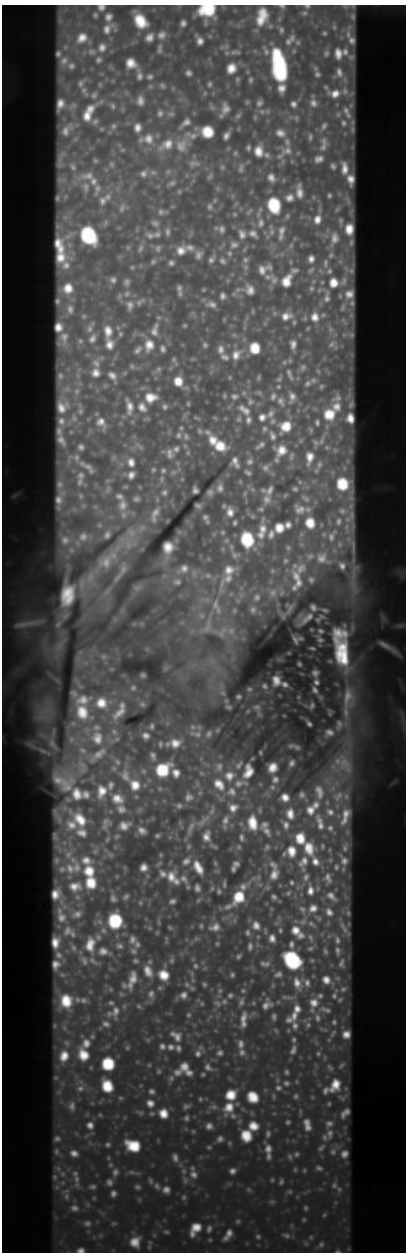

$1.000 \mathrm{~ms}$

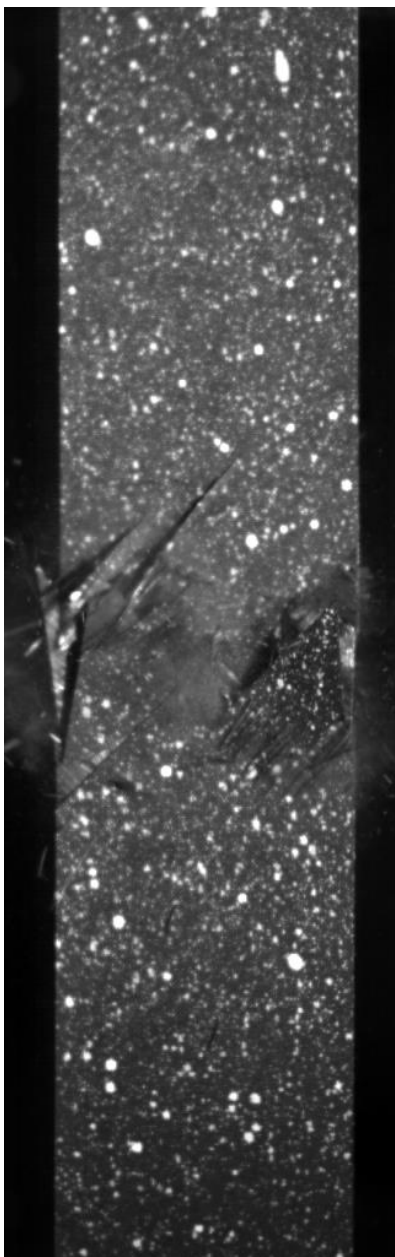

$1.750 \mathrm{~ms}$

Figure 6.8 Stills from high speed camera video recording of a $150 \mathrm{~g} / \mathrm{m}^{2}$ open-hole tensile failure mechanism (shot at 8,000 fps) 


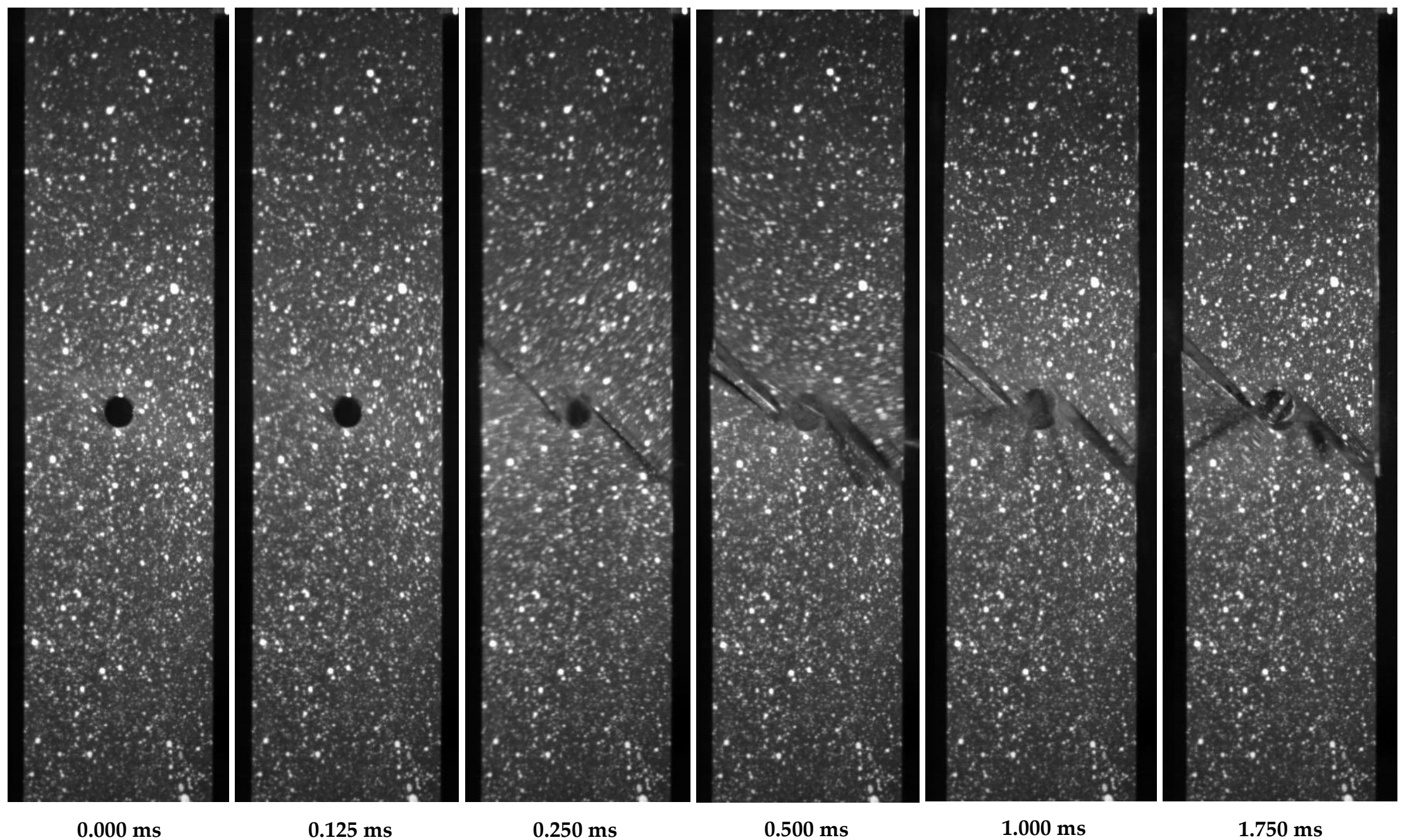

Figure 6.9 Stills from high speed camera video recording of a $300 \mathrm{~g} / \mathrm{m}^{2}$ open-hole tensile failure mechanism (shot at 8,000 fps) [initial failure, specimen 1] 


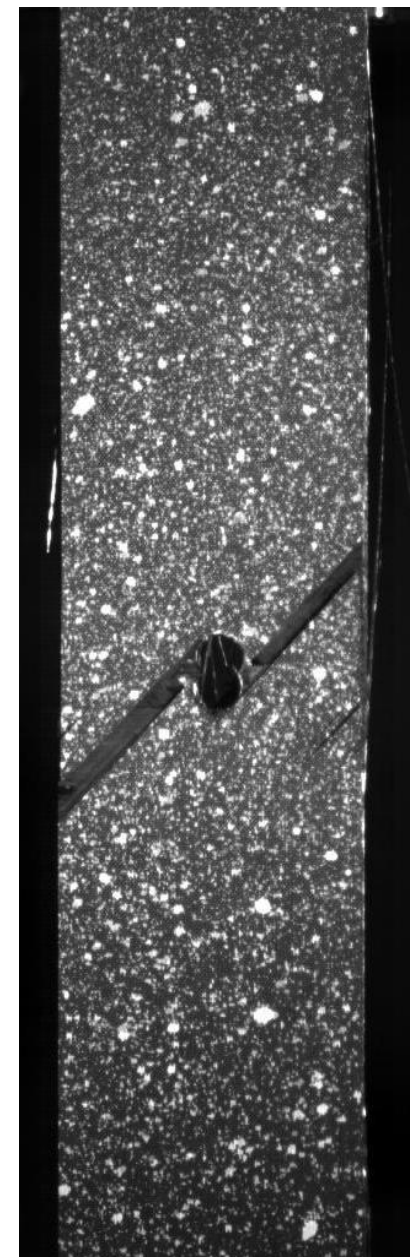

$0.000 \mathrm{~ms}$

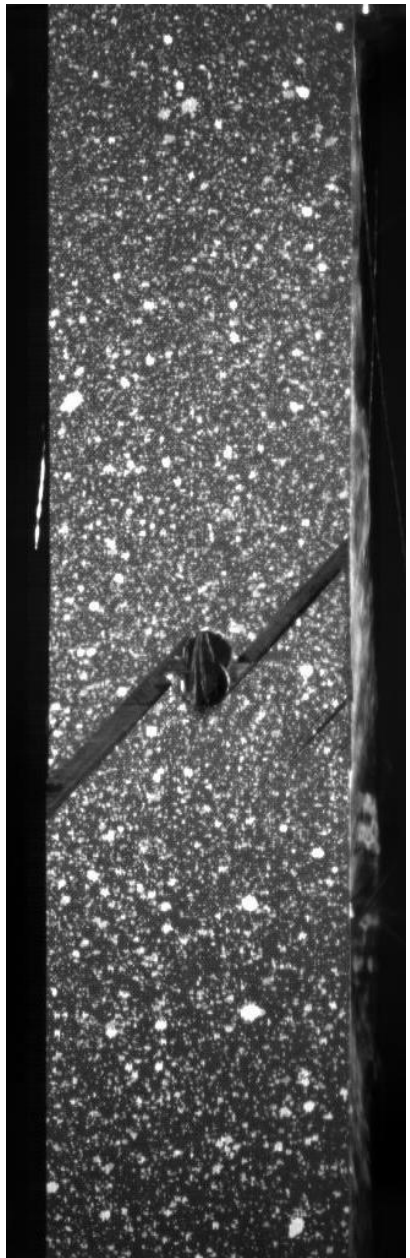

$0.125 \mathrm{~ms}$

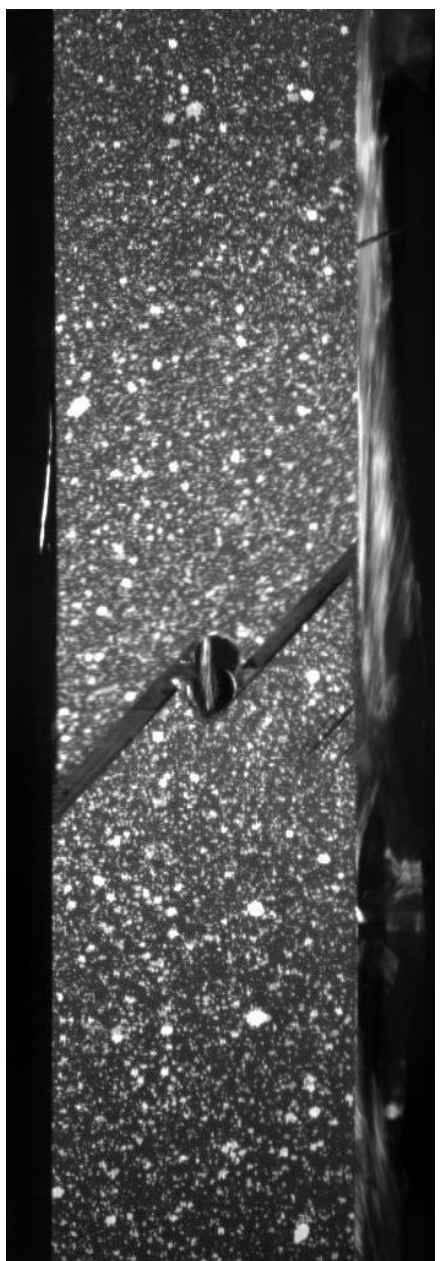

$0.250 \mathrm{~ms}$

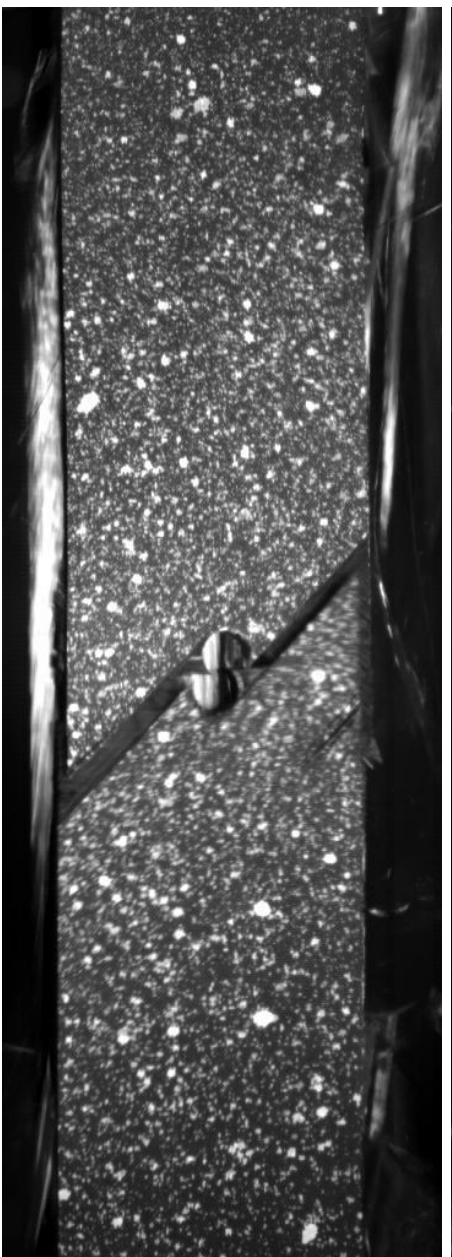

$0.500 \mathrm{~ms}$

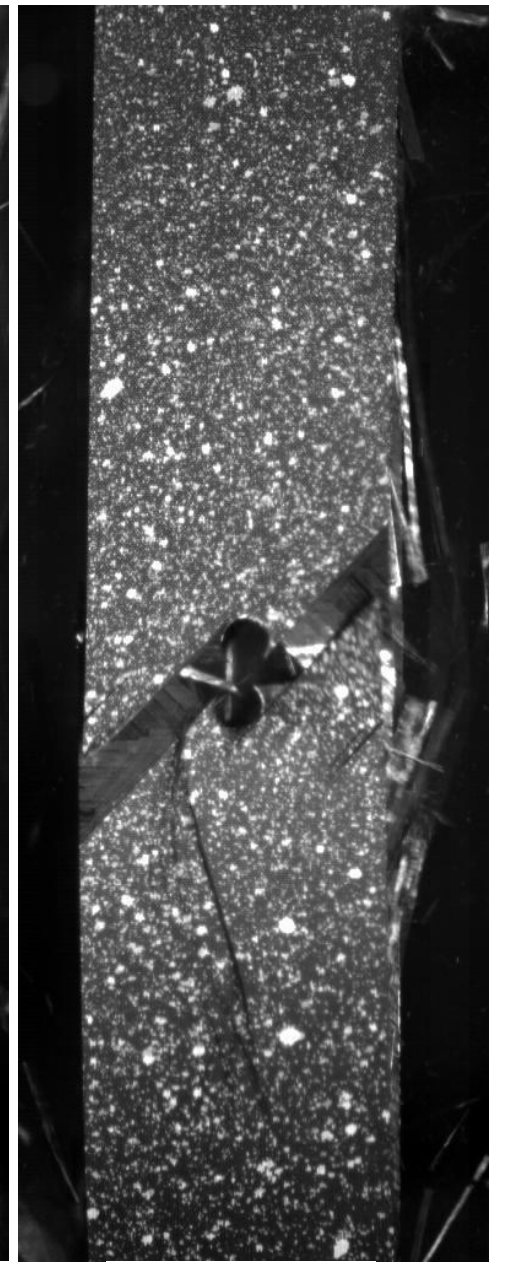

$1.750 \mathrm{~ms}$

Figure 6.10 Stills from high speed camera video recording of a $300 \mathrm{~g} / \mathrm{m}^{2}$ open-hole tensile failure mechanism (shot at 8,000 fps) [final failure, specimen 2] 
DIC was performed on one sample of each ply thickness material, as per the methodology in Section 3.6. The strain scales were set to the same upper and lower limits for each sample, to enable direct comparison of the results. Eleven marker points were placed in the same position on each sample (labelled A to K), to show the local strain at that particular area. Figure 6.11 shows the DIC strain maps immediately prior to sample failure for all three ply thickness materials.

The strain map for the $50 \mathrm{~g} / \mathrm{m}^{2}$ does not show a uniform strain increase for each marker point, unlike the $50 \mathrm{~g} / \mathrm{m}^{2}$ unnotched tensile sample. This is due to the stress concentration generated by the presence of the hole. As described earlier, the stresses around the hole are far greater laterally across the hole (see markers C and G), compared to directly above and below it (markers A and E). Aside from the strains immediately surrounding the hole, the local strains across the rest of the sample are largely uniform, as shown by markers I, J and K. On the contrary, the $150 \mathrm{~g} / \mathrm{m}^{2}$ and $300 \mathrm{~g} / \mathrm{m}^{2}$ samples show areas of increased strain at marker point $\mathrm{K}$, which is further away from the centre hole area. This is due to the larger interfacial stresses causing the off-axis plies to fail, therefore reducing the reliance of the stress concentration at the hole. 


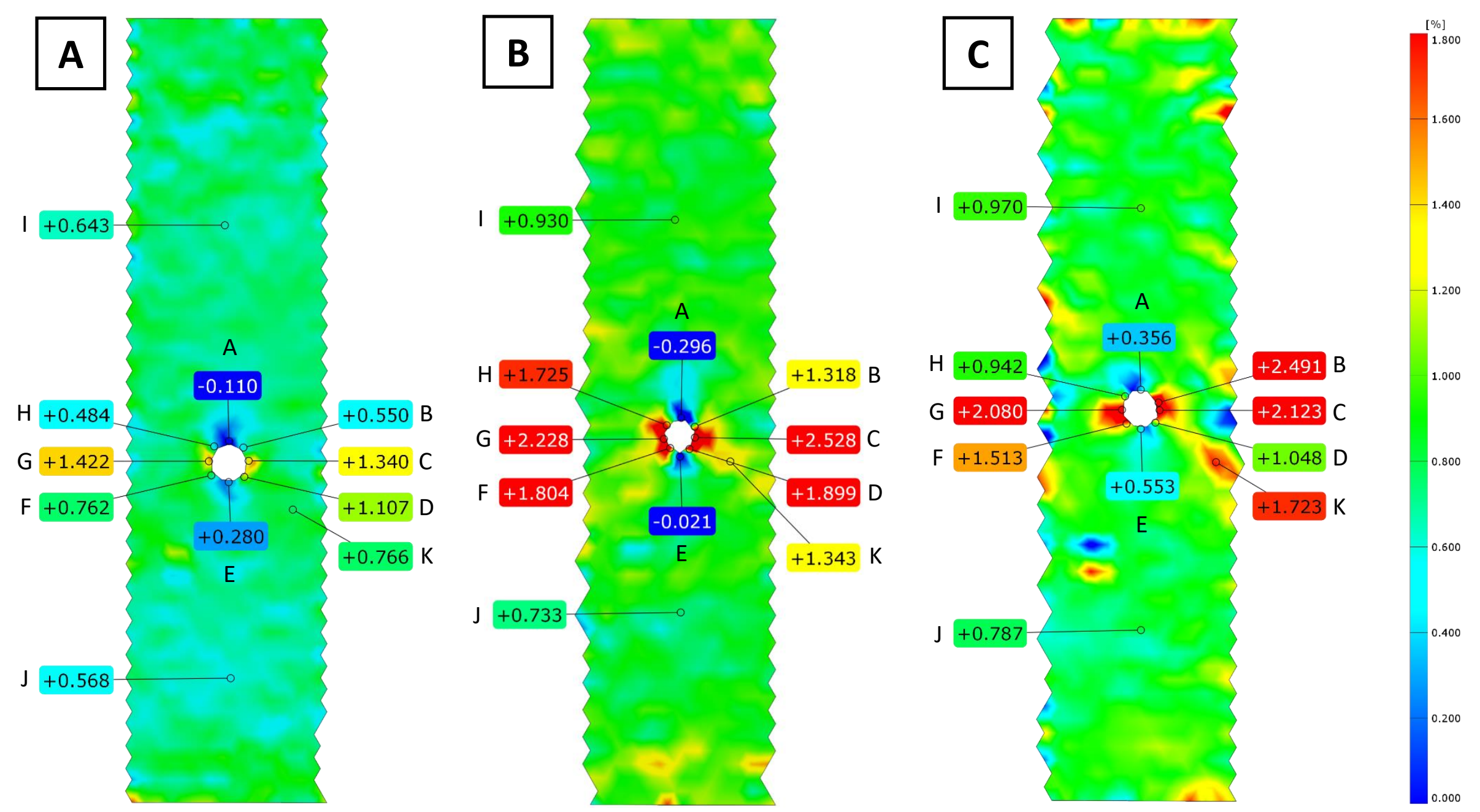

Figure 6.11 Change in strain (tensile load direction) during open-hole tensile tests: a) $50 \mathrm{~g} / \mathrm{m}^{2}$, b) $\left.150 \mathrm{~g} / \mathrm{m}^{2}, \mathrm{c}\right) 300 \mathrm{~g} / \mathrm{m}^{2}$ ). Images show strain map immediately prior to sample break 


\subsubsection{Quasi-isotropic Open-hole Tensile Behaviour at High Temperature}

Unlike the high temperature QI unnotched tensile results, the different ply thickness materials all followed the same trend when high temperature QI open-hole tensile behaviour was studied. That said, the results were different to what was expected. Based on the findings of the ambient temperature testing, it was hypothesised that the thin-ply coupons would have the lowest strength values at higher temperatures. This was found to be true. However, it was also hypothesised that the strength of the thicker ply samples would start to deteriorate at $150{ }^{\circ} \mathrm{C}$, due to the lower $\mathrm{T}_{\mathrm{g}}$ of the panels. This was not the case. As the summarised results in Table 6.3 show, the UTS of each sample increased with an increase in temperature.

Table 6.3 Mean QI open-hole tensile stress values in MPa (normalised) [minimum of five samples per test]

\begin{tabular}{|c|c|c|c|c|c|c|}
\hline \multirow{2}{*}{ Prepreg } & \multicolumn{2}{|c|}{$50 \mathrm{~g} / \mathrm{m}^{2}$} & \multicolumn{2}{|c|}{$150 \mathrm{~g} / \mathrm{m}^{2}$} & \multicolumn{2}{c|}{$300 \mathrm{~g} / \mathrm{m}^{2}$} \\
\cline { 2 - 7 } & Mean & $\begin{array}{c}\text { Standard } \\
\text { error }\end{array}$ & Mean & $\begin{array}{c}\text { Standard } \\
\text { error }\end{array}$ & Mean & $\begin{array}{c}\text { Standard } \\
\text { error }\end{array}$ \\
\hline Unconditioned & 447 & 3.4 & 551 & 17.0 & 565 & 12.1 \\
\hline$+120^{\circ} \mathrm{C}$ & 451 & 3.2 & 588 & 13.8 & 582 & 10.8 \\
\hline$+150^{\circ} \mathrm{C}$ & 486 & 6.8 & 598 & 19.0 & 626 & 10.4 \\
\hline
\end{tabular}

Similar to the QI unnotched tensile results, a possible mechanism for the increased UTS is that an increase in resin cure (achieved due to the high temperature) caused the overall material strength to increase. If the resin is stronger, the fibres are required to carry less load and therefore can withstand a greater stress before failure. The reason why the different materials had different increases in UTS could be due to the glass transition temperature of the laminates. The glass transition temperatures of each laminate used for open-hole tensile testing are shown in Figure 6.12. DMA analysis showed that the thin-ply samples had a higher $\mathrm{T}_{\mathrm{g}}$ compared to both the intermediate and thick-ply samples 
(possible reasons for this are explored in Section 6.2). Therefore, when the panels were heated during testing, the intermediate and thick-ply samples may have cured more than the thin-ply material, because the thin-ply coupons were already at a higher degree of cure. This additional curing could have led to the enhanced UTS. However, given that the cure cycle for the material was two hours at $130{ }^{\circ} \mathrm{C}$ followed by four hours at $165^{\circ} \mathrm{C}$, it is assumed that any curing which may have taken place at $150{ }^{\circ} \mathrm{C}$, or certainly at $120^{\circ} \mathrm{C}$, had already occurred, especially given the short length of time that the coupons were exposed to the test temperature (approximately five minutes).

A second hypothesis is that the higher temperature caused the resin to become weaker, but tougher and more flexible. The more flexible resin allowed the stress concentrations to even out, leading to the enhanced UTS. This mechanism has more of an effect with the open-hole tensile samples than the unnotched tensile samples, due to the large stress concentration of the hole. Also, the thicker ply samples benefit more from this, because they have larger interfacial stresses to begin with.

In Section 6.1.1.3, similar hypotheses (additional cure, or more flexible matrix) were discussed for the increase in UTS of QI unnotched tensile samples tested at high temperature. An experiment was carried out to see if the strength of the material increased after being exposed to a short cure at $150{ }^{\circ} \mathrm{C}$. The results suggested that the increase in strength was likely due to the resin becoming weaker and more flexible at high temperature and not due to additional curing. The same mechanism is thought to have occurred with the open-hole tensile samples. 


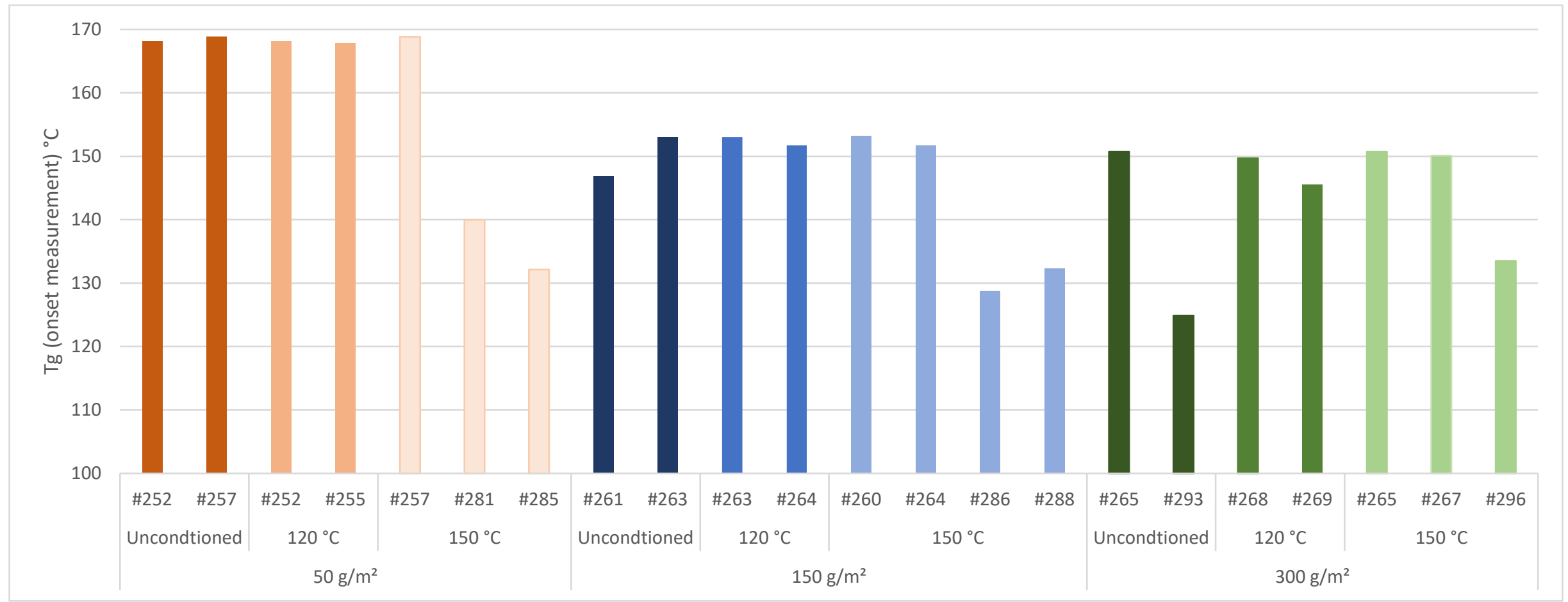

Figure 6.12 Graph to show the glass transition temperature of each panel used for the open-hole tensile samples, under various test conditions (50 g/ $\mathrm{m}^{2}$ samples: orange, $150 \mathrm{~g} / \mathrm{m}^{2}$ samples: blue, $300 \mathrm{~g} / \mathrm{m}^{2}$ samples: green) 


\subsubsection{Quasi-static Unnotched Compressive Behaviour}

\subsubsection{Unidirectional Compressive Behaviour at Ambient Temperature}

In contrast to the results of Amacher et al. [14], the compressive strength of the UD thin-ply material was lower than the intermediate-ply material. There are several, quite different, standards available for assessing compressive strength of fibre reinforced materials. Some of these are end-loaded techniques, others are shear loading. Amacher et al. [14] tested compressive properties of UD thin-ply material using a modified version of ASTM 5467, whereby load is applied to the sample (which is in the form of a sandwich panel) using a four-point bending mechanism. The use of different standards for the determination of compressive properties may account for aforementioned difference in results.

The results from the T800 TP135 material showed that the thin-ply material was slightly weaker than the thick-ply material. However, due to the lack of ply boundaries within the UD material, the two different ply thicknesses would be expected to give similar results. The compressive failure mode (fibre micro-buckling) is different to the tensile failure mode. Micro-buckling occurs in compression as a result of the differing thermal expansion properties of the fibre and resin. These differences lead to the fibres become slightly wavy during the curing process. This waviness is less of an issue when tested in tension, as the fibres are able to straighten, however in compression it can lead to micro-buckling within the material [116]. This explains why the compressive properties differ from tensile properties and could explain why the samples do not follow the UD tensile trend. The reason for the increased strength of the $150 \mathrm{~g} / \mathrm{m}^{2}$ sample could be due to the higher fibre volume fraction of this material. The thin-ply material had a lower fibre volume fraction compared to the intermediate-ply laminates. This small increase in resin content may have given the fibres more freedom to buckle, thus lowering the strength. The process of normalising the data (using Equation 6 in Section 3.2.2) ideally would have accounted for this, but a possible 
explanation is that the dependence of fibre content on compressive strength is stronger than a linear correlation, thus the compressive strength of the thin-ply samples was lower than the intermediate-ply samples.

\subsubsection{Quasi-isotropic Compressive Behaviour at Ambient Temperature}

When the same unnotched compression test was conducted on QI laminates, a different trend emerged. This time the thin-ply material had a $7 \%$ increase in strength compared to the intermediate ply coupons (769 MPa compared to $719 \mathrm{MPa})$. This is very similar to the results seen with UD and QI unnotched tension (UD tension saw minimal effects of ply thickness, whereas QI tension saw a large difference in properties with changes to ply thickness). As mentioned previously, compressive failure is dominated by micro-buckling of the $0^{\circ}$ plies. The $50 \mathrm{~g} / \mathrm{m}^{2}$ samples have thinner plies, therefore it is hypothesised that the higher strength is a result of the thinner plies having less space to buckle before the neighbouring ply constrains movement, in comparison to the thicker-ply samples. This would not occur with the UD samples, as all of the plies are orientated in the same direction. Furthermore, as discussed by Lee and Soutis [68] once micro-buckling has occurred, the damage can propagate across the thickness of the ply. Thus, if the ply thickness is greater, damage could propagate more readily, promoting earlier failure.

\subsubsection{Quasi-static Open-hole Compressive Behaviour}

This section will compare and discuss the open-hole compressive test results reported in Chapter 4 and Chapter 5. These tests include:

- Unconditioned QI open-hole compression

- High temperature QI open-hole compression

- Conditioned QI open-hole compression

Thin-ply material has been found to have enhanced open-hole compressive strength, as shown in Section 4.3.7. This is in contrast to the open-hole tensile 
results. As discussed previously, the tension and compression failure mechanisms are very different; this gives rise to the difference in thin-ply performance. Compressive failure of fibre composites is dominated by micro-buckling of the $0^{\circ}$ plies. As the $50 \mathrm{~g} / \mathrm{m}^{2}$ sample has thinner plies, there is a smaller area for the $0^{\circ}$ plies to buckle before the neighbouring ply constrains the movement. On the other hand, the thicker ply samples have a larger area within the ply for the fibres to buckle. It is thought that this enables the $0^{\circ}$ plies to buckle more easily and therefore fail sooner.

Again, in contrast to the open-hole tensile results, the open-hole compressive samples significantly decreased in strength when tested at both $120{ }^{\circ} \mathrm{C}$ and $150{ }^{\circ} \mathrm{C}$. This happened for all three materials. The mechanism for this decrease in strength is likely to be due to the resin becoming weaker, but more flexible at higher temperature, as is the case with the tensile samples. However, for compressive properties, the more flexible resin allows micro-buckling of the fibres to occur more easily, thus leading to lower strengths.

Open-hole compressive properties of samples conditioned in various humid environments were also investigated. Unlike the high temperature results, moisture ingress did not appear to negatively impact compressive strength. This was unexpected, because compressive strength is highly dependent on the matrix properties, thus increased water content would typically negatively impact compressive strength [117]. The strength of the samples conditioned until saturation at $45 \% \mathrm{RH}$ significantly increased for the thicker ply materials. The $65 \% \mathrm{RH}$ and the $85 \% \mathrm{RH}$ conditioned samples also performed well compared to the unconditioned specimens. Initially it was thought that the compressive strength of the conditioned samples would decrease, due to water ingress causing plasticisation of the matrix [99]. Plasticisation would cause the resin to become tougher and more flexible. This could then allow the fibres to buckle more easily, as was the case with the high temperature samples. Instead of becoming weaker, 
the specimens generally became stronger after conditioning in the humid environments. One hypothesis for this is that the samples experienced extra curing. During the conditioning process the specimens were maintained at a temperature of $70{ }^{\circ} \mathrm{C}$ until saturation, to speed up the ingress of moisture. For the various humid environments, the time taken for saturation was 51 days for $85 \% \mathrm{RH}, 77$ days for $65 \% \mathrm{RH}$ and 141 days for $45 \% \mathrm{RH}$. Prior to insertion into the humidity chambers, conditioning at this temperature was thought to be suitable, because it was significantly below the curing temperature of the laminates. Thus, no more curing was likely to occur. To test this theory a minimum of four open-hole compression samples, made from each of the three materials, were placed into an oven at a temperature of $70{ }^{\circ} \mathrm{C}$ for approximately 141 days. After this, the compressive strengths of the samples were tested. The results are shown in Figure 6.13. Surprisingly, despite the conditioning temperature being much lower than the curing temperature of the laminates, the samples cured in the oven for 141 days saw a significant increase in strength, compared to the unconditioned specimens. This occurred for all three of the materials. This suggests that the samples did benefit from an extra cure during the conditioning, despite the low temperature. It is thought that the relatively long length of time spent at this low temperature allowed more crosslinks to form, thus strengthening the matrix.

Given this new information, the humidity exposed sample results should be compared to the oven cured samples, not the 'as received' samples. Once this is taken into consideration, the humidity exposed samples did decrease in strength, which was as to be expected. The $65 \% \mathrm{RH}, 50 \mathrm{~g} / \mathrm{m}^{2}$ sample decreased in strength by $10 \%$ compared to the oven cured specimens. The $150 \mathrm{~g} / \mathrm{m}^{2}$ and the $300 \mathrm{~g} / \mathrm{m}^{2}$ samples decreased by $8 \%$ and $10 \%$ respectively. Interestingly, the intermediate and thick-ply samples conditioned at $45 \% \mathrm{RH}$ did not significantly decrease in strength compared to the oven cured samples. On the contrary, the thin-ply specimens did. In Section 5.2.2, it was discussed that the QI thin-ply material 
absorbed a greater level of moisture, compared to the thicker ply materials. It is possible that a greater level of moisture absorption caused the difference in compressive strength degradation. Contrary to this hypothesis, the $45 \% \mathrm{RH}$ conditioned thin-ply material still out-performed both the intermediate and thick-ply samples, for every test condition. Furthermore, the decrease in strength between the thin-ply oven cured samples and the $85 \% \mathrm{RH}$ samples was $12 \%$, whereas for the thick-ply samples, the decrease was $18 \%$. This shows that, despite absorbing more moisture, the thin-ply compressive strength was superior to the thicker-ply alternatives.

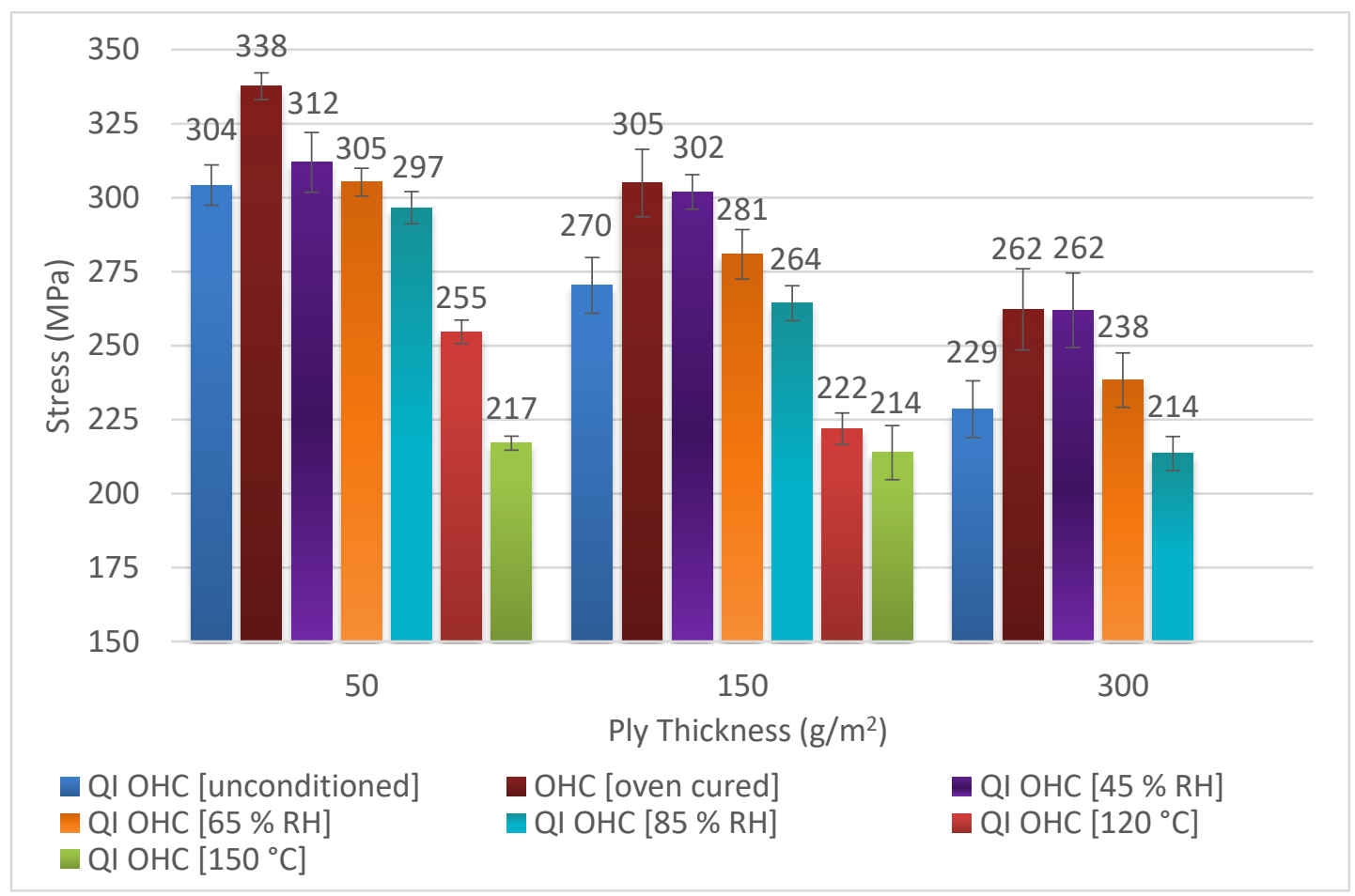

Figure 6.13 Mean QI open-hole compressive stress data, tested under different environmental conditions (normalised) [minimum of four samples per test]

\subsubsection{Interlaminar Shear Strength Behaviour}

Similar to the unidirectional tests discussed previously, the ILSS properties of UD laminates were not altered by changes to ply thickness. However, the QI thin-ply material had a $30 \%$ enhanced ILSS, compared to the QI $150 \mathrm{~g} / \mathrm{m}^{2}$ samples. As before, this increase in strength can be attributed to the lower interfacial stresses for the thin-ply material. 
The ILSS of the conditioned, unidirectional samples were largely unaffected by changes to ply thickness. The only instance where ply thickness had an impact was for the samples conditioned at $85 \% \mathrm{RH}$, where the thin-ply coupons had a $15 \%$ increase in ILSS compared to the intermediate-ply coupons. This is despite the thin-ply material absorbing a higher moisture content.

\subsubsection{In-plane Shear Behaviour $\left( \pm 45^{\circ}\right)$}

The thin-ply material performed well, compared to both the intermediate and thick-ply samples, when in-plane shear properties were tested. This applies for both the unconditioned state and after conditioning in humid environments. An important point to note when discussing the IPS results are the requirements outlined in ASTM D3518M [75] (the standard procedure for in-plane shear testing of a $\pm 45^{\circ}$ laminate). According to the standard, samples produced using UD tape (as was the case here), should have 16, 20 or 24 plies; a higher ply count tends to lead to higher failure forces. The objective of this work was to investigate ply thickness effect; therefore the decision was taken to maintain a constant overall coupon thickness, in an attempt to avoid volumetric size effects [14]. As a result, the number of plies within each test coupon differed depending on ply thickness. The $50 \mathrm{~g} / \mathrm{m}^{2}$ coupons had 48 plies, $150 \mathrm{~g} / \mathrm{m}^{2}$ had 16 and the $300 \mathrm{~g} / \mathrm{m}^{2}$ samples had 8. This large difference between the coupons is likely to be the cause of the differing strengths. It would be useful to produce IPS test coupons with the same number of plies, but different ply thicknesses, to see if the thin-ply coupons still have the greatest in-plane shear strength.

As expected, the conditioned IPS results had lower shear strengths than the unconditioned samples. Similar to the ILSS samples, the resin dominated test was negatively affected by the presence of moisture. 


\subsubsection{Mechanical Testing Summary}

A range of different mechanical tests were performed on materials manufactured from different ply thicknesses, to assess how thin-ply technology behaves under different mechanical loadings and after exposure to non-ambient conditions. A summary of these results is shown in graphical form in Figure 6.14. The investigation provided some interesting findings, with QI thin-ply materials showing enhanced mechanical properties under a range of testing environments. It has also been shown that the effect of ply thickness is less pronounced when the material is unidirectional.

Numerous failure mechanisms are thought to have led to changes in mechanical behaviour for the various materials. Firstly, the unidirectional tensile results showed no difference with changes to ply thickness. This suggests that the uniform distribution of fibres seen with thin-ply composites does not help to achieve higher stresses and therefore is unlikely to be an important consideration for UD tensile properties. On the contrary, the UD compressive strength values did change with ply thickness. The proposed mechanism for this is due to differences in fibre volume fraction, suggesting that this is important for compressive strength.

For QI laminates, interfacial stresses are thought to be the main cause for differences between thick and thin-ply materials. For unnotched tensile samples, the lower interfacial stresses enabled the thin-ply materials to withstand higher stresses. On the contrary, for open-hole tensile samples, the lower interfacial stresses caused the thin-ply material to decrease in strength. Holes give rise to localised stress concentrations. The large interfacial stresses seen with thicker ply samples led to the stress distribution around the hole becoming less dominant, resulting in a higher UTS and a more progressive failure mode (more delamination). The final mechanism is compressive failure due to micro-buckling of the $0^{\circ}$ plies. Adjacent plies with different fibre orientations constrain the ability 
for fibres to buckle, thus the thin-ply material is stronger, even with a large stress concentration like a hole.

The effects of both high temperature and water absorption had differing results, depending on the type of load applied. For example, with open-hole compressive properties, higher temperatures led to lower matrix strength and stiffness, but increased flexibility. In turn, this resulted in an overall strength reduction, because the fibres were able to buckle more readily. On the contrary, in tension, the higher toughness and flexibility of the resin at high temperatures generally led to a more flexible matrix, thus a more even stress distribution. This resulted in a higher UTS. For matrix dominated tests, moisture ingress lead to a reduction in strength for all test types. Effects of post curing, even at temperatures much lower than the $\mathrm{Tg}_{\mathrm{g}}$, have been shown to have an impact on the conditioned samples properties. This is something to consider if sample conditioning is conducted in any future work. 
TENSILE PROPERTIES

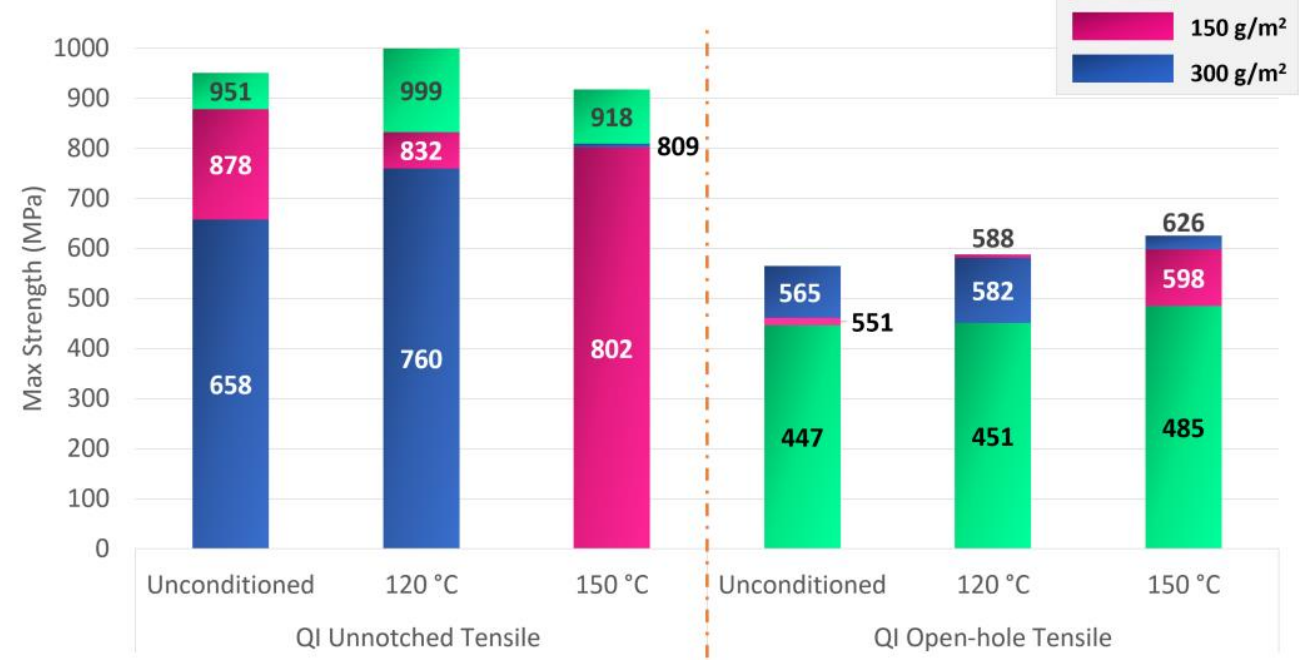

COMPRESSIVE PROPERTIES *300 gsm samples not tested

QI Open-hole Tensile
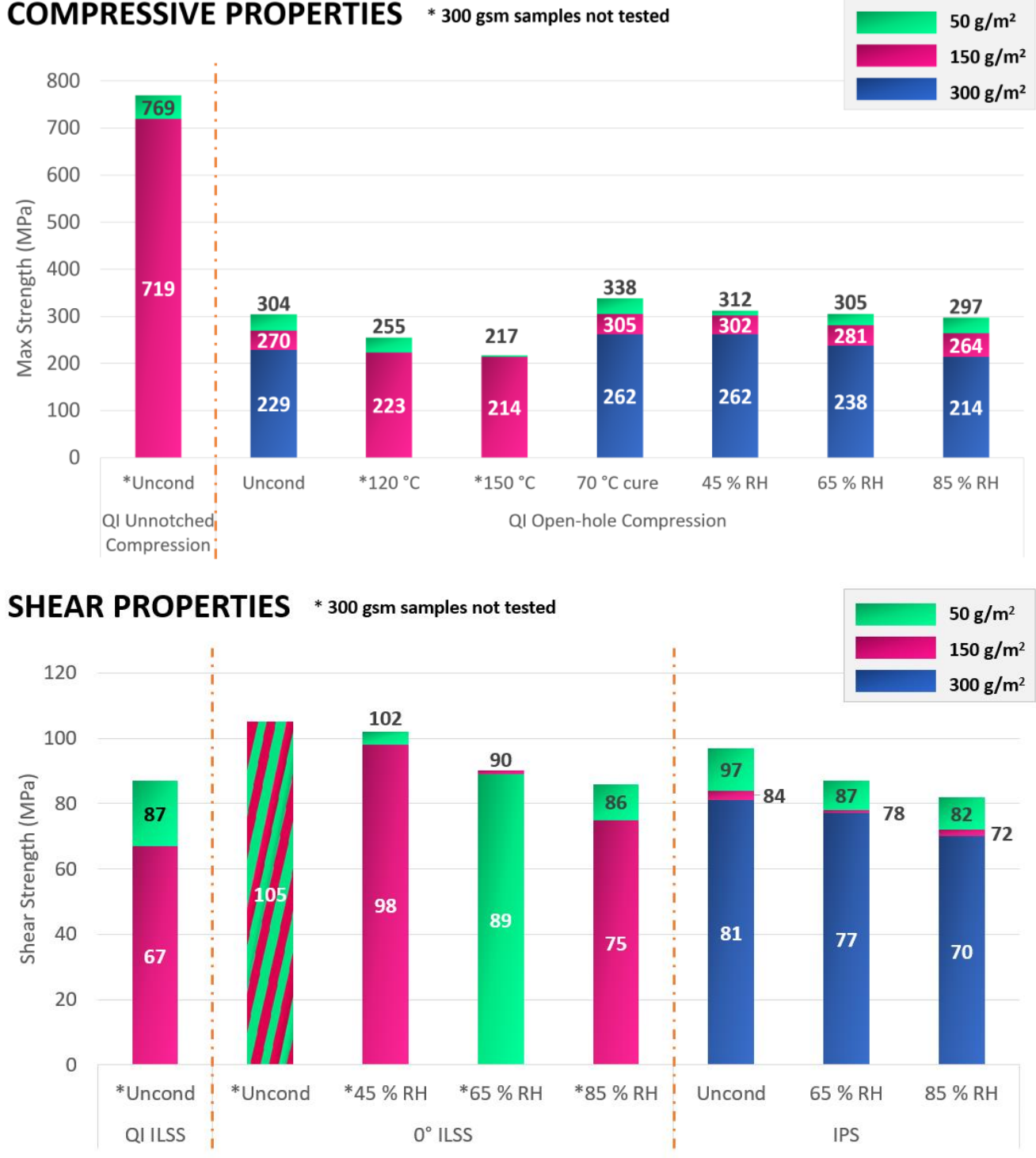

Figure 6.14 Bar charts to show the impact of ply thickness on different mechanical properties after exposure to various environment conditions (50 g/m²: green, $150 \mathrm{~g} / \mathrm{m}^{2}:$ pink, $300 \mathrm{~g} / \mathrm{m}^{2}$ : blue) 


\subsection{Thermal Analysis of Thin-ply Materials}

As discussed in Section 4.2.3, the glass transition temperature of the CFRP differed depending on ply thickness, with the thinner ply material having a higher mean $\mathrm{Tg}_{\mathrm{g}}$. As DMA is a test of the resin matrix, these differences were unexpected, because the resin is the same for all three FAW tested. It was decided that the results should be investigated further, to understand more about the effect that ply thickness has on material properties. The results in this section are based on analysis of the QI laminates, because this laminate orientation shows the behaviour of the resin well and these laminates had the biggest dependence on ply thickness in the mechanical tests.

As shown in Figure 4.2 and Figure 4.3 (Section 4.2.3), the $\mathrm{T}_{\mathrm{g}}$ of the material is generally greater for the thinner ply specimens, irrespective of laminate orientation. The first hypothesis for this was varying levels of post cure time, or temperature, having an impact on the overall sample cure. This was possible, because the samples were not all post cured at the same time. However, as discussed previously, this was not likely, because all of the samples were cured for two hours at $130{ }^{\circ} \mathrm{C}$ followed by four hours at $165{ }^{\circ} \mathrm{C}$. Furthermore, panels 250 to 277 were cured at the same time, in the same autoclave. Despite this, the $\mathrm{T}_{\mathrm{g}}$ differences between the thin and thicker ply samples were still found. This strengthens the argument that the difference in $\mathrm{T}_{\mathrm{g}}$ cannot be explained by a difference in cure time or temperature. The final reason why this hypothesis is unlikely is because the trend occurred consistently for each thin-ply sample, regardless of when it was cured.

The results discussed so far are based on analysis of one sample from each laminate used in the project. It was initially not deemed necessary to test multiple samples from individual panels, because the results (in theory) should have been similar for all samples. However, since the results were not as expected, some 
additional samples were analysed to ensure reliability. As a further check, the material manufacturer also conducted DMA analysis on the panels.

Analysis of multiple samples from the same panel gave varying results. Differences were firstly noted between results obtained by two different operators, using different DMA instruments. These results varied by as much as $20{ }^{\circ} \mathrm{C}$. This was thought to be too great to be a consequence of machine variation. A difference in $T_{g}$ was also seen on repeat samples tested by the same user, using the same machine and the same DMA method. The DMA method used for samples tested on the same machine had small variations throughout the project (in terms of span length and strain deformation), however this was found to have no influence on the results. An example of this is shown in Figure 6.15, where three DMA tan delta heating curves, relating to panel 255, are displayed. The difference between the tests represented by the blue and green curves is the single cantilever span length; the green curve represents a $10 \mathrm{~mm}$ span and the blue curve represents a $15 \mathrm{~mm}$ span. This confirms that changing the span length had very little effect on the results. What is interesting however, is that the green and blue curves differ to the red curve. The red curve is also a result from panel 255, tested using the same DMA methodology as the sample represented by the green curve. The only difference between the samples is the date at which they were tested, or, more importantly, the storage of the samples prior to testing. The samples represented by the green and the blue curves were stored at room temperature for several months prior to testing (the exact time at room temperature is unknown). The sample represented by the red curve was stored in a freezer at $-30{ }^{\circ} \mathrm{C}$ since delivery, up until approximately 24 hours before analysis. The differences in tan delta curves suggests that the samples represented by the blue and green curves experienced a form of aging prior to analysis, possibly due to moisture ingress, which led to a reduction in $\mathrm{Tg}_{\mathrm{g}}$. The glass transition temperatures of the materials used in this project were determined using the onset of the drop in storage modulus method, however the differences in $\mathrm{T}_{\mathrm{g}}$ can 
also easily be seen upon examination of the tan delta curves. The $\mathrm{T}_{\mathrm{g}}$ taken from the storage modulus onset was also depressed for the 'aged' samples, as shown in Table 6.4. This table also contains additional data for the original DMA analysis of panel 255, which was tested over a year before the other three samples. The tan delta curves have been used for this demonstration, as, in addition to $T_{g}$, the change in shape of the curve is also of interest. The 'aged' samples appear to have a much broader shaped tan delta curve, compared to the freezer stored sample.

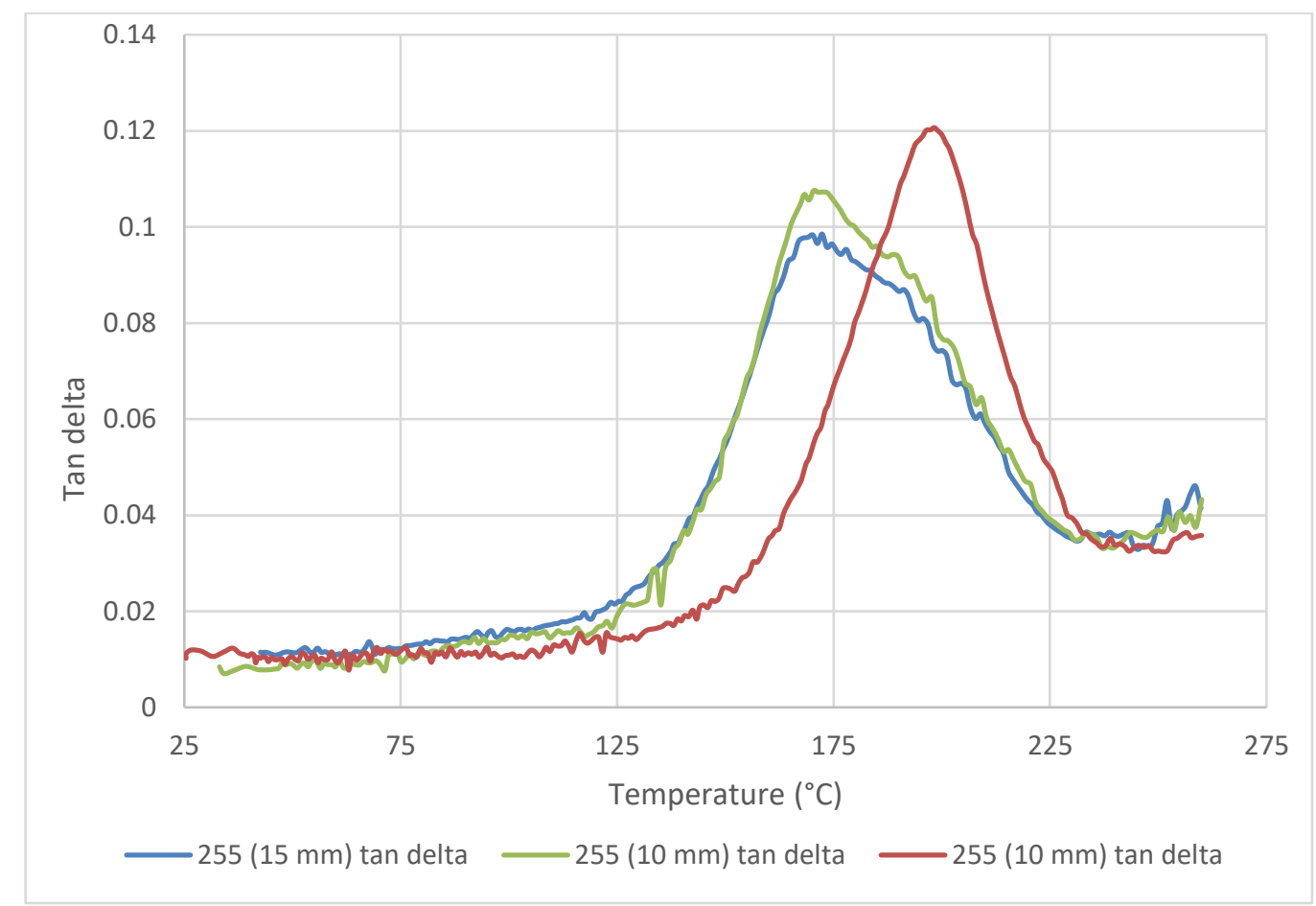

Figure 6.15 Graph showing tan delta curves for three different samples from panel 255, a) blue curve: $15 \mathrm{~mm}$ span and $0.05 \mathrm{~mm}$ strain deflection, b) green curve: $10 \mathrm{~mm}$ span and $0.03 \mathrm{~mm}$ strain deflection, $c$ ) red curve: $10 \mathrm{~mm}$ span and $0.03 \mathrm{~mm}$ strain deflection

Samples 1 and 4 have similar $\mathrm{T}_{\mathrm{g}}$ values, despite being tested over a year apart. The results suggest that storing the samples in a freezer reduced moisture ingress and the effect of aging. Some form of aging was possibly still occurring, as demonstrated by the $5{ }^{\circ} \mathrm{C}$ difference in storage modulus onset, but this is at a much lower rate compared to storage at room temperature. The samples stored at room temperature for several months had a $\mathrm{T}_{\mathrm{g}}$ reduction of over $20^{\circ} \mathrm{C}$. This finding is thought to be a potential cause of the $\mathrm{T}_{\mathrm{g}}$ variability. 
Table 6.4 Effect of storage environment on glass transition temperature for samples of panel $255\left(Q I, 50 \mathrm{~g} / \mathrm{m}^{2}\right)$

\begin{tabular}{|c|c|c|c|c|}
\hline Sample & $\begin{array}{c}\text { DMA test } \\
\text { date }\end{array}$ & $\begin{array}{c}\text { Storage } \\
\text { environment }\end{array}$ & $\begin{array}{c}\mathrm{T}_{\mathrm{g}} \\
\text { (storage } \\
\text { modulus } \\
\text { onset) }{ }^{\circ} \mathrm{C}\end{array}$ & $\begin{array}{c}\mathrm{T}_{\mathrm{g}} \text { (tan } \\
\text { delta } \\
\text { peak) }\end{array}$ \\
\hline $255(1)$ & $08 / 01 / 2018$ & Freezer & 167.9 & 199.4 \\
\hline $255(2)$ & $15 / 04 / 2019$ & Room temperature & 143.8 & 171.1 \\
\hline $255(3)$ & $15 / 04 / 2019$ & Room temperature & 146.8 & 172.0 \\
\hline $255(4)$ & $16 / 04 / 2019$ & Freezer & 162.9 & 197.7 \\
\hline
\end{tabular}

A reduction in the $\mathrm{T}_{\mathrm{g}}$ of the samples stored at room temperature was unexpected. To learn more, a study was conducted where the storage conditions of several samples, from the same panel, were controlled for a set time period. DMA analysis was then used to determine the $T_{g}$ of the samples. The aim of the investigation was to understand whether the depressed $\mathrm{Tg}_{\mathrm{g}}$ was due to moisture ingress.

\subsubsection{Investigation into Material Aging}

A study was conducted to investigate whether room temperature moisture ingress was causing a decrease in $\mathrm{T}_{\mathrm{g}}$. The investigation was conducted on laminates which had been exclusively stored in a freezer prior to starting the experiment. These laminates were chosen, because, theoretically, they should have minimal moisture ingress. One laminate for each ply thickness was tested, to investigate whether the same trends were seen independent of ply thickness. The experiment is detailed below:

- As per the methodology in Section 3.2.3, DMA samples were machined from each of the following panels; 283 (50 g/m², QI), 289 (150 g/m², QI) and 294 (300 g/m², QI). Each panel had been stored in a freezer at $-30{ }^{\circ} \mathrm{C}$ since delivery.

- One sample from each panel was tested within 24 hours of removal from the freezer, to determine the $\mathrm{T}_{\mathrm{g}}$ at the start of the investigation. 
- Two samples from each panel were stored in a temperature and humidity-controlled environment at $23{ }^{\circ} \mathrm{C} \pm 1{ }^{\circ} \mathrm{C}$ and $50 \% \mathrm{RH} \pm 5 \% \mathrm{RH}$ for approximately twelve weeks, followed by $\mathrm{T}_{\mathrm{g}}$ determination of one sample by DMA.

- Two samples from each panel were stored in distilled water (100\% RH) for approximately twelve weeks, followed by $\mathrm{T}_{\mathrm{g}}$ determination of one sample by DMA.

- Two samples from each panel were stored in desiccant at room temperature for approximately twelve weeks, followed by $\mathrm{T}_{\mathrm{g}}$ determination of one sample by DMA.

The glass transition temperatures of the samples stored in the various conditions for approximately twelve weeks are given in Table 6.5.

Table 6.5 Glass transition temperatures of samples with different ply thicknesses, stored in different environment for approximately 12 weeks

\begin{tabular}{|c|c|c|c|c|}
\hline \multirow{2}{*}{ Sample } & \multicolumn{4}{|c|}{ Storage modulus glass transition temperature $\left({ }^{\circ} \mathrm{C}\right)$} \\
\cline { 2 - 5 } & Freezer & Desiccant & $23{ }^{\circ} \mathrm{C}, 50 \% \mathrm{RH}$ & $23^{\circ} \mathrm{C}, 100 \% \mathrm{RH}$ \\
\hline $50 \mathrm{~g} / \mathrm{m}^{2}$ QI & 153.9 & 155.8 & 147.9 & 129.4 \\
\hline $150 \mathrm{~g} / \mathrm{m}^{2} \mathrm{QI}$ & 151.4 & 151.3 & 143.9 & 128.0 \\
\hline $300 \mathrm{~g} / \mathrm{m}^{2} \mathrm{QI}$ & 138.0 & 137.7 & 129.3 & 118.16 \\
\hline
\end{tabular}

The results show a clear trend for reduced $\mathrm{T}_{\mathrm{g}}$ with increasing moisture content. Given that the desiccant stored samples (the driest samples) maintained the same $\mathrm{T}_{\mathrm{g}}$, it is thought that the differences in $\mathrm{T}_{\mathrm{g}}$ are a result of plasticisation of the matrix due to moisture ingress.

In addition to the results discussed above, the $\mathrm{T}_{\mathrm{g}}$ of one $50 \mathrm{~g} / \mathrm{m}^{2}$ sample stored in each of the four environments was tested after storage for one month, as opposed to nearly three months. A slight reduction in $\mathrm{T}_{\mathrm{g}}$ was seen for the room temperature stored sample $\left(150.0^{\circ} \mathrm{C}\right)$ and the sample stored in water $\left(147.2^{\circ} \mathrm{C}\right)$, however the results were not as significant as the changes after three months. This 
suggests that the effect of moisture takes longer than one month to come into effect. It also strengthens the argument that the differences in measured $\mathrm{T}_{\mathrm{g}}$ for the various laminates are due to increasing water content.

\subsubsection{Effect of Ply Thickness on DMA Tan Delta}

For many materials a typical DMA tan delta curve would display a single peak at a temperature close to the glass transition temperature. Interestingly, the tan delta curves for the dry $50 \mathrm{~g} / \mathrm{m}^{2}$ material did not follow this trend. Instead, after heating to $250^{\circ} \mathrm{C}$ and then cooling to room temperature in the DMA, the tan delta curve transformed from one peak into two distinct peaks. These peaks were at approximately $175^{\circ} \mathrm{C}$ and $205^{\circ} \mathrm{C}$. Moreover, the distinct peaks were not formed on cooling of the dry $150 \mathrm{~g} / \mathrm{m}^{2}$ and the $300 \mathrm{~g} / \mathrm{m}^{2}$ samples. Instead, a single broad peak with a 'shoulder' of a second peak was seen, at a temperature of $200{ }^{\circ} \mathrm{C}$. In addition, the first heating of 'as received' $150 \mathrm{~g} / \mathrm{m}^{2}$ and $300 \mathrm{~g} / \mathrm{m}^{2}$ samples generally gave a broader tan delta curve, ranging between approximately $170{ }^{\circ} \mathrm{C}$ and $195^{\circ} \mathrm{C}$. In comparison, the thin-ply samples had a relatively sharp peak at $200{ }^{\circ} \mathrm{C}$. Example tan delta peaks for each ply thickness are shown in Figure 6.16 and Figure 6.17. The graphs show samples from panels 250 to 271. These samples were tested soon after delivery and therefore should have minimal impact of moisture ingress. The results for panels 260 and 265 have been removed, due to noise in the data and panel 266 has removed because it was tested over a year after delivery, thus may have been affected by moisture. The $50 \mathrm{~g} / \mathrm{m}^{2}$ samples are represented by the blue lines, orange represents the $150 \mathrm{~g} / \mathrm{m}^{2}$ samples and purple represents the $300 \mathrm{~g} / \mathrm{m}^{2}$ material.

A number of samples were re-heated in the DMA after this initial heat and cool, to see if the double tan delta peak was retained. One example result from this second heat and cool, for each ply thickness, is shown in Figure 6.18 to Figure 6.20 . 


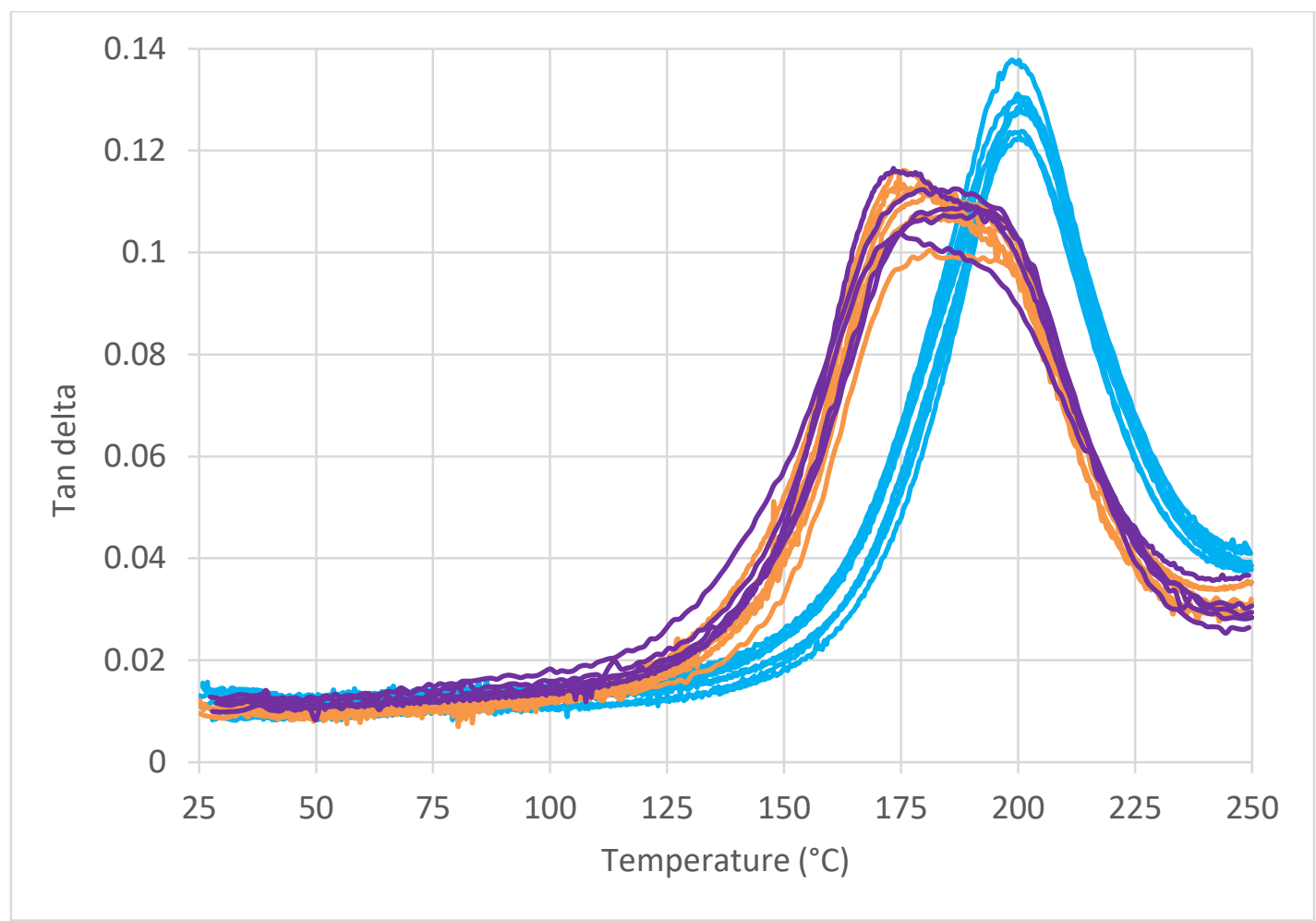

Figure 6.16 DMA tan delta heating curves for laminates with different ply thicknesses (50 $\mathrm{g} / \mathrm{m}^{2}:$ blue, $150 \mathrm{~g} / \mathrm{m}^{2}$ : orange, $300 \mathrm{~g} / \mathrm{m}^{2}$ : purple)

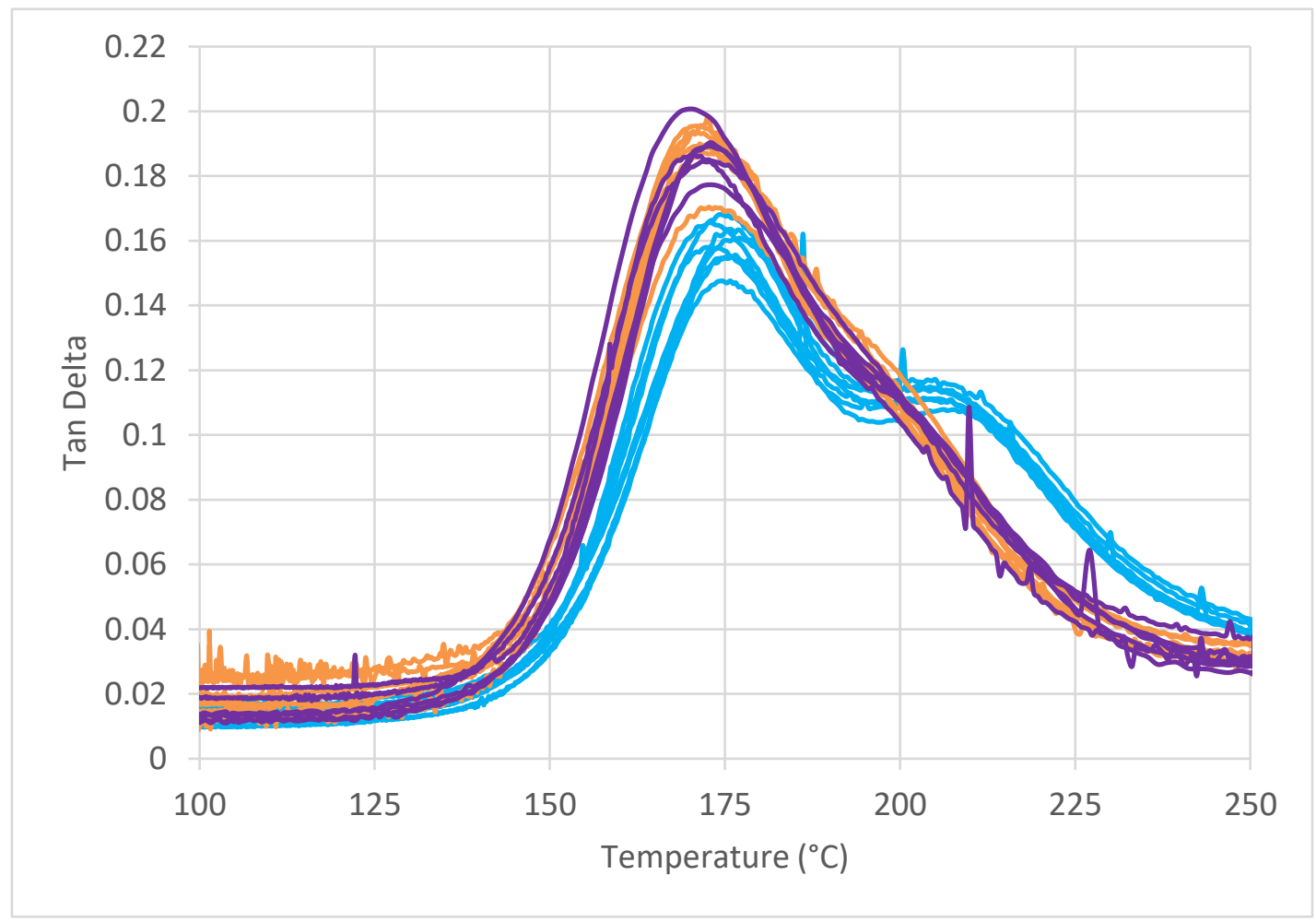

Figure 6.17 DMA tan delta cooling curves for laminates with different ply thicknesses (50 g/m²: blue, $150 \mathrm{~g} / \mathrm{m}^{2}$ : orange, $300 \mathrm{~g} / \mathrm{m}^{2}$ : purple) 


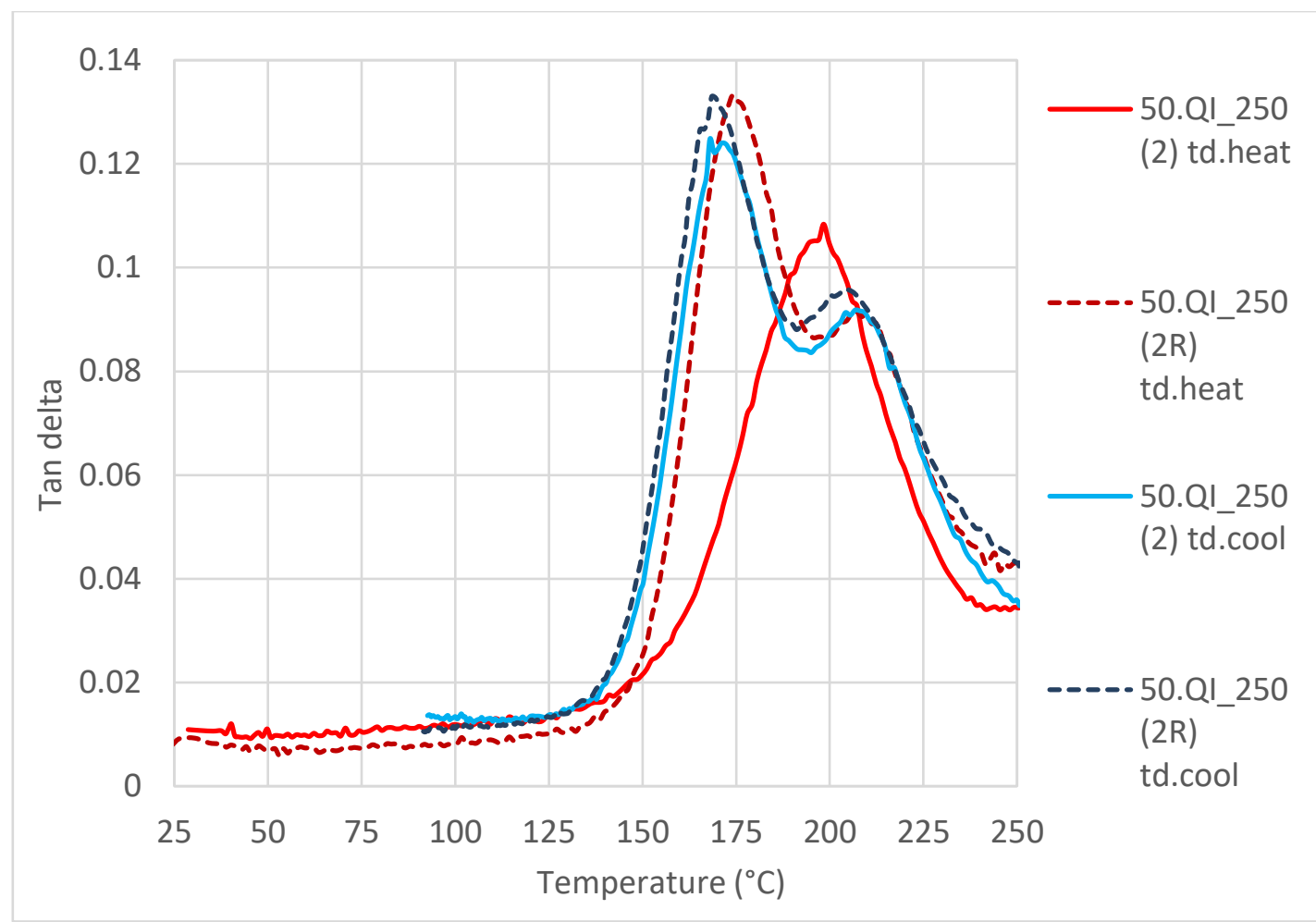

Figure 6.18 DMA tan delta curve for a $50 \mathrm{~g} / \mathrm{m}^{2}$ sample from panel number 250 (first heat and re-heat) [second heat and cool denoted by '( $2 R)$ ' and represented by dashed lines]

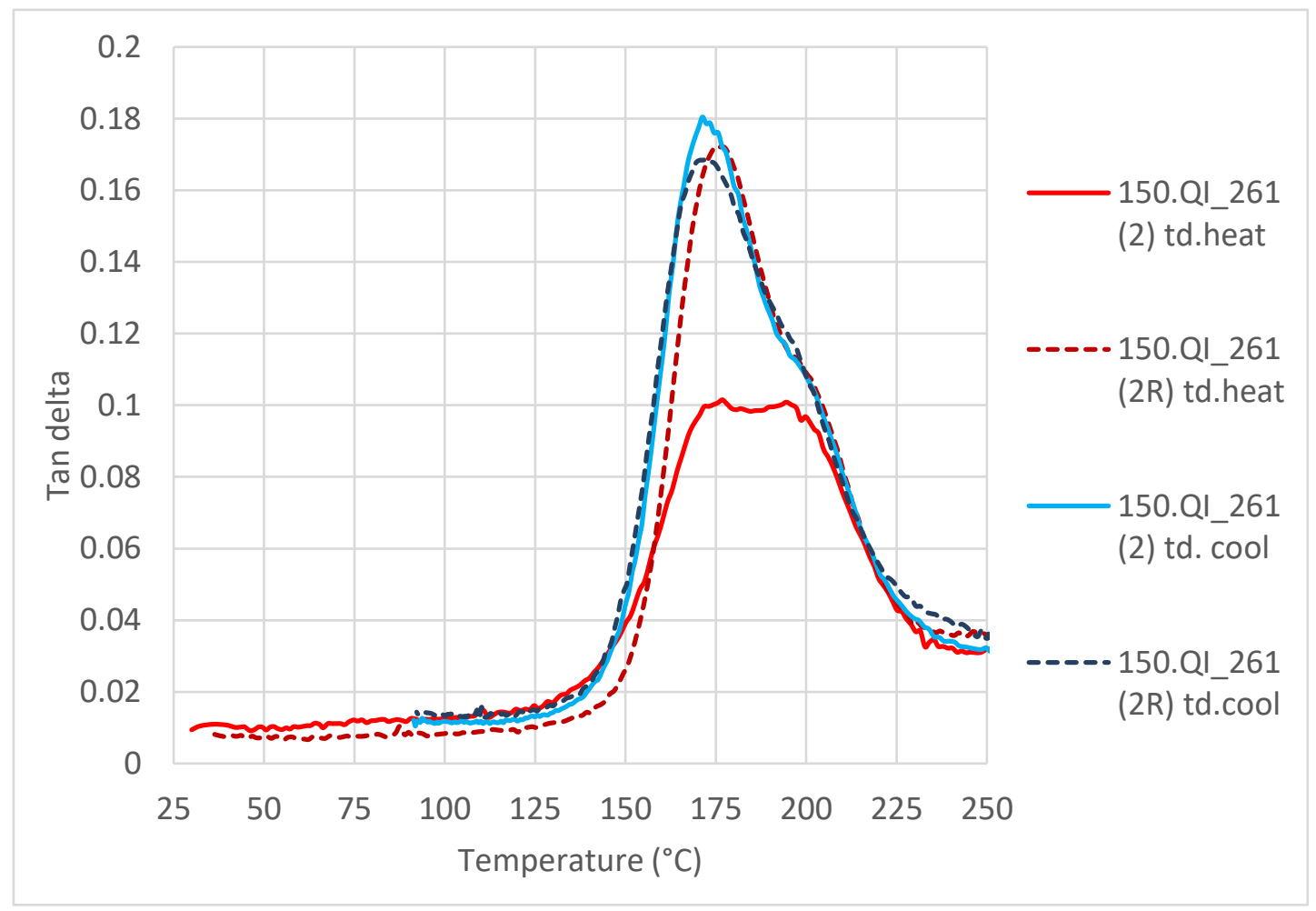

Figure 6.19 DMA tan delta curve for a $150 \mathrm{~g} / \mathrm{m}^{2}$ sample from panel number 261 (first heat and re-heat) [second heat and cool denoted by '(2R)' and represented by dashed lines] 


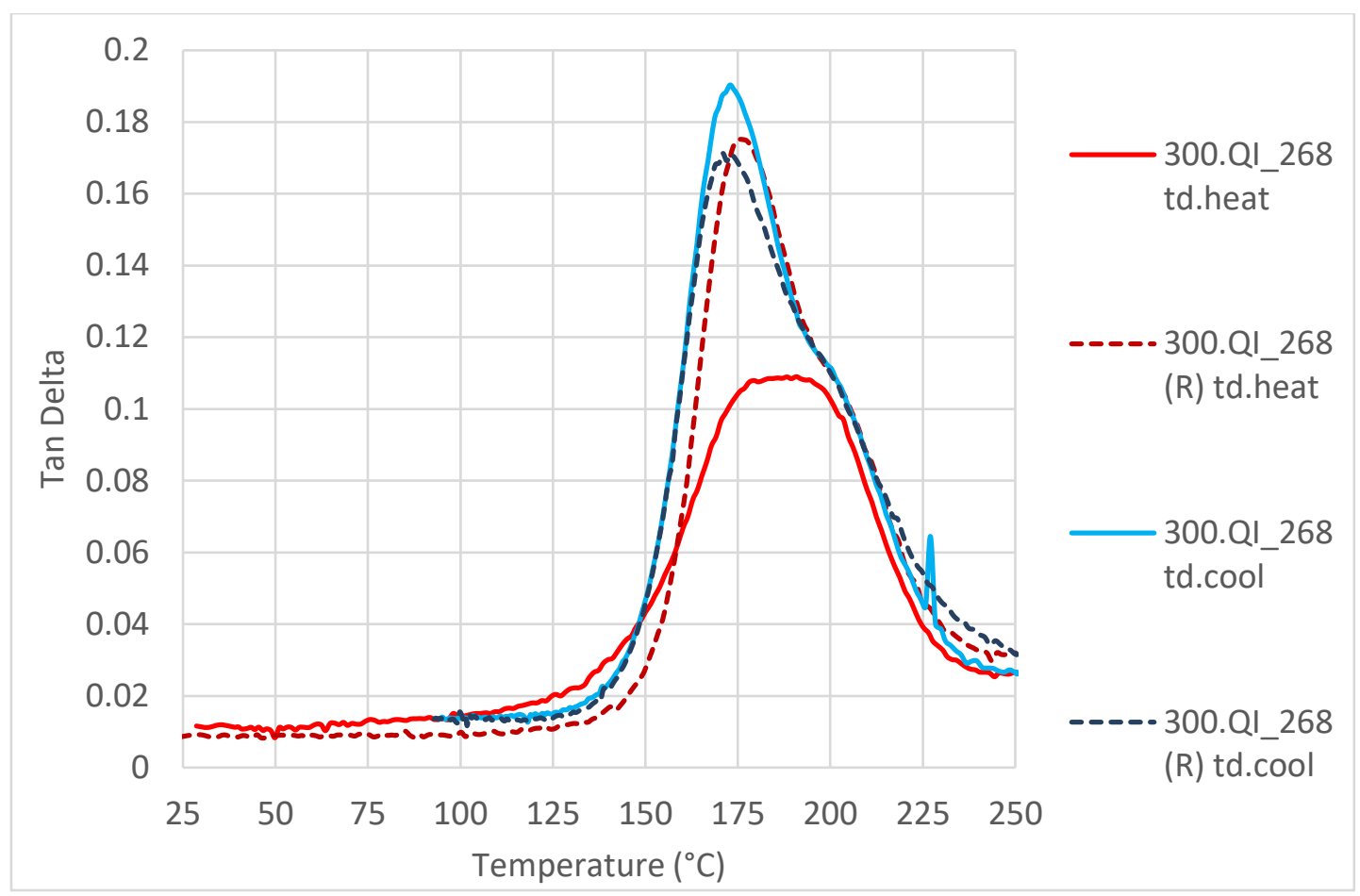

Figure 6.20 DMA tan delta curve for a $300 \mathrm{~g} / \mathrm{m}^{2}$ sample from panel number 268 (first heat and re-heat) [second heat and cool denoted by '( $R)^{\prime}$ ' and represented by dashed lines]

The tan delta peaks retained their shape after the first cool for both the re-heat and the second cooling. This suggests that a permanent change in the material occurred. This happened for all three of the ply thicknesses. In a further test, the material manufacturers conducted DMA analysis on the $50 \mathrm{~g} / \mathrm{m}^{2}$ T800 TP135 CFRP after being post cured at various temperatures [two hours at $130{ }^{\circ} \mathrm{C}$ followed by: a) four hours at $135^{\circ} \mathrm{C}, \mathrm{b}$ ) four hours at $150{ }^{\circ} \mathrm{C}, \mathrm{c}$ ) four hours at $165^{\circ} \mathrm{C}$ and d) four hours at $175^{\circ} \mathrm{C}$ ]. Of these, only the sample which was post cured at $175^{\circ} \mathrm{C}$ displayed a double tan delta peak on the first DMA heating run. The other three samples showed only one tan delta peak. As expected, all four samples showed a dual tan delta curve on the DMA re-heat.

It is not uncommon for a tan delta trace to migrate to a slightly higher temperature upon cooling or a second heat, due to the extra sample cure during the test. This is a likely explanation for the higher temperature peak of the cool and re-heat. The appearance of a second peak in the tan delta trace (like with the $50 \mathrm{~g} / \mathrm{m}^{2}$ samples) is unexpected, although not unheard of. One example of where it has been seen before is on epoxy composites which have been exposed to long-term 
water absorption tests [92]. To explore this, DMA tests were performed on the QI laminates, after conditioning in different relative humidity. Samples were conditioned until saturation at $85 \% \mathrm{RH}, 70{ }^{\circ} \mathrm{C}$ and $45 \% \mathrm{RH}, 70{ }^{\circ} \mathrm{C}$ to investigate the effect of moisture on storage modulus and tan delta. The results of these tests, for the $50 \mathrm{~g} / \mathrm{m}^{2}$ and $150 \mathrm{~g} / \mathrm{m}^{2}$ laminates, are shown in Figure 6.21 to Figure 6.24. The $300 \mathrm{~g} / \mathrm{m}^{2}$ panels behaved very similarly to the $150 \mathrm{~g} / \mathrm{m}^{2}$ samples and therefore are not shown.

Upon first heating of each moisture conditioned sample, a very distinct double tan delta peak was seen. The temperature of these peaks is dependent on moisture content, with the samples being conditioned at $85 \% \mathrm{RH}$ having lower temperature peaks in comparison to the $45 \% \mathrm{RH}$ samples. Upon reheating of the $50 \mathrm{~g} / \mathrm{m}^{2}$ samples (re-heat is denoted as " $\mathrm{R}$ " on the graphs and represented by dashed lines) the two distinct tan delta peaks were retained, for both conditioning environments. The peak at the higher temperature is now at a similar temperature to the second peak for the unconditioned sample. The lower peak remained at a lower temperature compared to the unconditioned sample. For the $150 \mathrm{~g} / \mathrm{m}^{2}$ specimens, the second tan delta peak lost some definition upon reheating of the conditioned samples (see Figure 6.23 and Figure 6.24). In comparison, the $150 \mathrm{~g} / \mathrm{m}^{2}$ unconditioned sample does not have a second tan delta peak.

Overall, it appears as though the material tends to a state of having two tan delta peaks: a larger peak at approximately $165^{\circ} \mathrm{C}$ and a smaller peak at $205^{\circ} \mathrm{C}$ (precise peak temperatures are dependent on ply thickness and moisture content). It appears as though the material can form this state upon heating of the sample and has shown signs of transitioning towards this state after storage at room temperature (hence the broader tan delta peak). Conditioning the materials at high humidity gives rise to this effect most clearly. 


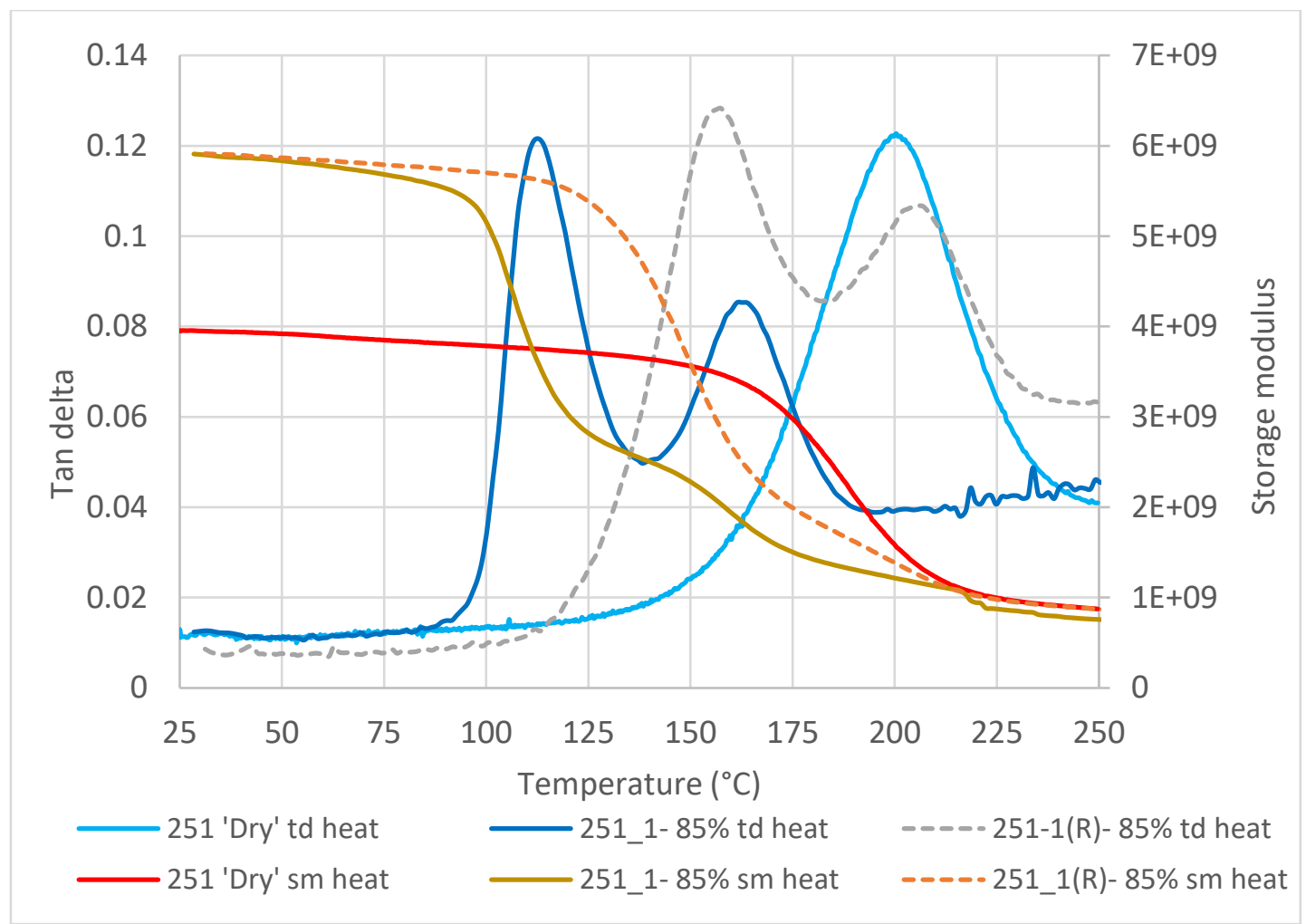

Figure 6.21 DMA tan delta and storage modulus heating curves for a $50 \mathrm{~g} / \mathrm{m}^{2}$ sample from panel number 251, after exposure to different humid environments [second heat denoted by ' $(R)^{\prime}$ and represented by dashed lines]

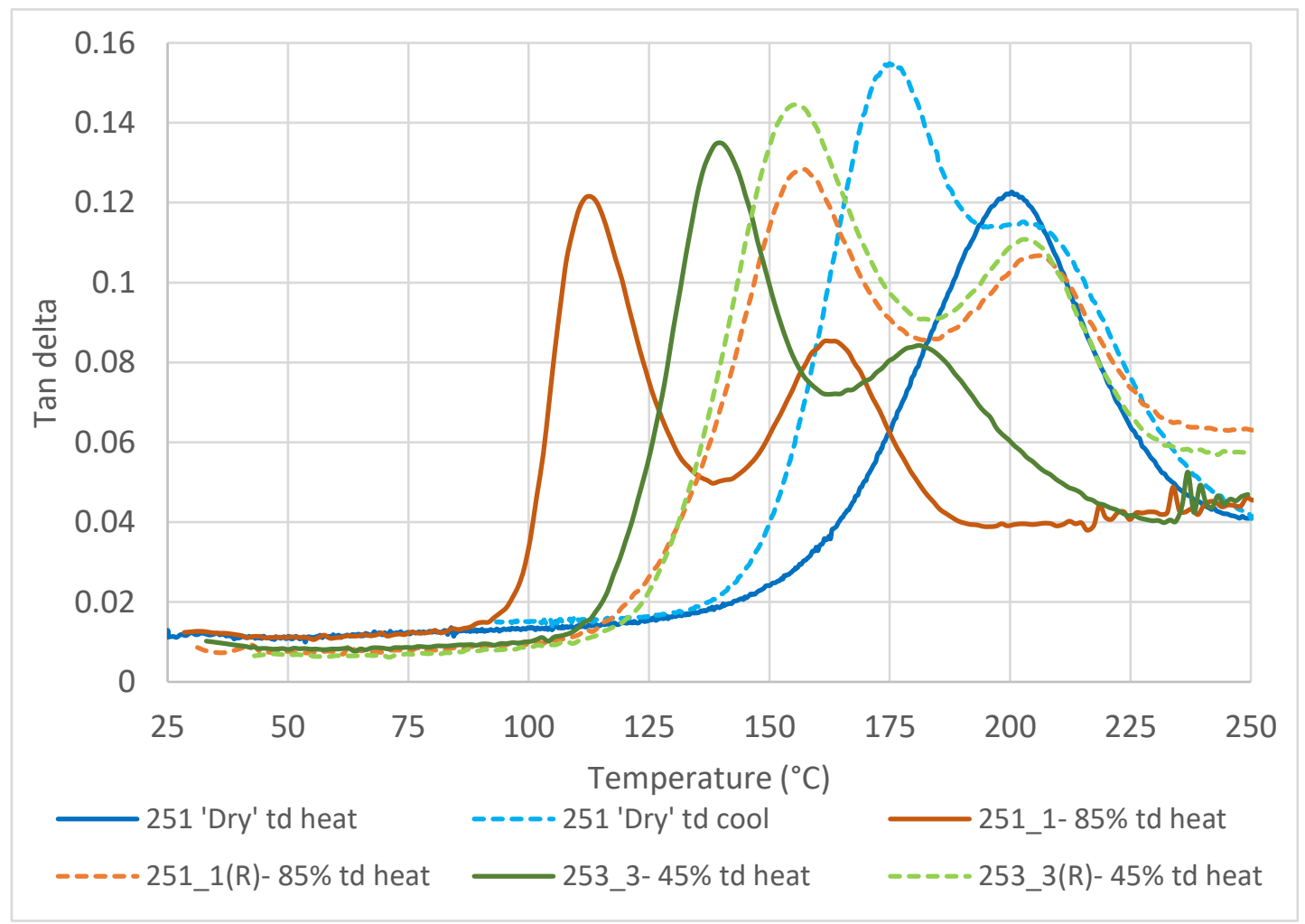

Figure 6.22 DMA tan delta curves for $50 \mathrm{~g} / \mathrm{m}^{2}$ samples from panel numbers 251 and 253, after exposure to different humid environments [second heat denoted by ' $(R)^{\prime}$ ] 


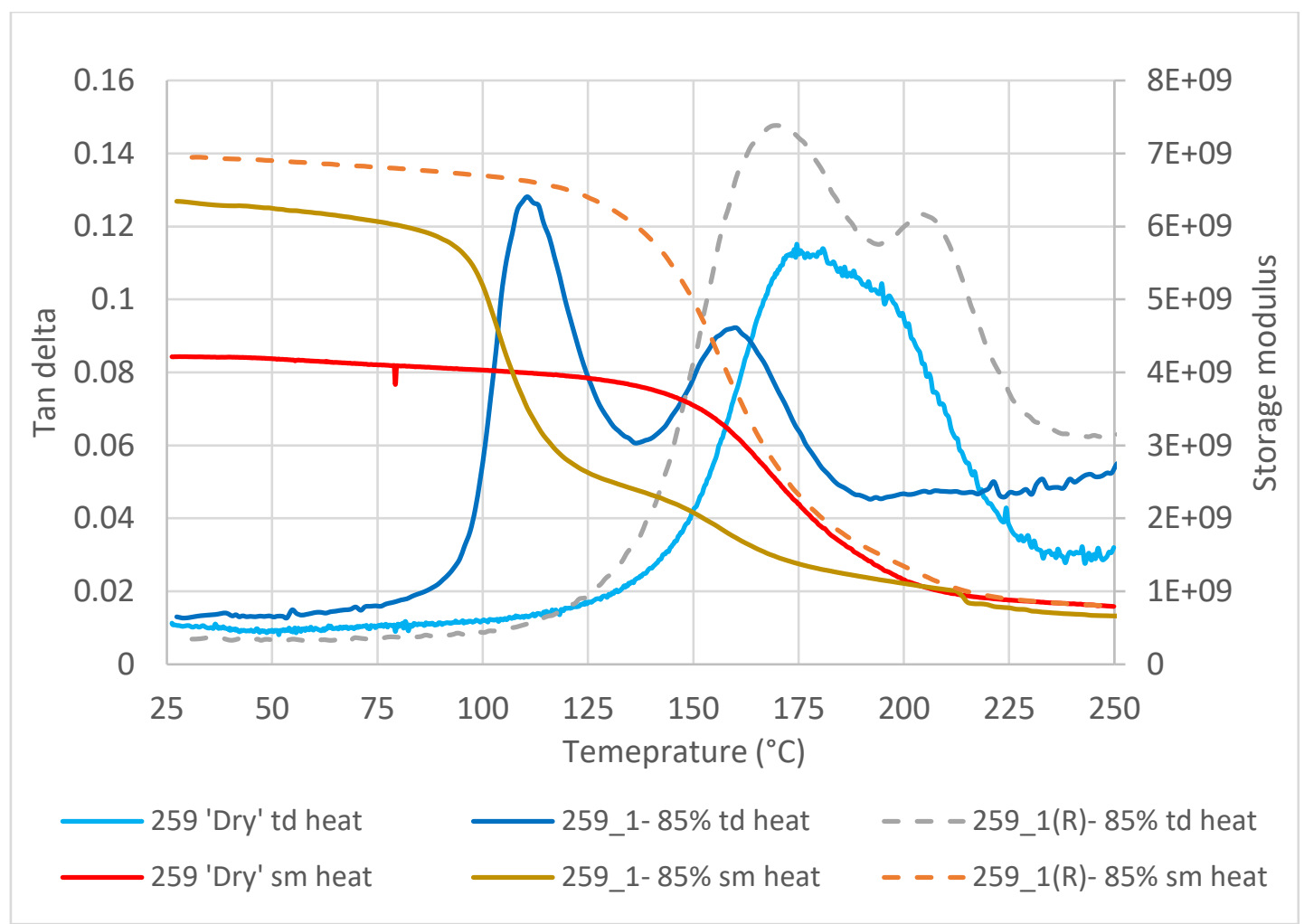

Figure 6.23 DMA tan delta and storage modulus heating curves for a $150 \mathrm{~g} / \mathrm{m}^{2}$ sample from panel number 259, after exposure to different humid environments [second heat denoted by ' $(R)^{\prime}$ and represented by dashed lines]

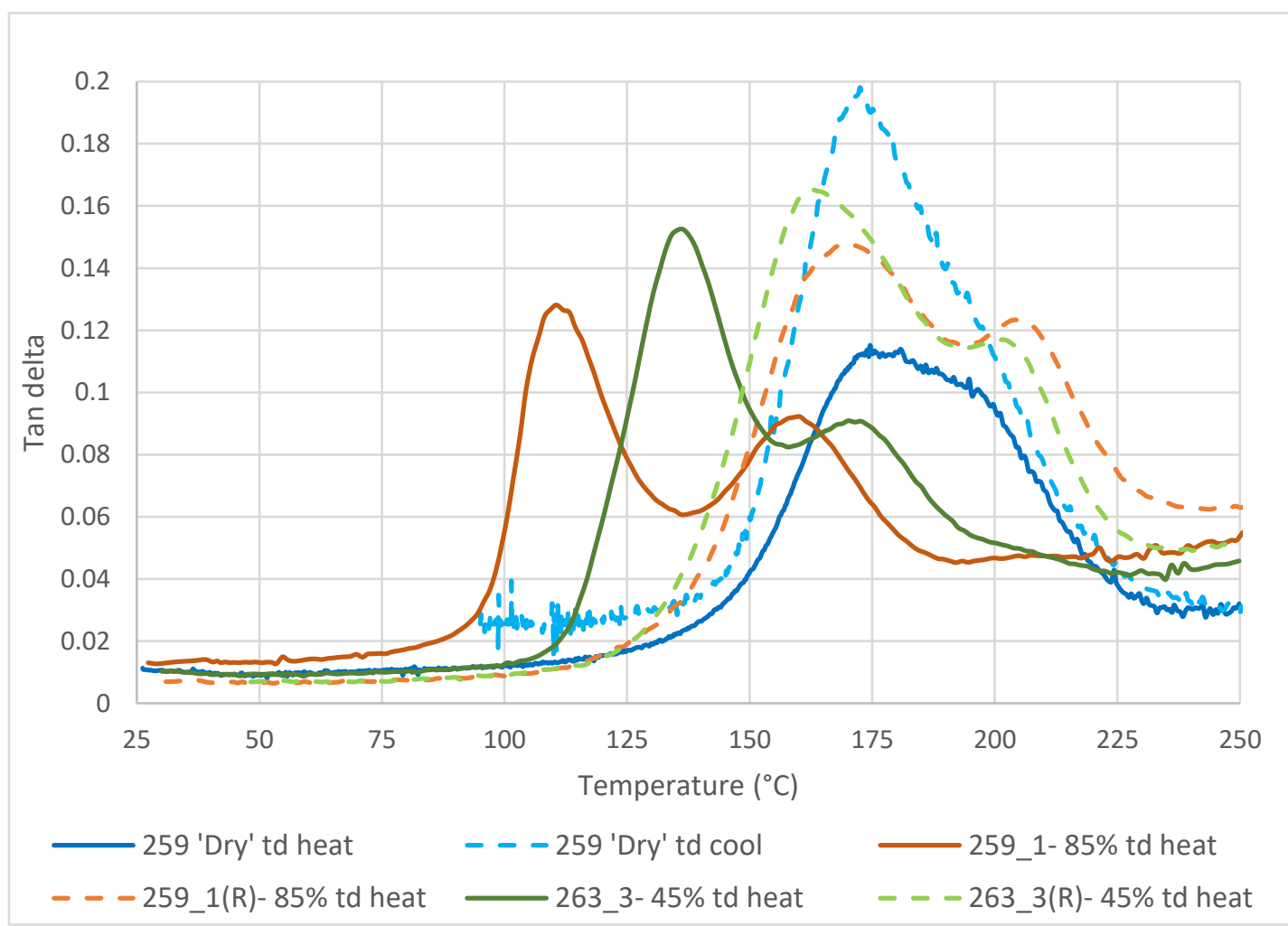

Figure 6.24 DMA tan delta curves for $150 \mathrm{~g} / \mathrm{m}^{2}$ samples from panel numbers 259 and 263, after exposure to different humid environments [second heat denoted by ' $(R)^{\prime}$ '] 
As mentioned previously, the formation of double tan delta peaks has been reported in literature when epoxy resins are exposed to long-term water absorption tests [92]. Typically, the first tan delta peak for wet samples corresponds to the $\mathrm{T}_{\mathrm{g}}$ of the material plasticised by water and the second peak is a result of the sample being dried during the test; the $T_{g}$ of the material therefore increases again. With the samples shown in Figure 6.23 and Figure 6.24, the second peak is retained after the sample has been dried, even on the re-heat curves. Furthermore, the formation of a double peak is also seen, to some extent, with the 'dry' samples. For the thin-ply samples, the double peak only occurs after the specimen has been heated to approximately $175^{\circ} \mathrm{C}$. The sample is essentially being dried during this heat cycle. If moisture ingress was causing the double tan delta peak in the thin-ply sample, it is thought that the two peaks would be seen on the first heating cycle, which they are not. This mechanism is therefore unlikely to be the reason for the double tan delta peak.

It is likely that the material naturally results to a state of two distinct phases. These phases seem to occur after polymer relaxation, for example moisture ingress followed by heating. The relaxation is shown as a larger tan delta peak (at approximately $165^{\circ} \mathrm{C}$ ) and a smaller peak at approximately $205^{\circ} \mathrm{C}$. The process appears to occur for all three of the prepregs used. In the thin-ply material, the state can almost be formed after heating to approximately $175^{\circ} \mathrm{C}$, but, in this instance, the two peaks are not as distinct as when the samples have been exposed to moisture.

One hypothesis for the formation of the two-phase structure is that the epoxy polymer matrix is behaving like a dual phase material, due to differing levels of polymer chain mobility in different regions of the polymer. For example, the areas of polymer close to the fibres are constrained by the fibres and hence are stiffer than the areas of resin alone, which are less tightly constrained. If this was the case, the phase separation would likely be more obvious in the thicker ply samples, due to the less uniform fibre distribution and hence greater number of 
resin rich areas (and therefore less tightly constrained polymer chains). Furthermore, if the tan delta peaks were a result of varying levels of polymer chain constraint, the tan delta trace would more likely be a broad peak, rather than two distinct peaks (as there are not two different materials present within the resin). Nevertheless, an investigation into material stiffness using atomic force microscopy was conducted, to see if it was possible to detect changes in polymer stiffness between areas of polymer constrained by fibres, compared to larger resin rich areas. AFM in force modulation mode and force mapping mode were used in an attempt to obtain data relating to the stiffness of the material, as described in Section 3.8. The material used was a $50 \mathrm{~g} / \mathrm{m}^{2}$ QI sample, which had been post cured for two hours at $180^{\circ} \mathrm{C}$. The post cure was conducted prior to AFM analysis to promote the formation of the dual tan delta peak. Examples of the data obtained are shown in Figure 6.25 to Figure 6.27. To obtain the images, the AFM data was post-processed using the JPK Instruments Data Processing software (version spm-5.1.4). Force modulation data was obtained at two magnifications, $25 \times 25 \mu \mathrm{m}$ and $5 \times 5 \mu \mathrm{m}$, each with a resolution of $1024 \times 1024$ pixels. Figure 6.26 shows a magnified version of Figure 6.25 (approximate area of magnification is highlighted in Figure 6.25). First order levelling was applied to the images (with an upper limit of $70 \%$ ). In the AFM height maps, brighter sections depict areas of material which are more proud. In the force modulation image, brighter sections are related to areas of greater stiffness. In force mapping mode, multiple force measurements are taken in a grid pattern over a specified area; an image is then produced by the software, using the force curves generated at each point within the grid. The force mapping mode data was collected over an area of $25 \times 25 \mu \mathrm{m}$. During post-processing the Hertz model was applied to the data, which is a standard method for analysing AFM force distance curves to obtain the Young's modulus [118].

As shown by the images in Figure 6.25 to Figure 6.27, it was not possible to determine changes in resin stiffness using AFM. In the force modulation mode 
images, the fibres would be expected to be much brighter in comparison to the resin, because the fibres are much stiffer. Furthermore, the force map data seen in Figure 6.27 (B) is largely noise, with no clear distinction of stiffness for areas of fibre and resin, which would be expected.

Maivald et al. [119] explored the use of force modulation mode to investigate variations in local surface elasticity in samples of CFRP. Using a customised AFM cantilever with a spring constant of $3000 \mathrm{~N} / \mathrm{m}$ they were able to distinguish between areas of resin and fibre; the fibres were displayed as very bright areas, whereas the resin was much darker. The lack of information obtained from the force modulation and force mapping data presented in this thesis is thought to be because the cantilevers used were not sufficiently stiff to resolve the sample stiffness. According to the manufacturer, the spring constant of the NanoWorld FM-50 cantilevers used is nominally $2.8 \mathrm{~N} / \mathrm{m}$ [120]; this is far more flexible than the cantilever used by Maivald et al. [119]. Niu et al. [121] used an AFM technique called Peak Force Quantitative Nano-Mechanics (PF-QNM) to characterise the interphase within CFRPs. PF-QNM is a technique which enables quantitative modulus data to be obtained. Using a cantilever with a nominal spring constant of $200 \mathrm{~N} / \mathrm{m}$ [122] Niu et al. [121] were successful in showing that the elastic modulus of the matrix was much lower than that of the fibres. Again, this spring constant was significantly greater than what was used in this project. Niu et al. [121] were also able to monitor changes in stiffness in the interphase area, showing that the area of resin directly next to the fibre had a higher modulus compared to the bulk resin. In order to examine similar properties within the thin-ply material used in this project, it is thought that a different cantilever tip would be required. 


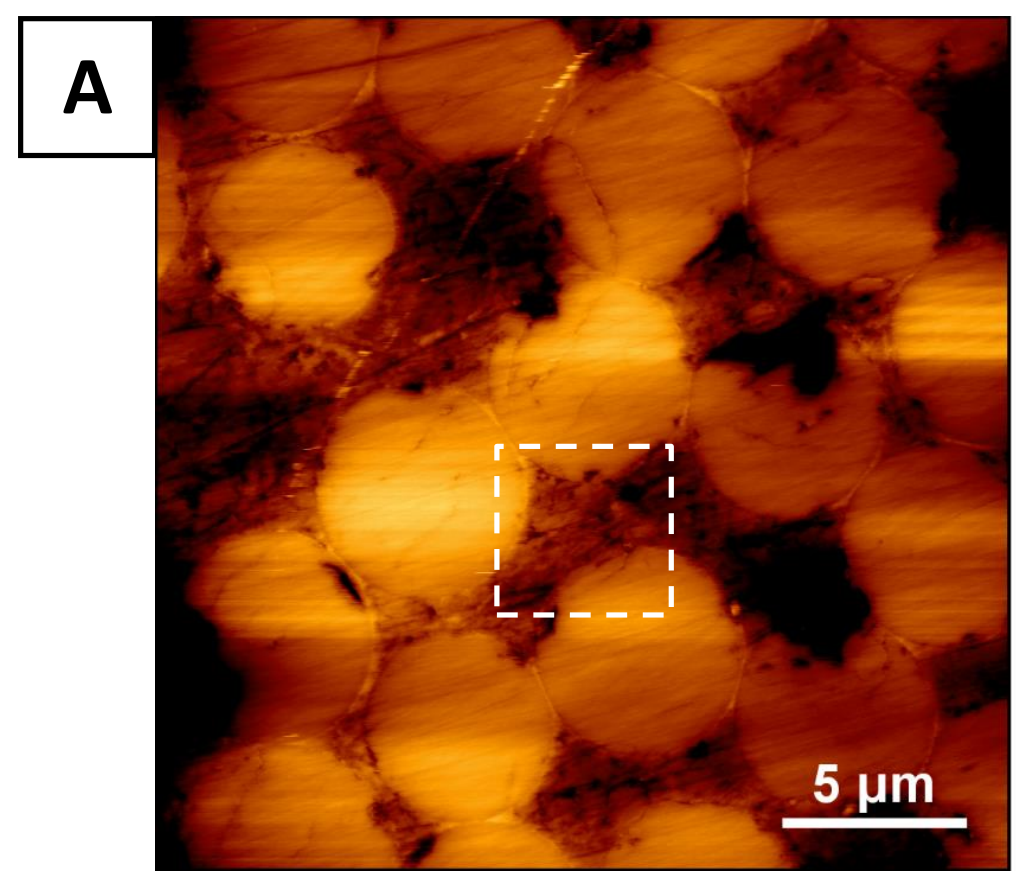

$175 \mathrm{~nm}$

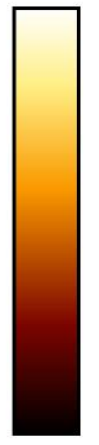

$0 \mathrm{~nm}$

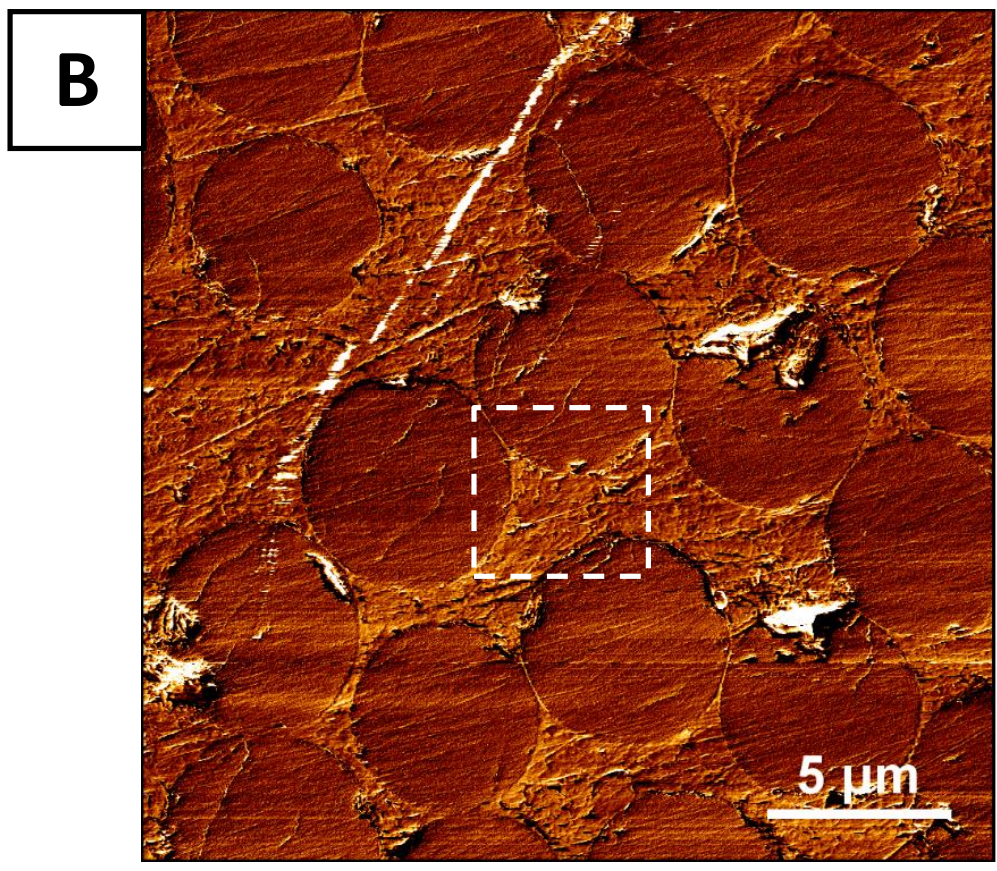

$497 \mathrm{pm}$

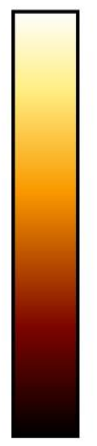

$0 \mathrm{pm}$

Figure 6.25 AFM images of a $50 \mathrm{~g} / \mathrm{m}^{2}$ sample: a) AFM height map (proud areas represented by brighter colours) b) force modulation image (stiffer areas represented by brighter colours). White box indicates the magnified area shown in Figure 6.26. 

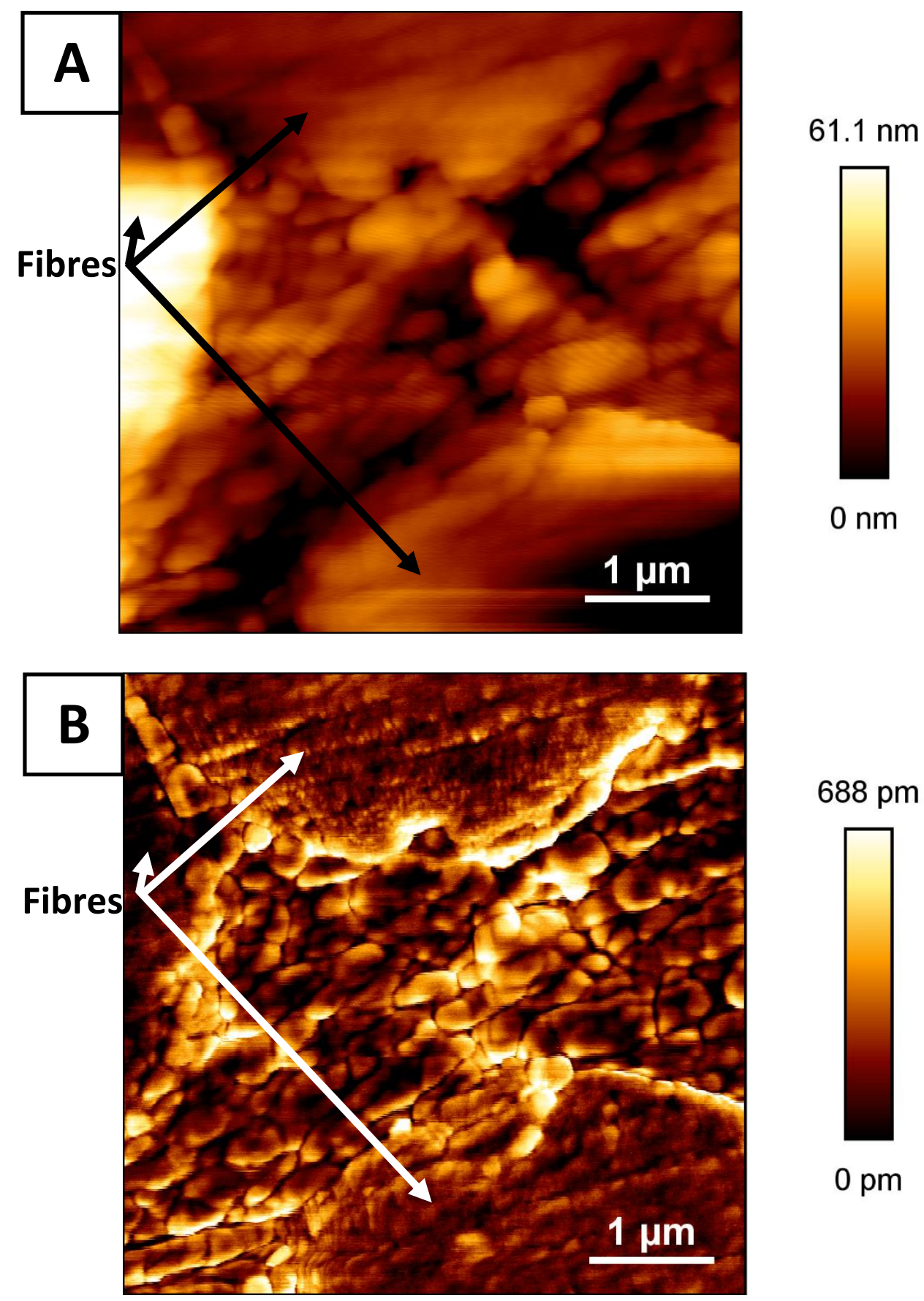

$688 \mathrm{pm}$

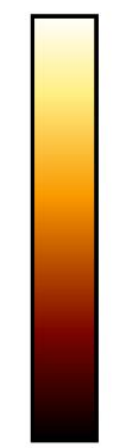

$0 \mathrm{pm}$

Figure 6.26 Higher magnification AFM images of the $50 \mathrm{~g} / \mathrm{m}^{2}$ sample shown in Figure 6.25: a) AFM height map (proud areas represented by brighter colours) b) force modulation image (stiffer areas represented by brighter colours) 


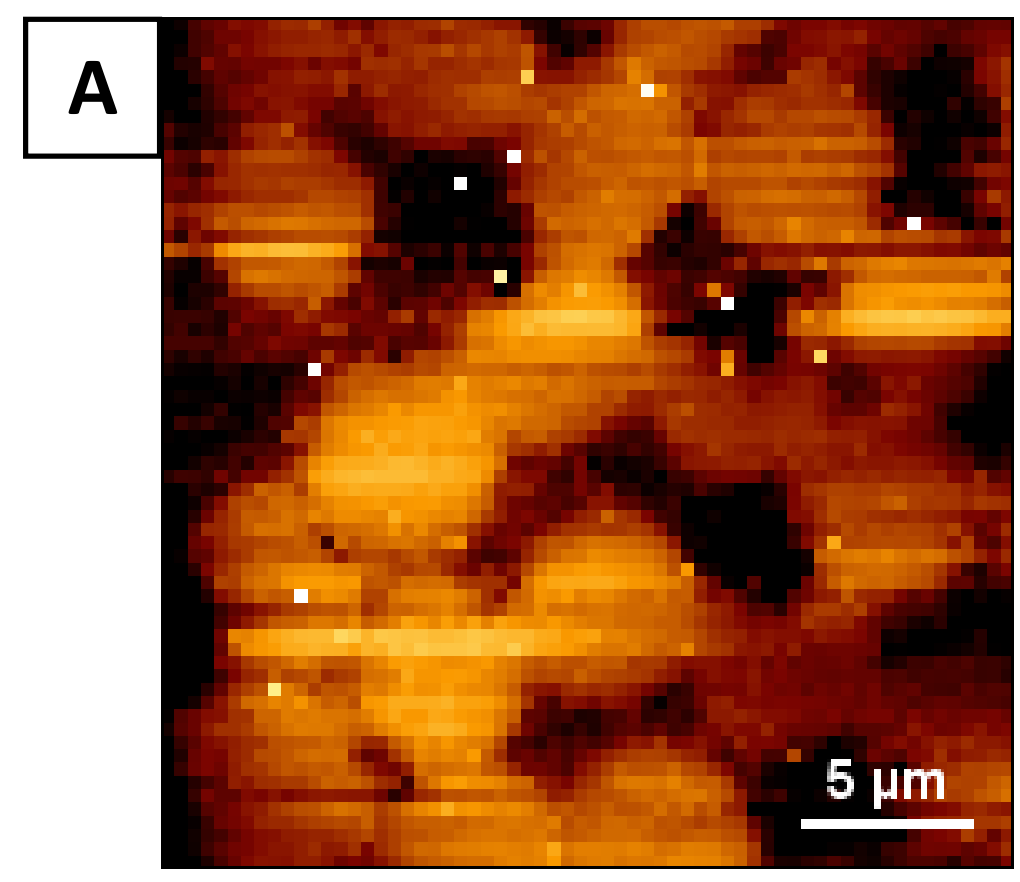

$148 \mathrm{~nm}$

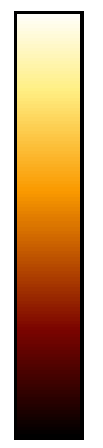

$0 \mathrm{~nm}$

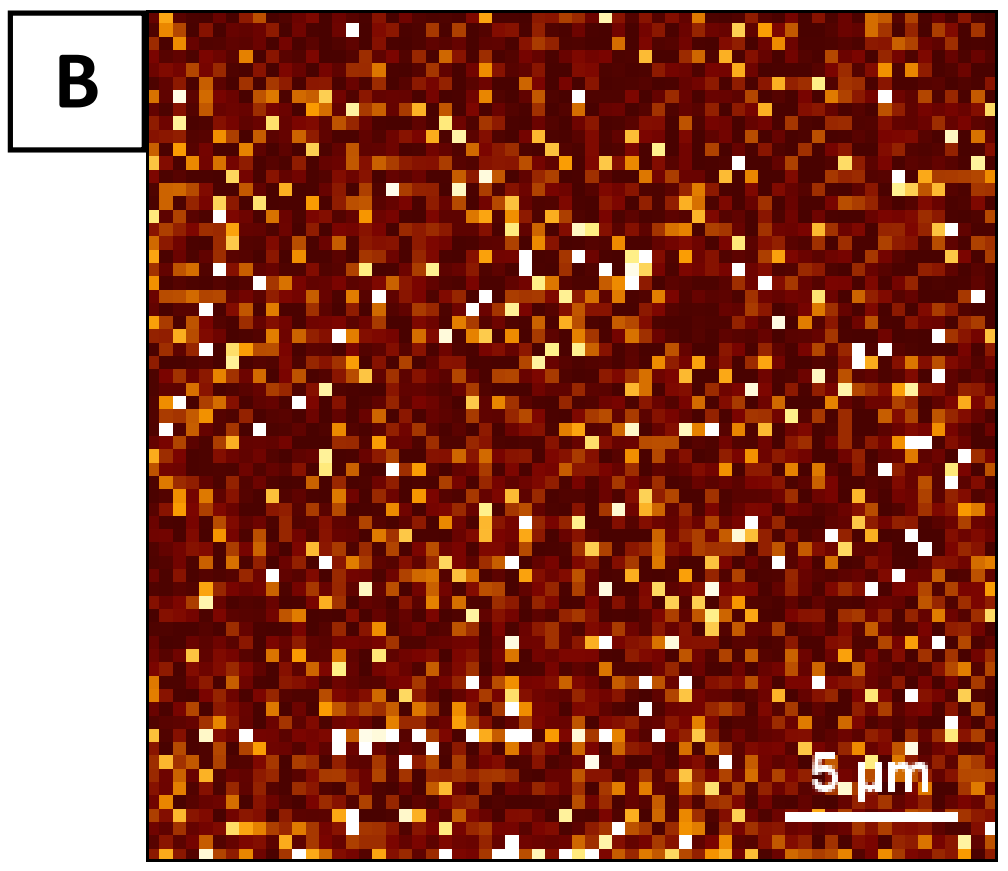

$193 \mathrm{GPa}$

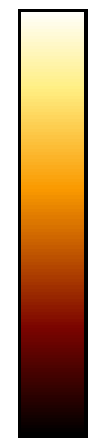

$0 \mathrm{GPa}$

Figure 6.27 AFM images of a 50g/ $\mathrm{m}^{2}$ sample: a) AFM height map (proud areas represented by brighter colours) b) force map data (stiffer areas represented by brighter colours). The force map image shows excessive noise.

As discussed earlier, the presence of a dual tan delta peak is likely due to a two-phase structure within the material. A second hypothesis for the presence of this structure, and one which is thought to be more likely, is due to the presence of poly-ether-sulfone (PES) toughening particles. Within the T800 TP135 matrix a PES toughening agent is present. The $\mathrm{T}_{\mathrm{g}}$ of PES is approximately between $205^{\circ} \mathrm{C}$ and 
$220{ }^{\circ} \mathrm{C}[123,124]$, which corresponds to the higher temperature tan delta peak. This second peak is typically smaller than the first, lower temperature peak, which is greater evidence for the presence of PES, because the PES toughening particles make up a smaller proportion of the overall material. The dual tan delta peak is therefore likely to be due to the presence of PES as separate particles to the epoxy matrix. When the samples are conditioned, it is likely that both the epoxy resin and the PES are plasticised, which leads to the reduction in temperature for both peaks. The presence of a dual tan delta peak for polymers combined with PES has been observed previously in the literature $[123,124]$. Mimura et al. [123] explain that the phase separation process is dictated by PES content or curing temperature, as shown in Figure 6.28.

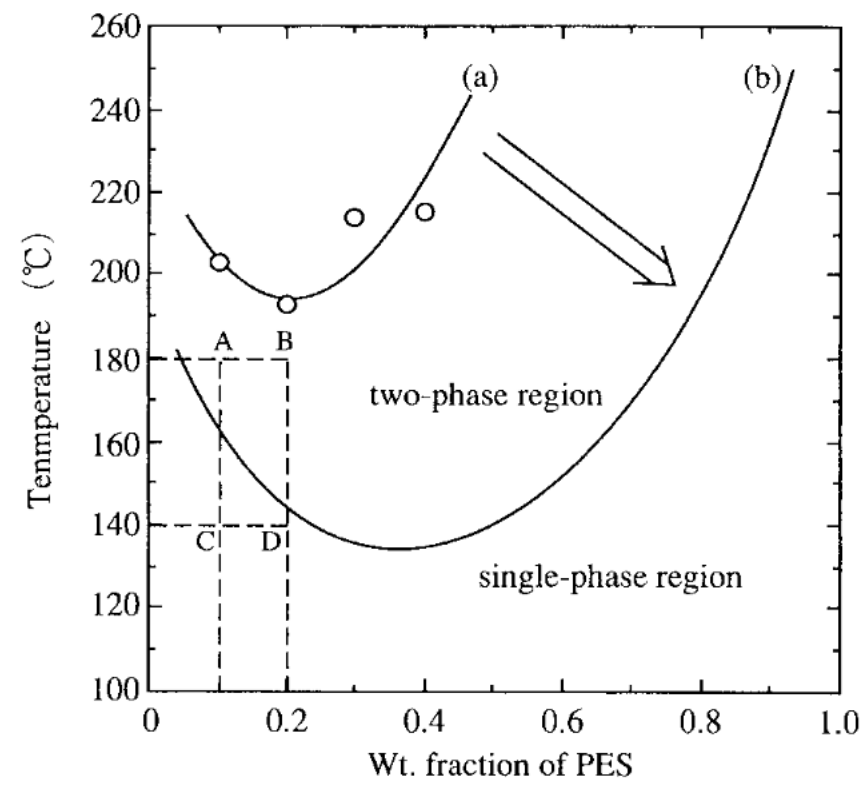

Figure 6.28 Epoxy resin, phenol resin and PES mixture phase diagram [123] ${ }^{6}$

Mimura et al. [123] found that the epoxy resin material toughened with PES displayed a single tan delta peak at cure temperatures below $140{ }^{\circ} \mathrm{C}$ and a double tan delta peak when cured at $180^{\circ} \mathrm{C}$. This is very similar to the behaviour of the T800 TP135 material. In addition, several authors noted a change in the

\footnotetext{
${ }^{6}$ Reprinted from Polymer, 41(12), Mimura K, Ito H, Fujioka H, Improvement of thermal and mechanical properties by control of morphologies in PES-modified epoxy resins, pp. 4451-4459, Copyright (2000), with permission from Elsevier.
} 
morphology of PES particles at different cure temperatures [123,124]. To investigate if this was the case for the T800 TP135 material, a FEG-SEM was used to examine the morphology of several thin and thick ply samples. Samples from all three of the ply thickness materials were examined, after exposure to different conditions: a) freezer stored, b) after a two hour cure at $180^{\circ} \mathrm{C}$ and c) after conditioning until saturation at $85 \% \mathrm{RH}, 70{ }^{\circ} \mathrm{C}$. Example images from each material are shown in Figure 6.29 to Figure 6.32. The materials investigated were QI.

It is thought that the second phase particles seen within the resin and fibres on the FEG-SEM images are PES toughening particles. The possible presence of PES on the fibres is thought to be a result of the toughening particles spreading from the resin onto the fibres during the polishing process. It is possible that energy-dispersive X-ray spectroscopy (EDS) could be used to confirm the presence these particles are rich in sulphur, and therefore likely to be PES. This would be useful to carry out in future work.

Several different morphologies of these second phase particles were found, ranging from globular, spherical particles, to what appears to be a merging of the particles to create a more complex structure. A similar morphology change was seen with PES toughened carbon fibre polybenzoxazine composites by Del Saz-Orozco et al. [124]. Upon inspection of the T800 TP135 samples after exposure to different environments, there does not seem to be a clear trend relating the second phase particle morphology to the presence of a second tan delta peak. For this, a more comprehensive microscope study would be needed, alongside chemical mapping of the materials to show that the particles seen are indeed PES. Aside from the presence of secondary particles within the material, the FEG-SEM data shows some interesting information regarding the condition of the fibres and matrix. Fibre damage and degradation of the fibre/matrix interface can be seen in some of the images. Future work could include a more comprehensive look at this 
damage, to see if there is a correlation between ply thickness and the level of defects found. This could then be compared to mechanical test data, to look for trends relating damage and reduction in properties. 



Figure 6.29 FEG-SEM images of freezer stored T800 TP135 QI material: a) $50 \mathrm{~g} / \mathrm{m}^{2}, \mathrm{~b}$ ) $\left.150 \mathrm{~g} / \mathrm{m}^{2}, c\right) 300 \mathrm{~g} / \mathrm{m}^{2}$ [note, arrows indicate example second phase particles within the materiall 

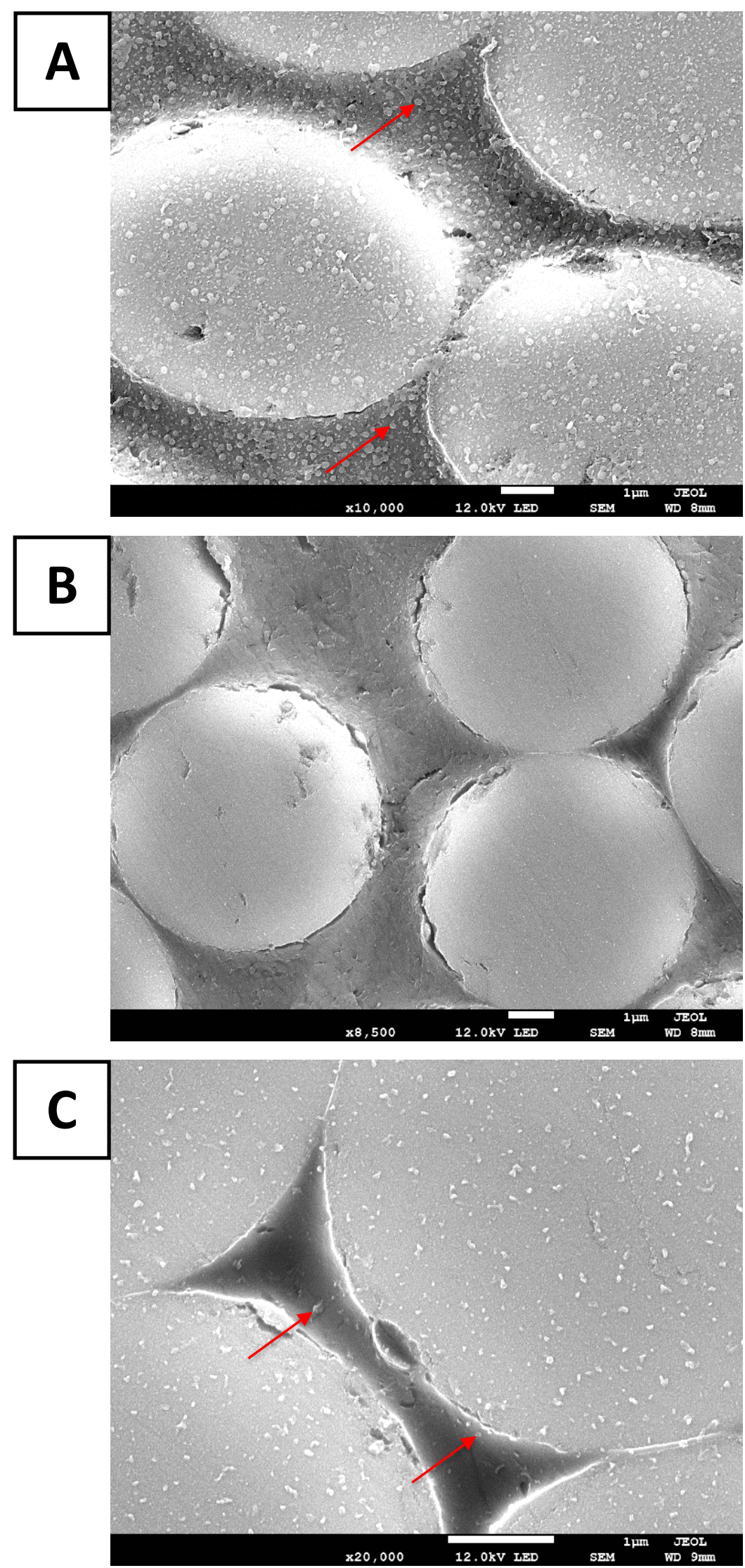

Figure 6.30 FEG-SEM images of T800 TP135 QI material stored at room temperature for three months: a) $50 \mathrm{~g} / \mathrm{m}^{2}$, b) $\left.150 \mathrm{~g} / \mathrm{m}^{2}, c\right) 300 \mathrm{~g} / \mathrm{m}^{2}$ [note, arrows indicate example second phase particles within the material] 

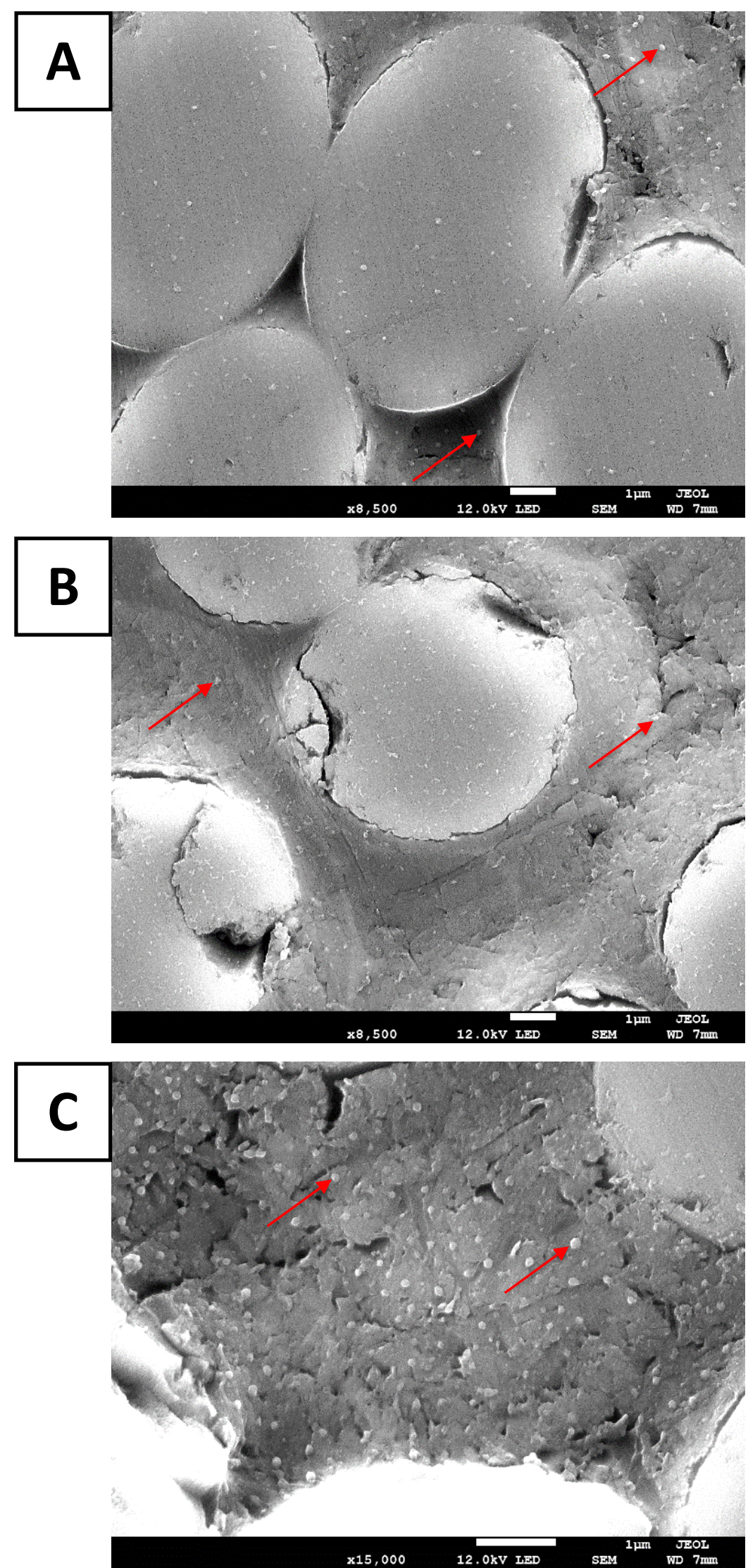

Figure 6.31 FEG-SEM images of T800 TP135 QI material after curing at $180{ }^{\circ} \mathrm{C}$ for two hours: a) $50 \mathrm{~g} / \mathrm{m}^{2}$, b) $150 \mathrm{~g} / \mathrm{m}^{2}$, c) $300 \mathrm{~g} / \mathrm{m}^{2}$ [note, arrows indicate example second phase particles within the material] 

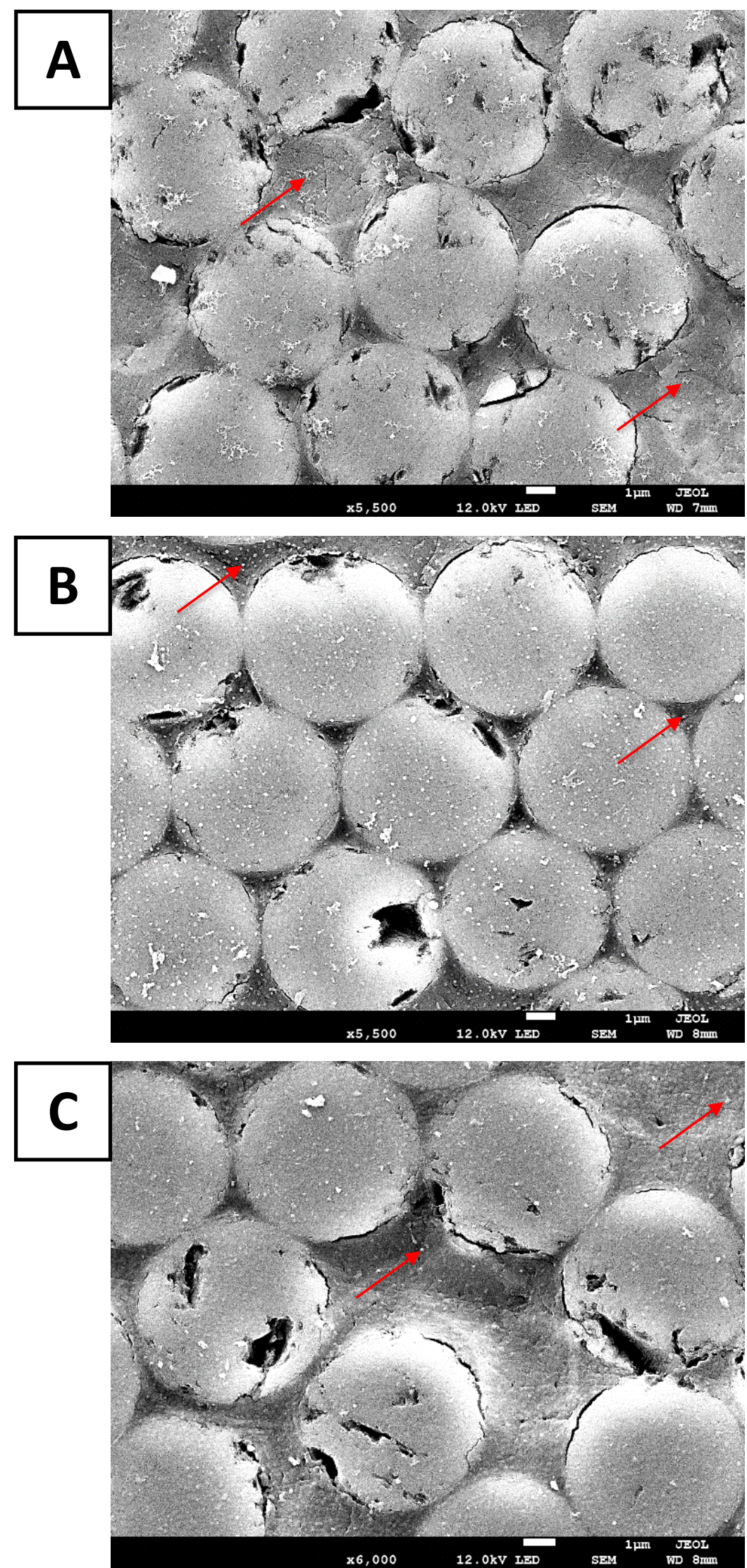

Figure 6.32 FEG-SEM images of T800 TP135 QI material after conditioning until saturation at $85 \% \mathrm{RH}, 70{ }^{\circ} \mathrm{C}$ : a) $50 \mathrm{~g} / \mathrm{m}^{2}$, b) $\left.150 \mathrm{~g} / \mathrm{m}^{2}, c\right) 300 \mathrm{~g} / \mathrm{m}^{2}$ [note, arrows indicate example second phase particles within the material] 


\subsubsection{Thermal Analysis Summary}

DMA was used to investigate the effect of ply thickness on the viscoelastic properties and the glass transition temperatures of CFRP. Initial analysis showed interesting results, with $\mathrm{T}_{\mathrm{g}}$ appearing to decrease with increasing ply thickness. Further investigations showed that this difference was likely due to varying levels of water content within the material. Storage of the material, prior to delivery from the manufacturer, was standard room temperature condition. After that, the material was stored in a freezer at $-30^{\circ} \mathrm{C}$. Storage at this low temperature is thought to have reduced moisture ingress and thus maintained $\mathrm{T}_{\mathrm{g}}$. During and after the production of DMA test coupons, the samples were again stored at room temperature. Prior to analysis, it was not thought that storage of the samples at room temperature should be controlled and, as such, the precise time period that each DMA sample was exposed to room temperature conditions (and therefore moisture ingress) is unknown. This is thought to be the source of variability in the DMA data obtained.

Further to $\mathrm{T}_{\mathrm{g}}$, distinct differences in the tan delta DMA traces of samples from the three different ply thicknesses were obtained. As explained previously, the material tends to achieve a state of two distinct phases, likely due to polymer relaxation. After water ingress and subsequent drying of the samples, each ply thickness material maintained the two-phase state, where one larger tan delta peak was formed at approximately $165^{\circ} \mathrm{C}$, and a second smaller peak at approximately $205^{\circ} \mathrm{C}$ (precise peak temperatures were dependent on ply thickness and moisture content). Interestingly, the thin-ply material appears to start achieving this state after heating above $175^{\circ} \mathrm{C}$. The two-phase state effect was less noticeable with just heating of the $150 \mathrm{~g} / \mathrm{m}^{2}$ and $300 \mathrm{~g} / \mathrm{m}^{2}$ materials, than it was after water ingress. It is thought that the two-phase state is likely to be a result of the presence of PES toughening particles within the matrix. What is less clear, is why ply thickness seems to impact the phase separation of epoxy and PES. In the 'as received' condition, the thin ply material displays a single, 
relatively sharp tan delta peak; seemingly the thin-ply material has the least phase separation at this point and therefore the toughening particles would have the least effect. This suggests that the toughness of the thin-ply material could be limited. Upon first heating of the thicker ply samples, the tan delta peak is slightly broader, suggesting that the phase separation is already taking place. Upon heating of the $50 \mathrm{~g} / \mathrm{m}^{2}$ sample (or water ingress with subsequent drying) the thin-ply material appears to phase separate more easily and therefore the toughening particles could have more of an effect on the material properties at higher temperatures. At high temperature, or with water ingress, the resin will be weaker, but more tough. Future thermal analysis work would be needed to further understand the effect of ply thickness on PES and epoxy phase separation. 


\section{Conclusions and Further Work}




\subsection{Conclusions}

The main objective of this thesis was to investigate the effect of ply thickness on the mechanical properties of carbon fibre composites, after exposure to different environmental conditions. A large mechanical testing programme was designed, to compare the properties of CFRPs manufactured using three different ply thicknesses, referred to as thin $\left(50 \mathrm{~g} / \mathrm{m}^{2}\right)$, intermediate $\left(150 \mathrm{~g} / \mathrm{m}^{2}\right)$ and thick-ply $\left(300 \mathrm{~g} / \mathrm{m}^{2}\right)$. The three materials comprised the same resin and fibre and were manufactured using the same cure schedules. Samples of each material were tested under various loading types, including tension, compression, and shear, and were subjected to both high temperature and various moisture environments. Techniques such as high-speed camera video recording, DIC, and thermal analysis were successfully used to understand more about how and why CFRPs made from spread-tow prepreg behave differently to conventional prepreg materials.

A number of different failure mechanisms led to the observed changes in mechanical behaviour for the three different materials. Dependence on ply thickness was shown to be greater when the material was not unidirectional. For unidirectional materials, the use of spread-tow prepreg had little benefit, despite the enhanced homogeneity of the microstructure. On the contrary, a large difference in mechanical properties was found for the QI and $\pm 45^{\circ}$ laminates. One of the main mechanisms influencing this is the difference in interfacial stresses, with thinner ply materials having lower interfacial stresses than thicker ply materials. This explains why unnotched tensile and shear properties increase with decreasing ply thickness. The lower interfacial stresses are also the reason given for the vastly different failure modes. Thin-ply coupons were shown to have a very brittle failure mode. This is due to the smaller interfacial stresses leading to failure only when the load bearing $0^{\circ}$ fibres break. Compared to the $0^{\circ}$ fibres, the off-axis plies do not carry as high a load. Therefore, when the $0^{\circ}$ fibres fail, the rest of the plies fail immediately. This type of failure is very constrained. 
On the contrary, thicker ply laminates have larger interfacial stresses. The larger stresses cause the $\pm 45^{\circ}$ plies to fail first, which, in turn, puts more load onto the intact $0^{\circ}$ plies. The result is that the thicker ply samples fail at lower stresses, with much greater widespread fracture and generation of debris.

The second failure mechanism to comment on is the effect of a large stress concentration and how this changes the way that samples with different interfacial stresses behave. When a large stress concentration (such as a hole) is present in the material, larger interfacial stresses are a benefit. This is because they help to relieve the stress concentration at the hole and ultimately lead to higher tensile strengths. The same mechanism (differing interfacial stresses) is used to explain the failure of both the unnotched and notched tensile samples, even though very different results were seen. That said, the same brittle and delamination failure modes were found for the thin and thick-ply samples respectively.

In compression, micro-buckling of the fibres is constrained by adjacent plies with different orientation; the thin-ply material is therefore stronger because the fibres have less freedom to buckle compared to samples where the plies are thicker.

Both high temperature and water absorption caused the resin matrix to increase in toughness but decrease in strength and stiffness. The effect of this differed depending on the type of loading applied. For example, the increase in toughness was positive for tensile properties, because the higher flexibility of the resin gave more freedom for adjacent plies to move next to each other. Therefore, an increase in strength was generally seen, because interfacial stresses were lowered. On the contrary, compressive properties were negatively affected by the reduction in resin strength and stiffness, along with the associated increased toughness. This promoted the ease of micro-buckling and thus reduced strength. 
Investigations into the effect of ply thickness on moisture absorption and diffusivity showed varying results. Although the diffusion coefficients did not vary significantly for the different ply thicknesses, the level of water ingress did change. The thin-ply material absorbed more water in comparison to the thicker ply material. It is possible that differences in the local microstructure played a role in this water ingress difference. That said, the reason for this not known and could be investigated further. Despite the increased moisture content, the effect of moisture on the mechanical testing results remained consistent across all three materials. Therefore, it appears that the thin-ply material was not negatively affected by the extra moisture absorption.

Thermal analysis was conducted on the material to understand the effect of ply thickness on viscoelastic properties. Interestingly, it was found that storage at room temperature lead to a decrease in $\mathrm{T}_{\mathrm{g}}$ after approximately 12 weeks. Furthermore, the material was shown to tend to a state of two distinct phases. This is thought to be due to the presence of PES toughening particles causing a phase separation. The thin-ply material appears to affect the phase separation differently to the thicker-ply material, but the reason for this requires further investigation.

Overall, the work has highlighted the impact of ply thickness on different mechanical loadings (tensile, compression and shear) and has shown the effects of both temperature and moisture ingress on spread-tow prepreg laminates. Generally, the thin-ply material performs well in a range of different loading environments.

\subsection{Future Work}

Within the thesis there are certain areas where future work would help to provide further insight into the behaviour of thin-ply material. To learn more about mechanical properties, a comparison of in-plane shear properties, using the same 
number of plies for each different prepreg thickness would help to understand if the increased strength was due to the spread tow prepreg, or just the large number of plies within the coupon. The reader is reminded that ASTM D3518M [75] (the standard procedure for in-plane shear testing of a $\pm 45^{\circ}$ laminate) recommends that samples produced using UD tape should have 16, 20 or 24 plies. It would be interesting to see if the thin-ply material still has increased in-plane shear strength, compared to the thicker-ply sample, if the ply count is equal.

Further to the mechanical testing, it would be useful to understand more about why the thin-ply material absorbs more water than the thicker-ply laminates. The thin-ply material had a lower fibre volume fraction, which will account for some of the higher water content, however it is thought that the difference is too great to be just a result of fibre volume fraction. A more detailed investigation into the microstructure of the samples could help to explain this difference.

Finally, further thermal analysis investigations could be carried out to learn more about why ply thickness appears to affect the phase separation of PES and epoxy. This could involve conducting DMA on samples with varying water contents or cure schedules, to understand at which point the phase separation begins to occur. It is also possible that EDS could be used to confirm whether the second-phase particles seen via FEG-SEM were rich in sulphur. If so, the particles would likely be PES. Following that, a more thorough FEG-SEM analysis could be carried out to see if trends emerge between the morphology of the second-phase particles and phase separation seen via thermal analysis. 


\section{References}

1. Cardarelli F. Composite Materials. In: Materials Handbook: A Concise Desktop Reference [Internet]. 2nd ed. London: Springer; 2008. p. 101935. Available from: http://link.springer.com/10.1007/978-1-84628-669-8

2. Masuelli MA. Introduction of Fibre-Reinforced Polymers - Polymers and Composites: Concepts, Properties and Processes. In: Fiber Reinforced Polymers - The Technology Applied for Concrete Repair [Internet]. InTechOpen; 2013. p. 3-40. Available from: http://www.intechopen.com/books/fiber-reinforced-polymers-thetechnology-applied-for-concrete-repair/introduction-of-fibrereinforced-polymers-polymers-and-composites-concepts-propertiesand-processes

3. Hull D, Clyne TW. An Introduction to Composite Materials. 2nd ed. Cambridge: Cambridge University Press; 1996.

4. Soutis C. Fibre reinforced composites in aircraft construction. Progress in Aerospace Sciences. 2005;41(2):143-51.

5. Dragan K, Leski A. Failure of polymer matrix composites in defence applications. In: Failure Mechanisms in Polymer Matrix Composites [Internet]. Woodhead Publishing; 2012. p. 279-99. Available from: https://linkinghub.elsevier.com/retrieve/pii/B9781845697501500094

6. Zhang J, Chaisombat $\mathrm{K}$, He S, Wang CH. Hybrid composite laminates reinforced with glass/carbon woven fabrics for lightweight load bearing structures. Materials and Design. 2012;36:75-80.

7. Hollaway LC. A review of the present and future utilisation of FRP composites in the civil infrastructure with reference to their important in-service properties. Construction and Building Materials. 2010;24(12):2419-45.

8. Mouritz AP, Gellert E, Burchill P, Challis K. Review of advanced composite structures for naval ships and submarines. Composite Structures. 2001;53(1):21-42.

9. Holmes M. Global carbon fibre market remains on upward trend. Reinforced Plastics. 2014;58(6):38-45.

10. Holmes M. Carbon composites continue to find new markets. 
Reinforced Plastics. 2017;61(1):36-40.

11. Sauer M, Kuhnel M. Composites Market Report 2018 - Market developments, trends, outlook and chalenges [Internet]. 2018 [cited 2019 Nov 29]. p. 1-60. Available from: https://www.avktv.de/files/20181115_avk_ccev_market_report_2018_final.pdf

12. Cugnoni J, Amacher R, Kohler S, Brunner J, Kramer E, Dransfeld C, et al. Towards aerospace grade thin-ply composites: Effect of ply thickness, fibre, matrix and interlayer toughening on strength and damage tolerance. Composites Science and Technology. 2018;168:46777.

13. Frossard G, Cugnoni J, Gmür T, Botsis J. Ply thickness dependence of the intralaminar fracture in thin-ply carbon-epoxy laminates. Composites Part A: Applied Science and Manufacturing. 2018;109:95104.

14. Amacher R, Cugnoni J, Botsis J, Sorensen L, Smith W, Dransfeld C. Thin ply composites: Experimental characterization and modeling of sizeeffects. Composites Science and Technology. 2014;101:121-32.

15. Yokozeki T, Aoki Y, Ogasawara T. Experimental characterization of strength and damage resistance properties of thin-ply carbon fiber/toughened epoxy laminates. Composite Structures. 2008;82(3):382-9.

16. Sihn S, Kim RY, Kawabe K, Tsai SW. Experimental studies of thin-ply laminated composites. Composites Science and Technology. 2007;67(6):996-1008.

17. North Thin Ply Technology. The Thin Ply Advantage [Internet]. 2016 [cited 2019 Sep 4]. Available from: https:/www.thinplytechnology.com/technology/thin-ply-advantage

18. Garcez M, Meneghetti L, Da Silva Filho LCP. Structural Performance of RC Beams Poststrengthened with Carbon, Aramid, and Glass FRP Systems. Journal of Composites for Construction. 2008;12(5):522-30.

19. Chilali A, Zouari W, Assarar M, Kebir H, Ayad R. Analysis of the mechanical behaviour of flax and glass fabrics-reinforced thermoplastic and thermoset resins. Journal of Reinforced Plastics and Composites. 2016;35(16):1217-32.

20. El-Dessouky HM, Lawrence CA. Ultra-lightweight carbon 
fibre/thermoplastic composite material using spread tow technology. Composites Part B: Engineering. 2013;50:91-7.

21. Sonnenfeld C, Mendil-Jakani H, Agogué R, Nunez P, Beauchêne P. Thermoplastic/thermoset multilayer composites: A way to improve the impact damage tolerance of thermosetting resin matrix composites. Composite Structures. 2017;171:298-305.

22. Composites UK. Introduction to Composite Materials [Internet]. [cited 2017 Jan 12]. Available from: https:/compositesuk.co.uk/compositematerials/introduction

23. Airbus. Composites: Airbus continues to shape the future [Internet]. 2017 [cited 2019 Sep 4]. Available from: https:/www.airbus.com/newsroom/news/en/2017/08/composites-airbus-continues-to-shape-the-future.html

24. Hale J. Boeing 787 from the Ground Up [Internet]. Boeing. 2006 [cited 2019 Nov 20]. p. 23. Available from: https://www.boeing.com/commercial/aeromagazine/articles/qtr_4_06/a rticle_04_2.html

25. Composites UK. Methods of composite manufacture [Internet]. [cited 2019 Sep 4]. Available from: https://compositesuk.co.uk/compositematerials/processes

26. Kawabe K, Sasayama H, Tomoda S. New Carbon Fiber Tow-Spread Technology and Applications to Advanced Composite Materials. SAMPE Journal. 2009;45(2):6-17.

27. Windhorst T, Blount G. Carbon-carbon composites: A summary of recent developments and applications. Materials and Design. 1997;18(1):11-5.

28. Wang FK. Carbon fibers and their thermal transporting properties. In: Thermal Transport in Carbon-Based Nanomaterials [Internet]. 1st ed. Elsevier Inc.; 2017. p. 135-84. Available from: http://dx.doi.org/10.1016/B978-0-32-346240-2.00006-6

29. Alam P, Robert C, Ó Brádaigh CM. Tidal turbine blade composites - A review on the effects of hygrothermal aging on the properties of CFRP. Composites Part B: Engineering. 2018;149:248-59.

30. Chand S. Carbon fibers for composites. Journal of Materials Science. 2000;35(6):1303-13. 
31. Campbell FC. Matrix Resin Systems. In: ASM International, editor. Structural Composite Materials [Internet]. A S M International; 2010. p. 63-100. Available from: https://ebookcentral.proquest.com/lib/swanseaebooks/detail.action?docID=3002447

32. Campbell FC. Introduction to composite materials. In: ASM International, editor. Structural Composite Materials [Internet]. A S M International; 2010. p. 1-29. Available from: https://ebookcentral.proquest.com/lib/swanseaebooks/detail.action?docID=3002447

33. Unnikrishnan KP, Thachil ET. Toughening of epoxy resins. Designed Monomers and Polymers. 2006;9(2):129-52.

34. Zotti A, Zuppolini S, Zarrelli M, Borriello A. Fracture Toughening Mechanisms in Epoxy Adhesives. In: Adhesives - Applications and Properties [Internet]. InTech; 2016. p. 237-69. Available from: http://www.intechopen.com/books/adhesives-applications-andproperties/fracture-toughening-mechanisms-in-epoxy-adhesives

35. Thomas S, Sinturel C, Thomas R, editors. Introduction. In: Micro and Nanostructured Epoxy/Rubber Blends [Internet]. John Wiley \& Sons; 2014. p. 1-30. Available from: https://ebookcentral.proquest.com/lib/swanseaebooks/detail.action?docID=1780450

36. Rutnakornpituk M. Thermoplastic toughened epoxy networks and their toughening mechanisms in some systems. Naresuan University Journal. 2013;13(1):73-83.

37. Hodgkinson JM, editor. Mechanical Testing of Advanced Fibre Composites [Internet]. Cambridge: Woodhead Publishing Limited; 2000. Available from: https://www.sciencedirect.com/book/9781855733121/mechanicaltesting-of-advanced-fibre-composites

38. Jang J, Yang $H$. Toughness improvement of carbonfibre/polybenzoxazine composites by rubber modification. Composites Science and Technology. 2000;60(3):457-63.

39. Nguyen MH, Davidson P, Waas AM. Particle-toughened interlayers enhance mechanical response of composite laminates. Composites Science and Technology. 2019;182:1-11. 
40. Day RJ, Lovell PA, Wazzan AA. Toughened carbon/epoxy composites made by using core/shell particles. Composites Science and Technology. 2001;61(1):41-56.

41. Ricciardi MR, Papa I, Langella A, Langella T, Lopresto V, Antonucci V. Mechanical properties of glass fibre composites based on nitrile rubber toughened modified epoxy resin. Composites Part B: Engineering. 2018;139:259-67.

42. Varada Rajulu A, Babu Rao G, Ganga Devi L, Balaji PJ, He J, Zhang J. Interlaminar Shear Strength of Polycarbonate-Toughened Epoxy Composites Reinforced with Glass Rovings. Advances in Polymer Technology. 2003;22(4):373-7.

43. Park S-J, Seo M-K. Modeling of Fiber-Matrix Interface in Composite Materials. In: Interface Science and Composites [Internet]. Elsevier Ltd; 2011. p. 739-76. Available from: https://linkinghub.elsevier.com/retrieve/pii/B9780123750495000098

44. Sethi S, Ray BC. Environmental effects on fibre reinforced polymeric composites: Evolving reasons and remarks on interfacial strength and stability. Advances in Colloid and Interface Science. 2015;217:43-67.

45. Becker H, Locascio LE. Polymer microfluidic devices. Talanta. 2002;56(2):267-87.

46. Zhou J, Lucas JP. Hygrothermal effects of epoxy resin. Part II: variations of glass transition temperature. Polymer. 1999;40(20):5513-22.

47. Ngai K. The glass transition and the glassy state. In: Physical Properties of Polymers [Internet]. Cambridge: Cambridge University Press; 2004. p. 72-152. Available from: https://www.cambridge.org/core/product/identifier/CBO978113916516 7A034/type/book_part

48. Carbas RJC, Marques EAS, Da Silva LFM, Lopes AM. Effect of Cure Temperature on the Glass Transition Temperature and Mechanical Properties of Epoxy Adhesives. Journal of Adhesion. 2014;90:104-19.

49. Urbaniak M. A relationship between the glass transition temperature and the conversion degree in the curing reaction of the EPY epoxy system. Polimery. 2011;56(3):240-3.

50. Broughton W. Environmental induced failure in fibre-reinforced plastics. In: Failure Mechanisms in Polymer Matrix Composites 
[Internet]. Woodhead Publishing; 2012. p. 393-440. Available from: https://linkinghub.elsevier.com/retrieve/pii/B9781845697501500136

51. Luo S, Wong CP. Thermo-mechanical Properties of Epoxy Formulations with Low Glass Transition Temperatures. In: 8th International Symposium on Advanced Packaging Materials. 2002. p. 226-31.

52. Goertzen WK, Kessler MR. Dynamic mechanical analysis of carbon/epoxy composites for structural pipeline repair. Composites Part B: Engineering. 2007;38(1):1-9.

53. Tjong SC. Thermal Properties of Polymer Nanocomposites. In: Polymer Composites with Carbonaceous Nanofillers [Internet]. Weinheim, Germany: Wiley-VCH Verlag GmbH \& Co. KGaA; 2012. p. 103-41. Available from: http://doi.wiley.com/10.1002/9783527648726.ch3

54. Menard KP. Dynamic Mechanical Analysis A Practical Introduction [Internet]. CRC Press; 1999. Available from: http://sv.20file.org/up1/608_0.pdf

55. Bai Y, Keller T. Material States of FRP Composites under Elevated and High Temperatures. In: High Temperature Performance of Polymer Composites [Internet]. John Wiley \& Sons, Inc.; 2014. p. 21-37. Available from: https://onlinelibrary.wiley.com/doi/book/10.1002/9783527654147

56. Shah DU, Schubel PJ, Licence P, Clifford MJ. Determining the minimum, critical and maximum fibre content for twisted yarn reinforced plant fibre composites. Composites Science and Technology. 2012;72(15):1909-17.

57. Mehdikhani M, Gorbatikh L, Verpoest I, Lomov S V. Voids in fiberreinforced polymer composites: A review on their formation, characteristics, and effects on mechanical performance. Journal of Composite Materials. 2019;53(12):1579-669.

58. Park S-J, Heo G-Y. Precursors and Manufacturing of Carbon Fibers. In: Carbon Fibers [Internet]. Springer; 2015. p. 31-66. Available from: http://link.springer.com/10.1007/978-94-017-9478-7_2

59. Perez-Pacheco E, Cauich-Cupul JI, Valadez-Gonzalez A, HerreraFranco PJ. Effect of moisture absorption on the mechanical behavior of carbon fiber/epoxy matrix composites. 2013;48(5):1873-82.

60. Moon JB, Kim MG, Kim CG, Bhowmik S. Improvement of tensile properties of CFRP composites under LEO space environment by 
applying MWNTs and thin-ply. Composites Part A: Applied Science and Manufacturing. 2011;42(6):694-701.

61. Saito H, Morita M, Kawabe K, Kanesaki M, Takeuchi H, Tanaka M, et al. Effect of ply-thickness on impact damage morphology in CFRP laminates. Journal of Reinforced Plastics and Composites. 2011;30(13):1097-106.

62. Huang C, He M, He Y, Xiao J, Zhang J, Ju S, et al. Exploration relation between interlaminar shear properties of thin-ply laminates under short-beam bending and meso-structures. Journal of Composite Materials. 2017;1-12.

63. Nishikawa Y, Okubo K, Fujii T, Kawabe K. Fatigue crack constraint in plain-woven CFRP using newly-developed spread tows. International Journal of Fatigue. 2006;28(10):1248-53.

64. Wisnom MR, Khan B, Hallett SR. Size effects in unnotched tensile strength of unidirectional and quasi-isotropic carbon/epoxy composites. Composite Structures. 2008;84(1):21-8.

65. Chen BY, Tay TE, Baiz PM, Pinho ST. Numerical analysis of size effects on open-hole tensile composite laminates. Composites Part A: Applied Science and Manufacturing. 2013;47:52-62.

66. Wisnom MR. Size effects in the testing of fibre-composite materials. Composites Science and Technology. 1999;59(13):1937-57.

67. Sutherland LS, Shenoi RA, Lewis SM. Size and scale effects in composites: I. Literature review. Composites Science and Technology. 1999;59(2):209-20.

68. Lee J, Soutis C. Thickness effect on the compressive strength of T800/924C carbon fibre-epoxy laminates. Composites Part A: Applied Science and Manufacturing. 2005;36(2):213-27.

69. Fotouhi M, Jalalvand M, Wisnom MR. Notch insensitive orientationdispersed pseudo-ductile thin-ply carbon/glass hybrid laminates. Composites Part A: Applied Science and Manufacturing. 2018;110:29_ 44 .

70. Green BG, Wisnom MR, Hallett SR. An experimental investigation into the tensile strength scaling of notched composites. Composites Part A: Applied Science and Manufacturing. 2007;38(3):867-78. 
71. Wisnom MR, Hallett SR, Soutis C. Scaling Effects in Notched Composites. Journal of Composite Materials. 2010;44(2):195-210.

72. Huang C, Ju S, He M, Zheng Q, He Y, Xiao J, et al. Identification of failure modes of composite thin-ply laminates containing circular hole under tension by acoustic emission signals. Composite Structures. 2018;206:70-9.

73. Soutis C, Curtis PT, Fleck NA. Compressive Failure of Notched Carbon Fibre Composites. Proceedings: Mathematical and Physical Sciences. 1993;440(1909):241-56.

74. Amacher R, Smith W, Dransfeld C, Botsis J, Cugnoni J. Thin Ply: From Size-Effect Characterization to Real Life Design. In: CAMX 2014 - The Composites and Advanced Materials Expo. Orlando, FL, USA; 2014.

75. ASTM International. ASTM D3518/D3518M-18: Standard Test Method for In-Plane Shear Response of Polymer Matrix Composite Materials by Tensile Test of $\mathrm{a} \pm 45^{\circ}$ Laminate. ASTM; 2018.

76. British Standards Institute. BS EN ISO 14130:1998 Fibre-reinforced plastic composites - Determination of apparent interlaminar shear strength by short-beam method. BSI; 1998.

77. Huang C, He M, He Y, Xiao J, Zhang J, Ju S, et al. Mechanical behaviors of thin-ply composite laminates under short-beam shear and open-hole tensile loads: Pseudo-homogeneous and isotropic behaviors. In: ICCM21- 21st International Conferences on Composite Materials. Xi'an, China; 2017.

78. Sanchez-Saez S, Barbero E, Zaera R, Navarro C. Compression after impact of thin composite laminates. Composites Science and Technology. 2005;65(13):1911-9.

79. Liu TQ, Liu X, Feng P. A comprehensive review on mechanical properties of pultruded FRP composites subjected to long-term environmental effects. Composites Part B: Engineering. 2020;191:1-57.

80. Selzer R, Friedrich K. Mechanical properties and failure behaviour of carbon fibre-reinforced polymer composites under the influence of moisture. Composites Part A: Applied Science and Manufacturing. 1997;28(6):595-604.

81. Revathi A, Sendil Murugan M, Srihari S, Jagannathan N, Manjunatha CM. Effect of Hot-Wet Conditioning on the Mechanical and Thermal 
Properties of IM7/ 8552 Carbon Fiber Composite. Indian Journal of Advances in Chemical Science. 2014;2:84-8.

82. Ray BC. Temperature effect during humid ageing on interfaces of glass and carbon fibers reinforced epoxy composites. Journal of Colloid and Interface Science. 2006;298(1):111-7.

83. Tsai YI, Bosze EJ, Barjasteh E, Nutt SR. Influence of hygrothermal environment on thermal and mechanical properties of carbon fiber/fiberglass hybrid composites. Composites Science and Technology. 2009;69(3-4):432-7.

84. Arnold C, Korkees F, Alston S. The long-term water absorption and desorption behaviour of carbon-fibre / epoxy composites. In: ECCM15 15th European Conference on Composite Materials. Venice; 2012. p. 18.

85. Choi HS, Ahn KJ, Nam JD, Chun HJ. Hygroscopic aspects of epoxy/carbon fiber composite laminates in aircraft environments. Composites Part A: Applied Science and Manufacturing. 2001;32(5):709-20.

86. Korkees F, Arnold C, Alston S. An investigation of the long-term water uptake behavior and mechanisms of carbon fiber/977-2 epoxy composites. Polymer Engineering and Science. 2018;58(12):2175-84.

87. Arnold JC, Alston SM, Korkees F. An assessment of methods to determine the directional moisture diffusion coefficients of composite materials. Composites Part A: Applied Science and Manufacturing. 2013;55:120-8.

88. Korkees F, Alston S, Arnold C. Directional diffusion of moisture into unidirectional carbon fiber/epoxy Composites: Experiments and modeling. Polymer Composites. 2018;39(S4):E2305-15.

89. Humeau C, Davies P, Jacquemin F. An experimental study of water diffusion in carbon/epoxy composites under static tensile stress. Composites Part A: Applied Science and Manufacturing. 2018;107:94104.

90. Karbhari VM, Xian G. Hygrothermal effects on high VF pultruded unidirectional carbon/epoxy composites: Moisture uptake. Composites Part B: Engineering. 2009;40(1):41-9.

91. Alston S, Korkees F, Arnold C. Finite element modelling of moisture 
uptake in carbon fibre / epoxy composites: A multi-scale approach. In: ECCM15 - 15th Conference on Composites Materials. Venice, Italy; 2012. p. 24-8.

92. Otaluka EP, Arnold C, Alston S. The long term effects of water absorption, desorption and re-absorption in carbon-fibre/epoxy composites. In: 10th International Conference on Composite Science and Technology. Lisbon, Portugal; 2015.

93. Bao LR, Yee AF, Lee CYC. Moisture absorption and hygrothermal aging in a bismaleimide resin. Polymer. 2001;42(17):7327-33.

94. Grammatikos SA, Zafari B, Evernden MC, Mottram JT, Mitchels JM. Moisture uptake characteristics of a pultruded fibre reinforced polymer flat sheet subjected to hot/wet aging. Polymer Degradation and Stability. 2015;121:407-19.

95. Genna S, Trovalusci F, Tagliaferri V. Indentation test to study the moisture absorption effect on CFRP composite. Composites Part B: Engineering. 2017;124:1-8.

96. Kafodya I, Xian G, Li H. Durability study of pultruded CFRP plates immersed in water and seawater under sustained bending: Water uptake and effects on the mechanical properties. Composites Part B: Engineering. 2015;70:138-48.

97. Kumar SB, Sridhar I, Sivashanker S. Influence of humid environment on the performance of high strength structural carbon fiber composites. Materials Science and Engineering A. 2008;498(1-2):174-8.

98. Cao S, Wu Z, Wang X. Tensile properties of CFRP and hybrid FRP composites at elevated temperatures. Journal of Composite Materials. 2009;43(4):315-30.

99. Akay M, Kong Ah Mun S, Stanley A. Influence of moisture on the thermal and mechanical properties of autoclaved and oven-cured Kevlar-49/epoxy laminates. Composites Science and Technology. 1997;57(5):565-71.

100. British Standards Institute. BS ISO 14127:2008 Carbon-fibre-reinforcedcomposites. Determination of the resin, fibre and void contents. BSI; 2008.

101. ASTM International. ASTM D3039/D3039M-17 Standard Test Method for Tensile Properties of Polymer Matrix Composite Materials. ASTM; 
2017.

102. ASTM International. ASTM D6641/D6641M-16 Standard Test Method for Compressive Properties of Polymer Matrix Composite Materials Using a Combined Loading Compression (CLC) Test Fixture. ASTM; 2016.

103. ASTM International. ASTM D5766/D5766M-11(2018) Standard Test Method for Open-Hole Tensile Strength of Polymer Matrix Composite Laminates. ASTM; 2018.

104. BS ISO 12817:2013 Fibre-reinforced plastic composites. Determination of open-hole compression strength. BSI; 2013.

105. ASTM International. ASTM E1012-14 Standard Practice for Verification of Testing Frame and Specimen Alignment Under Tensile and Compressive Axial Force Application. ASTM; 2014.

106. Bai Y, Keller T. Mechanical Responses of FRP Composites. In: High Temperature Performance of Polymer Composites [Internet]. John Wiley \& Sons, Inc.; 2014. p. 133-82. Available from: https://onlinelibrary.wiley.com/doi/book/10.1002/9783527654147

107. Shen $\mathrm{CH}$, Springer GS. Moisture Absorption and Desorption of Composite Materials. Journal of Composite Materials. 1976;10(1):2-20.

108. Khechai A, Tati A, Guerira B, Guettala A, Mohite PM. Strength degradation and stress analysis of composite plates with circular, square and rectangular notches using digital image correlation. Composite Structures. 2018;185:699-715.

109. JPK Instruments. The NanoWizard ${ }^{\circledR}$ AFM Handbook. Version 2.2a; 2012.

110. JPK Instruments. NanoWizard ${ }^{\circledR} 3$ User Manual. SPM Software Release $4.2 ; 2012$.

111. Little JE, Yuan XW, Jones MI. Voids characterisation in carbon fibre/epoxy composite laminates. In: 18th International Conference on Composite Materials. Jeju Island, Korea; 2011.

112. Di Landro L, Montalto A, Bettini P, Guerra S, Montagnoli F, Rigamonti M. Detection of Voids in Carbon/Epoxy Laminates and Their Influence on Mechanical Properties. Polymers and Polymer Composites. 2017;25(5):371-80. 
113. Bhudolia SK, Joshi SC, Boon YD. Experimental and Microscopic Investigation on Mechanical Performance of Textile Spread-tow Thin Ply Composites. Fibers and Polymers. 2019;20(5):1036-45.

114. Instron. 7 Tips for Materials Testing [Internet]. 2006 [cited 2020 Aug 7]. Available from: https://www.instron.us/-/media/literaturelibrary/whitepapers/2007/03/7-tips-for-materials-testing.pdf?la=en

115. Urbaniak M. Glass transition temperature-temperature-property (TgTP) diagram for EPY ® epoxy system. Polimery. 2008;53(7-8):53743.

116. R-TECH Materials. A Practical Guide to Compression Testing of Composites [Internet]. [cited 2019 Sep 17]. Available from: https://www.r-techmaterials.com/news-and-blog/practical-guidecompression-testing-composites/

117. Mahendran R, Chen R, Wang L, Pandita SD, Machavaram VR, Kukureka SN, et al. Chemical process monitoring and the detection of moisture ingress in composites. In: Smart Sensor Phenomena, Technology, Networks, and Systems 2008. 2008.

118. JPK Instruments. JPK Data Processing Software Manual. Version 4.3; 2014.

119. Maivald P, Butt HJ, Gould SAC, Prater CB, Drake B, Gurley JA, et al. Using force modulation to image surface elasticities with the atomic force microscope. Nanotechnology. 1991;2:103-6.

120. NanoWorld Innovative Technologies. Force Modulation Mode [Internet]. [cited 2019 Nov 29]. Available from: https://www.nanoworld.com/pointprobe-force-modulation-afm-tip-fm

121. Niu Y, Yang Y, Gao S, Yao J. Mechanical mapping of the interphase in carbon fiber reinforced poly(ether-ether-ketone) composites using peak force atomic force microscopy: Interphase shrinkage under coupled ultraviolet and hydro-thermal exposure. Polymer Testing. 2016;55:25760.

122. Brucker AFM Probes. MPP-13100-10 [Internet]. [cited 2019 Nov 29]. Available from: https://www.brukerafmprobes.com/p-3333-mpp13100-10.aspx

123. Mimura K, Ito H, Fujioka H. Improvement of thermal and mechanical properties by control of morphologies in PES modified epoxy resins. 
Polymer. 2000;41(12):4451-9.

124. Del Saz-Orozco B, Ray D, Kervennic A, McGrail PT, Stanley WF. Toughening of carbon fibre/polybenzoxazine composites by incorporating polyethersulfone into the interlaminar region. Materials and Design. 2016;93:297-303. 